UNIVERSIDADE FEDERAL DO RIO GRANDE DO NORTE CURSO DE PÓS-GRADUAÇÃO EM ENGENHARIA DE PRODUÇÃO MESTRADO EM ENGENHARIA DE PRODUÇÃO

ILAYDIANY CRISTINA OLIVEIRA DA SILVA

APLICAÇÃO DE INDICADORES WEBOMÉTRICOS NOS PROGRAMAS DE PÓS-GRADUAÇÃO DAS ENGENHARIAS RECOMENDADOS PELA CAPES 
Divisão de Serviços Técnicos

Catalogação da Publicação na Fonte. UFRN / Biblioteca Central Zila Mamede

Silva, Ilaydiany Cristina Oliveira da.

Aplicação de indicadores webométricos nos programas de Pós-Graduação das engenharias recomendados pela CAPES / Ilaydiany Cristina Oliveira da Silva. - Natal, RN, 2011.

$130 \mathrm{f}$. il.

Orientador: José Alfredo Ferreira Costa. (Phd.)

Co-orientadora: Nadia Aurora Vanti Vitullo.(Dra.)

Dissertação (Mestrado) - Universidade Federal do Rio Grande do

Norte. Programa Pós-Graduação em Engenharia de Produção. Centro de Tecnologia.

1. 1. Estudo métrico - Dissertação. 2. Webometria - Dissertação. 3. Análise webométrica - Pós-Graduação em Engenharia - Dissertação. I. Costa, José Alfredo Ferreira. II. Vanti Vitullo, Nádia Aurora. III. Título 
UNIVERSIDADE FEDERAL DO RIO GRANDE DO NORTE CURSO DE PÓS-GRADUAÇÃO EM ENGENHARIA DE PRODUÇÃO

MESTRADO EM ENGENHARIA DE PRODUÇÃO

\section{APLICAÇÃO DE INDICADORES WEBOMÉTRICOS NOS PROGRAMAS DE PÓS-GRADUAÇÃO DAS ENGENHARIAS RECOMENDADOS PELA CAPES}

por

\section{ILAYDIANY CRISTINA OLIVEIRA DA SILVA}

BACHAREL EM BIBLIOTECONOMIA, UFRN, 2008

DISSERTAÇÃO SUBMETIDA AO PROGRAMA DE ENGENHARIA DE PRODUÇÃO DA UNIVERSIDADE FEDERAL DO RIO GRANDE DO NORTE COMO PARTE DOS REQUISITOS NECESSÁRIOS PARA OBTENÇÃO DO GRAU DE

MESTRE EM ENGENHARIA DE PRODUÇÃO

MAIO, 2011

(C) 2011 ILAYDIANY CRISTINA OLIVEIRA DA SILVA TODOS OS DIREITOS RESERVADOS

Assinatura do Autor:

APROVADO POR:

Prof $^{\circ}$. José Alfredo Ferreira Costa, D. Sc. - Orientador, Presidente (PEP/UFRN)

Profa . Nadia Aurora Vanti Vitullo, Dra . - Membro Examinador Interno (DEBIB/UFRN)

Profo $^{\circ}$. Eliane Ferreira da Silva, $\mathrm{Dr}^{\mathrm{a}}$. - Membro Examinador Interno (DEBIB/UFRN)

Prof ${ }^{\text {a }}$. Ana Cristina Cunha da Silva, Dr ${ }^{\text {a }}$ - Membro Examinador Externo (UESPI) 


\section{AGRADECIMENTOS}

Agradeço a minha família, a qual amo muito, pelo carinho, paciência e incentivo nessa caminhada.

Aos meus orientadores, José Alfredo e Nadia Vanti, que acreditaram em mim e contribuíram imensuravelmente com minha formação. Muito obrigada por todos os ensinamentos!

Aos professores do Programa de Pós-Graduação em Engenharia de Produção da UFRN por todos os ensinamentos ministrados.

A professora Mariana Almeida que me mostrou que tudo que conquistamos com dificuldade não nos enfraquece ao contrário nos fortalece e nos instiga a continuar seguindo.

As minhas professoras de graduação que sempre estiveram presentes em minha vida acadêmica me incentivando a dar continuidade aos meus estudos.

Aos meus amigos de classe pela troca de experiências e ensinamentos, em especial a Vanessa, Aline, Marcelo, Geilton e Anna Cristina que sempre estiveram ao meu lado, dando-me força e apoio.

E agradeço imensamente a Deus, por ter colocado todas essas pessoas (anjos) em meu caminho, por ter me dado sabedoria, paciência e perseverança na concretizaç'ão dos meus estudos. Por me amparar nos momentos difíceis, me dar força interior para superar as dificuldades, mostrar os caminhos certos nas horas incertas e me suprir em todas as minhas necessidades. Obrigada Deus por todas as minhas conquistas! 
Resumo da Dissertação apresentada como parte dos requisitos necessários para a obtenção do grau de Mestre em Ciências em Engenharia de Produção.

\title{
APLICAÇÃO DE INDICADORES WEBOMÉTRICOS NOS PROGRAMAS DE PÓS- GRADUAÇÃO DAS ENGENHARIAS RECOMENDADOS PELA CAPES
}

\section{ILAYDIANY CRISTINA OLIVEIRA DA SILVA}

\author{
$\mathrm{MAIO} / 2011$ \\ Orientador: José Alfredo Ferreira Costa \\ Co-orientadora: Nádia Aurora Vanti Vitullo \\ Curso: Mestrado em Ciências em Engenharia de Produção.
}

\section{RESUMO}

Objetiva-se identificar, através da aplicação de indicadores webométricos, quais Programas de Pós-Graduação (PPG's) em Engenharias recomendados pela Coordenação de Aperfeiçoamento de Pessoal de Nível Superior (CAPES) no Brasil se destacam no espaço web, em relação ao processo de comunicação e disseminação de informações científicas ao meio acadêmico. Para tanto, serão analisadas as estruturas de conteúdo dos sites, o uso, através do comportamento de pesquisas e buscas, a qualidade das informações disponibilizadas, bem como a estrutura dos hipertextos existentes nos sites desse universo de pesquisa. As ferramentas e os procedimentos metodológicos adotados para esse estudo são: motores de busca (Google, Yahoo), software mapeador (Xenu Link Sleuth) e software de análise e visualização de redes (Ucinet6 e NetDraw). Também são utilizados indicadores webométricos, como: tamanho dos sites web, visibilidade, fator de impacto web, luminosidade e densidade da rede. Estes instrumentos permitem uma análise sucinta e avaliativa para esse estudo webométrico. Portanto, a partir da incursão da literatura realizada, depreende-se que são muitas as vantagens do uso desse tipo de estudo métrico na denominada Sociedade da Informação. Os resultados obtidos nesse estudo foram capazes de identificar quais Programas de pós-graduação em engenharias possuem uma melhor disponibilização de suas informações na Web, como também definir qual destes programas destaca-se em relação ao uso de suas informações, quais tem se sobressaído no tocante ao fator de impacto dos mesmos e quais oferecem uma maior quantidade de links que servem como fonte de informação para seus usuários, contribuindo, por sua vez, com a navegabilidade dos mesmos na rede. Em suma, assevera-se que o estudo webométrico realizado, apresenta resultados bastante promissores, capazes de alcançar os objetivos propostos, bem como, identificar os fatores que contribuem significativamente para a boa visualização desses sites na rede, colaborando assim com a disseminação de informações e comunicação científica através do uso da Web.

Palavras-chave: Estudo métrico. Webometria. Pós-Graduação. Engenharias. 
Abstract of Master degree dissertation, presented as fulfillment of requirements to the degree of Master of Science in Production Engineering.

\title{
APPLICATION OF INDICATORS WEBOMETRICS IN PROGRAMMES DUSTS- GRADUATE OF ENGINEERING RECOMMENDED BY THE CAPES
}

\section{ILAYDIANY CRISTINA OLIVEIRA DA SILVA}

\author{
MAY/2011 \\ Thesis Supervisor: José Alfredo Ferreira Costa \\ Thesis Supervisor: Nadia Aurora Vanti Vitullo \\ Program: Master of Science in Production Engineering
}

\begin{abstract}
This study aims to identify, through the application of webometric indicators, which Post-Graduate Courses in Engineering recommended by the Coordination of Improvement of Higher Personnel Education (CAPES) in Brazil stand out in the web space, in relation to the communication process and dissemination of scientific information in the academic environment. For this, we analyzed the structures content of the sites, the use, through the conduct of investigations and searches, the quality of information available, as well as the structure of existent hypertexts in the sites of this universe of search. The tools and methodologies adopted for this study are: search engines (Google, Yahoo), Mapper software (Xenu Link Sleuth) and analysis software and visualization of networks (and Ucinet6 NetDraw). Webometric indicators are also used, such as size of the web sites, visibility, web impact factor, brightness and density of the network. These instruments provide a brief analysis and evaluation for this webometric study. Therefore, from the incursion of the literature used, it appears that there are many advantages of using this type of metric study in the so called Information Society. The obtained results could identify which postgraduate courses in engineering has a better availability of their information on the Web, as well to define which of these courses stands out in relation to the use of their information, which has been outstanding in respect to its impact factor and which offers a greater number of links that serve as a source of information for its users, contributing, in its turn, with the navigability of the same network. In summary, it is asserted that the webometric study presents promising results, which are able to achieve the proposed objectives, as well as identify the factors that contribute significantly to the good visualization of these sites in the network, thus helping the spread of information and scientific communication through the use of the Web.
\end{abstract}

Keywords: Metric study. Webometrics. Post-Graduation. Engineering. 


\section{LISTA DE FIGURAS}

FIGURA 1 - Relação percentual dos sites analisados.............................................. 48

FIGURA 2 - Matriz de adjacências dos PPG's em engenharias I.............................. 96

FIGURA 3 - Representação gráfica das conexões das redes sociais dos PPG's em engenharias I.

FIGURA 4 - Matriz de adjacências dos PPG's em engenharias II.............................. 98

FIGURA 5 - Representação gráfica das conexões das redes sociais dos PPG's em engenharias II.

FIGURA 6 - Matriz de adjacências dos PPG's em engenharias III............................. 100

FIGURA 7 - Representação gráfica das conexões das redes sociais dos PPG's em engenharias II.

FIGURA 8 - Matriz de adjacências dos PPG's em engenharias IV 103

FIGURA 9 Representação gráfica das conexões das redes sociais dos PPG's em engenharias IV.

FIGURA 10 - Representação gráfica das conexões das redes sociais dos PPG's em engenharias.

FIGURA 11 Representação gráfica das conexões das redes sociais entre os PPG's em engenharias. 


\section{LISTA DE TABELAS}

TABELA 1 - Relação de cursos recomendados e reconhecidos.................... 36

TABELA 2 - Relação da grande área de engenharias................................... 42

TABELA 3 - Relação do peso dos indicadores....................................... 46

TABELA 4 - Ranking geral dos grupos de engenharias............................... 77

TABELA 5 - Ranking webométrico....................................................... 89

TABELA 6 - Dados gerais da densidade de rede entre as engenharias......... 107 


\section{LISTA DE GRÁFICOS}

GRÁFICO 1 - Quantidade de Programas de Pós-graduação por grupo de engenharias.

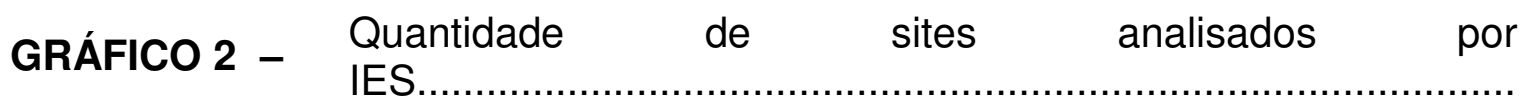

GRÁFICO 3 - IES com PPG's que integram as engenharias I

GRÁFICO 4 IES com PPG's que integram as engenharias II.

GRÁFICO 5 IES com PPG's que integram as engenharias III

GRÁFICO 6 IES com PPG's que integram as engenharias IV.

GRÁFICO 7 Percentual das IES

por

regiões brasileiras.

GRÁFICO 8 - Análise do indicador tamanho nas engenharias

GRÁFICO 9 - Análise do indicador tamanho nas engenharias II.

GRÁFICO 10 - Análise do indicador tamanho nas engenharias III.

GRÁFICO 11 - Análise do indicador tamanho nas engenharias IV.

GRÁFICO 12 - Análise do indicador tamanho por grupos de engenharias.

GRÁFICO 13 - Análise do indicador visibilidade nas engenharias I...

GRÁFICO 14 - Análise do indicador visibilidade nas engenharias II.

GRÁFICO 15 - Análise do indicador visibilidade nas engenharias III......

GRÁFICO 16 - Análise do indicador visibilidade nas engenharias IV.....

GRÁFICO 17 - Análise do indicador visibilidade por grupos de engenharias.....

GRÁFICO 18 - Análise do indicador FIW nas engenharias I.

GRÁFICO 19 - Análise do indicador FIW nas engenharias II

GRÁFICO 20 - Análise do indicador FIW nas engenharias III.

GRÁFICO 21 - Análise do indicador FIW nas engenharias IV.

GRÁFICO 22 - Análise do indicador FIW por grupos de engenharias.

GRÁFICO 23 - Análise do indicador luminosidade nas engenharias I.

GRÁFICO 24 - Análise do indicador luminosidade nas engenharias II.

GRÁFICO 25 - Análise do indicador luminosidade nas engenharias III..

GRÁFICO 26 - Análise do indicador luminosidade nas engenharias IV..............

GRÁFICO 27 - Análise do indicador luminosidade por grupos de engenharias.

GRÁFICO 28 - Análise do índice webométrico por grupos de engenharias. 
GRÁFICO 29 - Análise do indicador tamanho por Programa de Pósgraduação

GRÁFICO 30 - Análise do indicador visibilidade por Programa de Pósgraduação...

GRÁFICO 31 - Análise do indicador fator de impacto Web por Programa de Pós-graduação.

GRÁFICO 32 - Análise do indicador luminosidade por Programa de Pósgraduação. 


\section{LISTA DE APÊNDICES}

APÊNDICE A - Relação dos Programas e sites das Engenharias I dos IES do Brasil a serem contempladas no estudo.

APÊNDICE B - Relação dos Programas e sites das Engenharias II dos IES do Brasil a serem contempladas no estudo.

APÊNDICE C - Relação dos Programas e sites das Engenharias III dos IES do Brasil a serem contempladas no estudo.

APÊNDICE D - Relação dos Programas e sites das Engenharias IV dos IES do Brasil a serem contempladas no estudo.

APÊNDICE E - Relação dos cursos de acordo com os Programas

APÊNDICE F - Dados Webométricos gerais das engenharias I.

APÊNDICE G - Dados Webométricos gerais das engenharias II

APÊNDICE H - Dados Webométricos gerais das engenharias III. 125

APÊNDICE I - Dados Webométricos gerais das engenharias IV. 126

APÊNDICE J - Ranking webométrico das engenharias I.

APÊNDICE K - Ranking webométrico das engenharias II. 128

APÊNDICE L - Ranking webométrico das engenharias III.

APÊNDICE M - Ranking webométrico das engenharias IV 


\section{LISTA DE ABREVIATURAS, SIGLAS E SÍMBOLOS}

$\begin{array}{ll}\text { FUFSE } & \text { Fundação Universidade Federal de Sergipe } \\ \text { ITA } & \text { Instituto Tecnológico de Aeronáutica } \\ \text { PUC/RIO } & \text { Pontifícia Universidade Católica do Rio de Janeiro } \\ \text { UEM } & \text { Universidade Estadual de Maringá } \\ \text { UERJ } & \text { Universidade do Estado do Rio de Janeiro } \\ \text { UFBA } & \text { Universidade Federal da Bahia } \\ \text { UFC } & \text { Universidade Federal do Ceará } \\ \text { UFCG } & \text { Universidade Federal de Campina Grande } \\ \text { UFES } & \text { Universidade Federal do Espírito Santo } \\ \text { UFF } & \text { Universidade Federal Fluminense } \\ \text { UFJF } & \text { Universidade Federal de Juiz de Fora } \\ \text { UFMA } & \text { Universidade Federal do Maranhão } \\ \text { UFMG } & \text { Universidade Federal de Minas Gerais } \\ \text { UFMS } & \text { Universidade Federal do Mato Grosso do Sul } \\ \text { UFOP } & \text { Universidade Federal de Ouro Preto } \\ \text { UFPA } & \text { Universidade Federal do Pará } \\ \text { UFPB/J.P. } & \text { Universidade Federal da Paraíba } \\ \text { UFPE } & \text { Universidade Federal de Pernambuco } \\ \text { UFPR } & \text { Universidade Federal do Paraná } \\ \text { UFRGS } & \text { Universidade Federal do Rio Grande do Sul } \\ \text { UFRJ } & \text { Universidade Federal do Rio de Janeiro } \\ \text { UFRN } & \text { Universidade Federal do Rio Grande do Norte } \\ \text { UFSC } & \text { Universidade Federal de Santa Catarina } \\ \text { UFSCAR } & \text { Universidade Federal de São Carlos } \\ \text { UFSM } & \text { Universidade Federal de Santa Maria } \\ \text { UFU } & \text { Universidade Federal de Uberlândia } \\ \text { UNB } & \text { Universidade de Brasília } \\ \text { UNESP/IS } & \text { Universidade Estadual Paulista } \\ \text { UNICAMP } & \text { Universidade Estadual de Campinas } \\ \text { UNICASTELO } & \text { Universidade Camilo Castelo Branco } \\ \text { UNIVAP } & \text { Universidade do Vale do Paraíba } \\ \text { UPM } & \text { Universidade Presbiteriana Mackenzie } \\ \text { USP } & \text { Universidade de São Paulo } \\ \text { USP/SC } & \text { Universidade de São Paulo - Campus de São Carlos } \\ \text { UTFPR } & \text { Universidade Tecnológica Federal do Paraná } \\ & \end{array}$




\section{SUMÁRIO}

CAPÍTULO 1 - INTRODUÇÃO

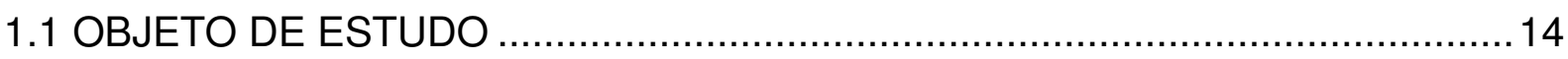

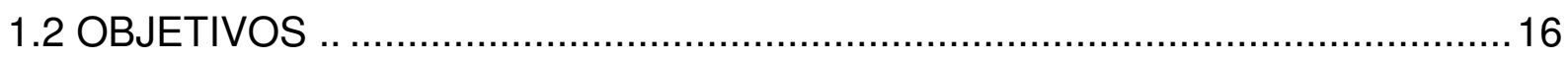

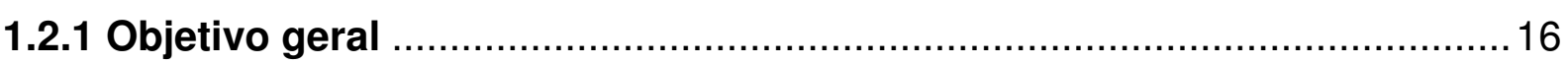

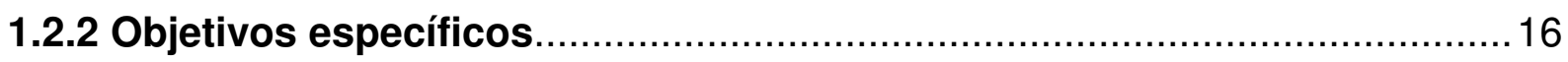

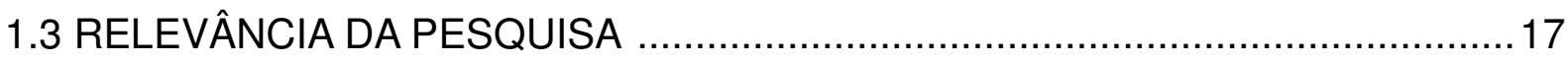

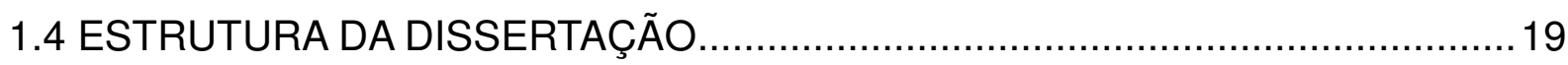

CAPÍTULO 2 - O IMPACTO DAS TECNOLOGIAS DE INFORMAÇÃO NA

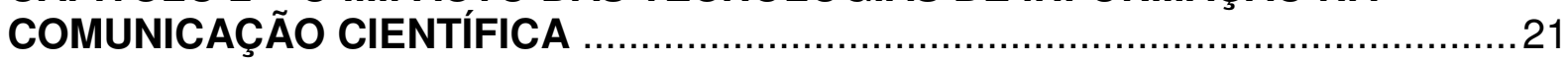

2.1 AS TECNOLOGIAS DE INFORMAÇÃO E COMUNICAÇÃO ............................21

2.2 A INFORMAÇÃO E COMUNICAÇÃO CIENTÍFICA ……................................24

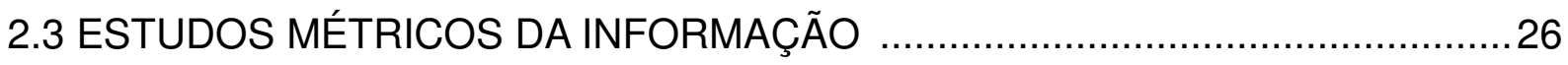

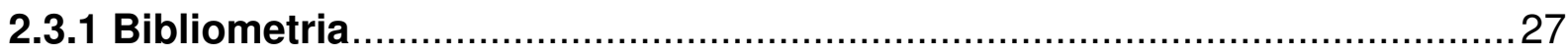

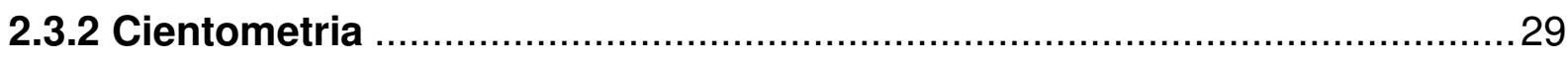

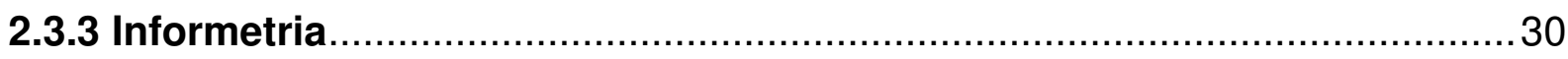

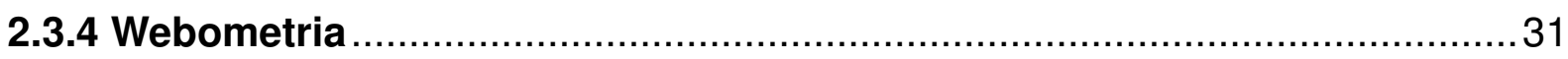

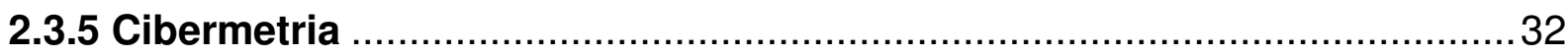

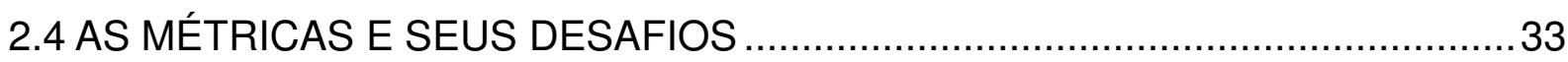

CAPÍTULO 3 - APLICAÇÃO DA WEBOMETRIA EM SITES ACADÊMICOS 35

3.1 A CAPES E O PROCESSO DE AVALIAÇÃO DOS SITES DOS PROGRAMAS DE PÓS-GRADUAÇÃO NO BRASIL ….............................................................. 35 3.2 ESTUDO WEBOMÉTRICO NOS PROGRAMAS DE PÓS-GRADUAÇÃO EM ENGENHARIAS RECOMENDADOS PELA CAPES 38

CAPÍTULO 4 - METODOLOGIA DA PESQUISA 41

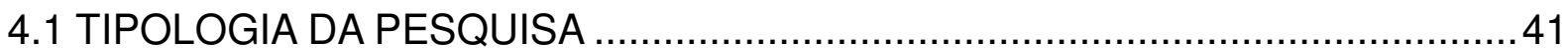

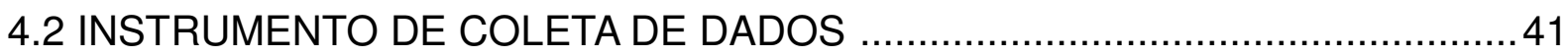

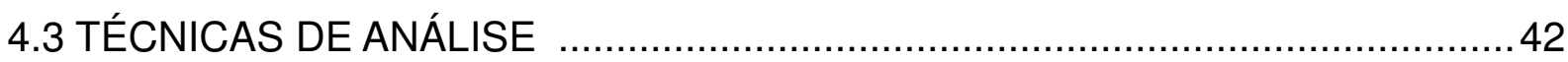

CAPÍTULO 5 - ANÁLISE DOS RESULTADOS E DISCUSSÕES

5.1 RESULTADOS DA PESQUISA APLICADA AOS GRUPOS DE ENGENHARIAS 53 5.1.1 Análise comparativa dos grupos de engenharias de acordo com 0 indicador tamanho dos sites. 
5.1.2 Análise comparativa dos grupos de engenharias de acordo com o indicador visibilidade

5.1.3 Análise comparativa dos grupos de engenharias de acordo com o indicador fator de impacto Web (FIW)

5.1.4 Análise comparativa dos grupos de engenharias de acordo com o indicador luminosidade

5.1.5 Análise comparativa dos grupos de engenharias de acordo com Ranking webométrico

5.2 RESULTADOS DA PESQUISA APLICADA AOS PROGRAMAS DE PÓS-

GRADUAÇÃO EM ENGENHARIAS

5.2.1 Ranking dos programas de pós-graduação em engenharias de acordo com o indicador Tamanho dos sites Web.

5.2.2 Ranking dos programas de pós-graduação em engenharias de acordo com o indicador visibilidade

5.2.3 Ranking dos programas de pós-graduação em engenharias de acordo com o indicador fator de impacto Web (FIW)

5.2.4 Ranking dos programas de pós-graduação em engenharias de acordo com o indicador luminosidade

5.2.5 Ranking webométrico dos programas de pós-graduação em engenharias

5.3 RESULTADOS DAS CONEXÕES DOS PROGRAMAS DE PÓS-GRADUAÇÃO

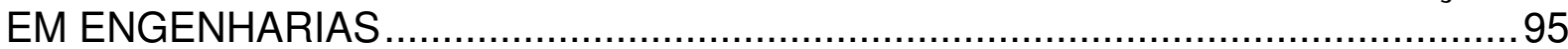

5.3.1 Conexões existentes entre os PPG's em engenharias $I$..........................95

5.3.2 Conexões existentes entre os PPG's em engenharias II ..........................97

5.3.3 Conexões existentes entre os PPG's em engenharias III .........................99

5.3.4 Conexões existentes entre os PPG's em engenharias IV ....................... 101

5.3.5 Conexões existentes nas engenharias...................................................104

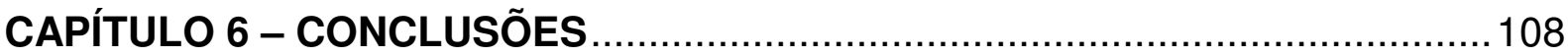

6.1 CONCLUSÕES ALINHADAS AOS OBJETIVOS ...........................................108

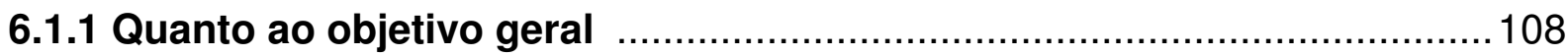

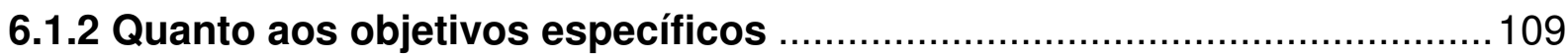

6.2 RECOMENDAÇÕES ALINHADAS ÀS LIMITAÇÕES ENCONTRADAS ............110

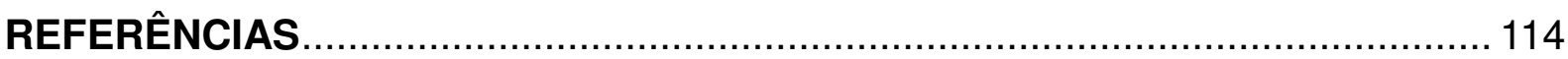

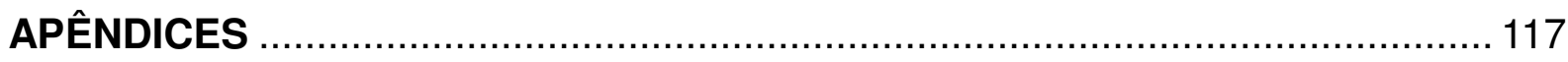


Capítulo 1

\section{INTRODUÇÃO}

Este capítulo apresenta uma contextualização sobre o tema tratado nesse estudo, bem como os objetivos geral e específicos que se pretendem alcançar. Também é abordada a relevância da pesquisa a ser desenvolvida e a estrutura da dissertação apresentada.

\subsection{OBJETO DE ESTUDO}

Após o advento das Tecnologias de Informação e Comunicação (TIC's), em especial a Web, vivencia-se uma Era denominada "Sociedade da Informação", assim intitulada devido a gama de informações disponíveis diariamente à sociedade.

Observa-se, que essa enxurrada informacional contribui tanto na construção do conhecimento dos indivíduos, como também favorece a formação de um verdadeiro caos informacional, pois diante de tantas informações, torna-se cada vez mais difícil discernir dentre as informações disponíveis quais aquelas que podem ser consideradas importantes à construção do intelecto do indivíduo, perante sua necessidade informacional.

A Web tem sido uma das maiores fontes de informação da atualidade, sendo caracterizada como um dos maiores depósitos intelectuais da sociedade. E diante desta asseveração, percebe-se cada vez mais intensamente a preocupação com a utilização, organização e avaliação deste espaço que vem sendo tema prioritário para os estudiosos de sistemas de informação.

Nesse contexto, surge uma nova área de estudos denominada webometria que visa analisar quantitativamente as informações disponíveis na Web através dos links dos sites. Estes links são ferramentas que proporcionam a navegabilidade dos internautas na Web em busca de informações.

A webometria utiliza-se de ferramentas como algoritmos, mecanismos de busca, diretórios, entre outros, como meio de obtenção de dados quantitativos para análise por meio de indicadores webométricos que, por sua vez, definem a presença da comunicação e informação científica na Web. 
A partir desses indicadores pode-se estabelecer um ranking dos sites, também chamados de URL, que ao serem analisados, apontam quais se destacam em relação à presença dos mesmos na rede, enfocando o seu reconhecimento nacional e internacional diante de outras instituições. Tal reconhecimento pode ser caracterizado a partir da integridade, disponibilidade e credibilidade das informações fornecidas por estas URL's através dos seus links.

Visto a crescente presença da webometria no contexto científico é que se despertou o interesse de investigar este método e suas aplicações com a intenção de descobrir como estão se comportando as informações científicas no meio acadêmico virtual, bem como averiguar como a webometria pode colaborar no processo de medição da quantidade de informações científicas e comunicações disponíveis na rede, despertando, consequentemente, o interesse de melhorias na qualidade dessas informações disponibilizadas.

Desse modo, este estudo apresenta conceitos sobre a Tecnologia de Informação e Comunicação e aponta seu impacto na atual sociedade. Ressalta a importância da informação e comunicação científica e as mudanças ocorridas nesse processo informacional após o advento das TIC's, bem como enfoca a atual necessidade da medição do fluxo dessas informações.

Também faz-se uma análise teórico-conceitual acerca dos estudos métricos da informação científica: a bibliometria, a cientometria, a informetria, a webometria e a cibermetria. Posteriormente, apresentam-se conceitos sobre a relevância da webometria e dos seus indicadores como ferramentas para a avaliação de sites.

Para tanto, se verificou a possibilidade de aplicar o método webométrico nos sites dos Programas de Pós-Graduação (PPG's) em Engenharia das Instituições de Ensino Superior (IES) no Brasil, tendo em vista que esta área do conhecimento tem colaborado substancialmente com pesquisas científicas que buscam minimizar problemas de aspectos humanos, econômicos, sociais e ambientais como a questão dos transportes, segurança pública, logística empresarial, saúde, meio ambiente, sistemas de informação, entre outros.

Porém, diante do elevado número de Programas em Engenharia existentes, buscou-se delimitar esse estudo, analisando os Cursos dos Programas de PósGraduação em Engenharias que possuem Mestrado acadêmico e Doutorado e que 
são recomendados pela Coordenação de Aperfeiçoamento de Pessoal de Nível Superior (CAPES), ou seja, aqueles que obtiveram nota igual ou superior a "3" na avaliação da CAPES e que, portanto, atendem ao requisito básico estabelecido pela legislação vigente para serem reconhecidos pelo Ministério da Educação por meio do Conselho Nacional de Educação (CNE) e, em decorrência, expedirem diplomas de mestrado e/ou doutorado com validade nacional. (CAPES, 2011). ${ }^{1}$

Os resultados que se pretende obter na pesquisa visam identificar quais sites, dentre os selecionados, se destacam no espaço Web, como se relacionam e quais possuem uma melhor disponibilização de suas informações. Ao atingir estes resultados será possível apontar quais sites vêm contribuindo com a disseminação da informação científica no espaço virtual, bem como sugerir melhorias ao uso desse tipo de estudo métrico na denominada Sociedade da Informação e, consequentemente, para com a Ciência da Informação.

Com esse pressuposto foram definidos os objetivos e a relevância deste estudo que serão demarcados em seguida.

\subsection{OBJETIVOS}

Os objetivos delimitados nesse estudo dividem-se em geral e específicos, os quais são definidos em seguida.

\subsubsection{Objetivo geral}

Identificar, através do método webométrico, quais Programas de PósGraduação em Engenharias do Brasil se destacam no espaço Web com primazia ao disponibilizar informações científicas ao meio acadêmico virtual.

\subsubsection{Objetivos específicos}

- Avaliar como a webometria tem contribuído no processo de medição da quantidade de informações científicas;

1 Documento eletrônico disponível em: http://www.capes.gov.br/cursos-recomendados. 
- Identificar quais Programas de Pós-Graduação em Engenharias das Instituições de Ensino Superior brasileiras possuem uma melhor disponibilização de suas informações no espaço virtual;

- Sugerir melhorias ao uso desse tipo de estudo métrico na denominada Sociedade da Informação.

\subsection{RELEVÂNCIA DA PESQUISA}

Com o intenso fluxo informacional existente na sociedade após o advento das TIC's, que por sua vez, contribuem consideravelmente com a produção e divulgação de pesquisas científicas, no tocante ao acesso, uso e disponibilidade dessas informações, percebe-se cada vez mais a importância da medição da qualidade das informações disponíveis no espaço virtual, e, notoriamente, das informações científicas, visto a necessidade de uma melhor disseminação das mesmas, de modo a contribuir com pesquisas, e, sobretudo, com o desenvolvimento do país.

Verifica-se que a ciência é fundamental para as mudanças sociais, pois a mesma é considerada como um fator de geração e produção de conhecimentos necessários para essas transformações. Além disso, contribui, significativamente, para a evolução das áreas do conhecimento, bem como para o desenvolvimento da pesquisa.

No Brasil, nas últimas décadas, é notório o aumento de pesquisas em diversas áreas do conhecimento, e consequentemente, a busca incessante de instituições e pesquisadores por apoio financeiro para a realização dessas pesquisas, como forma de contribuírem para a minimização, ou até mesmo resolução, de problemas de diversos aspectos existentes.

Como se sabe, o elemento fundamental para a produção de conhecimento é o financiamento dos seus custos, uma vez que a necessidade de prover despesas se torna progressivamente maior à medida que mais tecnologia é incorporada às técnicas científicas. (RODRIGUES, 2007).

Nesse tocante, agências de fomentos e governos que apóiam financeiramente as pesquisas, necessitam de indicadores que mensurem a importância das mesmas no meio científico, para que desse modo, possam definir 
quais, dentre as mais relevantes, devem ser providas dos recursos financeiros cabíveis.

Diante desse novo contexto, insere-se o surgimento dos estudos métricos que possuem por finalidade medir e avaliar informações disponíveis em diversos formatos.

Algumas agências de fomento como o Institute for Scientific Information (ISI) e a CAPES através do Qualis utilizam-se do método bibliométrico como mecanismo de medição dos índices acadêmicos, tornando-o um parâmetro de avaliação de pesquisadores e instituições.

A bibliometria é um método quantitativo que analisa os documentos no tocante a produção, disseminação e uso das informações disponibilizadas por suporte impresso. Entre os indicadores bibliométricos existentes, destacam-se o Fator de Impacto - que compara o desempenho de um periódico a outros do mesmo campo - e o índice $\mathrm{H}$ - que mede o desempenho de pesquisadores, através da relação entre suas produções científicas e seu índice de citações.

Diante dos novos suportes informacionais que surgiram, houve também a necessidade de medir as informações que se apresentam em outros suportes, daí surge nesse cenário a webometria, baseada no método da bibliometria, mas que objetiva avaliar quantitativamente as informações disponibilizadas através do suporte digital. Nesse sentido, a webometria se utiliza de indicadores que fazem uma análise dos links de sites que são utilizados como estratégia de citação a outras fontes de informação disponíveis na rede.

A partir de tais concepções, observa-se a asseveração de Thelwall (2009, tradução nossa) quando cita que para as teorias acadêmicas, seria interessante descobrir como os países e as universidades são mencionadas. Embora fosse impraticável descobrir isso off-line (por exemplo, através de telefonemas ou entrevistas com acadêmicos aleatórios em todo o mundo), seria muito mais fácil de fazer isso on-line, contando com a menção da Web e o uso de técnicas webométricas.

A webometria utiliza-se de ferramentas e indicadores capazes de medir a presença de determinados sites na rede, bem como sua relevância no mundo virtual e apontar quais destes sites oferecem um maior índice de perspectiva de 
contribuição para a ciência ao utilizar a Web como suporte para a comunicação científica na atualidade.

Por meio desses recursos pode-se também avaliar a evolução da presença de uma determinada instituição ou país na rede, assim como também é possível quantificar o crescimento ou perda de importância relativa de um tema ou área do conhecimento na rede Web. (VANTI VITULLO, 2007).

Observando a relevância do método webométrico no contexto atual, verificase a possibilidade de aplicação desse método quantitativo aos PPG's em Engenharias das IES no âmbito nacional, com o pressuposto de identificar quais Programas têm se destacado no tocante à disseminação de informações científicas no país.

A possibilidade de avaliar metodicamente a quantidade das informações e a comunicação científica dos sites disponibilizados por estes Programas contribuirá, posteriormente, na possível iniciativa de sugerir a criação, atualização e disponibilização das páginas Web dos Programas de Pós-Graduação brasileiros, como também, contribuir com o processo informacional científico na medida em que proporcionará uma maior difusão dessas informações na Web.

\subsection{ESTRUTURA DA DISSERTAÇÃO}

No primeiro capítulo, delineia-se uma breve introdução, na qual está descrita a contextualização do tema tratado, assim como os objetivos que este trabalho busca alcançar, reforçando-se a ideia principal através da mostra de sua relevância.

No segundo capítulo são apresentados aspectos histórico-conceituais das TIC's, enfocando o surgimento e características da nova sociedade informacional do século XXI. Também é apresentada a fundamentação teórico-conceitual dos estudos métricos, ou seja, bibliometria, cientometria, informetria, webometria e cibermetria e os desafios enfrentados para serem reconhecidos no âmbito científico.

O terceiro capítulo comtempla as metodologias empregadas nesse estudo, citando a tipologia da pesquisa, o plano de coleta de dados e instrumentos utilizados, bem como as técnicas de análise usadas. 
No quarto capítulo aborda-se o tema principal deste trabalho que enfoca a webometria e sua aplicação em sistemas de informação acadêmica. Ressalta-se o processo de avaliação da CAPES aos sites de programas de Pós-Graduação no Brasil, como também é enfocada a relevância da aplicação do estudo webométrico aos PPG's em engenharias recomendados pela CAPES, pretendendo-se evidenciar, de algum modo, o processo de análise da webometria no contexto científico atual.

No capítulo seguinte são apresentados os resultados e discussões sobre o tema tratado, verificando-se dessa forma, os resultados que foram alcançados e as principais dificuldades encontradas na elaboração dessa pesquisa.

Por fim, o último capítulo expõe as conclusões abarcadas nesse estudo que apresentam uma análise resumida das principais questões tratadas no trabalho, os resultados obtidos através da pesquisa webométrica realizada e ainda, pontos pertinentes à elaboração deste estudo, uma vez que foram ressaltados de forma geral. 
Capítulo 2

\section{O IMPACTO DAS TECNOLOGIAS DE INFORMAÇÃO NA COMUNICAÇÃO CIENTÍFICA}

Este capítulo apresenta o referencial teórico acerca de conceitos sobre as Tecnologias de Informação e Comunicação (TIC's). Ressalta a importância da informação e comunicação científica, bem como da atual necessidade de medição do fluxo dessas informações. Faz uma análise teórico-conceitual acerca dos estudos métricos da informação científica, ou seja: bibliometria, cientometria, informetria e a webometria. Em seguida, aborda os desafios encontrados pelas mesmas para alcançarem credibilidade nos resultados de suas pesquisas.

\subsection{TECNOLOGIAS DE INFORMAÇÃO E COMUNICAÇÃO}

As tecnologias de Informação e Comunicação podem ser compreendidas como um conjunto de recursos tecnológicos usado para produzir e disseminar informações. Essas tecnologias são ferramentas que permitem arquivar e manipular textos, sons e imagens e que permitem que nos comuniquemos. (SANCHES, ARAÚJO, 2003).

Após o advento das Tecnologias de Informação e Comunicação, em especial a Web, mudanças significativas aconteceram em contextos diversificados, tendo em vista a gama de informações disponíveis à sociedade.

Tal percepção pode ser evidenciada por Silva, Costa e Ramos (2010, documento eletrônico) quando ressalta que:

Dentre o leque de funcionalidades disponibilizadas pelas tecnologias, pode-se enfocar a criação dos computadores, da Internet e da Web como os grandes marcos históricos para a evolução tecnológica informacional, devido a sua contribuição como instrumentos essenciais no processo de gestão das informações para a sociedade e organizações empresariais.

É nesse contexto, que se insere a Era da "Sociedade da Informação", também denominada "Sociedade do Conhecimento". Esta era é marcada pelo intenso fluxo informacional, na qual as informações são consideradas fatores preponderantes 
para mudanças em diversos âmbitos, como social, político e cultural, bem como na construção do conhecimento e nas tomadas de decisão.

A Sociedade da Informação é marcada por diversas mudanças caracterizadas pelo processo de transferência de dados e informação, que por sua vez gera o desenvolvimento do conhecimento humano. Dessa forma, pode-se afirmar que a informação é caracterizada como insumo básico para a formação do conhecimento, sendo capaz de gerar mudanças significativas na sociedade.

De tal modo, torna-se relevante ressaltar que o processo de composição da informação dá-se através da absorção de dados pelo receptor, que ao decodificar esses dados os transforma em informação, que por sua vez, adicionado ao cabedal informacional do indivíduo, gera o conhecimento, o qual é primordial no processo de tomadas de decisão.

Esse processo nos leva à percepção de que toda informação transmitida é passível de transformação para sustentar uma nova construção de ideias, conforme a necessidade informacional de cada indivíduo.

Considerando que, é tamanha a importância do fluxo informacional na sociedade, se torna preponderante ressaltar que as informações passam a possuir um valor no momento em que o indivíduo receptor consegue transformar os dados que recebe, através dos vários suportes existentes, em informação substancial e, consequentemente, gerar o conhecimento capaz de criar ações que podem ser designadas como uso da inteligência, sendo esta a característica principal da Sociedade da Informação.

Porém, faz-se necessário ressaltar que a velocidade informacional existente é oriunda da TIC, destacando-se a Internet e, especialmente a Web como a precursora dessa era informacional.

Ao contrário do que normalmente se pensa, Internet e Web possuem diferenças significantes, pois a Web faz parte da Internet, ou seja, a Web é um sistema de informação disponibilizado pela Internet e que se utiliza dos serviços da mesma para oferecer seus recursos, como por exemplo, as hipermídias. (SILVA, 2008).

A Web e suas ferramentas modificaram tanto o modo de vida da sociedade, como também velhos paradigmas. Para tanto, utiliza-se da praticidade da 
comunicação e disponibilidade das informações através de vídeos, fotos, imagens, entre outros, que servem como suporte para sua difusão social. Um bom exemplo é a presença cada vez mais intensa das redes sociais que compartilham informações, conhecimentos, interesses e esforços em busca de objetivos comuns entre determinados grupos de indivíduos.

Em contrapartida, verifica-se que diante dessa explosão informacional há a necessidade cada vez mais intensa dos indivíduos selecionarem as informações úteis que necessitam e diante deste paradigma, percebe-se o surgimento de um novo aspecto nessa era, denominado "ansiedade da informação", tal sentimento é ocasionado devido à necessidade da sociedade em manter-se bem informada, tendo que saber selecionar dentre as informações disponíveis, aquelas que são consideradas lixo informacional daquelas que podem ser úteis.

O processo de depuração de informações, principalmente as disponíveis pela Internet, é um assunto bastante discutido na atualidade e nesse tocante torna-se oportuno ressaltar uma concepção de Eco (2009, documento on-line) ao responder a uma pergunta durante entrevista acerca das listas criadas pelo mecanismo de busca Google. Eco (2009) cita o perigo das informações disponibilizadas por esse mecanismo de busca para os jovens, visto que o aprendizado da fina arte de discriminar informações é algo que ainda precisa ser aperfeiçoado e, para tanto, as escolas devem inserir-se nesse contexto, como meio de contribuir nesse processo de aprendizado e diminuir a ansiedade da informação dos jovens.

Nesta mesma perspectiva, Turban et al. (2004, p. 569) ressaltam que um dos impactos negativos da era da informação é a ansiedade da informação. Essa ansiedade pode ser traduzida como um sentimento de inquietação que pode assumir diversas formas, como por exemplo, frustração com nossa incapacidade de nos mantermos atualizados com a quantidade de dados presentes em nossas vidas.

A partir desta asseveração percebe-se que as TIC's trouxeram consigo a disponibilidade e acessibilidade das informações, porém não detiveram o grau de integridade das mesmas.

Partindo desse pressuposto, percebe-se a necessidade cada vez mais intensa da avaliação das informações disponíveis na era da Sociedade da Informação, em especial, das informações capazes de contribuir com a minimização 
de problemas humanos, econômicos, sociais e ambientais, como é o caso das informações científicas.

\title{
2.2 A INFORMAÇÃO E COMUNICAÇÃO CIENTÍFICA
}

No contexto científico, as TIC's trouxeram mudanças substanciais como a difusão da ciência e o aumento gradativo da literatura e produções científicas. Utilizando-se da TIC e notoriamente da Web, percebe-se que a ciência difundiu-se em seu contexto, bem como causou grandes impactos.

Acerca da importância da literatura científica e sua difusão, torna-se relevante mencionar Dea (2006, p. 15) quando destaca que:

\begin{abstract}
A literatura científica forma a base que permite o avanço da ciência. Periódicos, livros, teses e dissertações, anais de reuniões científicas, informações veiculadas em redes eletrônicas e revistas de popularização da ciência, artigos de jornal em seções especializadas e outros tipos de publicações divulgam a ciência e funcionam como meio de comunicação. Cada um deles desempenha um papel próprio como instrumento de comunicação científica, servindo a propósitos diferentes, que se complementam.
\end{abstract}

Nesse contexto, percebe-se que a produção científica, utilizando-se dos canais formais e informais de comunicação disponibilizados através das Tecnologias de Informação e Comunicação, torna-se mais um instrumento no âmbito do ensino e da pesquisa, favorecendo a disseminação das pesquisas e ultrapassando as barreiras geográficas. (DEA, 2006).

A comunicação científica também foi beneficiada com o surgimento das TIC, visto que utilizando as redes eletrônicas de informação, o fluxo informacional científico passou a ter um acesso remoto mais ágil e amplo, independente do lócus geográfico do autor conteudista. Também é notório, que as pesquisas em rede cresceram. Fato este, que contribuiu com o processo de trabalho em equipe e integração entre os membros pesquisadores. (SILVA, 2008).

De acordo com Leite (2009) o uso das tecnologias no contexto da comunicação na ciência tem sido responsável por inúmeras transformações em seus processos. Diante dessas transformações, a utilização de recursos eletrônicos 
beneficia o processo de comunicação, sobretudo à medida que são aperfeiçoados e tornados mais ágeis os fluxos de informação e conhecimento científico.

No entanto, apesar dos diversos aspectos positivos oriundos das TIC's na comunidade científica, vale ressaltar os obstáculos e desafios surgidos a partir dessas tecnologias. Dentre os quais, pode-se citar: o controle de qualidade, veracidade e integridade das informações disponibilizadas; as desvantagens tecnológicas entre países e instituições; monopólio das informações pelos países desenvolvidos; e o crescimento descontrolado de informações científicas. Dentro desse contexto, surge a necessidade de se avaliar e acompanhar os avanços científicos no cenário da Sociedade da Informação.

Ao se tratar de critérios de avaliação da informação, torna-se justificável mencionar Silva (2008, p. 25), ao ressaltar a importância de ferramentas avaliativas da informação científica, quando afirma:

Mediante essa diversidade de canais de comunicação houve a
necessidade do surgimento de ferramentas avaliativas de medição
das taxas de produtividade de pesquisadores e dos centros de
pesquisa, como forma de avaliar o fluxo e a qualidade das
informações disponibilizadas por essas pesquisas. Isto se deu em
função da necessidade de se estabelecer então as prioridades para
prover recursos financeiros destinados às essas pesquisas. (SILVA,
2008, p. 25).

Nesse cenário, inserem-se então, os estudos métricos da informação, conhecidos por suas técnicas avaliativas, que objetivam definir o grau de relevância das informações disponibilizadas, bem como apontar aos governos responsáveis pela distribuição de investimentos nesta área, quais pesquisas e instituições tem se destacado na busca de melhorias e minimização dos problemas de diversos aspectos.

Porém, é notório que todo processo de avaliação apresenta prós e contras, e não é diferente nos estudos métricos de informação, visto que as técnicas avaliativas da comunicação científica estão em constante aperfeiçoamento, buscando novas ferramentas e indicadores, e, consequentemente, melhorias nos resultados apresentados.

A preocupação com o processo de avaliação de informações científicas é uma realidade vivenciada, notoriamente, pela Coordenação de Aperfeiçoamento de 
Pessoal de Nível Superior (CAPES) que tem sido alvo de várias críticas ao utilizar o Qualis como um conjunto de procedimentos para estratificação da qualidade da produção intelectual dos programas de pós-graduação, utilizando-se da análise dos periódicos científicos.

Essa realidade vivenciada pela CAPES também ocorre em outras instituições, visto que ao se tratar de índices quantitativos e qualitativos de análise de informação científica há muitas barreiras a serem quebradas, pois são diversas as discussões existentes, as quais buscam integrar o uso de diversos indicadores que consigam mensurar todos os níveis de produção e qualidade das informações científicas dos pesquisadores, de modo a resultar valores concretos no processo seletivo de qualidade.

Nessa perspectiva, ressalta-se a relevância dos estudos métricos da informação na sociedade científica, bem como o intenso processo de aperfeiçoamento de suas técnicas em prol de um processo avaliativo das informações científicas disponibilizadas.

\subsection{ESTUDOS MÉTRICOS DA INFORMAÇÃO}

Diante da necessidade da medição das informações científicas, surgem os estudos métricos da informação que objetivam estabelecer critérios para medir a quantidade e qualidade das informações científicas disponíveis, e consequentemente, avaliar como determinadas áreas do conhecimento estão se portando em determinado contexto.

De tal forma, ressalta-se que:

Nos últimos cinqüenta anos ocorreram duas grandes mudanças
tecnológicas nas publicações acadêmicas, como as mudanças
editoriais a partir da informatização do processo de impressão,
reduzindo significativamente os custos e permitindo mais revistas e
livros na mídia impressa e a conversão de artigos e publicações para
a Internet, possibilitando a comunicação mais rápida e possivelmente
mais barata. (THELWALL, 2007, tradução nossa).

Portanto, diante da gama informacional disponibilizada, há a necessidade de processos de avaliação das áreas do conhecimento, buscando a valorização dos estudos que cada área oferece, para que a mesma possa ter reconhecimento 
nacional e internacional através de suas pesquisas e difusão de suas informações científicas.

Visando atingir essa perspectiva surgem os estudos métricos da informação que objetivam avaliar as informações através de técnicas quantitativas, citando a bibliometria, cientometria e informetria (que medem informações registradas) e as mais recentes, a webometria e a cibermetria (que medem informações disponíveis na Web e na Internet em formato digital).

Essas técnicas apesar de possuírem um objetivo comum, diferenciam-se em seus aspectos de acordo com seus respectivos objetos de estudo, conforme será exposto nos tópicos seguintes.

\subsubsection{Bibliometria}

A Bibliometria trata da medição das propriedades dos documentos. $\mathrm{Na}$ prática, a bibliometria é aplicada principalmente aos documentos relacionados com a ciência. Há muitas técnicas como a contagem de frequência de palavras, a análise de co-citação, análise de co-texto, de contagem de documento com o número de autoria única, artigos de autoria múltipla, etc. (JALAL; BISWAS; MUKHOPADHYAY, 2009).

Cabe enfatizar que a bibliometria utiliza-se de métodos matemáticos e estatísticos em livros, documentos, revistas e artigos, solicitados por usuários com o objetivo de definir o grau de relevância dos documentos em relação ao assunto pesquisado.

O termo bibliometria é uma junção do grego biblion, que significa livro, com o latim metricus e o grego metrikos, que significam mensuração. Então, esse tipo de estudo métrico refere-se a um processo de medida relacionada ao livro ou documento. (DEA, 2006).

A origem do termo bibliometria advém do século XX. Nesse período tornou-se possível identificar o fenômeno da plurissignificação de sentido desse termo, haja vista que alguns autores afirmam que o termo bibliometria, ou melhor, Bibliometrie foi utilizado pela primeira vez por Paul Otlet em 1934 em sua obra Traité de documentatión. (FONSECA, 1986). 
Porém, outros registros identificam que o pesquisador Ranganathan utilizou o termo "bibliotecometria" em meados de 1948, durante a Conferência da Aslib (Association for Information Management) em Leamington Spa, quando sugeriu a necessidade do seu desenvolvimento por parte dos bibliotecários, visto que as bibliotecas lidavam com grande abundância de números. (FONSECA, 1986).

Em 1969, o termo "bibliotecometria" foi substituído definitivamente por "bibliometria" e teve a sua primeira aparição também nos trabalhos de Ranganathan. Essa ocorrência se deu durante o Seminário Anual do Documentation Research and Training Centre (DRTC), cujo trabalho apresentou exemplos de aplicação estatística na área da Biblioteconomia, popularizando definitivamente esse termo. (VANTI VITULLO, 2007).

Todavia, o pesquisador Sengupta afirma que o pesquisador Alan Pritchard foi o primeiro a utilizar esse termo em suas pesquisas em 1969. Já outros afirmam que Pritchard, na verdade, tinha apenas popularizado o uso da palavra bibliometria, quando o mesmo sugeriu que este termo viesse a substituir a expressão bibliografia estatística. (FONSECA, 1986).

Os cálculos bibliométricos são realizados através dos índices de revocação (que medem a quantidade de itens relevantes, dentre os que foram recuperados) e 0 índice de precisão (que mede a quantidade de documentos irrelevantes) que foram encontrados em uma determinada consulta.

Em meio aos estudos da bibliometria, podem ser citados três autores que contribuíram, imensuravelmente, com as pesquisas bibliométricas, ou seja: Lotka, Zipf e Bradford. Esses três autores realizaram pesquisas significativas, criando leis que ajudam na realização da avaliação dos indicadores bibliométricos.

A lei de Lotka, também pode ser chamada de Lei do Quadrado Inverso, estuda a produtividade científica dos autores em um conjunto de documentos. A lei de Zipf ou Lei do Mínimo Esforço analisa a frequência das palavras de um documento de uma determinada disciplina. Já a Lei de Bradford, conhecida como Lei de Dispersão avalia a produtividade de periódicos, com o propósito de estabelecer o núcleo e as áreas de dispersão sobre um determinado assunto em um mesmo conjunto de revistas. (BORSCHIVER; GUEDES, 2005). 
Com o passar dos tempos, diante das necessidades surgidas, verifica-se 0 surgimento de um novo método de medição das informações, denominado cientometria, mas que possui um diferente objeto de estudo.

\subsubsection{Cientometria}

A cientometria tem como objetivo compreender como e quando os cientistas se comunicam, de modo a identificar onde os assuntos de interesse estão concentrados, suas áreas e campos científicos e tecnológicos, assim como suas disciplinas, atividades científicas, colégios invisível; dissertações, teses e documentos tecnológicos (patentes). (SILVA, 2008).

A criação e a aplicação da matemática, notoriamente dos modelos estatísticos para a cientometria e campos relacionados parecem completamente óbvios. Em especial, as ligações criadas por relações de co-autoria, pelo índice de citações recebidas e dadas formas complexas de redes de comunicação científica, que podem melhor serem descritas e analisadas com a ajuda das ferramentas matemáticas. (GLÄNZEL, 2010, p. 2, tradução nossa).

Porém o termo que designa tal método tem causado uma intensa divergência entre autores da área no Brasil, quanto à tradução do termo Scientometrics como sendo: cientometria ou cienciometria.

No entanto, estudos recentes como os dos pesquisadores Stumpf et al. (2006), mostram que o termo cientometria é derivado da palavra ciência, que por sua vez, tem origem na expressão latina scientia e as derivações lexicais que advém deste termo são escritas com 't' em português, como: cientificar, cientificismo, cientologia, científico, cientista, entre outros.

A partir da análise do estudo anteriormente citado é que se definiu empregar tal terminologia neste estudo.

O termo cientometria surgiu na Antiga união Soviética (URSS) e na Europa Oriental em 1969, sendo utilizado por Dobrov e Karennoi, referindo-se à aplicação de métodos quantitativos à história da ciência e do progresso científico, ganhando notoriedade em 1977 com a publicação da revista Scientometrics na Hungria, que foi um projeto entre as editoras científicas Elsevier de Amsterdã e a editora da 
Academia Húngara de Ciência, atualmente a revista é editada na Holanda. No entanto, Spinak (1996) considera que a obra que inaugurou este campo foi "Little Science, Big Science" de Derek de Solla Price, em 1963. (VANTI VITULLO, 2007).

Um importante disseminador dos estudos cientométricos, conhecido mundialmente, é o Institute for Scientific Information (ISI) ou Instituto para a Informação Científica que é uma organização fundada em 1958, por Eugene Garfiel, na Filadélfia. É uma importante fonte utilizada para os indicadores cientométricos, pois o ISI processa um alto número de periódicos, anualmente, que abarcam diversas áreas do conhecimento.

Os indicadores cientométricos, desse modo, ganham força em suas avaliações, pois contam com o ISI como colaborador para a disponibilização dos dados relacionados aos periódicos científicos, tornando-se um aliado na acessibilidade do conhecimento sobre os assuntos de interesse, áreas e campos científicos e tecnológicos, assim como disciplinas e atividades científicas que estão sendo mais utilizadas na produção científica.

Outro método quantitativo de informação que tem ganhado espaço é o chamado informetria que se caracteriza por ser mais abrangente que os demais métodos.

\subsubsection{Informetria}

A informetria é um método quantitativo que possui por finalidade a melhoria do processo de recuperação da informação ao identificar as relações existentes nos sistemas de informação.

Nesse mesmo contexto, Tague-Sutcliffe (1992, p. 1, tradução nossa) ressalta sua concepção acerca da informetria ao defini-la como sendo "o estudo dos aspectos quantitativos da informação, sob qualquer forma, não apenas de registros ou bibliografias e, em qualquer grupo social, não apenas o dos cientistas."O termo informetria surgiu em 1979, por Otto Nacke, diretor do Institut für Informetrie, em Bielferd, Alemanha. O termo teve sua total aceitação em 1989, quando o Encontro Internacional de Bibliometria passou a se chamar Conferência Internacional de Bibliometria, Cientometria e Informetria. (VANTI VITULLO, 2007). 
A informetria é concebida também como sinônimo da cientometria por alguns autores como Sengupta (1992) e Gläzel e Schoepflin (1994), porém outros autores como Russell (1994), Egghe (1994) e Tague-Sutckiffe (1992), consideram a informetria como um campo mais amplo que engloba a bibliometria e até a cientometria. (VANTI, 2006).

Apesar dos diversos aspectos similares existentes entre estas métricas, verifica-se o surgimento do método webométrico que mede as informações em suporte diferenciado, ou seja, a Web.

\subsubsection{Webometria}

A webometria analisa quantitativamente as informações disponíveis na Web, através de estudo dos links dos sites. Para tanto, utiliza-se de ferramentas, tais como: algoritmos, mecanismos de buscas, diretórios, operadores booleanos, entre outros. Estas ferramentas são responsáveis pela obtenção de dados quantitativos necessários para a aplicação dos indicadores webométricos, que por sua vez, medem a presença da comunicação científica virtual.

A webometria, segundo Daniel e Facca (2010) é uma disciplina científica que estuda os aspectos quantitativos e os recursos de informação em documentos Web e sua utilização, sendo baseada em métodos bibliométricos e informétricos, englobando duas categorias básicas: estrutura de links da Web e a avaliação dos motores de busca usando métodos informétricos.

O termo webometrics foi utilizado inicialmente por Almind e Ingwersen em meados de 1997 e desde então, se tem um registro intenso de terminologias utilizadas no decorrer da última década do século $X X$, bem como da primeira do século XXI.

Com isso, tornou-se possível identificar uma base terminológica a respeito da avaliação do fluxo informacional na WWW, ou seja, termos do tipo: "influmetrics" Cronin e Weaver (1995); "Internetmetrics" Shiri (1998); "netometrics" Marcia J. Bossy (1995); "Internetometrics" Almind e Ingwersen (1996) e Quoniam e Rostaing (1997); "Webometry" Abraham (1997); e “Web bibliometry" Chakrabarti et al. (2002). 
Ainda a respeito da terminologia, a razão pela qual se utiliza o termo webometrics traduzido como webometria no Brasil, deve-se ao fato de significar uma herança na bibliometria e na informetria e ainda destacar uma perspectiva da Ciência da Informação para os estudos da Web. (VANTI VITULLO, 2007).

Apesar de ainda serem poucos os estudiosos dessa área métrica no Brasil, pesquisadores como Vanti Vitullo (2002); Dea (2006); Gouveia (2008), Leta (2008) e Silva (2008) adotam a terminologia denominada "webometria" para definir essa área de estudos no país.

Nessa perspectiva, verifica-se a crescente difusão desse tema no Brasil buscando melhorias na qualidade da comunicação científica disponibilizada no espaço virtual atual.

Outro método que vem se firmando no espaço acadêmico é o denominado cibermetria que também avalia as informações no espaço virtual, porém de modo mais abrangente que a webometria.

\subsubsection{Cibermetria}

A cibermetria ou cybermetria ou ainda cybermetrics pode ser compreendida como os estudos quantitativos de toda a Internet e páginas Web, isso inclui os chats, grupos de discussões, redes sociais, blogs, entre outros.

O termo cybermetrics é derivado da junção das palavras cyberespacy e metrics, referindo-se a medição do universo formado pelas redes de computadores, acessadas pela Tecnologia de Informação e Comunicação. No Brasil, o termo mais empregado pelos pesquisadores tem sido cibermetria, como será evidenciado nesse estudo.

É verificada na literatura internacional e nacional a utilização do termo cibermetria como sendo equivalente a webometria, porém estudos mostram que ambas possuem diferenças, visto que essas métricas apesar de quantificarem informações digitais, apresentam finalidades distintas, conforme é analisado a seguir: 
A cibermetria teria um escopo mais amplo do que a webometria, pois compreende a aplicação das tradicionais técnicas informétricas a qualquer tipo de informação disponível na Internet. A webometria, [...] seria mais restrita, pois utiliza técnicas quantitativas para medir, especificamente, a informação disponível na Web, sendo assim uma parte do universo maior da cibermetria. (VANTI VITULLO 2005).

Desse modo, constata-se que a cibermetria possui suas particularidades e que atualmente tem ganhado espaço principalmente nas empresas que utilizam essa métrica como estratégia de medição estatística de acesso aos portais na Internet por seus usuários, verificando suas necessidades, e, consequentemente alcançando seu público alvo.

\subsection{AS MÉTRICAS E SEUS DESAFIOS}

Os estudos métricos da informação surgiram no meio acadêmico com o pressuposto de contribuírem no processo de avaliação quantitativa e qualitativa das informações científicas. Verifica-se que os indicadores utilizados nesse processo são de grande valia para órgãos financiadores de pesquisas que os utilizam como suporte de análise para estabelecerem quais instituições devem receber investimentos nas suas áreas de estudos.

E diante da grande relevância dos métodos métricos de informação no meio científico, há a preocupação em aprimorá-los cada vez mais, de forma a minimizarem os erros que podem cercar todas as pesquisas realizadas por essas métricas no processo avaliativo.

$\mathrm{Na}$ atualidade alguns pesquisadores posicionam-se contra a aplicação e aceitação dos estudos métricos da informação como avaliadores de indicadores científicos, ao afirmaram que esses métodos podem desprezar a avaliação de outros fatores preponderantes nos processos acadêmicos. E propõem que a bibliometria deveria passar a ser uma técnica de suporte e ser somada a outras técnicas na realização de estudos concretos.

Um dos indicadores que tem sido alvo de discussões é o Fator de Impacto bibliométrico utilizado pelo ISI e pela CAPES para medir o impacto de uma determinada obra levando em conta a quantidade de citações que a mesma recebe, 
ressaltando assim a relevância do estudo e da produtividade dos autores dessas pesquisas.

E diante dos problemas de fraudes científicas - como foi documentado em entrevista por Andrew Jacobs, do New York Times em meados de $2010^{2}$ - que incluem descobertas de falsos currículos, falsos valores e resultados obtidos em pesquisas científicas, plágios de produções científicas, entre outros, percebe-se que certos pesquisadores de má fé se utilizam de indicadores métricos consagrados para referendar resultados errôneos de seu interesse.

Segundo Fang Shimin (2010, documento on-line), um escritor sensacionalista que se tornou um famoso defensor da integridade acadêmica, diz que o problema começou com o sistema universitário estatal, no qual burocratas nomeados politicamente têm pouca experiência nas áreas que supervisionam. $E$ devido à grande concorrência para bolsas de estudos, auxílio moradia e aperfeiçoamento de carreira, os funcionários baseiam suas decisões no número de artigos publicados sem se preocuparem em averiguar a veracidade das informações que são disponibilizadas pelos pesquisadores.

É notório que diante das facilidades atuais de disponibilizar informação na rede, proporcionadas pelas TIC's, torna-se cada vez mais difícil controlar a veracidade das informações que circulam neste meio. Exatamente pela natureza livre e democrática da rede é que qualquer pessoa pode fazer circular qualquer tipo de informação, cabendo ao leitor selecionar e conferir a veracidade das informações que são disponibilizadas.

2 Entrevista concedida ao portal G1, em 21 de outubro de 2010. <http://g1.globo.com/mundo/noticia/2010/10/fraudes-generalizadas-ameacam-ascensao-economicachinesa.html> 
Capítulo 3

\section{APLICAÇÃO DA WEBOMETRIA EM SITES ACADÊMICOS}

$\mathrm{Na}$ atualidade a webometria tem se destacado no meio científico ao avaliar as informações que são importantes no meio acadêmico, fazendo instituições voltarem seus olhares para as informações científicas que estão sendo disponibilizadas no meio acadêmico virtual. Nessa perspectiva, o presente capítulo irá abordar o processo de avaliação dos sites dos Programas de Pós-graduação do Brasil que são recomendados pela CAPES, abordando a relevância da aplicação do método webométrico nos sites que integram os PPG's em Engenharias.

\subsection{A CAPES E O PROCESSO DE AVALIAÇÃO DOS SITES DOS PROGRAMAS DE PÓS-GRADUAÇÃO NO BRASIL}

A Coordenação de Aperfeiçoamento de Pessoal de Nível Superior foi criada em 11 de julho de 1951, com o pressuposto de "assegurar a existência de pessoal especializado em quantidade e qualidade suficientes para atender às necessidades dos empreendimentos públicos e privados que visam ao desenvolvimento do país". (CAPES, 2010, documento eletrônico).

Verifica-se que após a criação e atuação da CAPES houve um aumento vertiginoso da quantidade de PPG's no Brasil, pois ao analisar os dados disponibilizados pelo site da instituição percebe-se que em 1987 havia 815 Programas de Pós-Graduação no Brasil, em 2007 esse número atingiu 2.448 e em 2011 esses valores correspondem a 2.928, sendo divididos entre os Programas de Mestrado acadêmico, Doutorado, Mestrado profissional e Mestrado e Doutorado. Conforme pode ser ilustrado na TABELA 1 a seguir: 
TABELA 1 - Relação de cursos recomendados e reconhecidos

\begin{tabular}{lccccc}
\hline \multirow{2}{*}{ GRANDE ÁREA } & \multicolumn{5}{c}{ Programas de Pós-Graduação } \\
\cline { 2 - 7 } & Total & $\mathbf{M}$ & $\mathbf{D}$ & $\mathbf{F}$ & $\mathbf{M} / \mathbf{D}$ \\
\hline CIÊNCIAS AGRÁRIAS & 322 & 117 & 2 & 16 & 187 \\
CIÊNCIAS BIOLÓGICAS & 237 & 56 & 2 & 11 & 168 \\
CIÊNCIAS DA SAÚDE & 484 & 129 & 15 & 52 & 288 \\
CIÊNCIAS EXATAS E DA TERRA & 278 & 97 & 8 & 11 & 162 \\
CIÊNCIAS HUMANAS & 406 & 184 & 4 & 7 & 211 \\
CIÊNCIAS SOCIAIS APLICADAS & 376 & 192 & 1 & 53 & 130 \\
ENGENHARIAS & 328 & 131 & 3 & 49 & 145 \\
LINGÜÍSTICA, LETRAS E ARTES & 161 & 78 & 0 & 0 & 83 \\
MULTIDISCIPLINAR & 336 & 144 & 15 & 85 & 92 \\
Brasil: & $\mathbf{2 . 9 2 8}$ & $\mathbf{1 . 1 2 8}$ & $\mathbf{5 0}$ & $\mathbf{2 8 4}$ & $\mathbf{1 . 4 6 6}$ \\
\hline
\end{tabular}

LEGENDA: M - Mestrado Acadêmico; D - Doutorado; F - Mestrado Profissional; M/D - Mestrado Acadêmico / Doutorado. Fonte: CAPES, 2011.

A CAPES tem a responsabilidade de avaliar esses atuais 2.928 Programas de Pós-Graduação, como também disponibilizar o acesso e divulgação da produção científica, dispor investimentos na formação de recursos de alto nível no país e exterior e promover a cooperação científica internacional.

Todo esse aparato serve de suporte para a comunidade universitária na busca de um padrão de excelência acadêmica para os mestrados e doutorados brasileiros. A partir dos resultados obtidos nas pesquisas quantitativas realizadas pela CAPES é que se torna possível a formulação das políticas para a área de Pós-Graduação, bem como para o dimensionamento das ações de fomento, que englobam as bolsas de estudo, auxílios e apoios.

Para tanto, o Conselho Técnico da CAPES (CTC) definiu em 2006, a Ficha de Avaliação a ser utilizada pelas Comissões de área. Cabendo a cada área definir a proposta de detalhamento da ficha a ser adotada por ela, respeitadas as orientações deliberadas por este órgão (MOREIRA, 2008).

A Ficha de Avaliação contém cinco quesitos a serem considerados no processo avaliativo, sendo eles: Proposta de Programa; Corpo Docente; Corpo Discente, Teses e Dissertações; Produção Intelectual; e Inserção Social.

No quesito Inserção Social é avaliada a visibilidade ou transparência dada pelo programa à sua atuação. Este item se refere à manutenção de página Web para a divulgação de forma atualizada, de seus dados internos, critérios de seleção de alunos, parte significativa de sua produção docente, financiamentos recebidos da 
CAPES e de outras agências públicas e entidades privadas etc. Como também a garantia de amplo acesso a teses e dissertações, pela Web, conforme a Portaria CAPES 13/ 2006, que torna obrigatória essa providência. (CAPES, 2010).

Diante da difusão das informações através dos suportes tecnológicos, notadamente, da Internet e da Web, verifica-se a necessidade de aperfeiçoamento desses quesitos avaliativos por parte dos PPG's, visto que é cada vez mais perceptível a busca por informações no meio virtual e consequentemente a necessidade de uma disseminação de informações acadêmicas através do suporte digital.

Por isso, desde 2006 a CAPES vem recomendando aos PPG's que criem suas páginas Web, para tanto, disponibiliza através de seu site um aplicativo que permite aos PPG's do Brasil montar de maneira fácil e amistosa suas páginas na rede mundial de computadores.

Através desse recurso a CAPES pretende viabilizar o Sistema Nacional de Pós-Graduação, tornando-o mais transparente e divulgando informações importantes de cada Programa, como a relação do corpo docente com o respectivo curriculum vitae, seus critérios de seleção com a bibliografia exigida, as ementas das disciplinas ministradas e parte representativa da produção científica dos docentes e discentes.

Isso tem o pressuposto de facilitar para o candidato a mestrado ou doutorado, a escolha do programa onde deseja estudar, bem como promover uma divulgação cada vez maior do conhecimento científico pela rede de computadores, de modo que alunos dos mais distintos cursos de mestrado e doutorado - e também os de graduação - se beneficiem dos textos e obras acessíveis pela Web.

Diante da adoção desse quesito avaliativo, verifica-se a preocupação do Conselho Técnico da CAPES tornar disponíveis informações científicas e acadêmicas relevantes através do uso da Web, difundindo assim pesquisas e melhorando o processo de comunicação científica por meio virtual.

Porém, alguns PPG's ainda não possuem sites com as informações necessárias que a CAPES recomenda e outras possuem páginas que não são atualizadas e/ou ainda possuem informações errôneas a respeito de seus Programas de Pós-Graduação. 
Diante dessa realidade constatada, verifica-se a necessidade da adoção de métodos informacionais e indicadores que sejam capazes de medir quantitativamente as informações que estão sendo disponibilizadas pelos sites dos Programas de Pós-Graduação, como também mensurar a comunicação científica existente.

\subsection{ESTUDO WEBOMÉTRICO NOS PROGRAMAS DE PÓS-GRADUAÇÃO EM ENGENHARIAS RECOMENDADOS PELA CAPES}

O estudo webométrico, ao ser aplicado aos Programas de Pós-Graduação em Engenharias que são recomendados pela CAPES, poderá avaliar os sites desses Programas, de forma a detectar a presença dos mesmos na rede, através da análise de seus hipenlinks ou links que são as ferramentas que proporcionam a navegabilidade dos usuários Web em busca de informações.

Esse estudo faz o levantamento dos dados que estão sendo disponibilizados na Web e verifica a funcionalidade dos links desses Programas em termos de acesso através mecanismos de buscas no espaço Web.

Ao utilizar essas e outras ferramentas é possível utilizar os indicadores webométricos que, por sua vez, determinam a presença desses sites neste imenso sistema de informação que é a Web.

E através da elaboração de um ranking é possível apontar qual dos sites analisados se destaca em relação ao tamanho, número de links, fator de impacto e de conexões, enfocando, assim, o seu reconhecimento nacional e internacional diante de outras instituições. Sendo relevante ressaltar que os sites que possuem maior visibilidade, tendem a ter um maior reconhecimento, pois quanto mais uma instituição é utilizada como referência pelas demais, mais credibilidade ela possui, justamente por ser portadora de informações com características tais como integridade, confiabilidade e frequente atualização.

Desse modo, pode-se afirmar que a webometria é um método capaz de verificar o reconhecimento de sites na rede, disponibilizando seus resultados como suporte de informação para a ciência e a academia, setores aos quais os estudos quantitativos têm servido. (DEA, 2006). 
E diante da necessidade da medição das informações disponibilizadas em meio eletrônico pelos sistemas de informação, torna-se oportuno ressaltar Rodríguéz (2006, p.[6], tradução nossa) quando afirma que:

O crescimento rápido e cada vez maior da informação eletrônica, junto com o amplo potencial das tecnologias e mídias emergentes têm atraído a atenção de pesquisadores de informação, a fim de refletir sobre a medição e métricas quantitativas de fontes de informação, serviços e meios neste ambiente.

A webometria tem se destacado cada vez mais no cenário científico devido à precisão dos seus resultados estatísticos de análise do fluxo informacional de determinados sites na Web. Dessa forma, os sites analisados colaboram com a realização das pesquisas que fornecem mais progresso para a ciência, tendo como suporte de estudo e divulgação a Web.

Esse método tem sido bastante difundido no meio científico, principalmente após a criação do Webometrics Ranking of World Universities, uma iniciativa do Cibermetrics $L a b$, um grupo de pesquisadores pertencentes ao Consejo Superior de Investigaciones Científicas (CSIC) da Espanha. (WEBOMETRICS, 2009).

Estes pesquisadores analisam a presença de sites acadêmicos na Web, ou seja, de todas as universidades do mundo na Web e divulgam periodicamente um Ranking das universidades mais reconhecidas e conectadas na Web por outras instituições.

A avaliação webométrica consiste em analisar entre as páginas da Web quais se destacam em estrutura de conteúdo; uso, através do comportamento de pesquisas e busca; qualidade das informações disponibilizadas; e, ainda, através da estrutura dos hipertextos existentes nos sites.

A partir dessa perspectiva, observa-se a extrema importância de levar em consideração a publicação na Web não só como principal ferramenta para comunicação acadêmica, mas também como um verdadeiro reflexo da organização global e, consequentemente, do desempenho das universidades. (AGUILLO; ORTEGA; FERNÁNDEZ, 2008, tradução nossa).

Nessa perspectiva, observa-se a importância de se analisar sites acadêmicos que vem se destacando no cenário científico atual, no tocante a disponibilização de pesquisas e informações científicas. 
E diante desse contexto verifica-se a possibilidade de analisar os sites dos PPG's em Engenharias das IES que são recomendados pela CAPES, por se destacarem em quantidade de pesquisas que contribuem na minimização de diversos problemas, e consequentemente, em receberem fomentos direcionados para a realização dessas pesquisas. Diante disso, torna-se relevante identificar como essas instituições estão se comportando também no meio acadêmico virtual no tocante ao processo de disseminação de suas informações e pesquisas científicas.

É notório que atualmente alguns Programas de Pós-Graduação em Engenharia das IES do Brasil não disponibilizam em seus sites informações relevantes sobre seus Programas, o que dificulta o fluxo de informações científicas na rede. E diante dessa realidade, torna-se pertinente averiguar a comunicação científica desses sites no âmbito virtual, bem como, identificar quais das engenharias vêm se destacando nesse espaço por divulgar suas pesquisas e por serem utilizados como fonte de informação para pesquisadores.

Além da visibilidade do fluxo de informações existentes nas engenharias, também se torna oportuno verificar como estas estão se relacionando na Web. Para tanto, é necessário descobrir como estão sendo linkados, ou seja, quais PPG's estão se citando na Web ao fornecer o link dos outros Programas como fonte de informação aos seus usuários virtuais.

Cabe enfatizar que ao se avaliar metodicamente a quantidade das informações disponibilizadas por esses sites, tem-se a possibilidade de sugerir a criação, atualização e disponibilização de páginas Web dos Programas de PósGraduação brasileiros. Isso pode contribuir com o processo informacional acadêmico na medida em que proporciona uma maior difusão das informações científicas na Web, e, consequentemente, colabora diretamente no desenvolvimento das pesquisas científicas ao utilizar o suporte digital como fonte de informação. 
Capítulo 4

\section{METODOLOGIA DA PESQUISA}

Nesse estudo, busca-se um respaldo metodológico específico para a sua prática investigativa, no qual se procura fazer, de início, uma incursão pela literatura. A partir disso, passa-se então a uma análise sistemática de pesquisas teóricas, tanto de publicações impressas, como eletrônicas e, ainda, de trabalhos dedicados aos estudos métricos, de forma a coletar informações e contribuir na construção do conhecimento sobre a temática em discussão. Nesse capítulo é abordado o tipo de pesquisa realizada, quais instrumentos são utilizados para coleta de dados e quais técnicas de análise são empregadas para a realização desse estudo.

\subsection{TIPOLOGIA DA PESQUISA}

De tal modo, define-se a elaboração de um estudo de caso de aspecto quantitativo dos sites dos PPG's em Engenharias das Instituições de Ensino Superior que possuem Mestrado acadêmico e Doutorado e que são recomendados pela CAPES, ou seja, que possuem conceito 3 ou superior, o que totaliza 149 sites.

\subsection{INSTRUMENTO DE COLETA DE DADOS}

A obtenção da relação dos sites a serem analisados é alcançada através da página on-line da Coordenação de Aperfeiçoamento de Pessoal de Nível Superior ${ }^{3}$, que disponibiliza uma relação sumaria dos Programas de Pós-Graduação em Engenharias das Instituições de Ensino Superior do Brasil, tal relação teve sua última atualização em 24 de janeiro de 2011. Já para as demais instituições que não apresentam seus respectivos sites através da página da CAPES ou ainda que disponibilizam sites que remetem a páginas não existentes, deverá ser realizada uma busca através do motor de busca Google (http://www.google.com.br/) para a aquisição dessas informações que englobam a pesquisa. A coleta de todos os

\footnotetext{
${ }^{3}$ http://www.capes.gov.br/cursos-recomendados
} 
dados ocorre no segundo semestre do ano de 2010 e meados de janeiro e fevereiro de 2011.

Para que haja uma melhor compreensão do estudo realizado, procura-se apresentar os Programas de Pós-Graduação de acordo com os grupos de Engenharias ao qual cada programa faz parte, sendo estes grupos divididos em: Engenharias I Engenharias II, Engenharias III e Engenharias IV. Conforme mostra a TABELA 2 e o APÊNDICE A, APÊNDICE B, APÊNDICE C e APÊNDICE D.

Já os cursos que estão subdivididos dentro dos quatro Programas existentes e podem ser melhor visualizados através do APÊNDICE E que é mostrado nesse estudo.

TABELA 2 - Relação da grande área de engenharias.

\begin{tabular}{lccccc}
\hline \multirow{2}{*}{ ÁREA (ÁREA DE AVALIAÇÃO) } & \multicolumn{7}{c}{ Programas de pós-graduação } \\
\cline { 3 - 6 } & Total & M & D & F & M/D \\
ENGENHARIA AEROESPACIAL (ENGENHARIAS III) & 3 & 0 & 0 & 1 & 2 \\
ENGENHARIA BIOMÉDICA (ENGENHARIAS IV) & 10 & 2 & 0 & 3 & 5 \\
ENGENHARIA CIVIL (ENGENHARIAS I) & 62 & 32 & 0 & 9 & 21 \\
ENGENHARIA DE MATERIAIS E METALÚRGICA & 26 & 7 & 0 & 3 & 16 \\
(ENGENHARIAS II) & & & & & \\
ENGENHARIA DE MINAS (ENGENHARIAS II) & 4 & 3 & 0 & 0 & 1 \\
ENGENHARIA DE PRODUÇÃO (ENGENHARIAS III) & 44 & 18 & 0 & 10 & 16 \\
ENGENHARIA DE TRANSPORTES (ENGENHARIAS I) & 8 & 3 & 0 & 0 & 5 \\
ENGENHARIA ELÉTRICA (ENGENHARIAS IV) & 59 & 24 & 0 & 6 & 29 \\
ENGENHARIA MECÂNICA (ENGENHARIAS III) & 58 & 21 & 1 & 11 & 25 \\
ENGENHARIA NAVAL E OCEÂNICA (ENGENHARIAS III) & 3 & 1 & 0 & 0 & 2 \\
ENGENHARIA NUCLEAR (ENGENHARIAS II) & 8 & 2 & 0 & 1 & 5 \\
ENGENHARIA QUÍMICA (ENGENHARIAS II) & 36 & 16 & 2 & 3 & 15 \\
ENGENHARIA SANITÁRIA ( ENGENHARIAS I) & 24 & 11 & 0 & 6 & 7 \\
Brasil: & $\mathbf{3 4 5}$ & $\mathbf{1 4 0}$ & $\mathbf{3}$ & $\mathbf{5 3}$ & $\mathbf{1 4 9}$ \\
\hline
\end{tabular}

Fonte: CAPES, 2010.

\subsection{TÉCNICAS DE ANÁLISE}

Após a obtenção dos sites dos Programas de Pós-graduação em engenharia, busca-se extrair e minerar os dados através das ferramentas webométricas e em 
seguida, a partir de uma análise através dos indicadores webométrico, transformálos em informação e conhecimento.

No processo de avaliação dos dados obtidos são utilizados os indicadores webométricos: tamanho dos sites Web; visibilidade; fator de impacto Web (FIW); luminosidade; e densidade da rede (DR). Esses indicadores foram escolhidos por se destacarem em atuais pesquisas como as de Thelwall e Vaughan (2003); Rodríguez (2006), Vanti Vitullo (2007); e Silva (2008). E para uma melhor compreensão, os indicadores a serem utilizados serão detalhados a seguir:

1. TAMANHO DOS SITES WEB: Define a quantidade de páginas que determinado site possui na Web, seu tamanho é estabelecido através da soma de todas as páginas que fazem parte de um mesmo domínio. (VANTI VITULLO, 2007).

2. VISIBILIDADE: indica como determinado site é conectado ou "citado" pela rede através dos inlinks de domínios de outras instituições, ou seja, relaciona a quantidade de páginas de outras instituições que linkam para o site analisado. (WEBOMETRICS, 2010).

3. FATOR DE IMPACTO WEB (FIW): serve para medir e comparar a atratividade de sites da Web, baseando-se na soma do número de páginas que levam a um determinado site (visibilidade), dividido pelo logaritmo do número de páginas deste site (tamanho), apresentado sob a seguinte fórmula:

$$
F I W=\frac{\text { Visibilida de }}{\log (\text { Tamanho })}
$$

4. LUMINOSIDADE: analisa o número de links externos que um site apresenta, apontando para outros sites ou URLs, ou seja, verifica como o site analisado aponta o resto da Web, indicando o seu grau de conectividade. (RODRÍGUEZ, 2006).

5. DENSIDADE DA REDE: analisa as redes sociais na Web, de forma a mostrar o quanto uma população se relaciona entre si. Para tanto, torna-se imperativo estabelecer a população que deseja estudar ("nós") dentro da Web e, após, 
identificar todas as relações (inks) existentes entre estes "nós". Contudo, divide-se o número de relações (links) pela quantidade de "nós" da população estudada, multiplicando por este mesmo número menos 1. Como mostra a fórmula, sugerida por Vanti Vitullo (2007), a seguir:

$$
D R=\frac{\text { links }}{n \cdot(n-1)}
$$

De tal modo, percebe-se que para o levantamento dos indicadores, faz-se necessário a utilização de determinadas ferramentas. Entre as utilizadas neste estudo citam-se:

1. MOTORES DE BUSCA: também conhecidos como sites de busca, estes têm como finalidade contabilizar o número total de páginas, documentos em determinados formatos e links em um espaço Web.

2. PROGRAMAS MAPEADORES: são softwares que quantificam as unidades de informação.

3. PROGRAMAS PARA ANÁLISE E VISUALIZAÇÃO DE REDES: representam graficamente as relações, comportamentos e propriedades estabelecidas entre diversos atores em uma rede de interação social na Web, utilizando-se de softwares especializados que possibilitam avaliar os vínculos sociais.

Através das ferramentas e indicadores apresentados, os quais são utilizados pela webometria, é que se avalia e mede as informações disponibilizadas no ambiente virtual. Portanto, essa métrica traz subsídios para a melhoria dos sites analisados, através da análise das informações coletadas, colaborando por sua vez com a melhor divulgação da ciência na Web.

A técnica utilizada para aplicação de cada indicador é muito importante para se obter resultados eficientes e diante desse princípio, torna-se oportuno mostrar os passos necessários para aplicação desses indicadores.

Para medir o indicador tamanho dos sites, faz-se o uso do motor de busca Google na sua interface de pesquisa avançada 
(http://www.google.com.br/advanced_search?hl=pt-BR) o qual totaliza, através de um Ranking, o número total de páginas de cada site analisado. A escolha deste buscador deve-se ao fato de que o Google conta com uma base de dados mais abrangente do que outros buscadores, mostrando um número maior de páginas pertencentes a um mesmo site, o que o torna mais adequado para mensurar 0 tamanho destes. (VANTI VITULLO, 2007).

No indicador visibilidade utiliza-se o motor de busca Yahoo, porém em sua interface de pesquisa avançada (https://siteexplorer.search.yahoo.com/br/mysites), que permite selecionar somente os inlinks externos, ou seja, os links de outros sites que remetem ao site analisado. Com esse indicador é possível saber como determinado site é "citado" na rede, o que define o seu reconhecimento no âmbito virtual. $\mathrm{O}$ motor de busca Yahoo foi escolhido por oferecer delimitadores adequados para este tipo de busca.

O fator de impacto Web (FIW) permite definir o nível de atratividade de cada site analisado ao relacionar o número total de links que determinado site recebe de outras instituições pelo logaritmo da quantidade de páginas que o site analisado possui. Conforme é mostrado na Fórmula (1) anteriormente.

Para quantificar a luminosidade se utiliza o software Xenu Link Sleuth (http://home.snafu.de/tilman/xenulink.html) que mapeia os sites, ao entrar em seus domínios e diretórios, e, consequentemente, extrai informações através dos links dos sites, disponibilizando uma listagem detalhada dos links internos (links que remetem a páginas dentro do seu próprio domínio), links externos (links de outras instituições que remetem a página analisada), links válidos (links que remetem a páginas disponíveis) e links quebrados (links que remetem a páginas não disponíveis). (SILVA, 2008). A partir dessa listagem é possível definir quais e quantos sites citam a página analisada, e dessa forma, estabelecer o grau de conectividade desse site na rede.

Com o propósito de obter os dados do indicador densidade da rede dos sites em questão, utilizam-se novamente as informações obtidas através do software Xenu Link Sleuth. A partir de uma análise do mapeamento dos links de cada site dos PPG's em Engenharias das IES do Brasil é possível estabelecer uma matriz de adjacências, que apontará quais das instituições abarcadas nesse estudo estão se conectando via Web. A partir desses dados é possível aplicar o cálculo de densidade 
da rede (fórmula (2)) que é estabelecida através da relação da população que deseja estudar ("nós") dentro da Web com as relações (links) de um mesmo tipo existente entre estes nós.

A partir das observações acerca da densidade da rede é possível representar essa densidade através de grafos que mostram as redes de "nós" existentes entre os sites desse estudo. Para tanto, se utiliza o software Ucinet6 (http://www.analytictech.com/ucinet/) para criar a matriz de adjacências em formato DL. Após essa transformação é utilizado o software NetDraw (http://www.analytictech.com/) que importa a matriz em formato DL e gera o grafo que representa a rede de "nós" existentes.

Através das ferramentas e indicadores apresentados, é elaborado um Ranking, o qual apresenta em nível decrescente a relação dos programas que mais se destaca nesse estudo, levando em consideração valores que se referem aos determinados pesos, conforme é apresentado na TABELA 3 que se segue:

TABELA 3 - Relação do peso dos indicadores.

\begin{tabular}{lc}
\multicolumn{1}{c}{ INDICADORES } & PESOS \\
\hline VISIBILIDADE & $50 \%$ \\
FATOR DE IMPACTO WEB & $20 \%$ \\
LUMINOSIDADE & $20 \%$ \\
TAMANHO DO SITE & $10 \%$ \\
TOTAL & $\mathbf{1 0 0 \%}$ \\
\hline
\end{tabular}

Fonte: Elaborado pela autora.

Nessa perspectiva, a densidade da rede não está incluída nesse peso, visto que este indicador apresenta seus resultados através de grafos, indicando as conexões existentes. Como pode ser observado na TABELA 3, o peso atribuído ao indiciador visibilidade é mais alto que a dos outros indicadores $(0,5$, ou $50 \%$,). Já para o Fator de Impacto e para a Luminosidade o peso utilizado foi $(0,2$ ou $20 \%)$. Enquanto que para o Tamanho do site, o peso a ser contabilizado é de $(0,1$ ou $10 \%)$.

A justificativa para a definição desses valores deve-se ao fato de que a visibilidade se refere ao reconhecimento científico de cada site na Web e por este ser um dos indicadores mais utilizados nas pesquisas webométricas atualmente. $O$ 
Fator de impacto Web obteve tal peso por medir o nível de atratividade de cada site, o que está inteiramente relacionado com sua visibilidade. Já o indicador Luminosidade por se referir a quantidade de links que remetem a outras páginas fora do seu domínio, contribuindo diretamente com a disseminação de fontes de informação. E por fim, o Tamanho do site obteve tal peso por apresentar dados que se referem à quantidade de páginas que o site possui, ou seja, a estrutura do site.

Os valores estabelecidos no peso dos indicadores são baseados no trabalho do Grupo de pesquisa Cybermetrics Lab, responsáveis pelo Webometrics Ranking of World Universities, como também em estudos recentes como o de Aguillo, Ortega e Fernandez (2008); Aguillo (2009); Aguillo et al (2010a) e Aguillo et al (2010b).

Através dos indicadores webométricos é possível medir as informações disponibilizadas no ambiente virtual, podendo estabelecer melhorias nos sites analisados, através da análise das informações coletadas, colaborando por sua vez com a melhor divulgação da ciência na Web.

Dentre a seleção dos sites, visto o objeto de pesquisa do determinado estudo, foram selecionados apenas os sites que se referem às Instituições de Ensino Superior que possuem Mestrado e Doutorado,

Foram descartadas as URL's que possuem subdiretórios, como por exemplo: http://www.unifei.edu.br/pos-graduacao/engenharia-producao/mestrado-engenhariaproducao, pois essa URL pode trazer resultados errôneos neste estudo visto que o buscador utilizado pode confundir as páginas disponibilizadas pelo domínio (www.unifei.edu.br), e pelos diretórios (/pos-graduacao/) e subdiretório (/engenhariamecanica/mestrado-doutorado-engenharia-mecanica) podendo ser acrescentado links de páginas não relacionadas com o estudo em questão.

Também foram descartados os sites duplicados, os quais suas respectivas URL's remetem para uma mesma página, e sites que se encontram em manutenção. Desse modo, dos cento e quarenta e nove (149) sites, apenas cento e nove (109) sites dos Programas de Pós-Graduação em Engenharias das IES do Brasil estão contemplados nesse estudo, conforme mostra a FIGURA 1 a seguir: 
FIGURA 1 - Relação percentual dos sites analisados.

Filtro 1: sites de Programas de Pós-

Graduação em engenharias

Filtro 2: sites com Mestrado e

Doutorado.

Filtro 3: sites ativos e sem subdiretórios

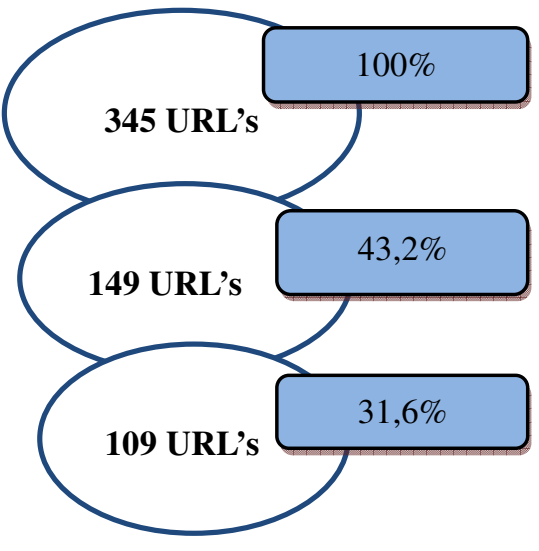

Fonte: Elaborado pela autora.

A partir da análise webométrica desses 109 sites que se referem a 31,6\% do total existente e disponível para a realização do estudo, pretende-se verificar as conexões e disponibilização de informações científicas na Web dos PPG's em Engenharias das IES, conceituados pela CAPES.

Verifica-se que os 109 sites a serem analisados estão distribuídos em grupos de engenharias, conforme é mostrado no GRÁFICO 1 que segue:

GRAFICO 1 - Quantidade de Programas de Pós-graduação por Grupo de Engenharias.

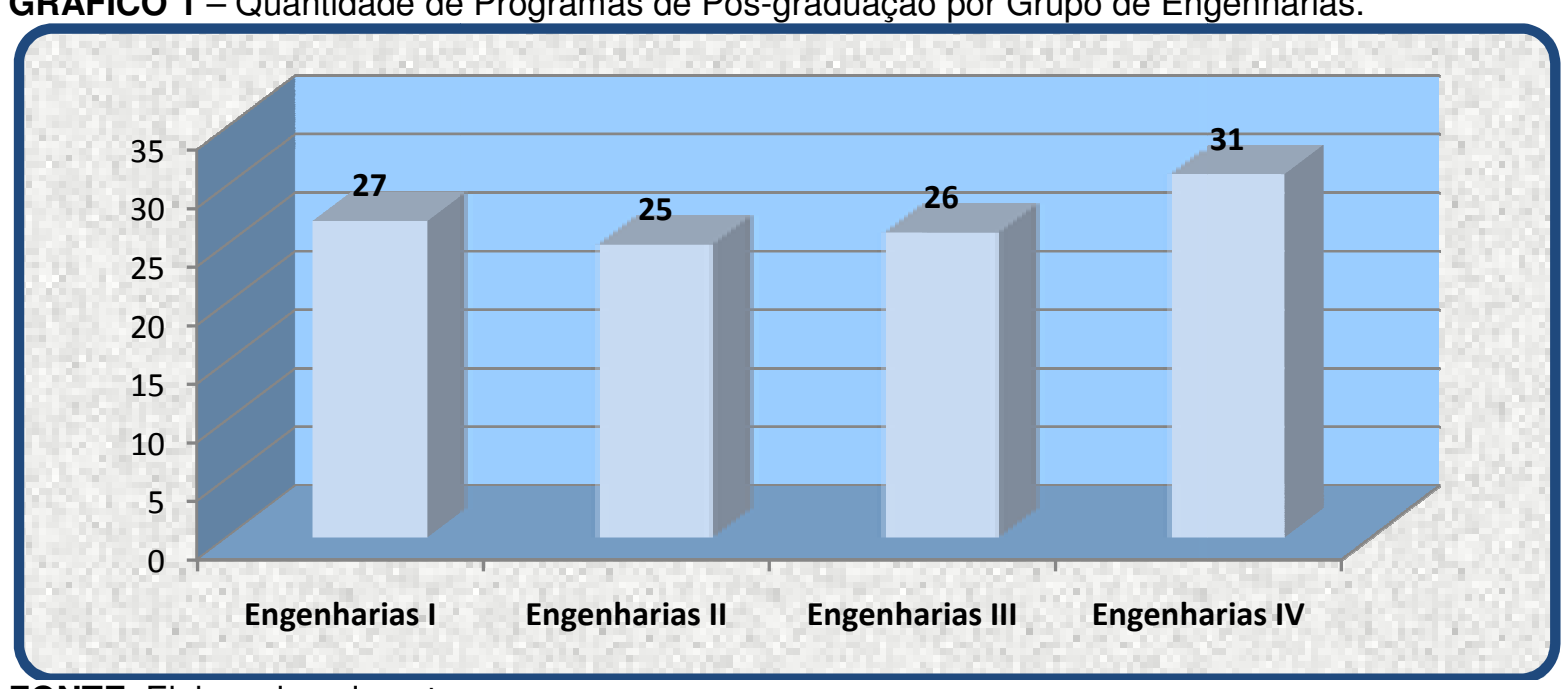

FONTE: Elaborado pela autora.

Da mesma forma, esses Programas estão divididos entre trinta e cinco (35) Instituições de Ensino Superior, conforme é apresentado no GRÁFICO 2, a seguir: 
GRÁFICO 2 - Quantidade de sites analisados por IES.

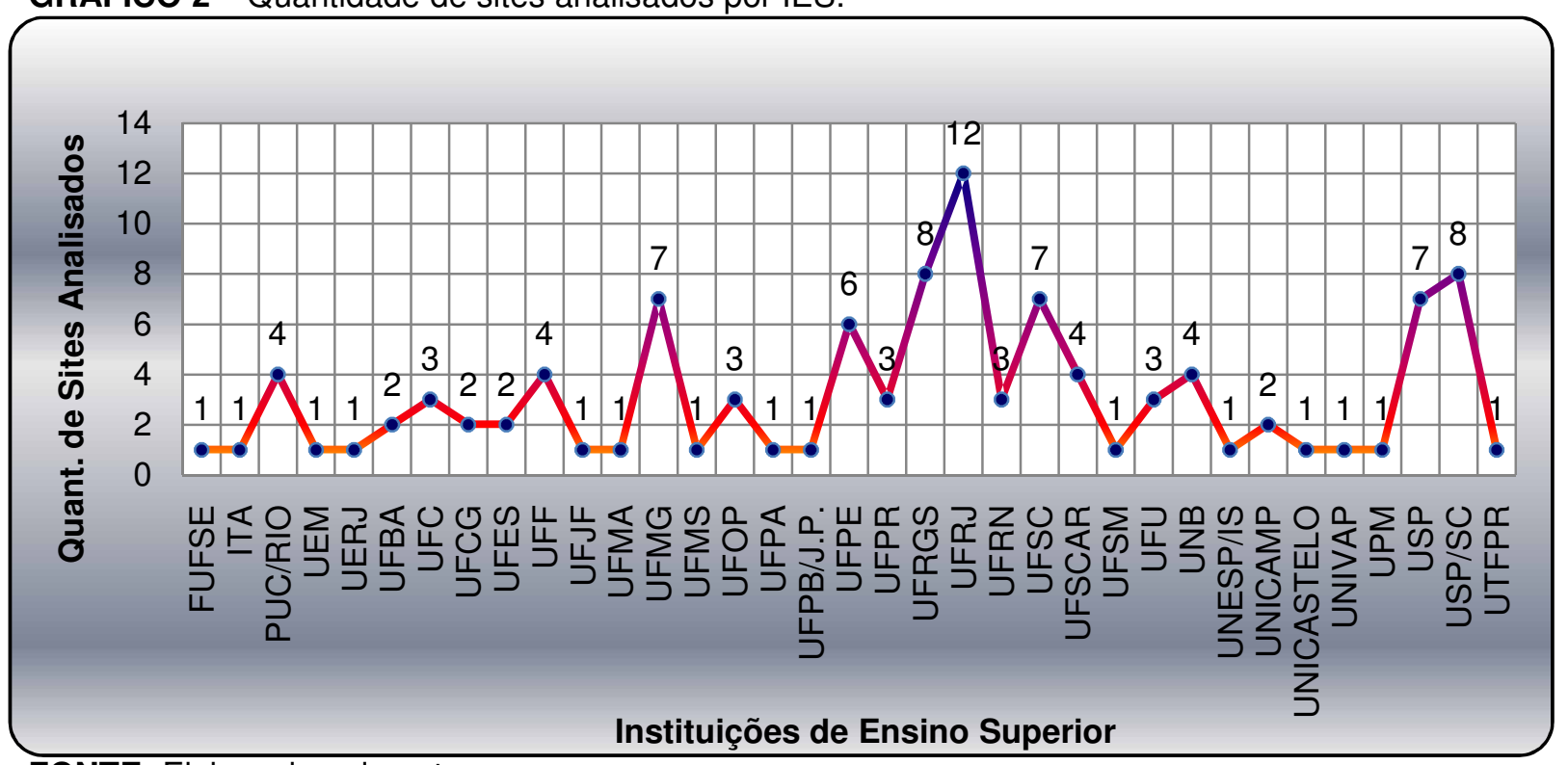

FONTE: Elaborado pela autora.

As 35 Instituições que integram este estudo possuem PPG's em diversos grupos das engenharias e a distribuição desses programas por IES podem ser melhor visualizada através do GRÁFICO 3, GRÁFICO 4, GRÁFICO 5 e GRÁFICO 6 , a seguir:

GRÁFICO 3 - IES com PPG's que integram as engenharias I.

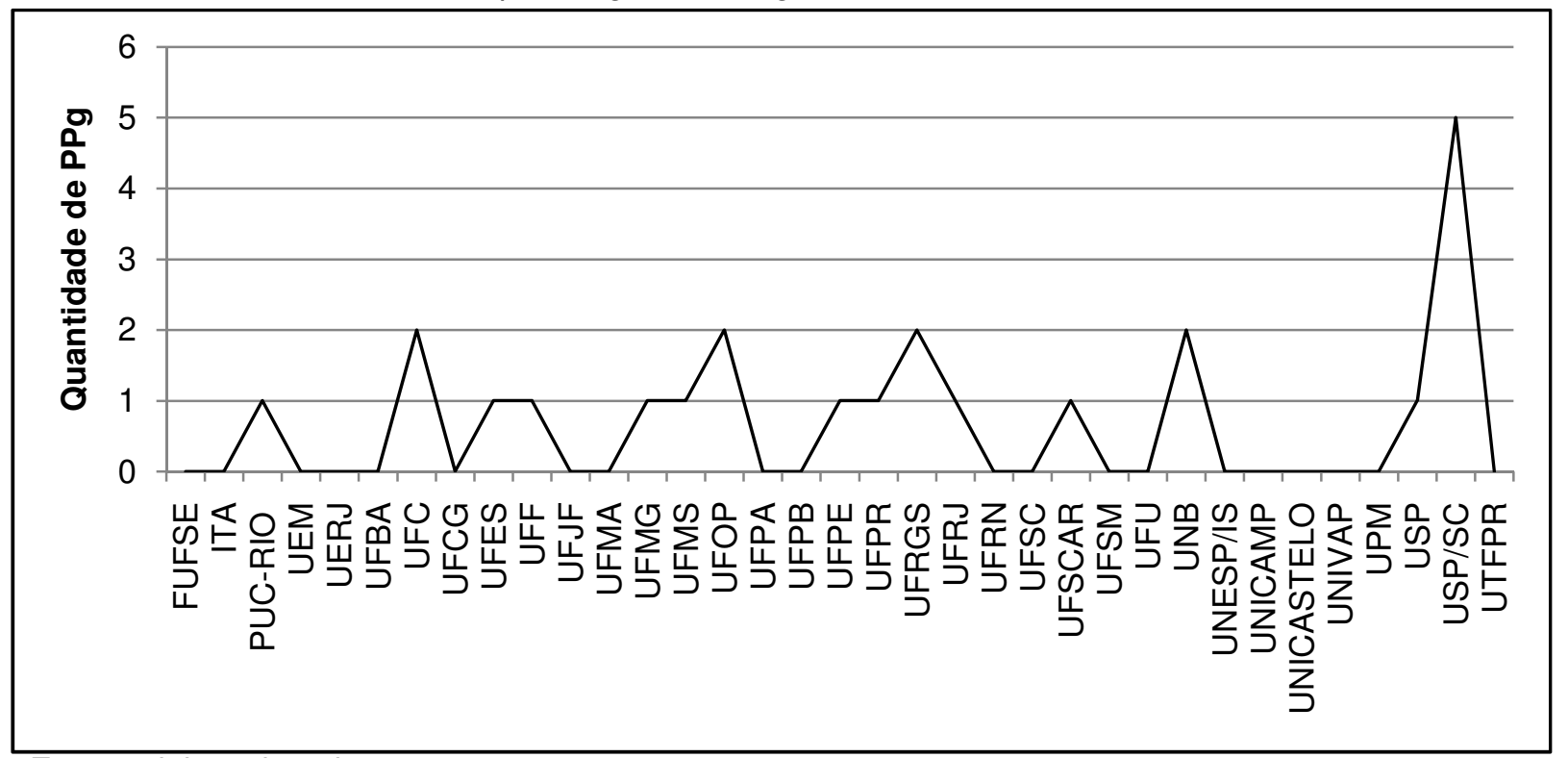

Fonte: elaborado pela autora.

Através do GRÁFICO 3 é percebido que os 23 programas de pós-graduação que integram as engenharias I estão distribuídos entre $15 \mathrm{IES}$, sendo que a Universidade de São Paulo, campus São Carlos é a instituição que possui uma maior quantidade de programas nas engenharias I que participam desse estudo. 
GRÁFICO 4 - IES com PPG's que integram as engenharias II.

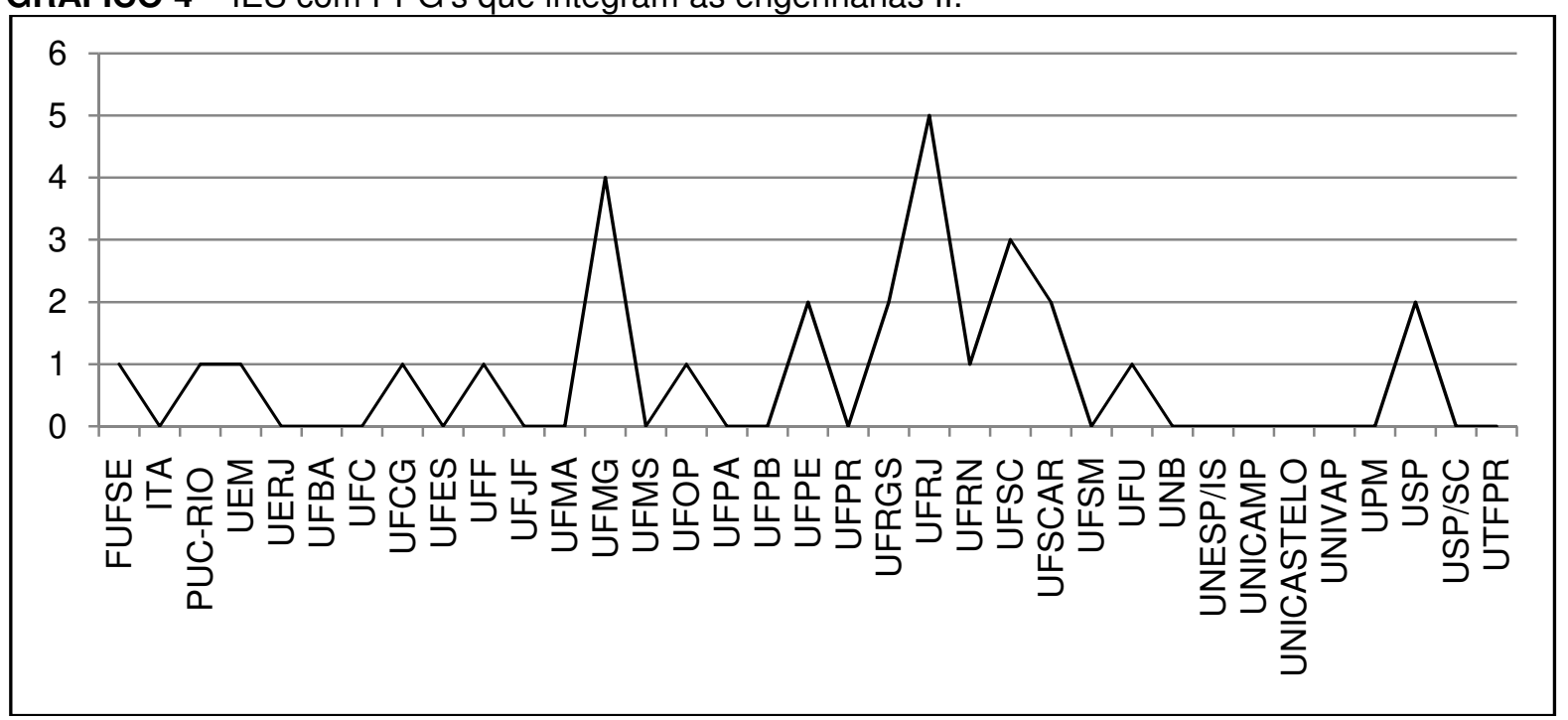

Fonte: elaborado pela autora.

O GRÁFICO 4 mostra que 28 PPG's integram as engenharias II e que estes programas estão dispersos entre 15 Universidades, sendo que a Universidade Federal do Rio de Janeiro oferece a maior quantidade de PPG's nas engenharias II.

GRÁFICO 5 - IES com PPG's que integram as engenharias III.

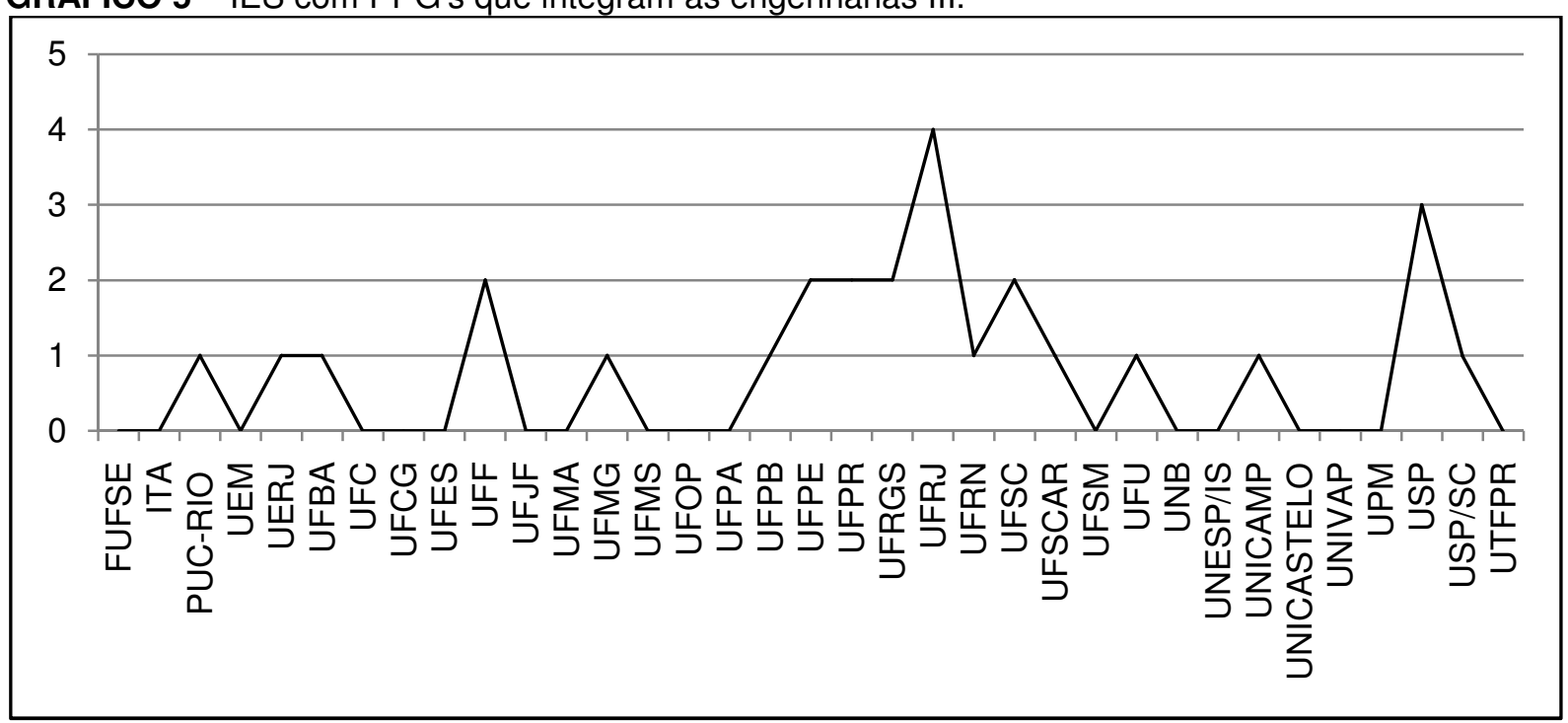

Fonte: elaborado pela autora.

O GRÁFICO 5 mostra que há 27 Programas de Pós-graduação participantes desse estudo e que 17 IES disponibilizam esses cursos, sendo que a Universidade Federal do Rio de Janeiro é a que mais possui cursos que integram as engenharias III, assim como também as engenharias II, conforme foi exposto anteriormente. 
GRÁFICO 6 - IES com PPG's que integram as engenharias IV.

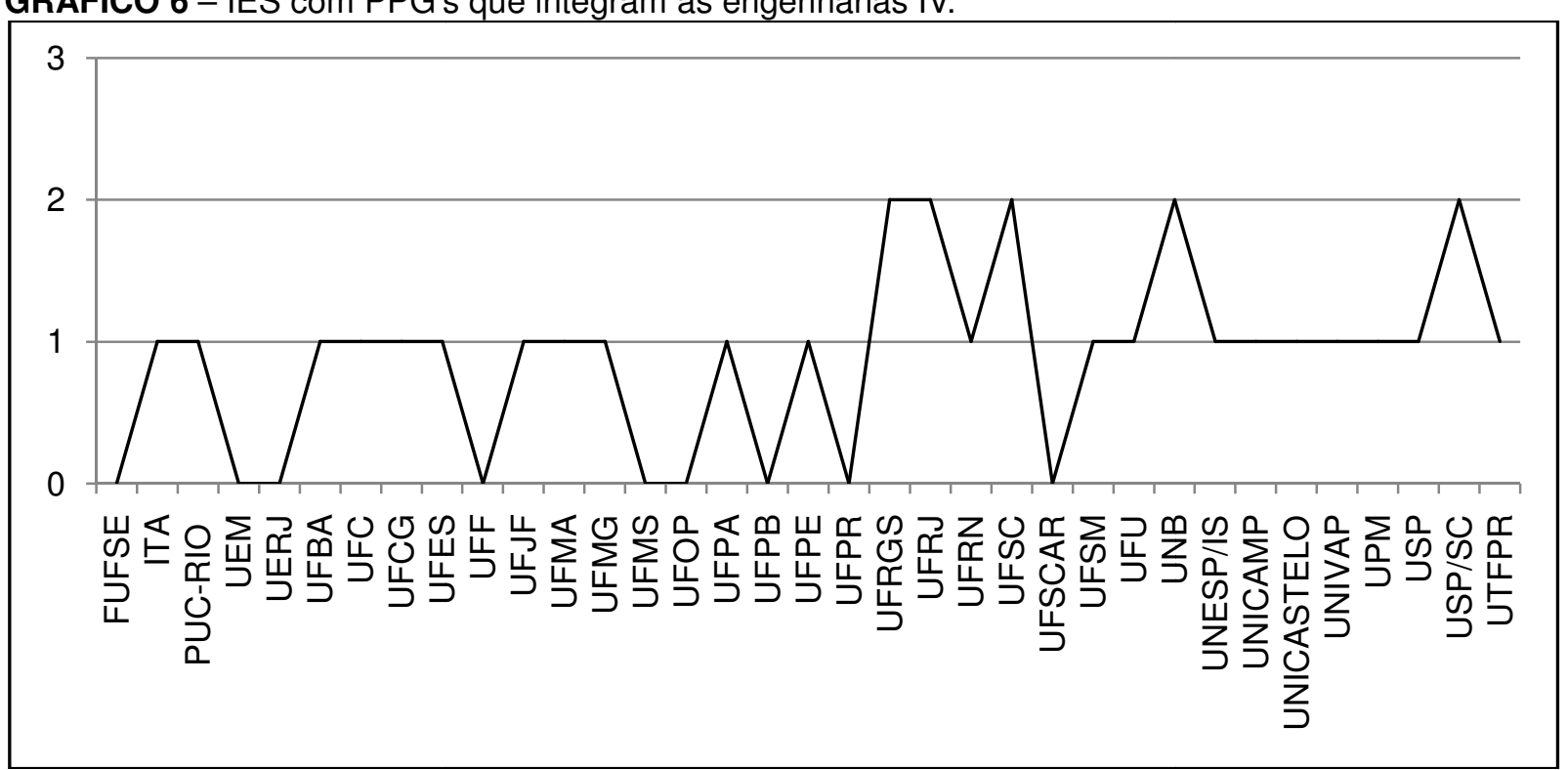

Fonte: elaborado pela autora.

Ao se analisar o GRÁFICO 6, pode-se ressaltar que 31 programas de pósgraduação integram as engenharias IV nesse estudo e estes PPG's estão dispersos entre 26 IES. Fato que nos faz perceber que o grupo de Engenharias IV são os que apresentam uma maior quantidade de universidades participando desse estudo.

Nessa perspectiva, observa-se que as 35 IES que fazem parte desse estudo estão localizadas em quatro das cinco regiões brasileiras, conforme é apresentado no GRÁFICO 7, que segue:

GRÁFICO 7 - Percentual das IES por regiões brasileiras.

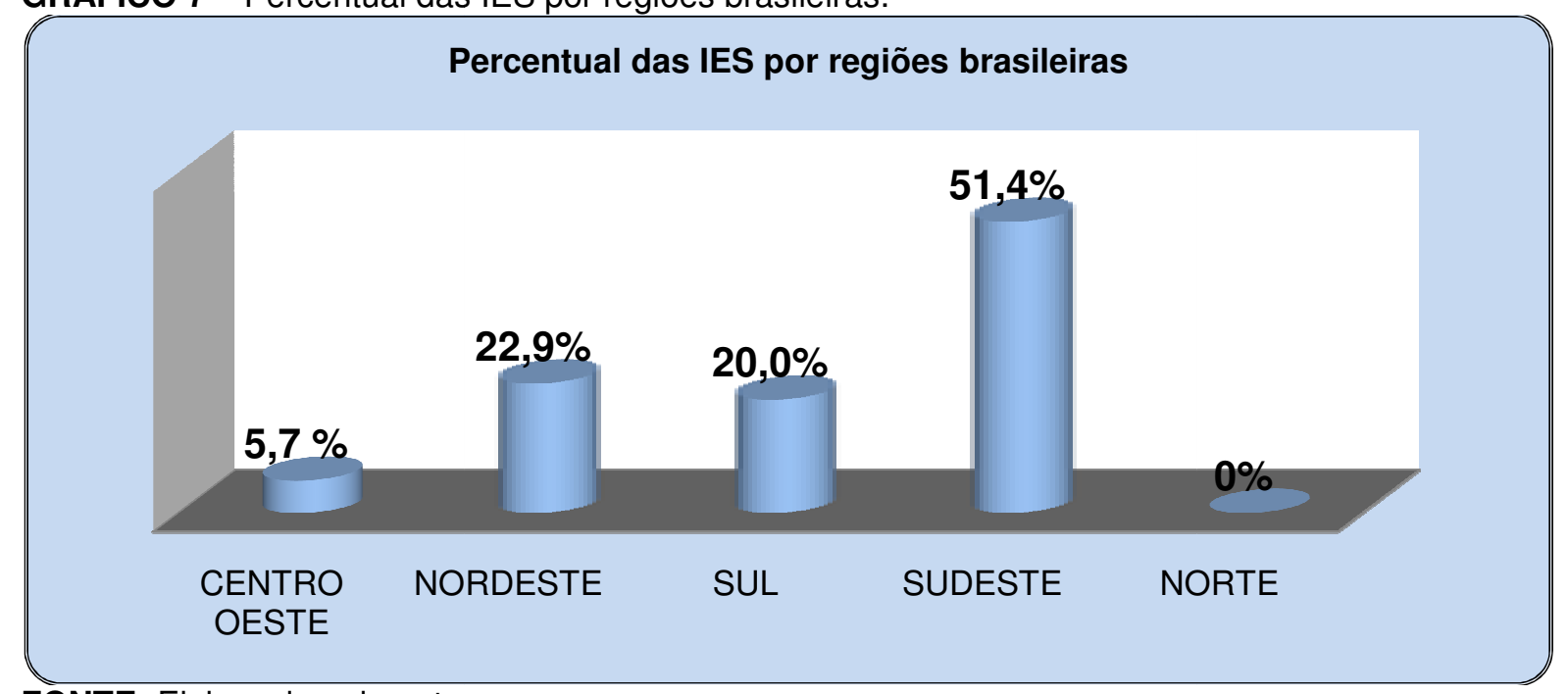

FONTE: Elaborado pela autora. 
A partir da análise do gráfico acima, verifica-se que $51,4 \%$ dessas IES são parte integrante da região Sudeste do Brasil, 22,9\% pertence à região Nordeste, 20,0\% é da região Sul e 5,7\% encontram-se na região Centro-Oeste, observando-se que as IES da região Norte não se integraram neste estudo, devido aos critérios estabelecidos na pesquisa.

A partir da análise dos sites dos Programas de Pós-graduação em Engenharias dessas IES brasileiras, será possível verificar a funcionalidade das ferramentas e indicadores webométricos na avaliação da execução operacional dos sites institucionais e identificar quais PPG's em Engenharias das Instituições de Ensino Superior se destacam nos quesitos de disponibilidade de informações e comunicação científica na Web. 
Capítulo 5

\section{ANÁLISE DOS RESULTADOS E DISCUSSÕES}

O presente capítulo tem o objetivo de apresentar os dados coletados nessa pesquisa. E através dos mesmos, descrever uma análise dos principais resultados obtidos através da aplicação das ferramentas e indicadores webométricos.

Inicialmente são apresentados os resultados da análise comparativa dos grupos de engenharias, ou seja, engenharias I, II, III e IV. Posteriormente são analisados os resultados encontrados em cada Programa de Pós-graduação.

Por fim, são apresentadas as conexões de rede existentes entre os Programas de Pós-graduação de cada grupo de engenharias, em seguida é apresentada a rede totalitária que mostra todas as conexões que existem entre os PPG's que fazem parte deste estudo. Para tanto, foi utilizado o indicador densidade da rede que serviu como base para a definição das conexões existentes.

\subsection{RESULTADOS DA PESQUISA APLICADA AOS GRUPOS DE ENGENHARIAS}

Os resultados aqui apresentados estão de acordo com a análise de quatro (4) indicadores webométricos, estes foram aplicados aos grupos de engenharias I, II, III e IV, com o objetivo de identificar quais destes se destacam nos índices webométricos.

Estes grupos de engenharias também foram analisados através do ranking webométrico, que se trata da soma de todos os indicadores aqui apresentados, conforme foi exposto anteriormente através da TABELA 3.

Através desse ranking webométrico torna-se possível ter um panorama geral dos dados coletados, indicando qual das engenharias está se destacando no espaço Web, através de fluxo informacional existente na rede Web.

\subsubsection{Análise comparativa dos grupos de engenharias de acordo com 0 indicador tamanho dos sites}

Ao analisar o grupo de engenharias I no GRÁFICO 8, se verifica que o Programa de Engenharia civil da UFRJ destaca-se com um total de 16.600 páginas em seu domínio Web, seguida pelo PPG em Engenharia (engenharia de estruturas) 
da USP/SC com um total de 6.290 páginas e em seguida apresenta-se o programa de Engenharia de transportes da UFC com 5.430 páginas.

Observa-se o que a Universidade Federal do Rio de Janeiro apresenta uma quantidade bastante significativa de páginas no site do Programa de Pós-graduação em Engenharia civil, destacando-a intensamente em meio aos demais sites analisados. E torna-se oportuno enfocar que este site disponibiliza grande quantidade de informações acerca do seu PPG, de seus grupos de pesquisa e das páginas de seus docentes, fato que pode ter contribuído com o resultado apresentado.

GRÁFICO 8 - Análise do indicador tamanho nas engenharias I.

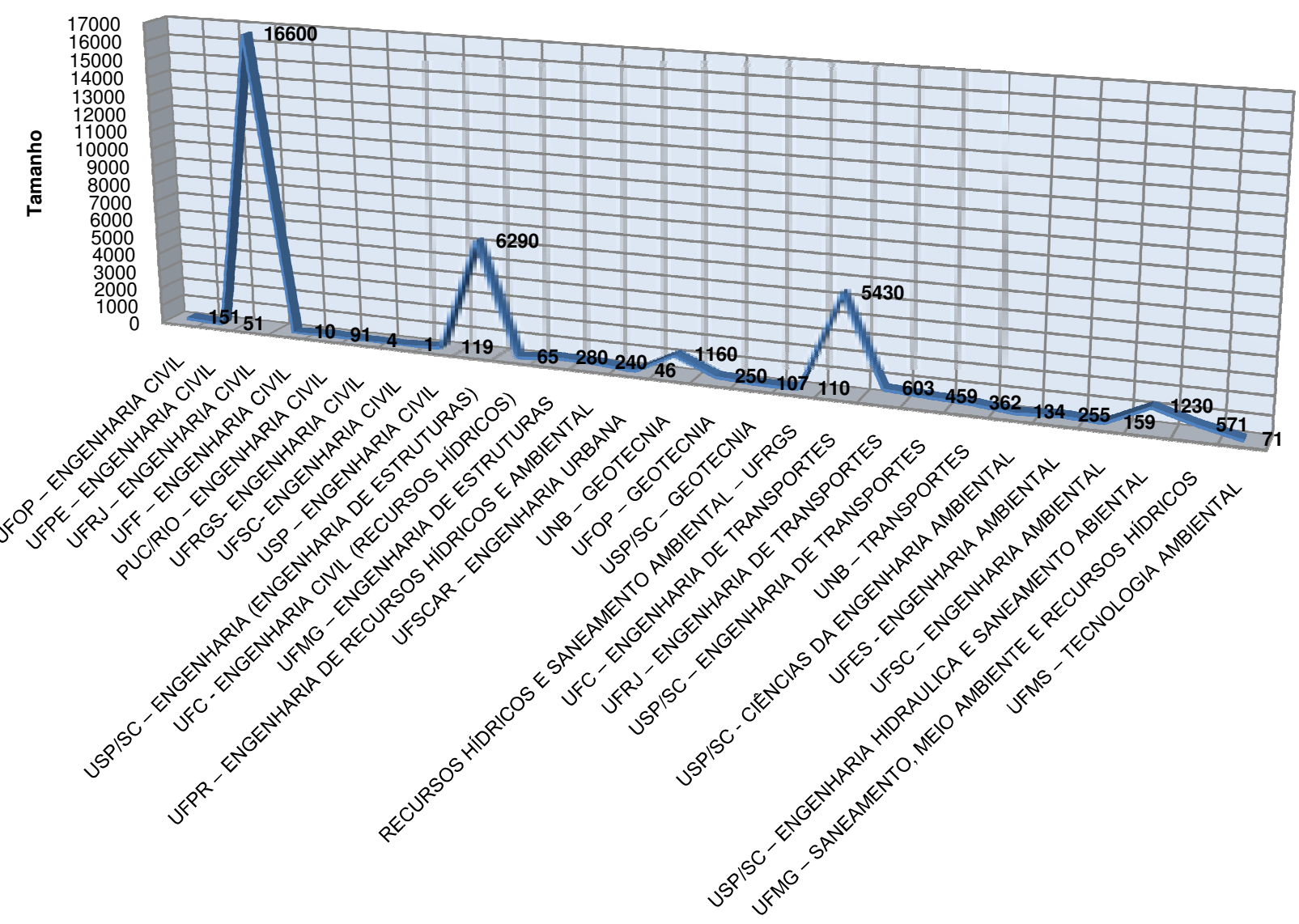

Programas de pós-graduação em engenharias I

FONTE: Elaborado pela autora. 
Ao se analisar o indicador tamanho nas engenharias $I$, nota-se que 0 programa de Engenharia de materiais e de processos químicos e metalúrgicos da PUC-RIO apresenta um valor de 1.310 páginas, seguido pelo PPG em Ciência e tecnologia de polímeros da UFRJ com um total de 896 páginas e pelo programa de Tecnologia de processos químicos e bioquímicos também da UFRJ.

Desse modo, observa-se que as universidades do Rio de Janeiro se destacam das demais quando analisado o tamanho das páginas dos sites dos PPG's que fazem parte do grupo de Engenharias II.

GRÁFICO 9 - Análise do indicador tamanho nas engenharias II.

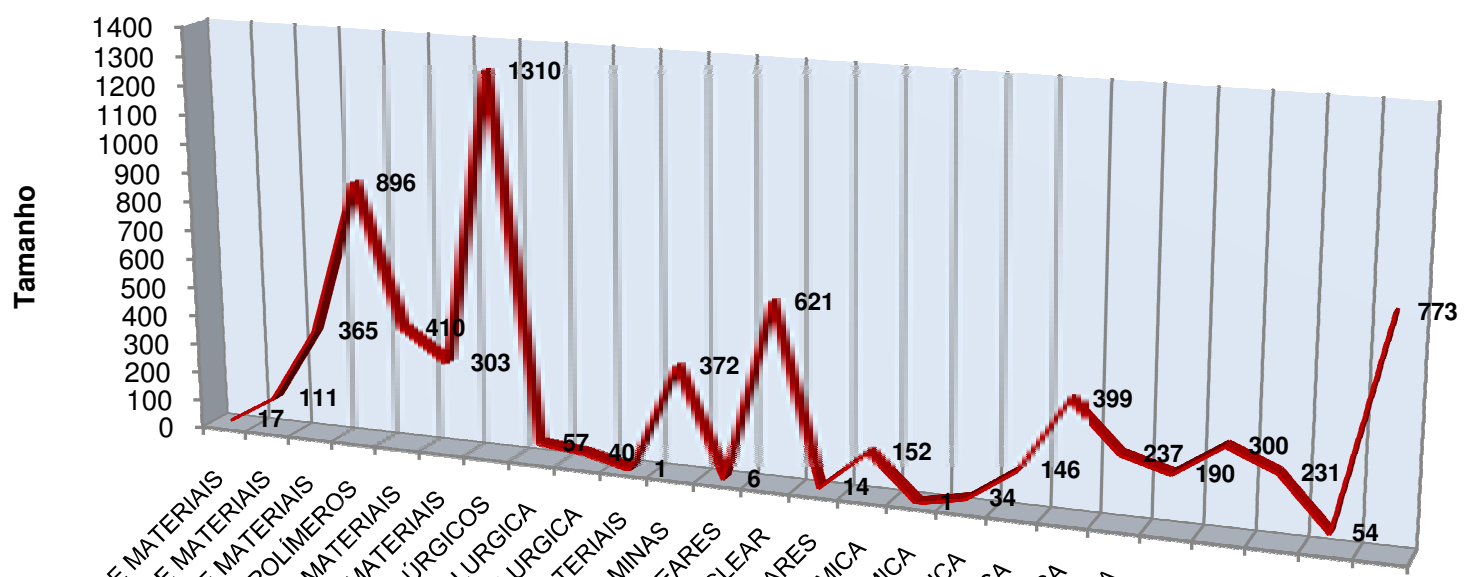

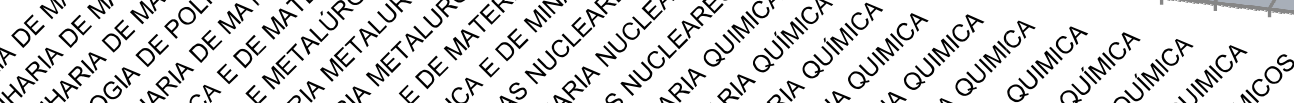

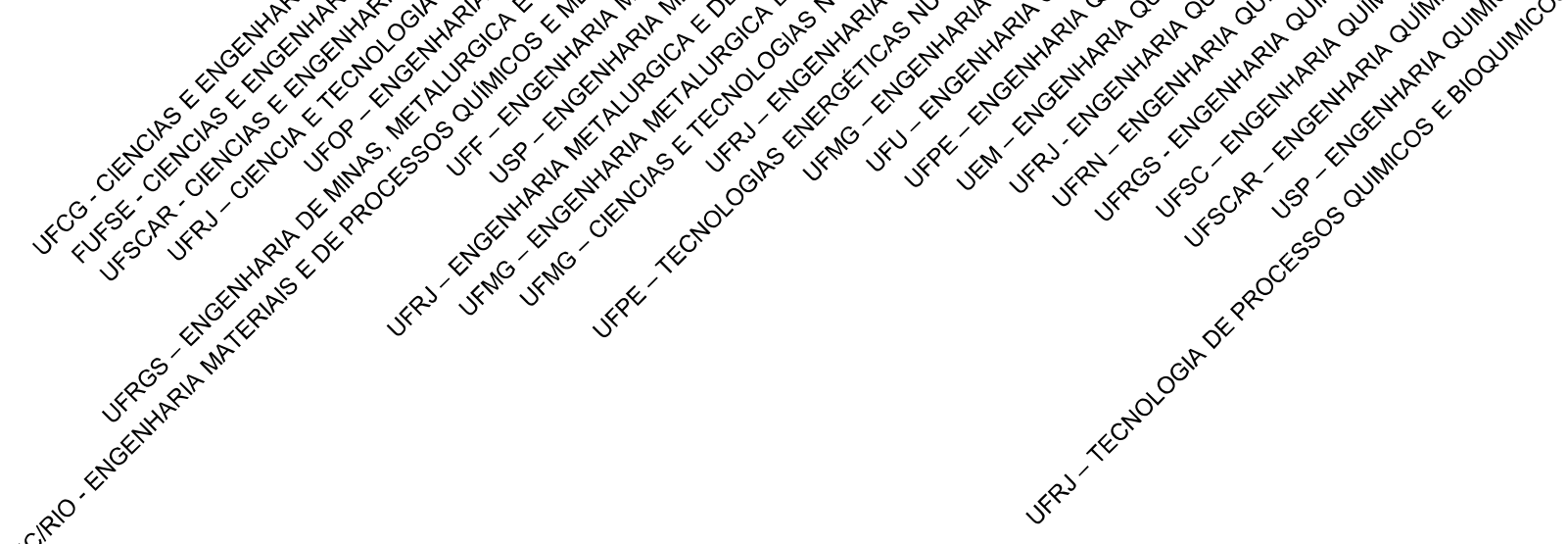

Programas de pós-graduação em engenharias II

FONTE: Elaborado pela autora. 
Quando aplicado o indicador tamanho no grupo das engenharias III, verificase que o Programa de Engenharia oceânica da UFRJ apresenta um total de 9.850 páginas. Desse modo, observa-se que outro PPG da Universidade Federal do Rio de Janeiro também se destaca no grupo de engenharias III. Em seguida apresenta-se o PPG em engenharia de produção da UFRGS com 2.300 páginas e o programa de Engenharia mecânica da UFPB com 1.440 páginas.

GRÁFICO 10 - Análise do indicador tamanho nas engenharias III.

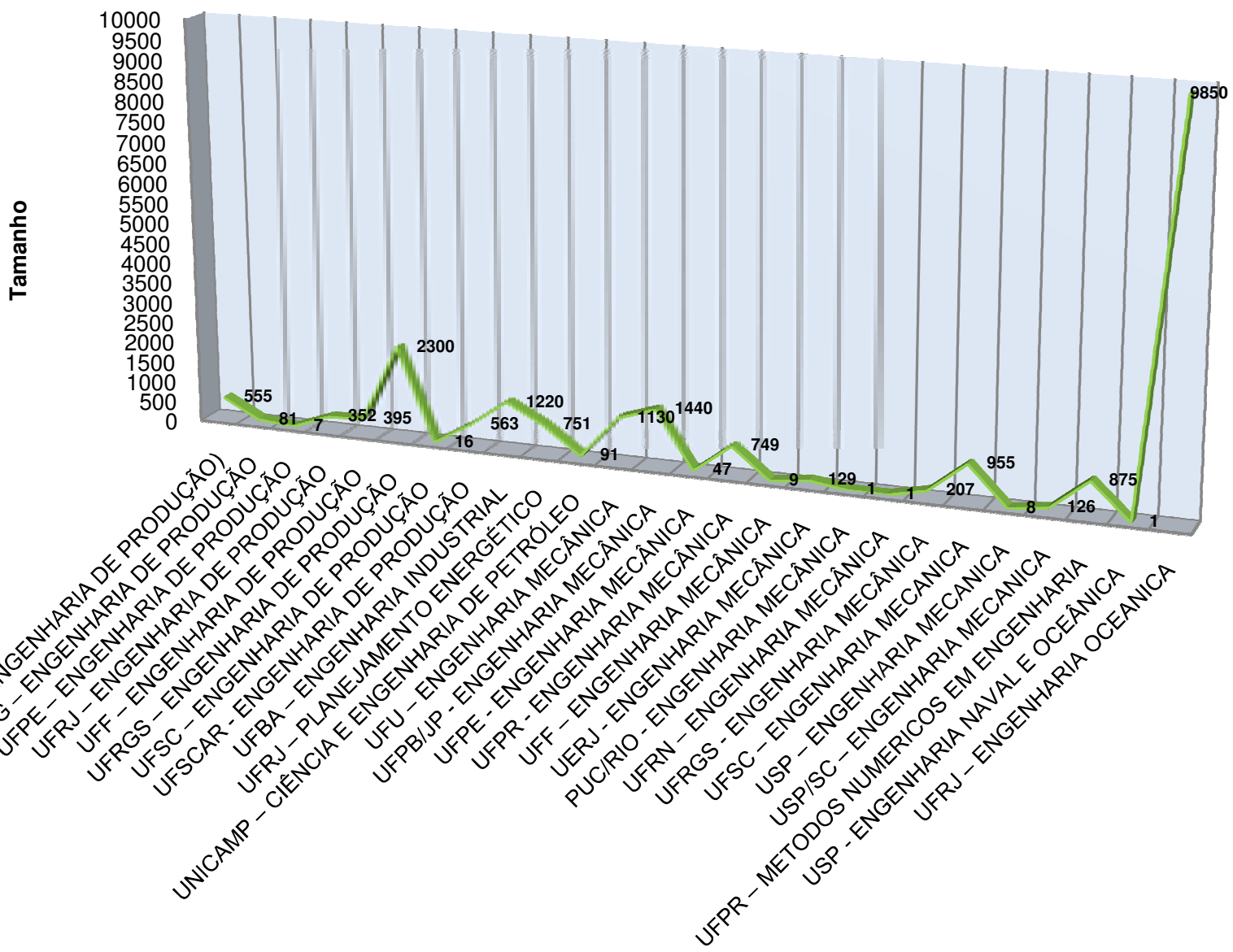

Programas de pós-graduação em engenharias III

FONTE: Elaborado pela autora. 
Ao analisar o gráfico abaixo se percebe que o Programa com maior número de páginas que faz parte do grupo de Engenharias IV é o PPG em Engenharia elétrica da UFCG com 3.750 páginas no domínio de seu site, seguido pelo programa em Engenharia elétrica da UFRJ e pelo programa de Engenharia de eletricidade da UFMA.

GRÁFICO 11 - Análise do indicador tamanho nas engenharias IV.

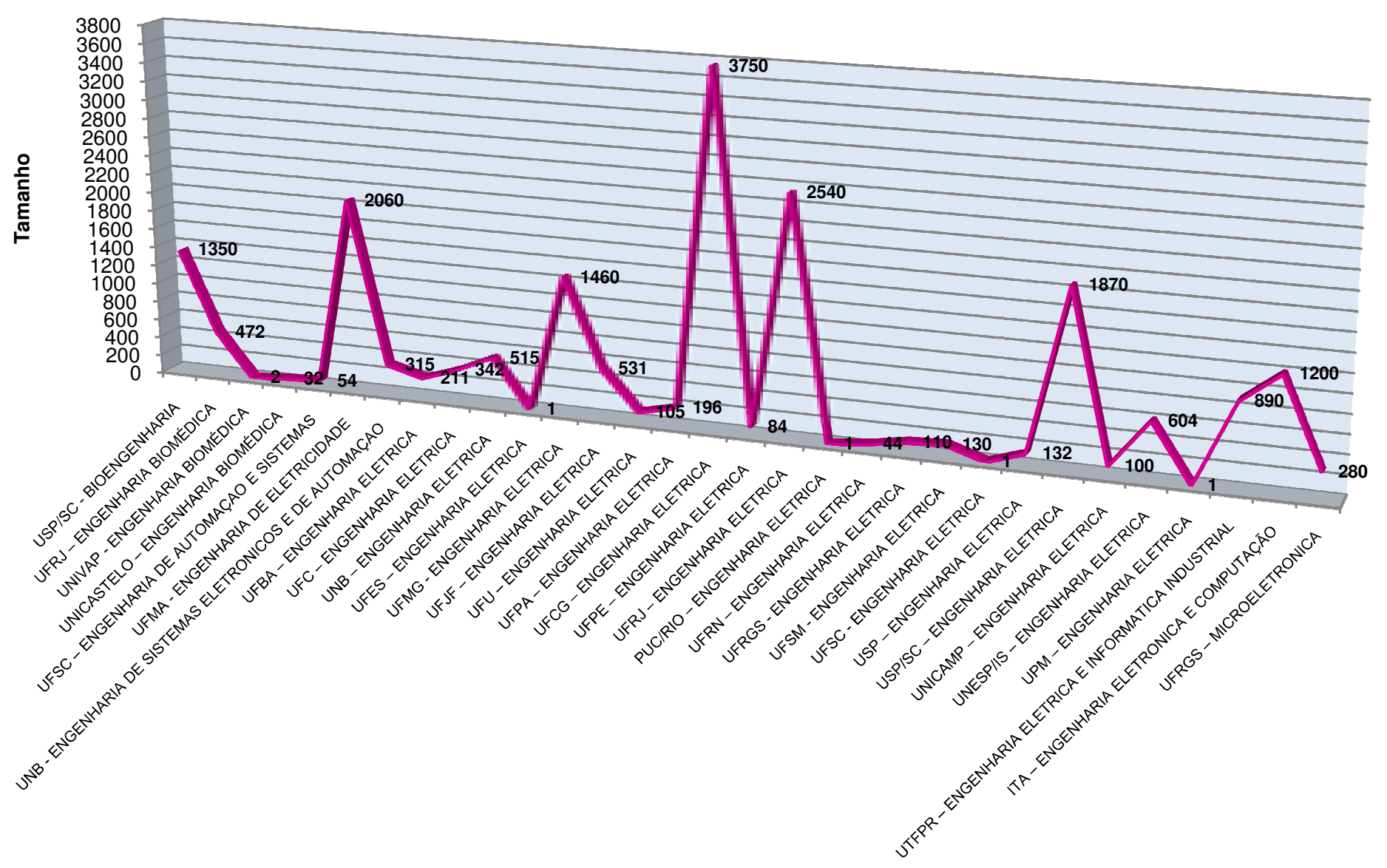

Programas de pós-graduação em engenharias IV

FONTE: Elaborado pela autora. 
Através dos dados obtidos pôde-se fazer uma análise comparativa entre os grupos de engenharias e verificou-se que as Engenharias I destaca-se como sendo o grupo que possui um maior número de páginas nos sites dos seus PPG's. E, apesar desta possuir alguns PPG's com tamanho de páginas relativamente pequeno, verifica-se que o somatório do número de páginas de todo o grupo é bastante elevado, totalizando o valor de 34.849 páginas de sites que integram as Engenharias I.

Logo em seguida destacam-se, respectivamente, as Engenharias III com 21.859 páginas, Engenharias IV com 19.383 páginas e por fim as Engenharias II com um total de 7.040 páginas. Conforme é mostrado no GRÁFICO 12, que segue:

GRÁFICO 12 - Análise do indicador tamanho por grupos de engenharias.

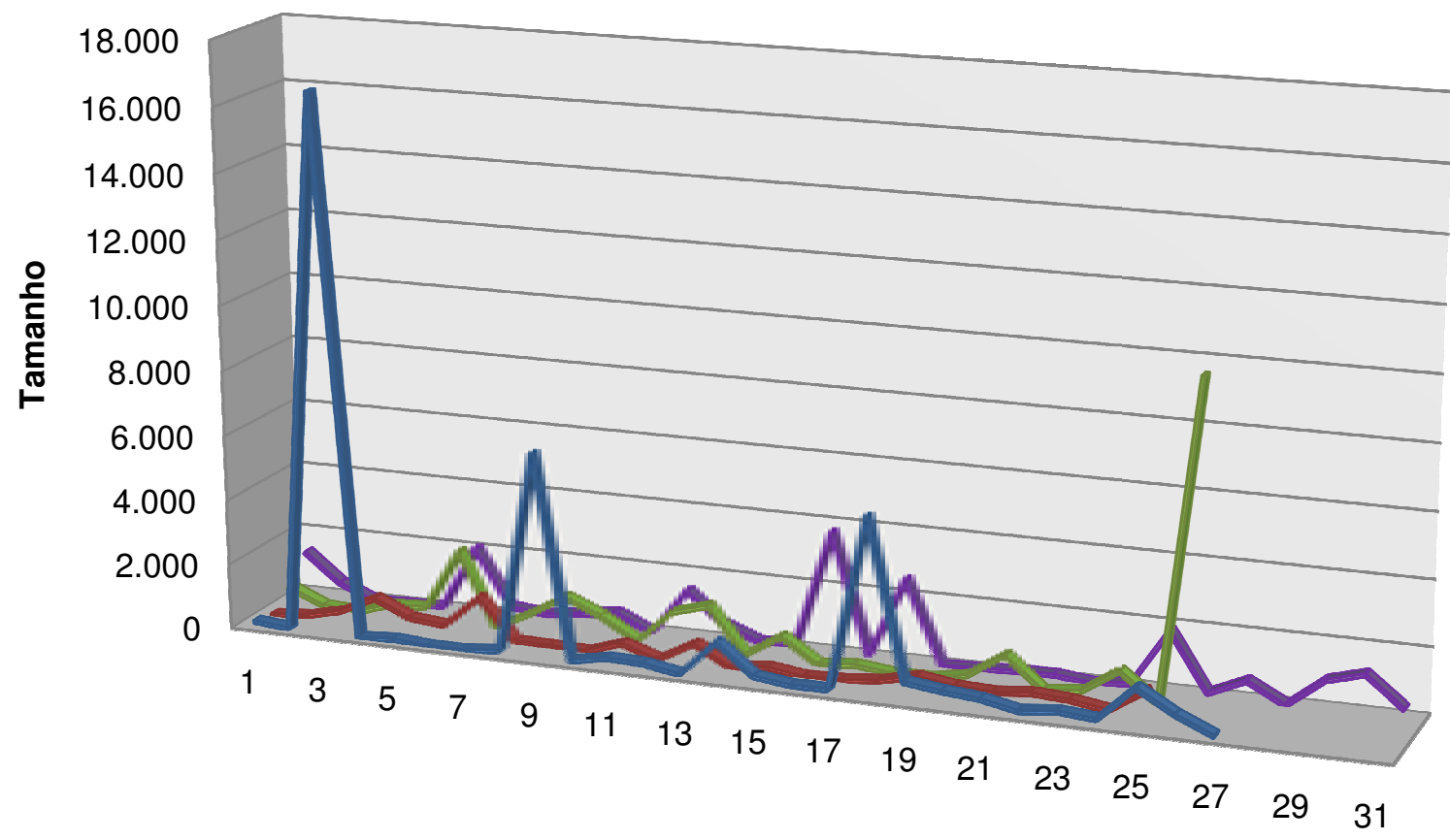

Programas de Pós-graduação

¿Engenharias $\mathrm{I}($ Tamanho=34.849)

$\square$ Engenharias III(Tamanho=21.859) $\square$ Engenharias $I($ Tamanho=7.040)

$\square$ Engenharias IV(Tamanho=19.383)

FONTE: Elaborado pela autora. 
Esse resultado nos dá a possibilidade de ressaltar que os PPG's que integram as Engenharias I, possuem uma maior disponibilização de informações na web, visto a quantidade de páginas disponibilizadas virtualmente, fato este, que favorece uma maior disseminação na Web de informações acerca das engenharias que englobam o Grupo de Engenharias I.

\subsubsection{Análise comparativa dos grupos de engenharias de acordo com 0 indicador visibilidade}

Ao se aplicar o indicador visibilidade no grupo de engenharias I, observa-se que o Programa de Engenharia civil da PUC/RIO possui um total de 39 links de outras instituições que remetem as suas páginas, em seguida apresenta-se o PPG em Engenharia de transportes da UFRJ e o da USP/SP, ambos com 38 links em sua visibilidade, conforme é mostrado no gráfico abaixo.

GRÁFICO 13 - Análise do indicador visibilidade nas engenharias I.

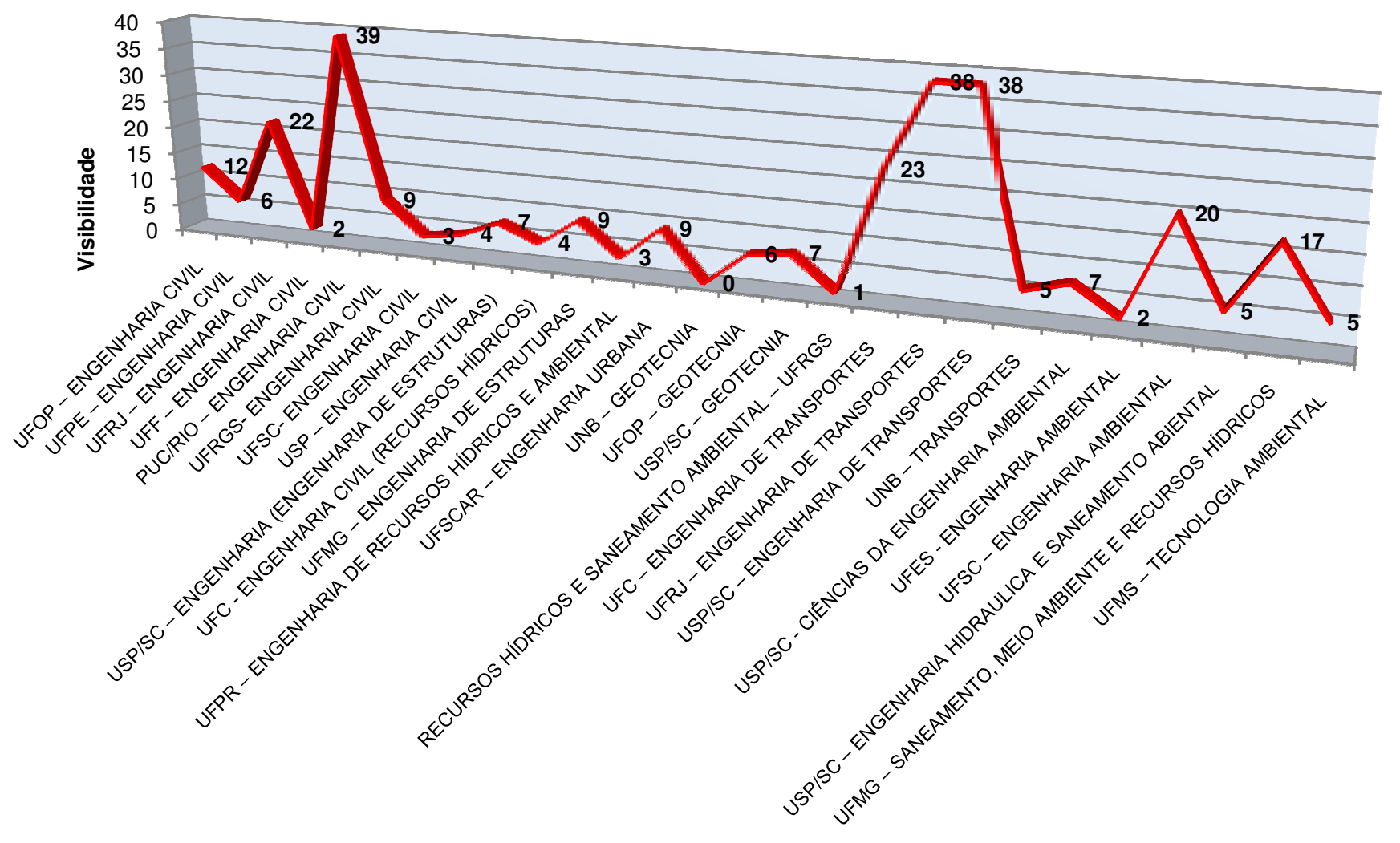

Programas de pós-graduação em engenharias I

FONTE: Elaborado pela autora. 
Quando aplicado o indicador visibilidade nas engenharias II, verifica-se que o PPG que mais se destaca é o de Ciência e tecnologia de polímeros da UFRJ que obteve 71 links em sua visibilidade, logo em seguida apresenta-se o programa de engenharia química da UFRJ com 48 links e posteriormente o programa de Ciência e engenharia de materiais da UFSCAR.

Torna-se relevante ressaltar que o PPG em Ciência e tecnologia de polímeros da Universidade Federal do Rio de Janeiro também se destaca no indicador tamanho, fato que reforça o entendimento de que este site possui algumas características de integridade, credibilidade e disponibilidade das informações que são disponibilizadas nas páginas de seu site.

GRÁFICO 14 - Análise do indicador visibilidade nas engenharias II.

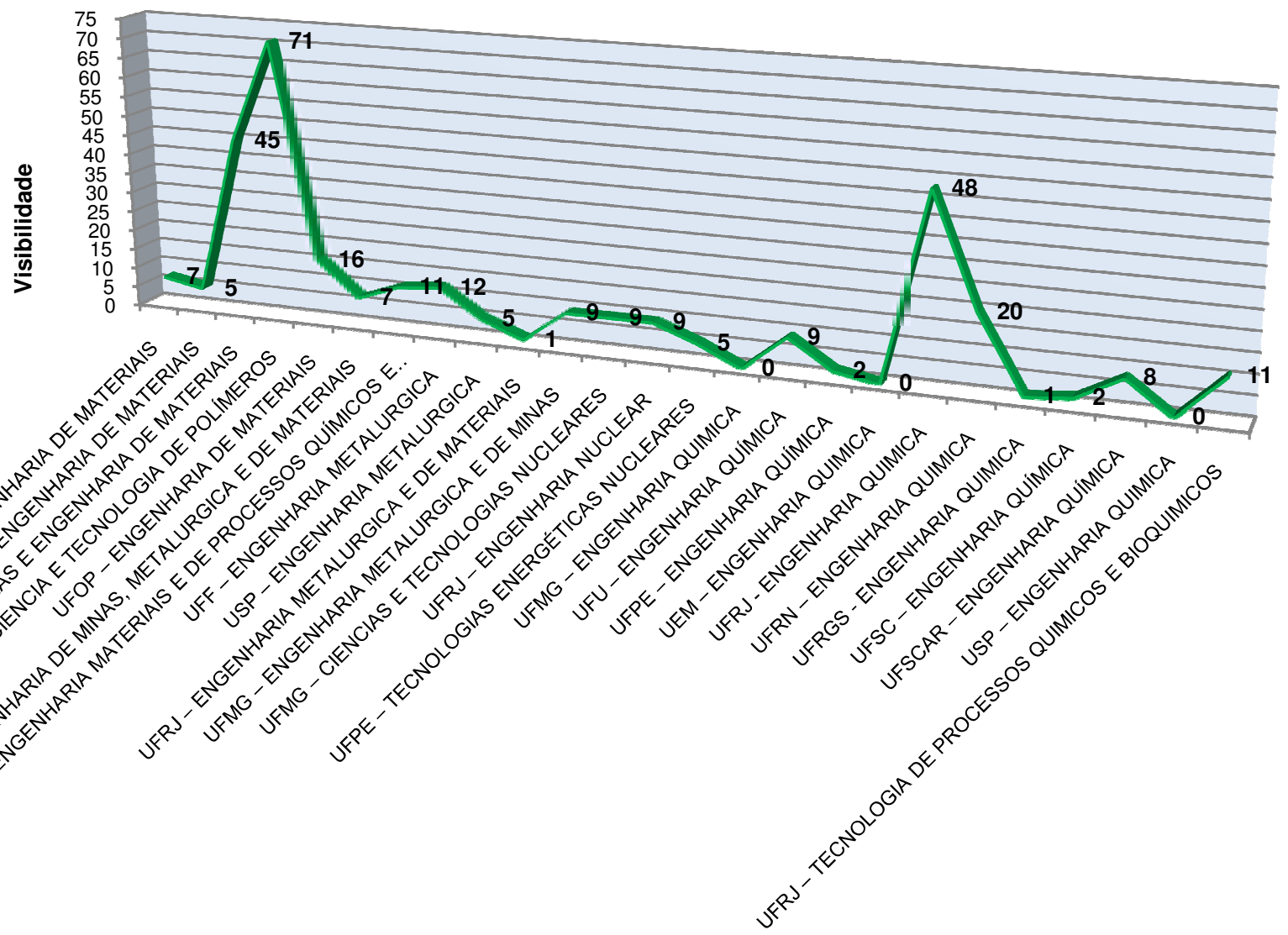

Programas de pós-graduação em engenharias II

FONTE: Elaborado pela autora. 
O indicador Visibilidade mostra que nas engenharias III o programa de Planejamento energético da UFRJ destaca-se ao obter 56 links em sua visibilidade, posteriormente tem destaque os programas de Engenharia de Produção da UFRJ e da UFRGS com um total de 42 links.

Nessa perspectiva, percebe-se a relevância dos sites dos PPG's em engenharia de produção das IES brasileiras no tocante a visibilidade, visto que ao analisar o gráfico abaixo, verifica-se que estes PPG's apresentam valores bem elevados, destacando-se na escala apresentada.

GRÁFICO 15 - Análise do indicador visibilidade nas engenharias III.

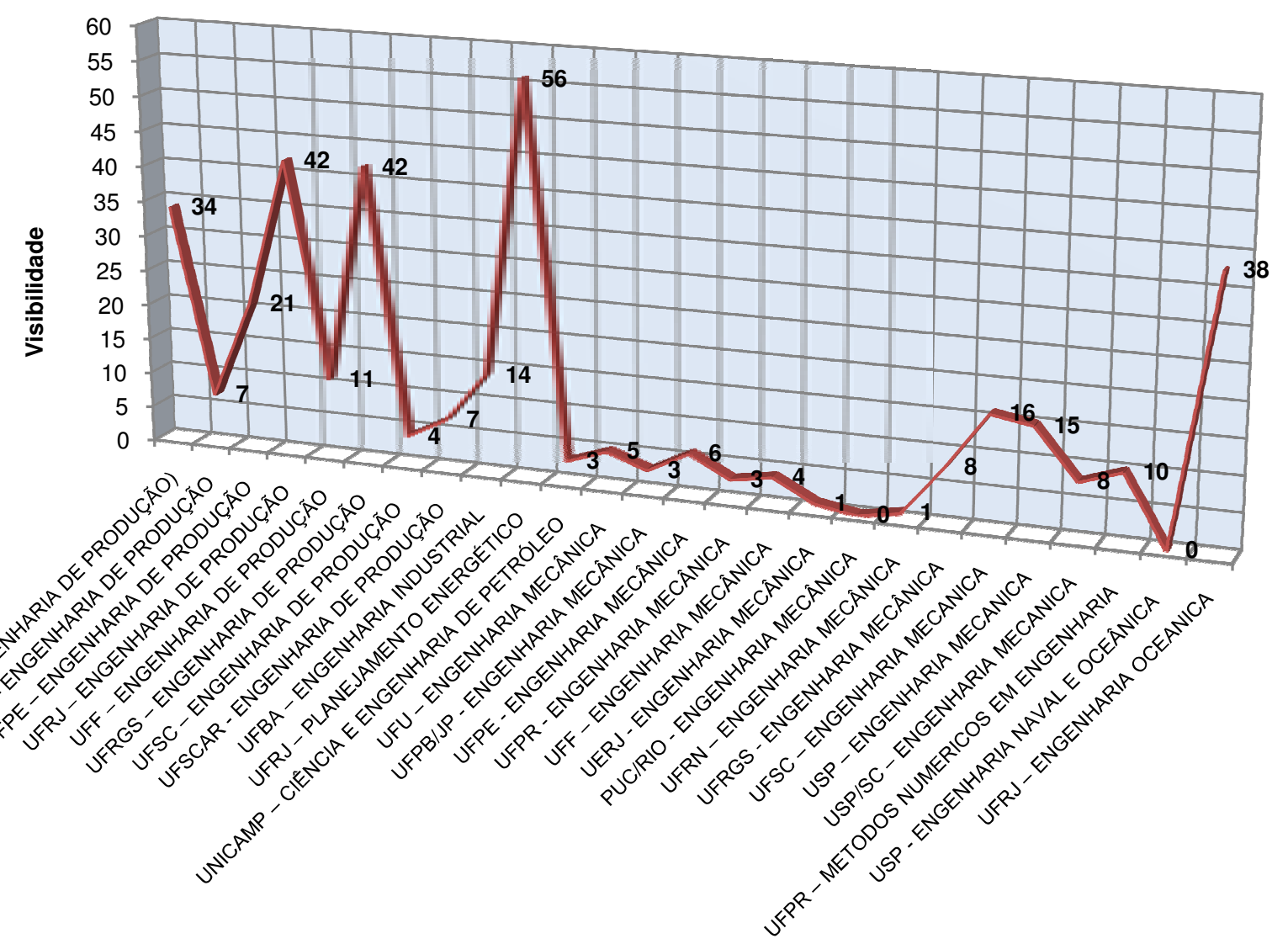

Programas de pós-graudação em engenharias III

FONTE: Elaborado pela autora. 
Quando analisada a visibilidade dos sites dos PPG's no grupo de Engenharias IV, observa-se que o Programa de Engenharia elétrica da UNB destaca-se ao possuir 64 links externos que remetem as suas páginas, já o PPG em Engenharia biomédica da UFRJ apresentam 49 links, seguido pelo programa em Engenharia elétrica da UFCG, conforme é detalhado no gráfico a seguir:

GRÁFICO 16 - Análise do indicador visibilidade nas engenharias IV.

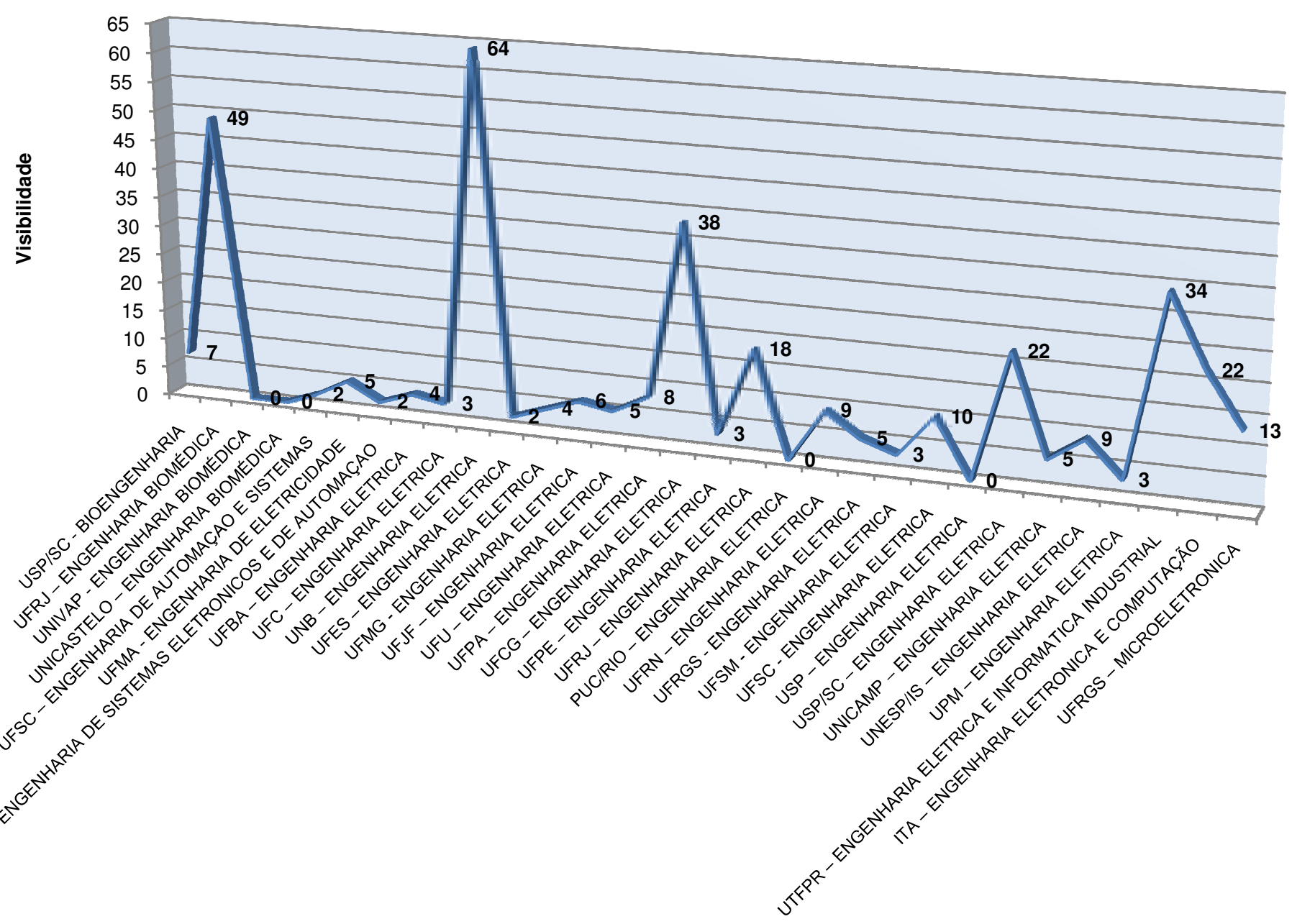


FONTE: Elaborado pela autora.A partir da análise do indicador visibilidade no grupo de engenharias verifica-se que os grupos de engenharias apresentaram valores de visibilidade bastante similares. Isso nos faz perceber que todas as engenharias estão com um nível de reconhecimento nivelado, pois as quantidades de links que estes PPG's recebem de outras instituições são bastante proporcionais na escala verificada.

Os dados mostraram que as Engenharias III destacaram-se com um total de 359 links recebidos por outros sites, seguido das Engenharias IV que obtiveram 355 links, em seguida destaca-se as Engenharias II com um total de 313 e as Engenharias I com 303 links. A distribuição dos links por PPG's pode ser melhor visualizadas a partir do GRÁFICO 17 que segue abaixo:

GRÁFICO 17 - Análise do indicador visibilidade por grupos de engenharias.

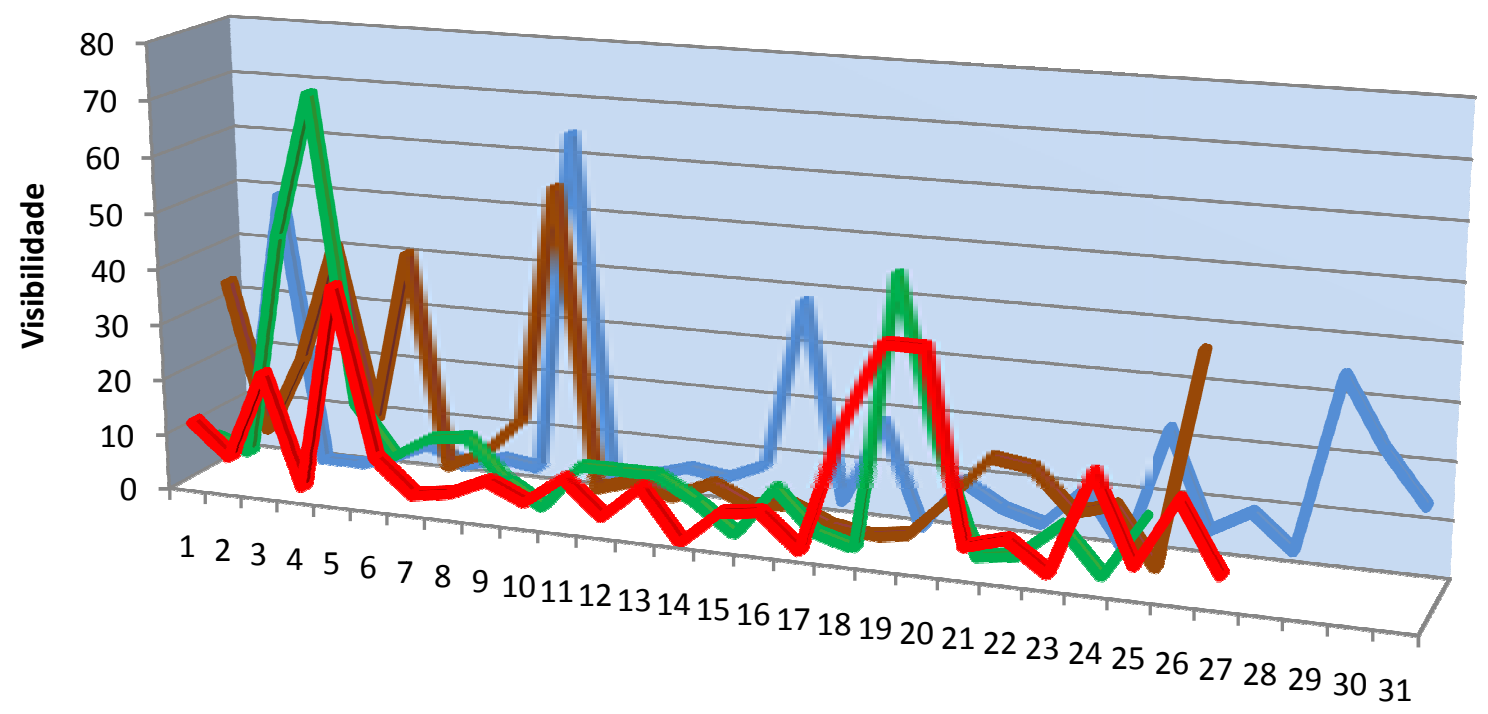

Programas de Pós-graduação

EEngenharias I (Visibilidade =303) \Engenharias II (Visibilidade =313)

ZEngenharias III (Visibilidade =359) ШEngenharias IV (Visibilidade =355)

FONTE: Elaborado pela autora.

Com os resultados obtidos pode-se inferir que todos os quatro grupos de engenharias aqui estudados apresentam um reconhecimento científico considerável na rede, visto a quantidade de links que os mesmos recebem de outras instituições, 
pois, supõe-se que quem recebe muitos links é tido como referência, por apresentar informações confiáveis.

Essa análise é baseada na interpretação de que uma relação virtual de conexões entre instituições se dá através da confiabilidade e importância das informações que são disponibilizadas por estes sites. Contudo, verifica-se que todas as engenharias no âmbito nacional estão equivalentes em relação a sua importância informacional no meio virtual.

\subsubsection{Análise comparativa dos grupos de engenharias de acordo com 0 indicador fator de impacto Web (FIW)}

Ao analisar os grupos de engenharias pelo indicador fator de impacto web, pôde-se verificar que dentre os programas que fazem parte das engenharias I, destaca-se o programa de Engenharia Civil da PUC/RIO com 18,808 de fator de impacto.

Esse resultado deve-se aos altos valores obtidos por este programa no indicador visibilidade, como foi explanando anteriormente, pois demonstra que ao relacionar a quantidade de links que remetem as suas páginas pela quantidade de páginas que possuem em seu site, pode-se perceber o quanto este site possui uma presença e impacto na Web ao ser utilizado como fonte informacional por instituições nacionais e internacionais no âmbito virtual.

O segundo programa que também resultou em dados relevantes foi o PPG em Engenharia civil da UFRGS com 14,849 de FIW, porém, notoriamente esse programa apresentou valores relativamente baixos nos indicadores tamanho e visibilidade, mas quando relacionado esses dois indicadores pôde-se perceber que apesar desse PPG possuir poucas páginas em seu domínio Web, observa-se que essas mesmas páginas apresentam uma boa quantidade de links remissivos oriundo de outras instituições, fato este que confirma a credibilidade das informações que estão sendo disponibilizadas por este programa em seu site.

Outro programa que se destacou foi o de Engenharia de transportes da USP/SC com 14,278 de fator de impacto. Nota-se que este mesmo programa também se destacou em relação ao indicador visibilidade aplicado nesse estudo, fato este que contribuiu diretamente com os resultados obtidos pelo indicador fator de impacto Web, conforme é explanado no GRÁFICO 18 a seguir: 
GRÁFICO 18 - Análise do indicador FIW nas engenharias I.
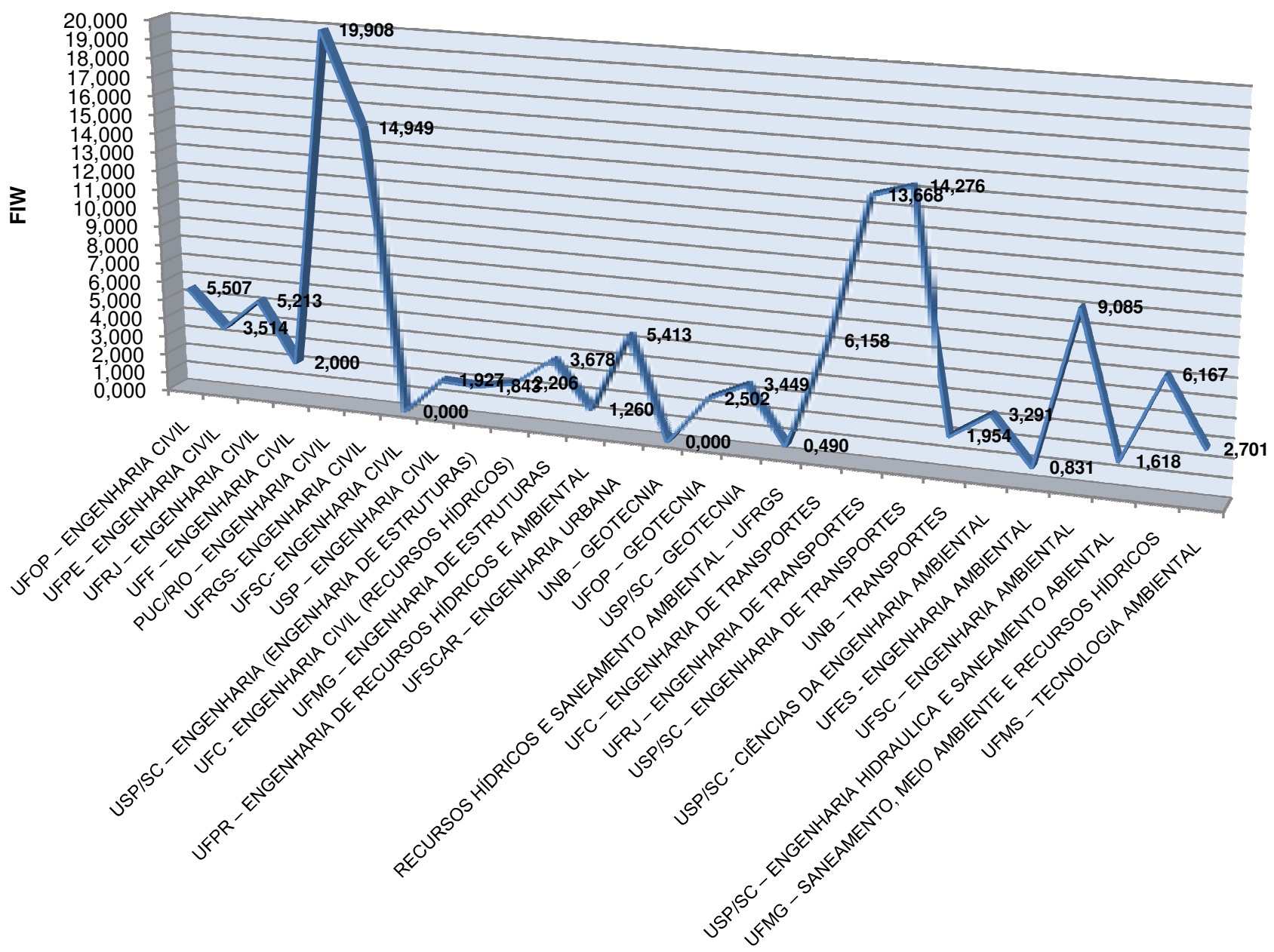

Programas de pós-graduação em engenharias I

FONTE: Elaborado pela autora.

Ao aplicar o indicador FIW no grupo de engenharias II (GRÁFICO 19), obtiveram-se alguns resultados os quais mostraram que o programa em Ciência e tecnologia de polímeros da UFRJ possui um dos mais altos índices nas engenharias IV, que resultou em 24,049 de fator de impacto, em seguida veio o programa em Engenharia química da UFRJ com o valor de 18,455 e posteriormente destaca-se o PPG em Ciência e engenharia de materiais UFSCAR. Observa-se que estes três 
PPG's também apresentaram resultados bem relevantes quando analisado os indicadores tamanho e visibilidade, o que reforça a eficácia do método utilizado nesta pesquisa.

GRÁFICO 19 - Análise do indicador FIW nas engenharias II.

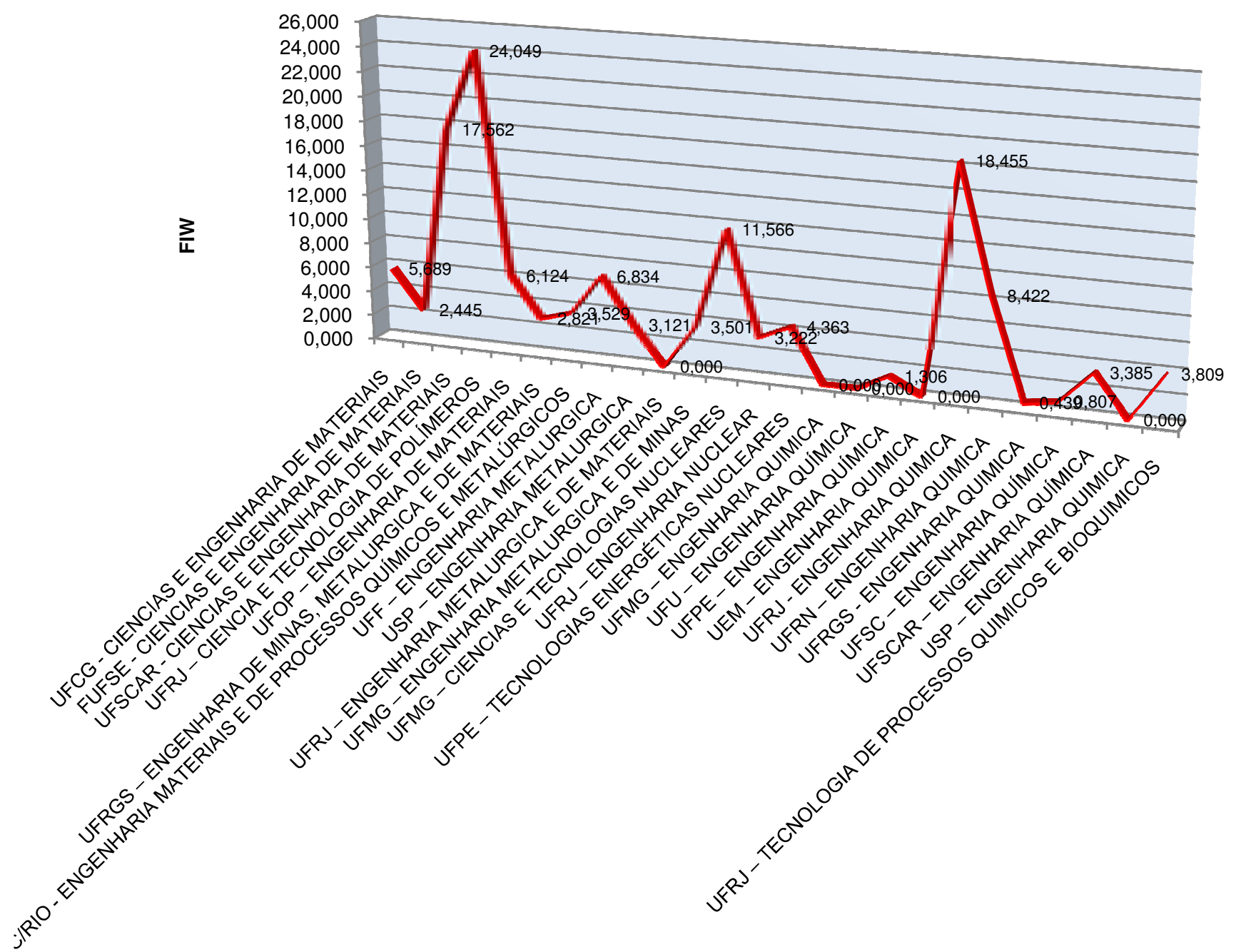

Programas de pós-graduação em engenharias II

FONTE: Elaborado pela autora. 
Quando analisado o fator de impacto no grupo de Engenharias III (GRÁFICO 20), pôde-se notar que o programa em Engenharia de produção da UFPE apresentou o valor de 24,849, sendo este um dos resultados mais relevantes entre os PPG's deste grupo, posteriormente apresenta-se o programa de Planejamento energético da UFRJ com o FIW igual a 19,474, como destaque temos também o programa em Engenharia mecânica da USP com 16,610 em seu fator de impacto web.

Pôde-se ressaltar que estes três programas não apresentaram altos valores no indicador tamanho, porém quando aplicado o indicador visibilidade, estes apresentaram relevantes valores, o que contribui com o resultado do indicador fator de impacto web aqui analisado.

GRÁFICO 20 - Análise do indicador FIW nas engenharias III.

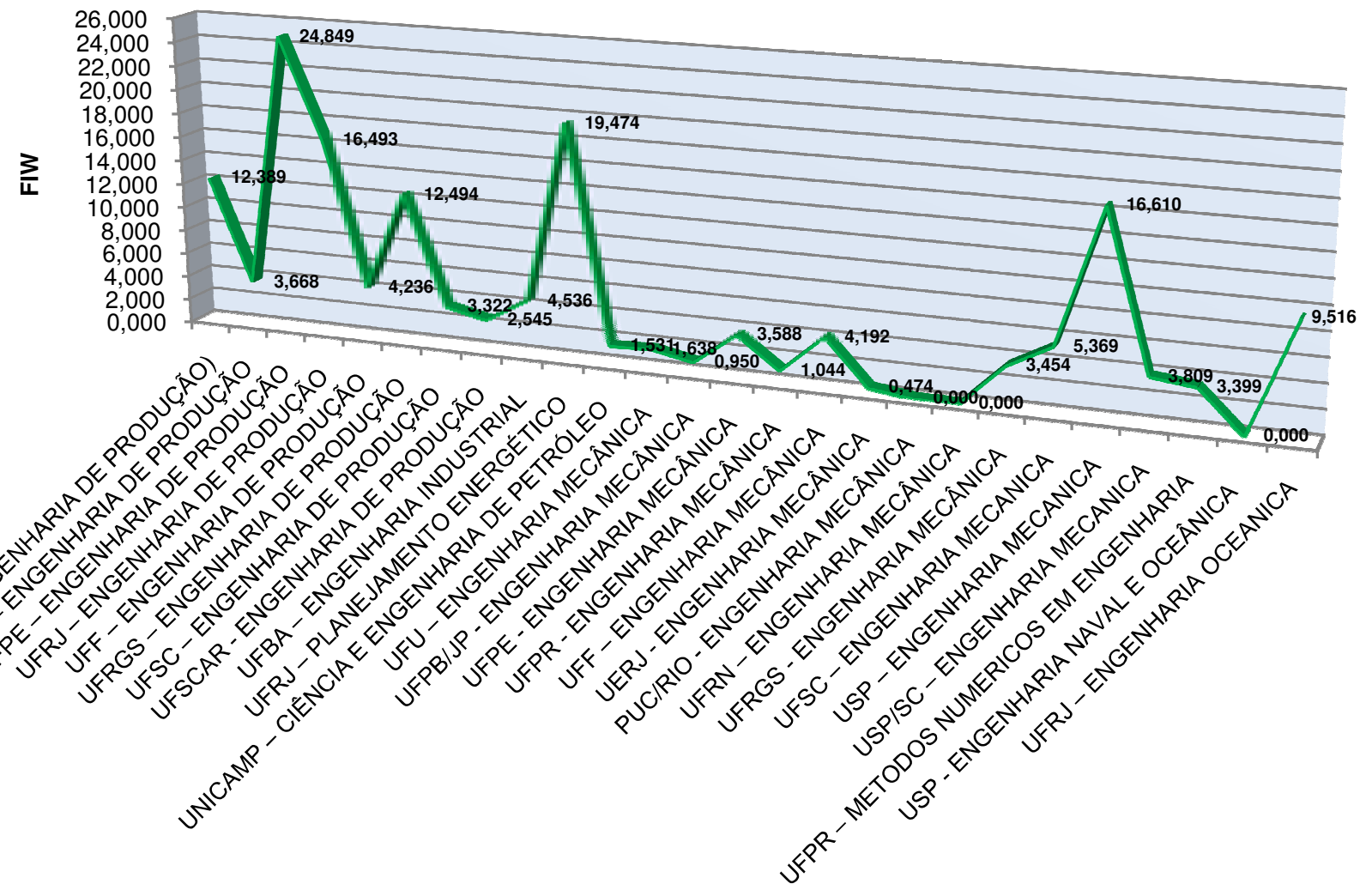

Programa de pós-graduação em engenharias III

FONTE: Elaborado pela autora. 
No grupo de Engenharias IV o indicador FIW apresentou resultados bem significativos (GRÁFICO 21), que mostraram que o programa em Engenharia elétrica da UNB possui 23, 600 de fator de impacto, seguido do Programa em Engenharia biomédica da UFRJ com 18, 325 e do PPG em Engenharia elétrica e informática industrial da UTFPR que apresentou 11,528 no indicador de fator de impacto web.

Observa-se que quando comparado os resultados dos três PPG's que se destacaram no FIW aos resultados do tamanho e visibilidade aplicados anteriormente nas Engenharias IV, verifica-se que estes mesmos PPG's apresentaram resultados bem significativos em todos os indicadores. Isso reforça a coerência dos resultados alcançados na aplicação destes indicadores no estudo.

GRÁFICO 21 - Análise do indicador FIW nas engenharias IV.

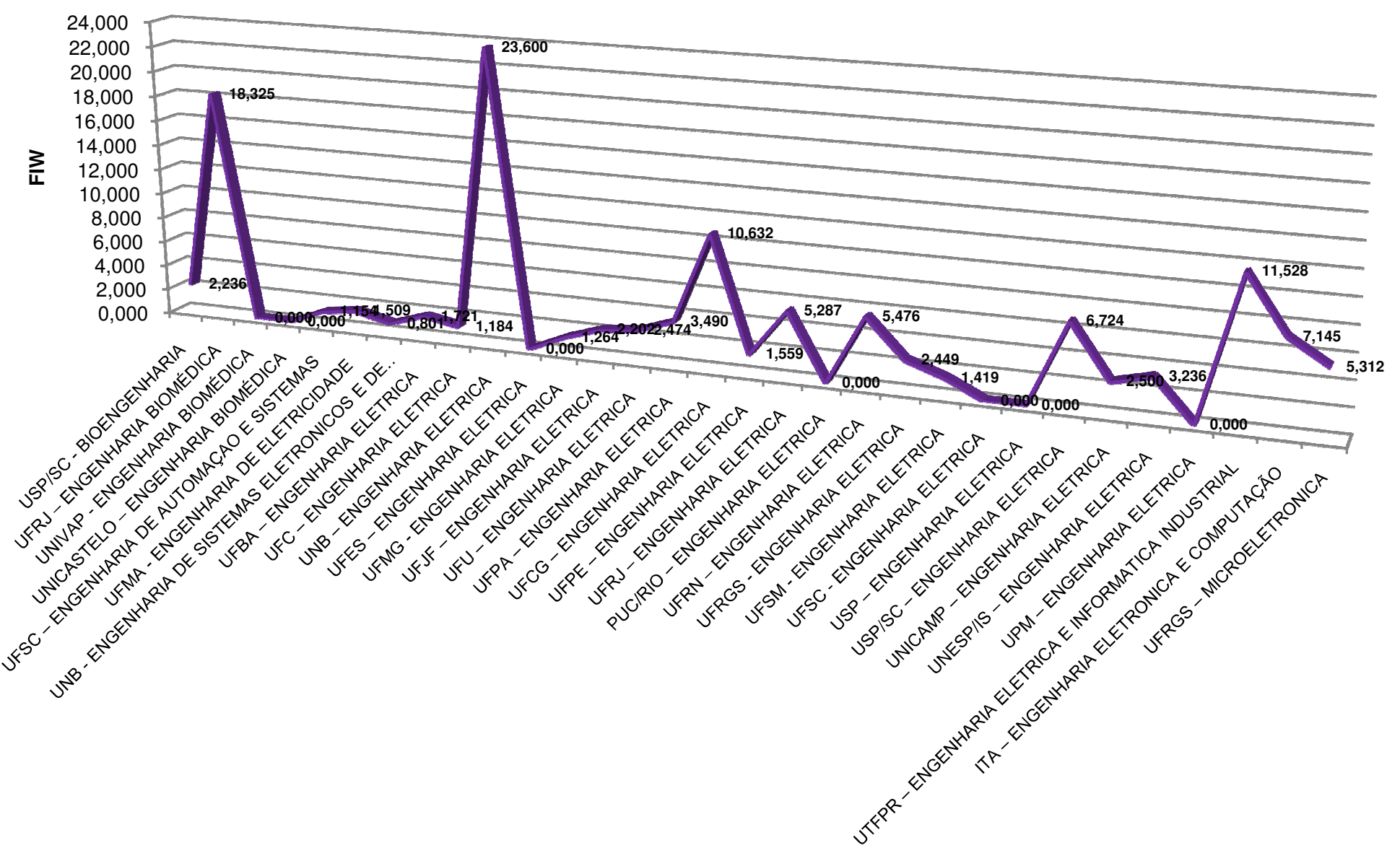

FONTE: Elaborado pela autora. 
Com a coleta de dados e análise do índice de impacto dos grupos de engenharias na Web, pode-se perceber que o nível de atratividade dos sites aqui analisados são no geral satisfatórias. Esse nível define-se pela relação com quantidade de páginas existentes e visibilidade dessas páginas a partir de outras instituições.

Para uma melhor compreensão dos resultados alcançados, faz-se uma comparação dos resultados alcançados no indicador FIW entre os grupos de engenharias aqui estudados.

Para tanto, analisa-se a distribuição dos valores alcançados e explanados nessa pesquisa, conforme é mostrado no GRÁFICO 22.

Para facilitar o entendimento, delimita-se uma média dos valores obtidos no indicador FIW destes Programas de pós-graduação, que totalizou 5,00. A partir deste valor, é estabelecido que valores acima da média são considerados de FIW alto, e valores abaixo da média possuem FIW baixo.

Verifica-se que um número pouco relevante de PPG's apresenta um valor de FIW acima dessa média. Este fato pressupõe que os Programas de Pós-graduação em engenharias ainda precisam melhorar seu FIW. Para tanto, é necessário melhorar a relação dessas instituições na rede, ou seja, sua visibilidade, a partir da quantidade e qualidade das informações disponibilizadas pelas páginas desses PPG's.

Já quando é analisado o indicador FIW em sua somatória de totalidade dos PPG's, obtém-se resultados que mostram que dentre os grupos de engenharias analisados, as Engenharias III é a que apresenta o maior índice, totalizando 159,579 de FIW, em seguida surgem as Engenharias I com 133,608, posteriormente as Engenharias II com 131,447 e as Engenharias IV com um índice de 123,228 de FIW.

Esses resultados podem ser melhor visualizados através do GRÁFICO 22 que segue abaixo. 
GRÁFICO 22 - Análise do indicador FIW por grupo de engenharias.

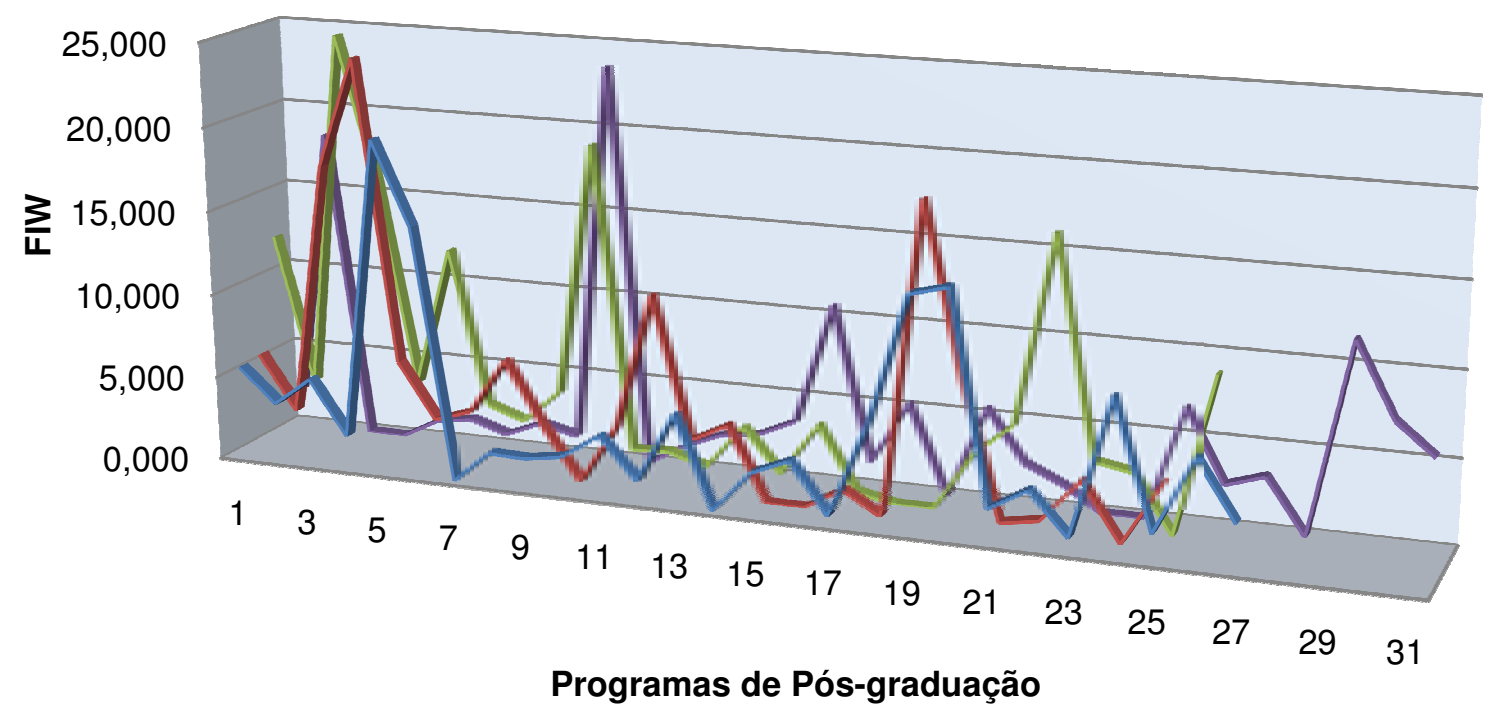

- Engenharias I (FIW=133,608) Engenharias II(FIW=131,447)

Engenharias III(FIW=159,579) $\backsim$ Engenharias IV(FIW=123,228)

FONTE: Elaborado pela autora.

Ao se comparar o FIW aos indicadores aplicados anteriormente nesse estudo, pôde-se perceber que os Grupos de Engenharias que se destacaram com maior tamanho dos sites, permaneceram no topo das escalas do FIW, o que sustenta a idéia de que estes indicadores estão inteiramente interligados e que a quantidade de páginas e importância de informações existentes em um site interfere diretamente no seu impacto na Web.

\subsubsection{Análise comparativa dos grupos de engenharias de acordo com 0 indicador luminosidade}

Ao verificar o indicador luminosidade nos grupos de Engenharias, pretende-se identificar quais programas estão utilizando a Web como fonte informacional ao disponibilizar links de outras instituições em seu site, contribuindo assim com a disseminação da informação. 
Nesse tocante, verifica-se que no grupo de Engenharias I (GRÁFICO 23), 0 programa que mais se destaca é o de Engenharia Civil da USP, com um total de 814 links em sua luminosidade, posteriormente cita-se o programa de Engenharia civil da UFSC e o de Engenharia de transportes da UFC, com respectivamente 589 e 384 links em suas páginas que remetem a outras instituições.

GRÁFICO 23 - Análise do indicador luminosidade nas engenharias I.

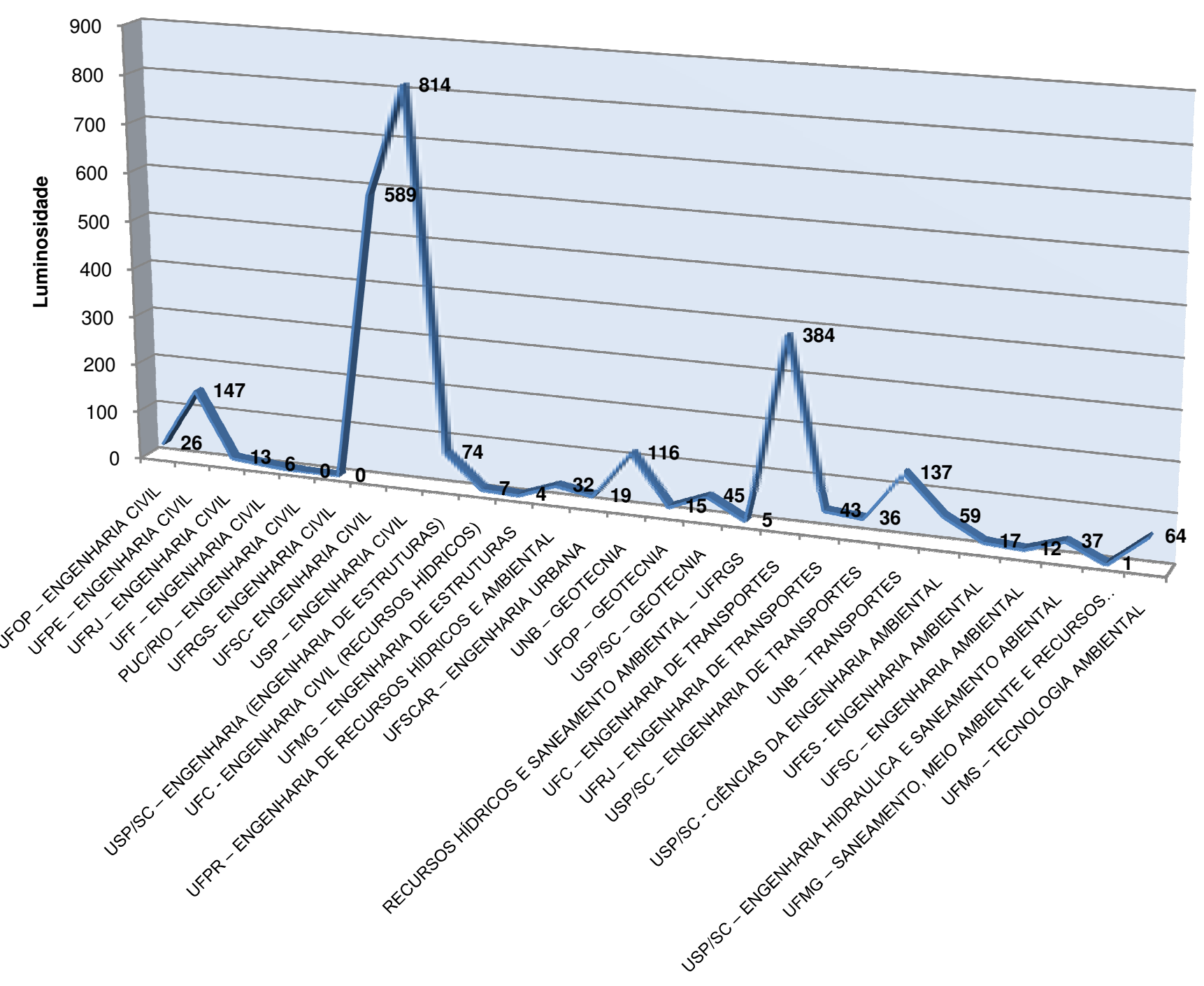

Programas de pós-graduação em engenharias I

FONTE: Elaborado pela autora. 
Ao analisar os resultados da luminosidade aplicada nas engenharias II (GRÁFICO 24), nota-se que o Programa de processos químicos e bioquímicos da UFRJ apresenta uma luminosidade de 512, seguido pelo programa de Engenharia química da UFRJ que apresentou um valor de 230 e do PPG em Ciência e tecnologia de polímeros também da UFRJ que obteve 202 links de luminosidade em suas páginas Web.

GRÁFICO 24 - Análise do indicador luminosidade nas engenharias II.

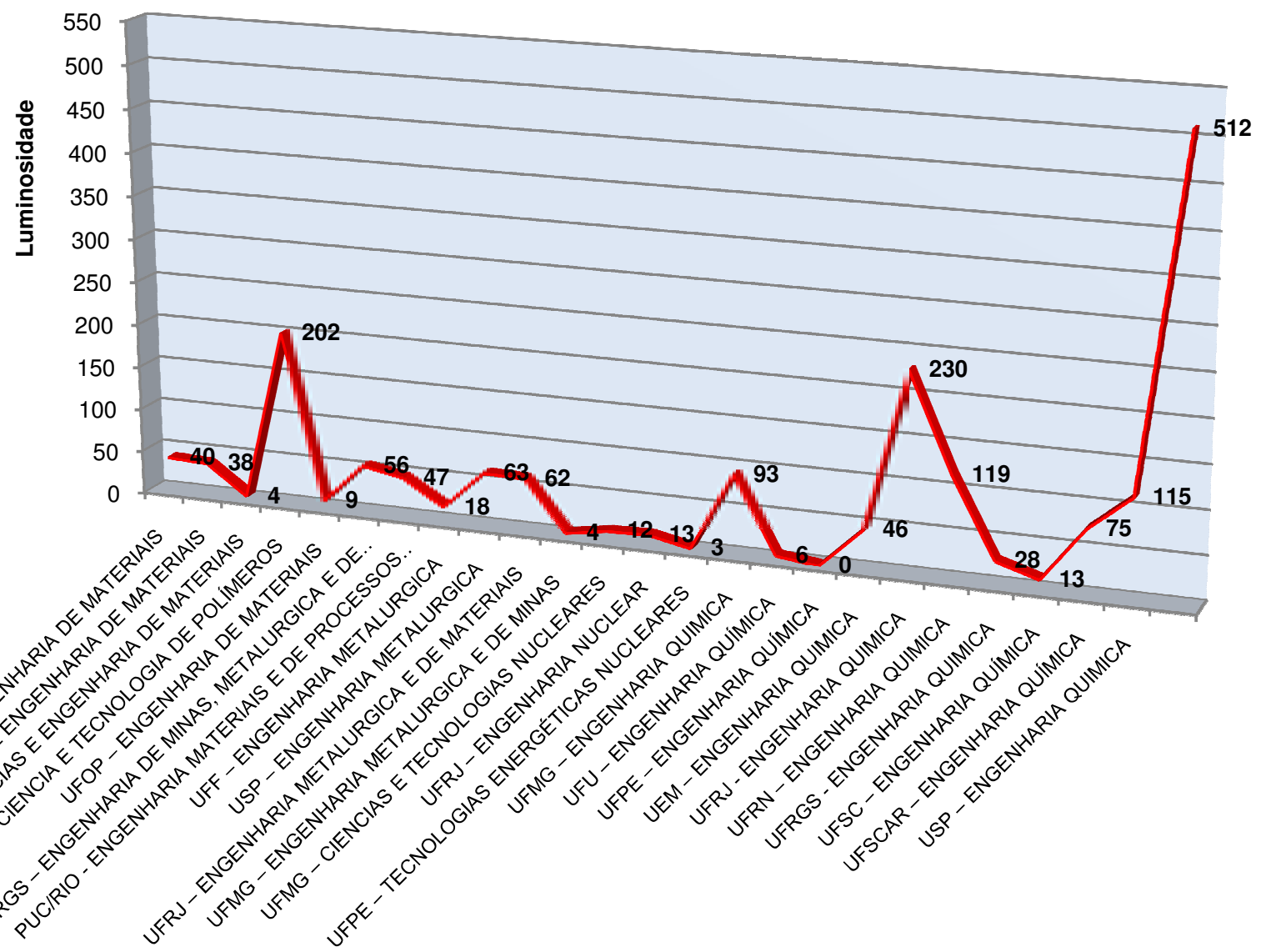


Ao empregar o indicador luminosidade no grupo de engenharias III (GRÁFICO 25), observa-se que o Programa de Engenharia mecânica da USP/SC apresenta 480 links em sua luminosidade, seguido pelo programa de Engenharia industrial da UFMA com 223 links e o PPG em Engenharia de produção da UFRGS com 157 links em suas páginas que remetem a outros sites na Web.

GRÁFICO 25 - Análise do indicador luminosidade nas engenharias III.

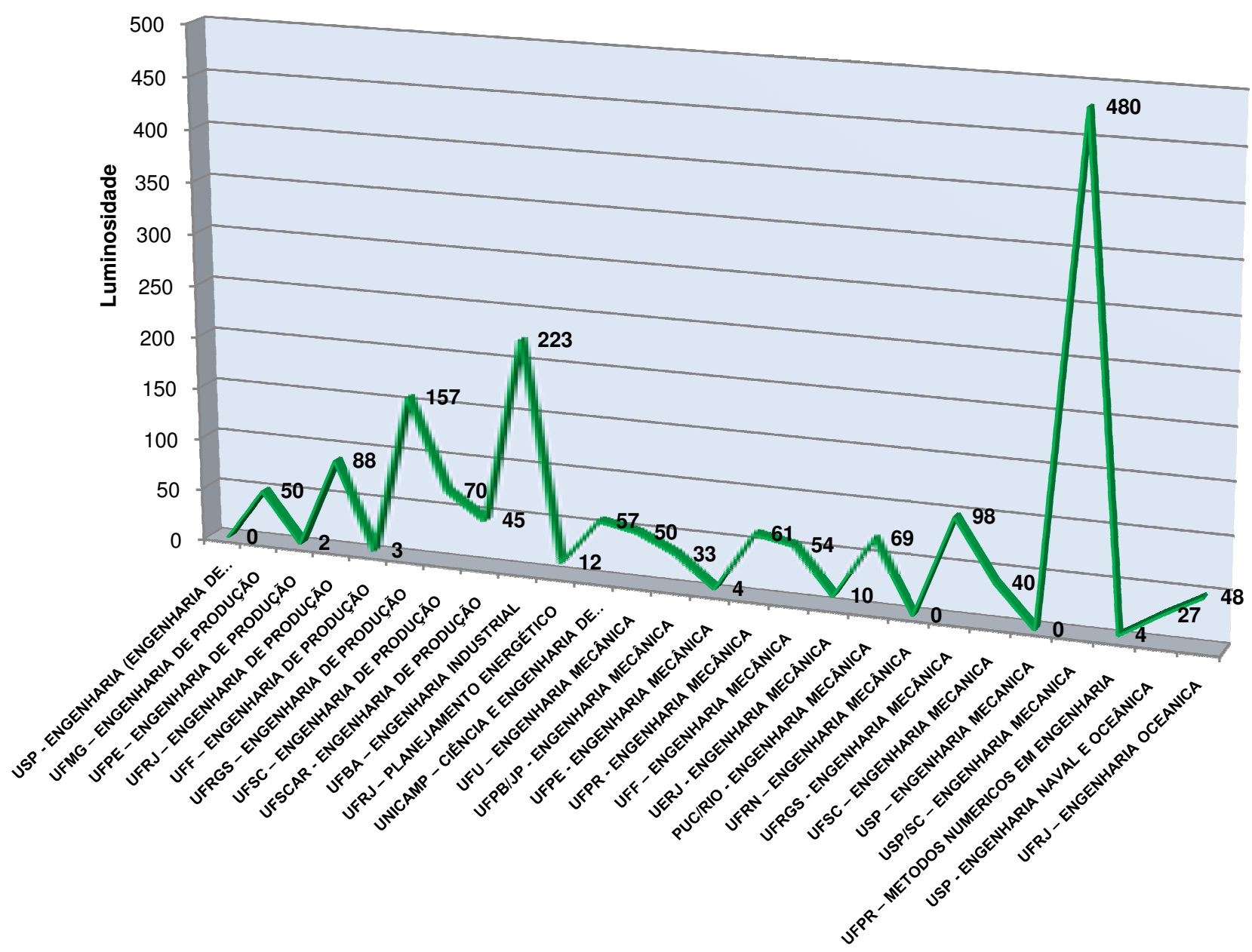

Programas de pós-graduação em engenharias III

FONTE: Elaborado pela autora. 
No mesmo tocante, pôde-se verificar que quando analisada as Engenharias IV através do indicador luminosidade (GRÁFICO 26), o Programa em Engenharia elétrica da UPM apresentou 2.584 links externos para outras instituições em seu site, posteriormente apresenta-se o programa em Engenharia elétrica da USP/SC com 517 links em sua luminosidade e o programa em Engenharia elétrica da UFMG com 315 links.

GRÁFICO 26 - Análise do indicador luminosidade nas engenharias IV.

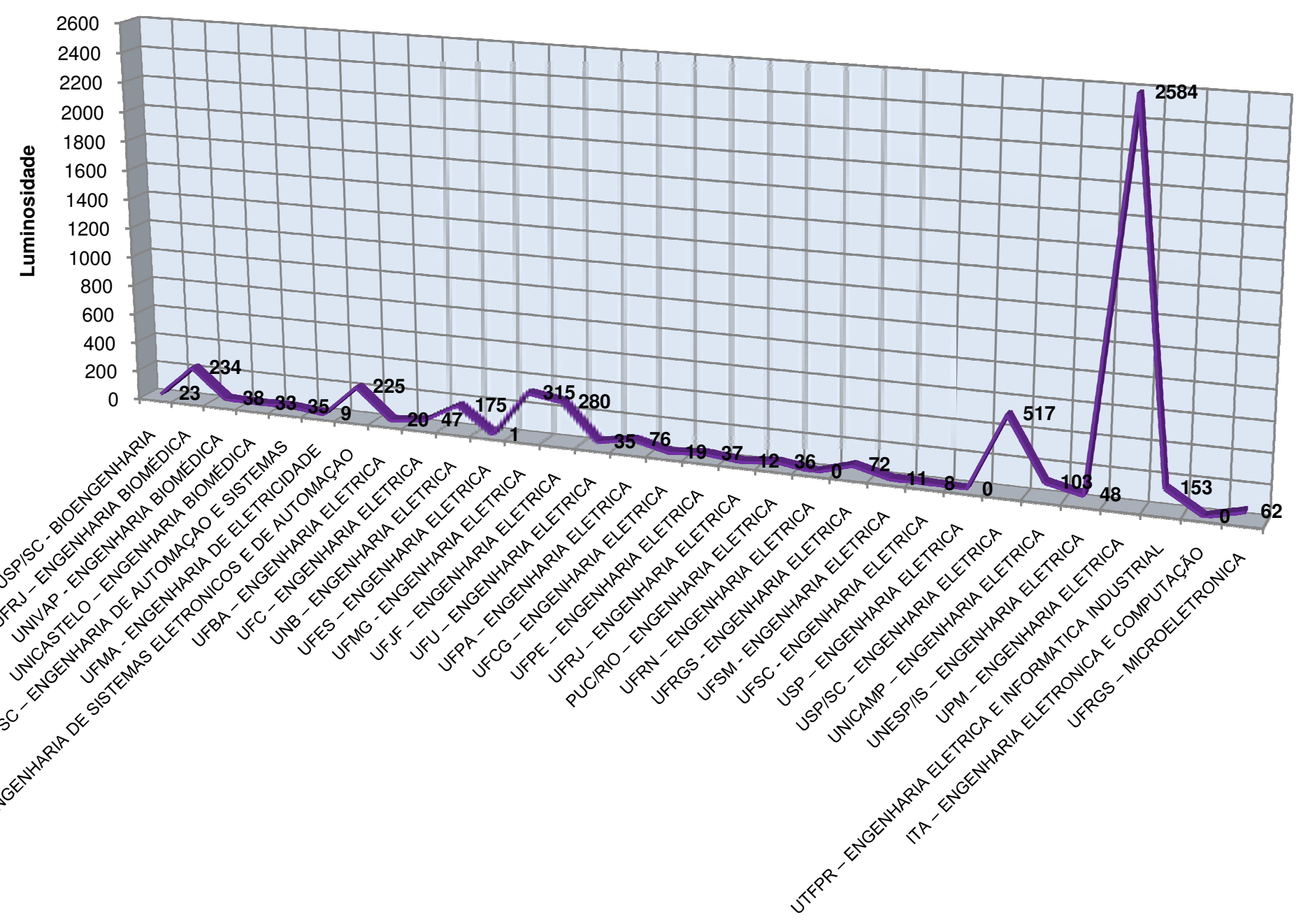

Programas de pós-graduação em engenharias IV

FONTE: Elaborado pela autora. 
Com os resultados que foram obtidos na pesquisa percebe-se que alguns PPG's do Brasil valorizam a importância da Web como suporte para a difusão informacional.

$\mathrm{Na}$ análise do indicador luminosidade dos grupos de engenharias as que mais se destacaram foram as Engenharias IV que possuem um total de 5.208 links que remetem para outras instituições, posteriormente aparecem as Engenharias I com 2.702 links, Engenharias II com um total de 1.808 e por último, as Engenharias III com 1.685 links que remetem para sites fora de seu domínio Web.

A distribuição desses dados pode ser melhor visualizada através do GRÁFICO 27, que segue:

GRÁFICO 27 - Análise do indicador luminosidade por grupos de engenharias.

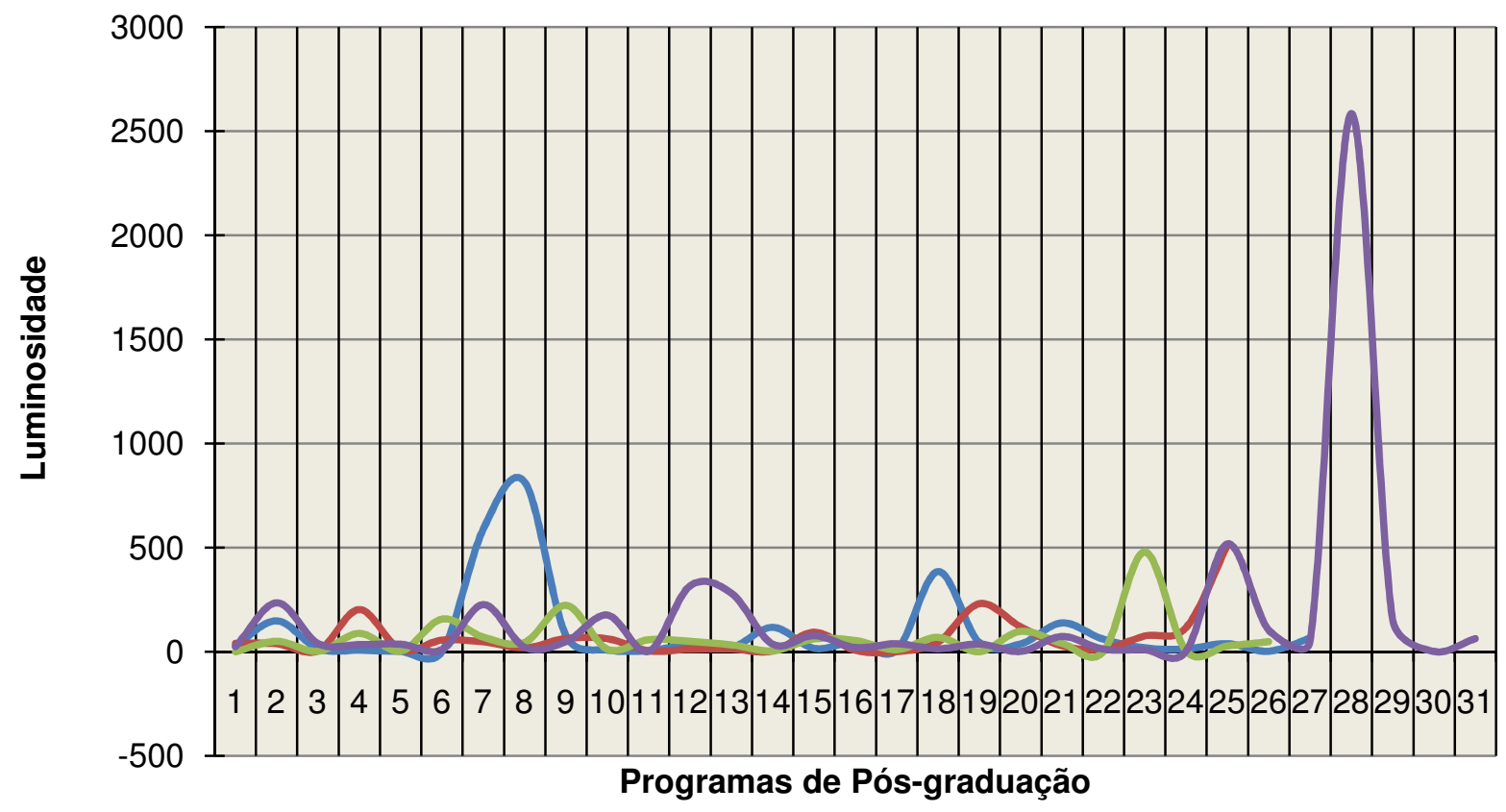

—Engenharias I(Luminosidade=2.702) —_Engenharias II(Luminosidade=1.808)

Engenharias III(Luminosidade $=1.685$ ) Engenharias IV(Luminosidade=5.208)

FONTE: Elaborado pela autora.

Ao se analisar o indicador luminosidade no contexto científico, verifica-se a relevância do uso de links remissivos, pois se percebe que as Engenharias IV ao disponibilizar esse alto índice de links, colaboram diretamente com a navegabilidade dos seus usuários e internautas em busca de integridade, veracidade e disponibilidade das informações, as quais necessitam. 
Nesse contexto, percebe-se o valor do uso de links externos para os PPG's, pois quanto mais fontes de informações são apontadas na Web, maior é a possibilidade de comunicação científica na rede, e, consequentemente, maior a possibilidade de divulgação de pesquisas e estudos nesta área.

\subsubsection{Análise comparativa dos grupos de engenharias de acordo com Ranking webométrico}

Através dos cálculos de pesos dos resultados anteriores, foi possível estabelecer um ranking webométrico que define qual dos Grupos de Engenharias se destaca no estudo em questão.

Os resultados mostram que as Engenharias I apresentam-se como primeira colocada, pois possuem um valor de 4.204 de índice webométrico, logo em seguida destacam-se as Engenharias IV com um índice referente à 3.182, a terceira colocada é as Engenharias III com 2.734 e a quarta colocada é as Engenharias II com 1.248 de índice webométrico.

Os resultados podem ser visualizados através do GRÁFICO 28, que segue abaixo:

GRÁFICO 28 - Análise do índice webométrico por grupos de engenharias.

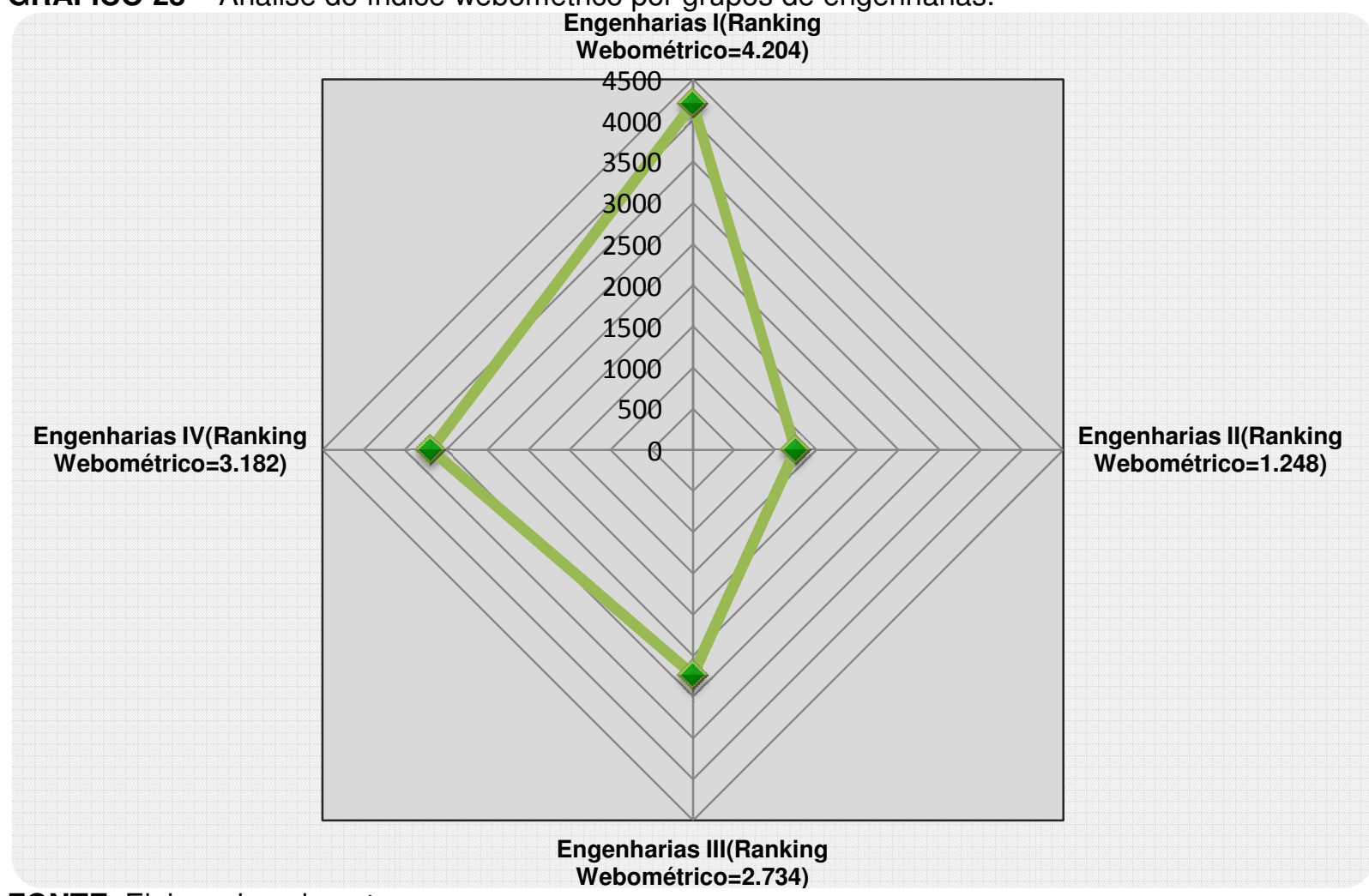

FONTE: Elaborado pela autora. 
De acordo com os resultados obtidos na aplicação desses indicadores e posterior criação do ranking webométrico, assevera-se que as Engenharias I possuem os Programas de Pós-graduação que mais se destacam.

Para uma melhor compreensão, pode-se analisar a TABELA 4, abaixo, que apresenta o ranking geral dos Grupos de engenharias de acordo com os indicadores utilizados, bem como seu índice webométrico.

TABELA 4 - Ranking geral dos Grupos de Engenharias.

\begin{tabular}{cccccc}
\cline { 1 - 1 } Ranking & \multicolumn{4}{c}{ INDICADORES } & Índice \\
\cline { 3 - 5 } & Tamanho & Visibilidade & FIW & Luminosidade & webométrico \\
\hline $\mathbf{1}^{\mathbf{0}}$ & Engenharias I & Engenharias III & Engenharias III & Engenharias IV & Engenharias I \\
$\mathbf{2}^{\mathbf{0}}$ & Engenharias III & Engenharias IV & Engenharias I & Engenharias I & Engenharias IV \\
$\mathbf{3}^{\mathbf{0}}$ & Engenharias IV & Engenharias II & Engenharias II & Engenharias II & Engenharias III \\
$\mathbf{4}^{\circ}$ & Engenharias II & Engenharias I & Engenharias IV & Engenharias III & Engenharias II \\
\hline
\end{tabular}

FONTE: Elaborado pela autora.

Ao analisar os PPG's que integram as Engenharias I, constatou-se que em relação ao indicador tamanho, esses sites possuem uma grande quantidade de conteúdo de suas páginas disponibilizadas em seus sites, favorecendo uma melhor recuperação das informações por meio de mecanismos de buscas. Este fato vem a contribuir com o alcance do primeiro lugar das Engenharias I, quando comparadas aos demais grupos de engenharias.

Tal êxito, porém não se repete quando o indicador analisado é a visibilidade, visto que quando comparado aos outros grupos as Engenharias I ficaram na última colocação. Verifica-se que há uma maior necessidade de conexões entre os Programas de Pós-graduação em engenharias I, de modo que essas instituições se "linkem" mais, e dessa forma, contribuam com o intercâmbio de informações para seus usuários, e consequentemente, com a visibilidade de seus PPG's na rede.

Ao se verificar o fator de impacto das Engenharias I na Web, observa-se que as mesmas alcançaram o segundo lugar e este fato deve-se provavelmente pelo equilíbrio entre a quantidade de páginas disponibilizadas e a quantidade de links que essas páginas recebem. Isso reforça a ideia da importância da disseminação de informações de forma estruturada na rede. Pode-se perceber que quando há 
organização das informações através do uso de páginas independentes, isso contribui diretamente na possibilidade de acesso e visibilidade dessas informações, ao contrário de páginas que possuem informações dispersas ou muita quantidade de informações sem nenhuma organização.

Também se verificou que as Engenharias I ocuparam o $2^{\circ}$ lugar ao serem comparadas com as demais engenharias no que diz respeito à luminosidade, pois a quantidade de links desses sites que remetem para outras instituições foi bastante satisfatória. A luminosidade dos sites é de grande relevância para a disseminação de fontes de informação na Web. E percebe-se através desse estudo que os PPG's em engenharias I já despertaram para essa realidade e tem contribuído significativamente nesse aspecto.

\subsection{RESULTADOS DA PESQUISA APLICADA AOS PROGRAMAS DE PÓS- GRADUAÇÃO EM ENGENHARIAS}

Nesse sub-capítulo é realizada uma análise de cada site, dos cento e nove (109) Cursos, dos PPG's integrados nessa pesquisa, com o propósito de alcançar os objetivos iniciais desse estudo.

Para tanto é feita uma análise através dos resultados obtidos pelos indicadores webométricos: tamanho dos sites, visibilidade, fator de impacto Web (FIW) e luminosidade que foram aplicados em cada site dos 109 cursos dos PPG's em engenharias.

Estes PPG's também são analisados através de um Ranking webométrico, que aponta qual dos PPG's tem melhor contribuído com a disseminação de informações e comunicação científica na rede. O índice webométrico é calculado através do peso dos indicadores utilizados, de acordo com a TABELA 3 que foi explanada anteriormente.

Esses resultados ajudam a identificar como os mesmos comportam-se em relação às estruturas de conteúdo dos sites, o uso dessas informações, através do comportamento de pesquisas e busca realizada, a qualidade das informações disponibilizadas, através de uma análise de credibilidade dessas informações, bem como a estrutura dos hipertextos existentes nos sites desse universo de pesquisa. 


\subsubsection{Ranking dos programas de pós-graduação em engenharias de acordo com o indicador Tamanho dos sites Web}

No que diz respeito a presença dos Programas de Pós-graduação em engenharias na Web, pode-se perceber que estes têm disponibilizado uma quantidade bastante relevante de páginas com informações acerca de assuntos que abarcam as áreas de engenharias. Fato que contribui com uma melhor divulgação das pesquisas existentes e assuntos dessa área do conhecimento.

E nessa perspectiva verifica-se através deste estudo que o Programa de Pósgraduação em engenharia civil da UFRJ, destaca-se em primeiro lugar dentre os demais Programas analisados nesse estudo, apresentando um total de 16.600 páginas em seu site. O segundo colocado é o PPG em engenharia oceânica da UFRJ, com 9.850 páginas e o terceiro colocado é o PPG em engenharia civil (engenharia estruturas) da USP/SC com 6.290 páginas em seu site, conforme é apresentado no GRÁFICO 29.

De modo geral, verifica-se que alguns sites apresentam-se bem estruturados em relação à quantidade de páginas para divulgação dos assuntos pertinentes aos seus Programas, porém, em outros sites pode-se verificar uma quantidade de informações muito extensas, expostas em poucas páginas e em alguns casos em apenas uma página. Essa característica dificulta o acesso às informações que os PPG's possuem e que devem divulgar para seu corpo docente e discente, de modo a colaborar com o fluxo informacional da Instituição.

Também se torna relevante ressaltar que alguns sites possuem diversas páginas e que a maioria não é atualizada frequentemente, disponibilizando assim informações antigas aos seus usuários. $E$ isto, se deve ao fato de que muitas das instituições não possuem responsáveis pela atualização dessas informações ou até mesmo por não terem despertado a importância do uso das mesmas na rede.

É preponderante ressaltar o valor das informações que os PPG's disponibilizam na Web, como também a responsabilidade dessas informações divulgadas, visto que na atualidade a Web tem sido utilizada como fonte de informação em diversos contextos, principalmente no científico. 
GRÁFICO 29 - Análise do indicador tamanho por Programa de Pós-graduação.

Análise do Indicador tamanho dos sites web

UFRJ-ENGENHARIA CIVIL

USPISC - ENGENHARIA (ENGENHARIA DEESTRUTURAS)

UFC - ENGENHARIA DETRANSPORTES

UFCG-ENGENHARIA ELETRICA
UFRJ-ENGENHARIA ELETRICA

UFRGS - ENGENGARIA DE PRODUČCAO UFMA - ENGENHARIA DE ELETRICIDADE

USISC - ENGENHARIA ELETRICA

UFMG-ENGENHARA ELETRICA

USPISC - BIOENGETHARIA

PUCIRIO - ENGENHARIA MATERIAIS EDE PROCESSOS QUIMICOSE. USPISC - ENGENHARIA HIDRA ULICA E SANEAMENTOABIENTAL

UFBA - ENGENHARIA INDUSTRIAL
ITA - ENGENHARIA ELETRONICA E COMPUTACCAO UFU-ENGENHA - GEOTECNIA MECANNICA UFSC-ENGENHARIA MECANICA

UFRJ-CIENCIA E TECNOLOGIA DE POLIMEROS

UTFPR - ENGENHARA UFPR - METODOS NUMERICOS EM ENGENHARIA UFRJ - TECNOLOGIA DE PROCESSOS QUIMICOS EBIOQUIMICOS

UFRJ-PLANEJAMENTOENERGETCO UFR

UNESPIIS - ENGENHARIA NUCLEAR

UFRJ - ENGENHARIA DE TRANSPORTES

MEIOA MEIENTEE RECURSOS HIDRICOS

USP - ENGENAHARIA (ENGENHARIA DE PRODUÇAOO) UFJF - ENGENHARIA ELETRICA UNB - ENGENHARIA ELETRICA USPISC - ENGENHARIA DE TRANSPORTES
UFOP-ENGENHARIA DEMA TERIAIS

UFP - UFRJ-ENGENHARIA OUIMCA
UFF - ENGENHARIA DE PRODUCAO UFMG-ENGENHARIA METALURGCA EDEMINAS UFSCAR - CIENCIA S EENGENHARIA DE MA TERIAIS UNAB - TRANSPORTES

UFRJ-ENGENHARIA DE PRODUCAOO

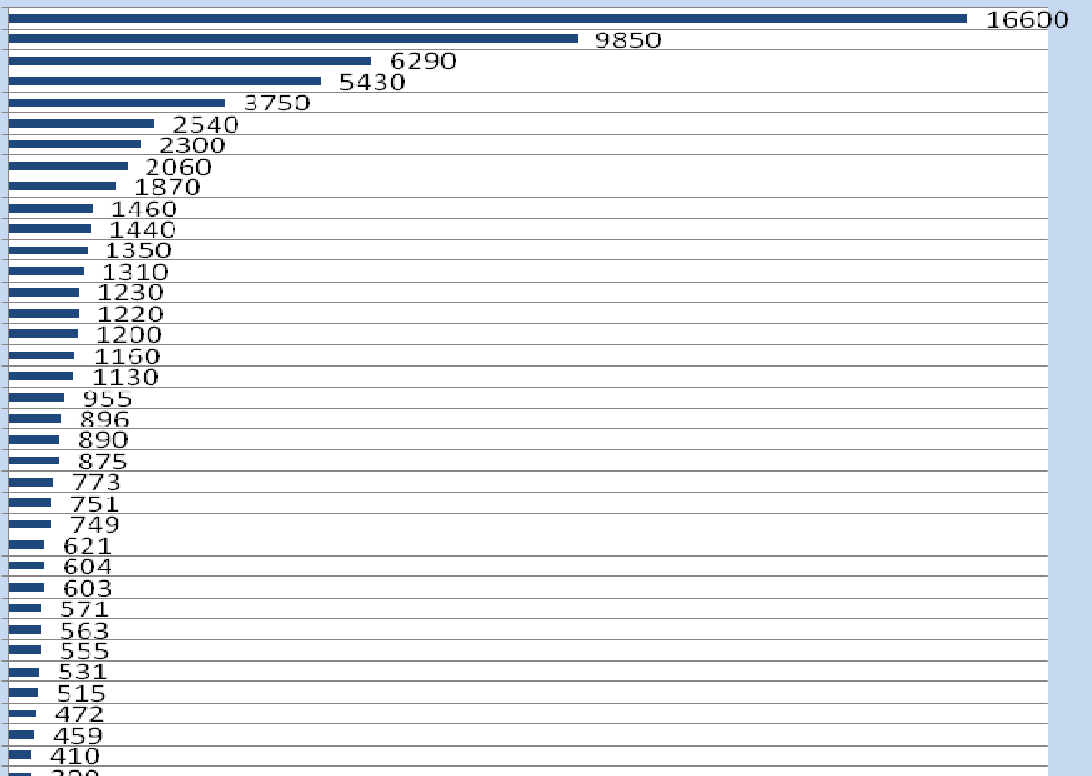

UNE - ENGENHARIA DE SISTEMAS ELETRONICOS E DE AUTOMA CAO

UFRGS - ENGENHA RIA DE MINAS, METALURGICA EDE MA TERIAIS
UFSC - ENGENHARIA QUIMICA

UFMG - ENGENHARIA DEESTRUTURAS UFES - ENGENHARIA AMBAENTAL UFOP-GEOTECNIA

UFPR - ENGENHARIA DERECURSOS HIDRICOS EAMBIENTAL
UFRN - ENGENHARIA OUIMCA UFSCAR - ENGENHARIA QUIMCA UFBA - ENGENHARIA ELETRICA

UFRGS - ENGENHARIA MECÂNICA UFPA - ENGENHARIA ELETRICA
UFRGS - ENGENHARIA OUIMCA UFRGS - ENGENHARIA OUIMCA
UFSC-ENGENHARIA AMBIENTAL UFSC-ENGENHARIA AMBAENTAL JFMG - ENGENHARIA QUIMICA
UFOP - ENGENHARIA CIVIL JEM-ENGENHARIA OUIMICA

USPISC - CIENNGIA S DA ENGENHARIA AMBIENTAL USP-ENGENHARIA ELETRICA UFSM - ENGENHARIA ELETRCA USPISC-ENGENHARIA MECANCA USP-ENGENHARIA CIVIL

FUFSE - CIENGIASE ENGENHARIA DE MATERIAIS
UFRGS - ENGENHARIA ELETRICA
CURS UFRGS - ENGENHARA ELETRICA
UFRGS - RECURSOS HIDRICOSE SANEAMENTOAMEIENTAL
USPISC-GEOTECNIA
UFU - ENGENHARIA ELETRACA

UNICA MP - CIEENCIA E ENGENHARIA DE PETRÓLEO PUCIRIO - ENGENHARIA CIVIL JFMG - ENGENHA RIA DE PRODUÇĀO UFMS - TECNOLOGIA AMBIENTAL UFC - ENGENHARIA CIVIL (RECURSOS HIDRICOS) UFF - ENGENHARIA METALURGCA DE AUTOMACAOE SISTEMAS
USP-ENGENHARIA OUIMCA USP - ENGENHARIA OUIMCA UFPE-ENGENHARIA CIVIL UFPE - ENGENHARIA MECÃNICA UFSCAR-ENGENHARIA UREANA USP - ENGENHARIA METALURGCA
UFPE - ENGENHA RIA OUIMCA

UNICASTELO - ENGENHA RIA BIOMEDICA

UFCG-CIENCIAS E ENGENHARIA DE MA TERIA IS UFPE - TECNOLOGIAS E ENHARIA DE PRODUÇÃO UFF-ENGENHA RIA CIVII

UFF-ENGENHARIA MECANCA USP-ENGENHARIA MECANICA UFPE-ENGENHARIA DE PRODUCCAO
DIENCIAS E TECNOLOGIAS NUCLEARES UFMG-CIENCIAS E TECNOLOGIASNUCLEARES UFRGS-ENGENHARIA CIVIL
UNIVAP-ENGENHARIA BIOMEEICA UPM - ENGENHARIA ELETRICA
UFSC-ENGENHARAA ELETRICA PUCIRIO - ENGENHARA ELETTICA

USP - ENGENHARIA NAVALEOCLEARICA UFRN-ENGENHARIA MECAANCA UFU-ENGENHARA

UFU-ENGENHARIA QUIMCA
UFRJ-ENGENHARIA METALURGICA D DE MA TERIAIS
UFSC-ENGENHARIA CIVIL

FONTE: Elaborado pela autora. 
Diante do destaque desses três PPG's em relação a quantidade de suas páginas, despertou-se o interesse em descobrir se diante de tantas informações, houve o empenho dos mesmos em cumprir as recomendações da CAPES no tocante a estrutura das páginas dos sites dos PPG's, que compõe-se em: colocar na sua página o seu corpo docente com o respectivo curriculum vitae; seus critérios de seleção com a bibliografia exigida; as ementas das disciplinas ministradas; parte representativa da produção científica dos docentes e discentes; e divulgação das teses e dissertações.

Para tanto foram acessados esses sites e verificou-se que os três PPG's em engenharias que se destacaram em relação ao indicador tamanho possuem todos os critérios estabelecidos pela CAPES, o que pode ter contribuído significativamente com o alcance dos primeiros lugares nesse ranking.

\subsubsection{Ranking dos programas de pós-graduação em engenharias de acordo com o indicador visibilidade}

No contexto científico atual pode-se notar que a relação entre instituições via Web é algo de grande relevância, pois ao utilizar a Web como suporte do fluxo informacional, há a contribuição dessas instituições com a divulgação da ciência. $E$ para medir essa relação entre instituições utilizou-se o indicador visibilidade nesse estudo.

De modo que ao se analisar a visibilidade dos sites dos PPG's em engenharias pôde-se notar que apenas uma pequena parte não possui nenhum link externo que remeta às suas páginas. Isso reforça a percepção de que uma quantidade considerável dos PPG's em engenharias do Brasil possui reconhecimento científico na rede e credibilidade nas informações que estão sendo divulgadas pela Web.

Sendo assim, verifica-se que o PPG em ciências e tecnologia de polímeros da UFRJ apresenta-se como o primeiro colocado com um total de 71 links de outras instituições que remete a suas páginas, o segundo é o PPG em engenharia elétrica da UNB que possui 64 links e o terceiro colocado é o PPG em Planejamento energético da UFRJ que apresentou 56 links recebidos. Esses resultados podem ser visualizados no GRÁFICO 30. 
GRÁFICO 30 - Análise do indicador visibilidade por Programa de Pós-graduação.

Análise do Indicador Wisibilidade

UFFU-CENCAE TECWCLOGH DE ROLUEROS

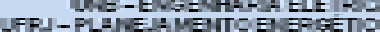

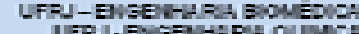

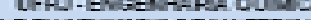

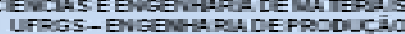

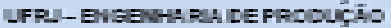

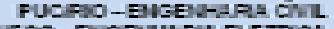

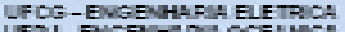

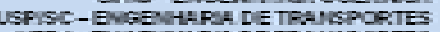

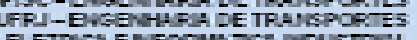

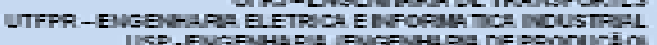

LSF-ENG UTC-

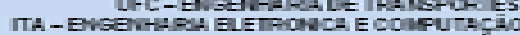

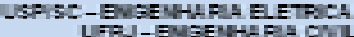

LFE- URRJ-BNGEMHAFICR

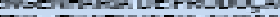

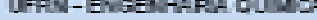

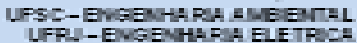

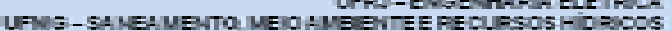

P.

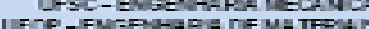

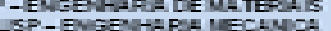

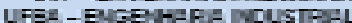

UfFos- MOPDEL ETPONDA

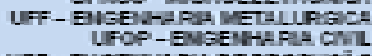

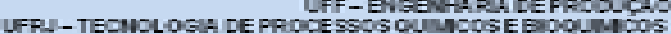

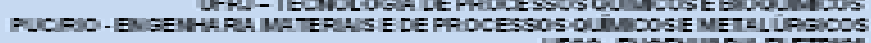
UFFF-VETOLOS

nos ne

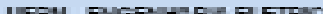
UF Lf Daver ou

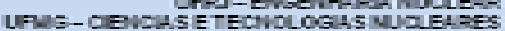
FScal 7 UPMG-

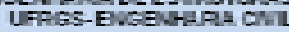
URA - ENGENHAIA ELTPIA

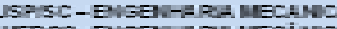

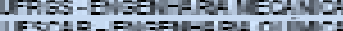

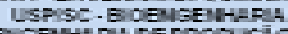

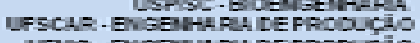

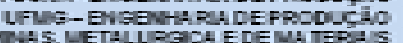

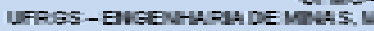

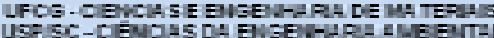

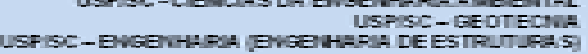

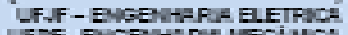

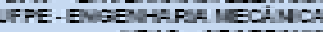

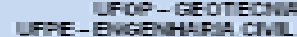

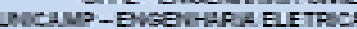

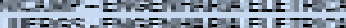
UT

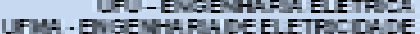

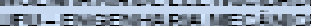

HATETS MUDFA =

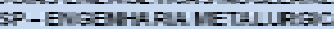

作

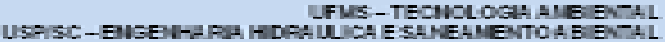

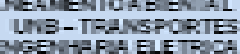

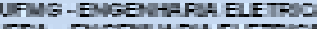

UFEA-ENGQWHASALERICA.

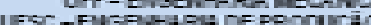

IFI- - 早 FiECUREDS HICFMCDS

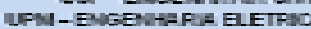

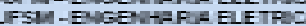
OUSENHLFA ELETPI IUFC-BUGEMHA-A ELETPUD

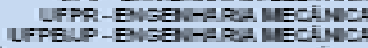

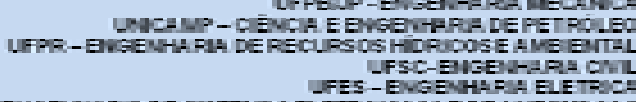

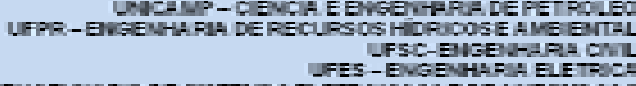

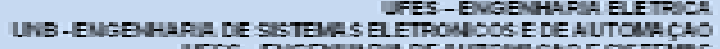

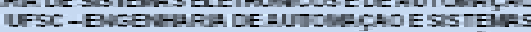

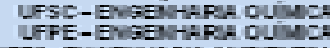
LFES- ENGENHARA A SEEMTEL

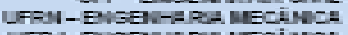
UERI-ENGE HAT FAR RECIMCA

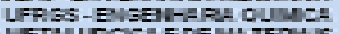

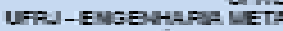

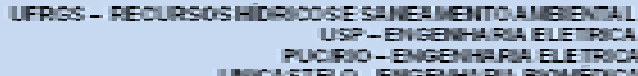

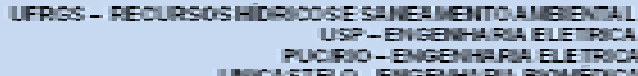
UNCASTED-ENGEHA PH SONED:

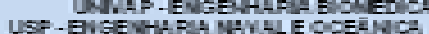

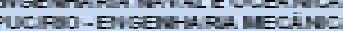

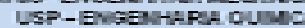
UEU-EWGENHA =IA DILACA

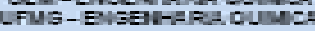
LWE-CEOTECNA

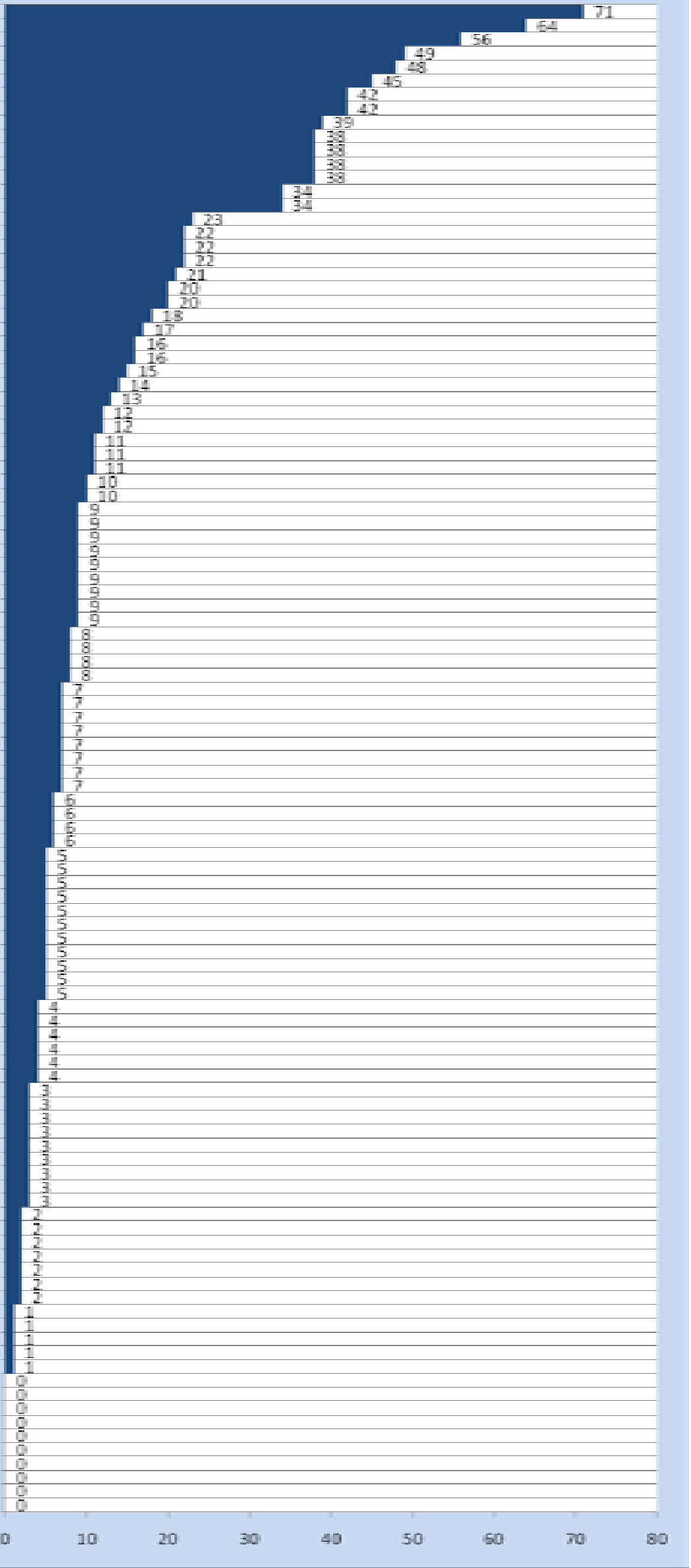

FONTE: Elaborado pela autora. 
A partir desses dados é possível constatar que os sites analisados tem se destacado na Web no que diz respeito ao reconhecimentode de suas IES, bem como de seus Programas de Pós-gradução.

Verifica-se no geral que esses Programas de Pós-graduação ainda estão se difundindo na rede e que isso ainda precisa ser bastante aperfeiçoado, visto que a maior parte deles possui valores pouco signicativos em relação a sua visibilidade. Para tanto faz-se necessário que esses PPG's se linkem entre si de forma a contribuirem com a difusão de pesquisas e estudos no âmbito nacional.

No entanto, no decorrer desta pesquisa observou-se que algun sites estão em constante modificação de suas URL's, o que dificulta a sua visibilidade, já que os links que remetem às suas páginas acabam por se tornarem inválidos.

Ao se comparar os resultados dos indicadores tamanho e visibilidade, podese perceber que a Universidade Federal do Rio de Janeiro e seus Progamas de Pósgraduação tem se destacado positivamente nos rankings estabelecidos. Isso reforça a percepção da credibilidade da instituição tanto no seu âmbito real quanto no virtual.

\subsubsection{Ranking dos programas de pós-graduação em engenharias de acordo com o indicador fator de impacto Web (FIW)}

O fator de impacto dos PPG's define-se pela relação entre a quantidade de páginas que os sites desses programas possuem e pela quantidade de links que a Web disponibiliza para suas páginas. Dessa forma é possível identificar o impacto desses Programas na rede.

Através de uma comparação do impacto das instituições na Web, pode-se verificar quais precisam se destacar ou se tornarem mais visíveis, de modo a colaborar mais favoravelmente com a divulgação de informações na Web.

Assim, verifica-se que o PPG em engenharia de Produção da UFPE apresenta-se em primeiro lugar com um total de 24,85 de fator de impacto, já o PPG em ciência e tecnologia de polímeros da UFRJ possui um valor de 24,05 e o PPG em engenharia elétrica da UNB atingiu o valor de 23,60, de acordo com o GRÁFICO 31, que se apresenta logo abaixo: 


\section{Análise do indicador Fator de Impacto Web}

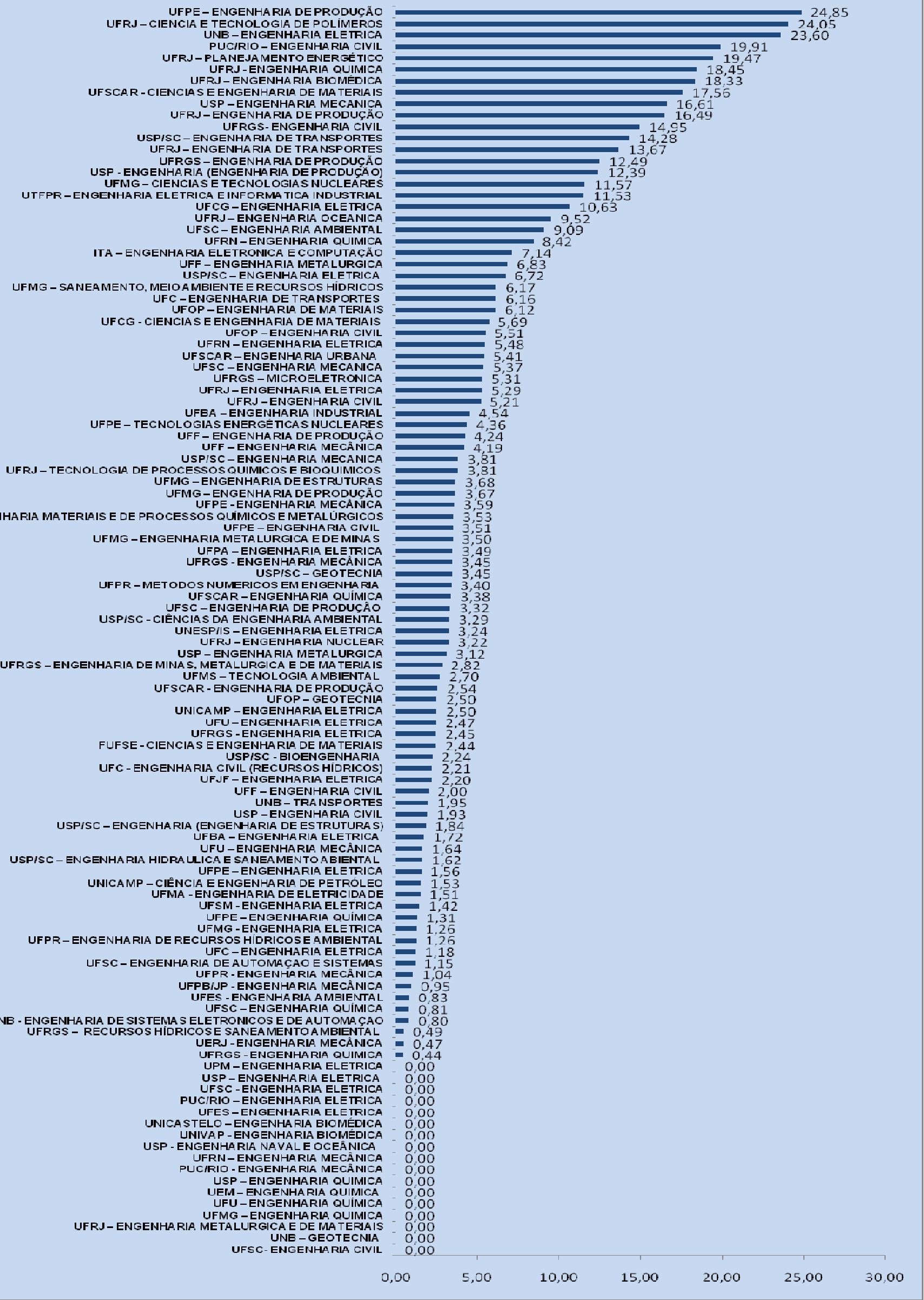

FONTE: Elaborado pela autora. 
Para compreender melhor os resultados obtidos pelo FIW utilizou-se novamente a média dos valores obtidos que se refere a 5,00 e a partir deste valor pode-se definir que os resultados abaixo dessa média são considerados PPG's com fator de impacto baixo e os PPG's com valores acima da média são considerados de fator de impacto alto.

A partir dessa definição, observa-se que dentre os 109 PPG's que englobam essa pesquisa, apenas 35 possuem FIW alto e 74 possuem FIW baixo. Isso nos faz perceber que ainda existem muitos PPG's que têm que buscar um maior destaque na Web, procurando estruturar melhor as suas páginas a fim de serem mais linkados por outras instituições.

Um fato importante a ser enfatizado é que dentre os PPG's que se destacam em relação ao seu FIW estão os Programas de ciência e tecnologia de polímeros da UFRJ e engenharia elétrica da UNB que também aparecem no topo do ranking na visibilidade. Isso reforça a eficácia da aplicabilidade dos indicadores webométricos aqui estudados, de modo a afirmar que os sites que possuem uma boa visibilidade na rede possuem uma maior possibilidade de obter um alto fator de impacto na Web.

\subsubsection{Ranking dos programas de pós-graduação em engenharias de acordo com $o$ indicador luminosidade}

A luminosidade dos Programas de Pós-graduação em engenharias apresentou-se bastante relevante, visto que muitos sites possuem uma boa quantidade de links que remetem a outras instituições. Estas ligações têm sido favorecidas com a utilização da Web como fonte informacional. Ressalta-se que para análise da luminosidade foram coletados apenas os links válidos, ou seja, aqueles que remetem a páginas que ainda estão em funcionamento.

Desse modo, verifica-se que o PPG em engenharia elétrica da UPM destacase em primeiro lugar no ranking com um total de 2.584 links para outras instituições, em segundo lugar encontra-se o PPG em engenharia civil da USP com 814 links em sua luminosidade e em terceiro lugar está o PPG em engenharia civil da UFSC com 589 links. O ranking pode ser visualizado através do GRÁFICO 32 que segue abaixo com a relação completa da análise do indicador luminosidade por Programas de Pós-graduação em engenharias do Brasil. 
GRÁFICO 32 - Análise do indicador Luminosidade por Programa de Pós-graduação.

Análise do Indicador Luminosidade

UPM - ENGENHARIA ELETRICA USP - ENGENHARIA CIVIL
UFSC-ENGENHARIA CIVIL

USPISC - ENGENHARIA ELETRICA

USPISC-ENGENHA RIA ELETRICA
UFRJ - TECNOLOGIA DE PROCESSOS SUIMICOSE BIOQUIMCOS
USPISC - ENGENHARIA MECANICA

UFC - ENGENHARIA DE TRANSPORTES

UFMG -ENGENHARIA ELETRICA

UFJF - ENGENHARIA ELETRICA

UFRJ - ENGENHARIA BIOMEDICA

UNB - ENGENHARIA DE SISTEMA S ELETRONICOS E DE AUTOMA ÇA

UFBA - ENGENHARIA INDUSTRIAL
UFRJ-CIENCIA E TECNOLOGIADE POLIMEROS UNB - ENGENHARIA ELETRICA

UTFPR - ENGENHARIA ELETRICA EINFORMA TICA INDUSTRIAL

UFPE-ENGENHARIA CIVIL UNB - TRANSPORTES

UFRN - ENGENHARIA QUIMICA
UNB - GEOTECNIA
USP - ENGENHARIA OUIMICA

UNICAMP -ENGENHARIA

UFRGS - ENGENHA RIA MECÂNICA

UFMG-ENGENHARIA QUIMICA

UFRJ-ENGENHARIA DEPRODUÇẮ

UFPA - ENGENHARIA ELETRICA

UFSCAR-ENGENHARIA QUIMICA
USPISC-ENGENHARIA (ENGENHARIA DEESTRUTURAS)

UFRGS-ENGENHARIA ELETRICA

UFSC - ENGENHARIA DE PRODUÇĀO

PUCIRIO - ENGENHARIA MECÁ IIICA

UFMS - TECNOLOGIA AMBIENTAL

UFMS - TECNOLOGIA AMBIENTAL
USP - ENGENHARIA METALURGICA UFRGS - MICROELETRONICA

UFRJ - ENGENHARIA METALURGICA E DE MA TERIAIS

USPISC-CIÊNCIASDR -ENGENHARIA MECÂNICA

USPISC - CIENNCIAS DA ENGENHARIA AMBIENTAL

UNICAMP - CIENCIA E ENGENHA RIA DE PETRÓLEO
UFRGS - ENGENHARIA DE MINA S, METALURGICA E DE MATERIAIS UFF-ENGENHARIA. MECÂNIICA
UFU-ENGENHARIA MECÂNICA

UFMG - ENGENHARIA DE PRODUÇÃO UFRJ-ENGENHARIA OCEA NICA
UFC-ENGENHARIA ELETRICA PUCIRIO - ENGENHARIA MATERIAIS E DE PROCESSOS QUIIMICOSE METALÚRGICOS UFSCAR - ENGENHARIA DEPRODUÇĂO

USPISC-GEOTECNIA
UFRJ-ENGENHARIA DE TRANSPORTES

UFCG-CIENCIA S EENGENHARIA DE MA TERIAIS

UNIVAP -ENGENHARIA BIOMEDICA
FUFSE - CIENCIASE ENGENHARIA DE MA TERIAIS

SE ENGENHARIA DE MATERIAIS
UFPE - ENGENHARIA ELETRICA UFPE - ENGENHARIA ELETRICA
USPISC-ENGENHARIA HIDRA ULICA E SANEAMENTO ABIENTAL

PUCIRIO - ENGENHARIA ELETRICA PUCIRIO -ENGENHARIA ELETRICA
USPISC-ENGENHARIA DETRA ISPORTES
UFU - ENGENHARIA ELETRICA
ENGENHARIA DE AUTOMAÇAO E SISTEMAS UFSC - ENGENHARIA DE AUTOMAÇAO E SISTEMAS
UNICASTELO - ENGENHARIA BIOMEDICA
UFPBIJP - ENGENHARIA MECÂN NICA

UFPR - ENGENHARIA DE RECURSOS HIDRICOSE AMBIENTAL
UFRGS - ENGENHARIA QUIMICA USP - ENGENHARIA NAVALE OCEÂNICA UFOP - ENGENHARIA CIVIL USPISC - EIOENGENHARIA
UFBA - ENGENHARIA ELETRICA UFBA - ENGENHA RIA ELETRICA UFSCAR-ENGENHARIA URBANA

UFSCAR-ENGENHARIA UREANA UFF- ENGENHARIA METALURGICA
UFES - ENGENHA RIA AMBIENTAL UFOP - GEOTECNIA
UFOP UFSC - ENGENHARIA QUIMICA UFRJ - ENGENHARIA NUCLEAR UFRJ - ENGENHARIA CIVIL UFRJ-ENGENHARIA ELETRICA UFMG - IERJ - PLANEJAMENTOENERGETICO IASE TECNOLOGIAS NUCLEARES
JFSC - ENGENHARIA AMIBIENTAL UFSC - ENGENHARIA AMBIENTAL
UFSM-ENGENHARIA ELETRICA UFSM -ENGENHARIA ELETRICA
UERJ - ENGENHARIA MECÂNICA

UFMA - ENGENHARIA DE ELETRICIDADE

UFOP - ENGENHARIA DE MATTEIAIS UF $S C$-ENGENHARIA ELETRICA UFSC - ENGENHARIA ELETRICA
UFC - ENGENHA RIA CIVIL (RECURSOS HIDRICOS)
UFU - ENGENHARIA QUIMICA UFRGS - RECURSOS HIDRICOS E SANEA MENTO AMEIENTAL UFPR - METODOS NUMERICOS EM ENGENHARIA UFPE - ENGENHARIA MECANNICA UFMG - ENGENHARIA METALURGICA EDE IMINAS
UFSCAR - CIENCIASE ENGENHARIA DE MATERIAIS DEESTRUTURAS UFF-ENGENHARIA DE PRODUÇĀO UFPE- TECNOLOGIAS ENERGETICAS NUCLEARES UFES - ENGENHARIA ELETRICA
UFMG - SA NEAMIENTO, MEIOAMBIENTEERECURSOS HIDRICOS ITA - ENGENHA RIA ELETRONICA E COMPUTAÇÃO USP - ENGENHARIA ELETRICA USP-ENGENHARIA MECANICA

UFRN-ENGENHARIA MECÂNICA
USP - ENGENHARIA (ENGENHA RA DE PRODUÇÂO
UFPE-ENGENHARIA QUIMICA
UFRGS-ENGENHARIA CIVIL
PUCIRIO - ENGENHARIA CIVIL

UFRN-ENGENHARIA MECÂNICA
USP - ENGENHARIA (ENGENHA RA DE PRODUÇÂO
UFPE-ENGENHARIA QUIMICA
UFRGS-ENGENHARIA CIVIL
PUCIRIO - ENGENHARIA CIVIL

UFRN-ENGENHARIA MECÂNICA
USP - ENGENHARIA (ENGENHA RA DE PRODUÇÂO
UFPE-ENGENHARIA QUIMICA
UFRGS-ENGENHARIA CIVIL
PUCIRIO - ENGENHARIA CIVIL

UFRN-ENGENHARIA MECÂNICA
USP - ENGENHARIA (ENGENHA RA DE PRODUÇÂO
UFPE-ENGENHARIA QUIMICA
UFRGS-ENGENHARIA CIVIL
PUCIRIO - ENGENHARIA CIVIL

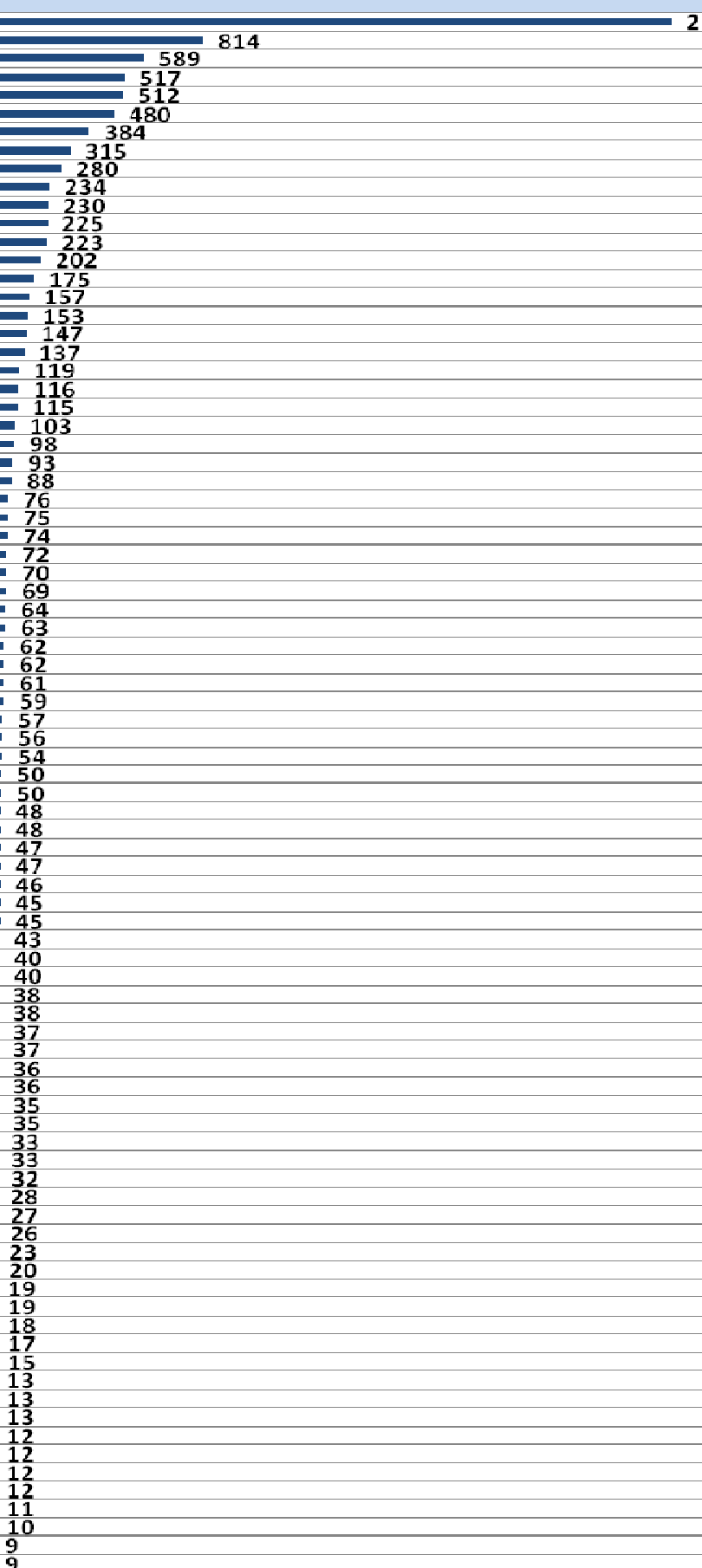

589

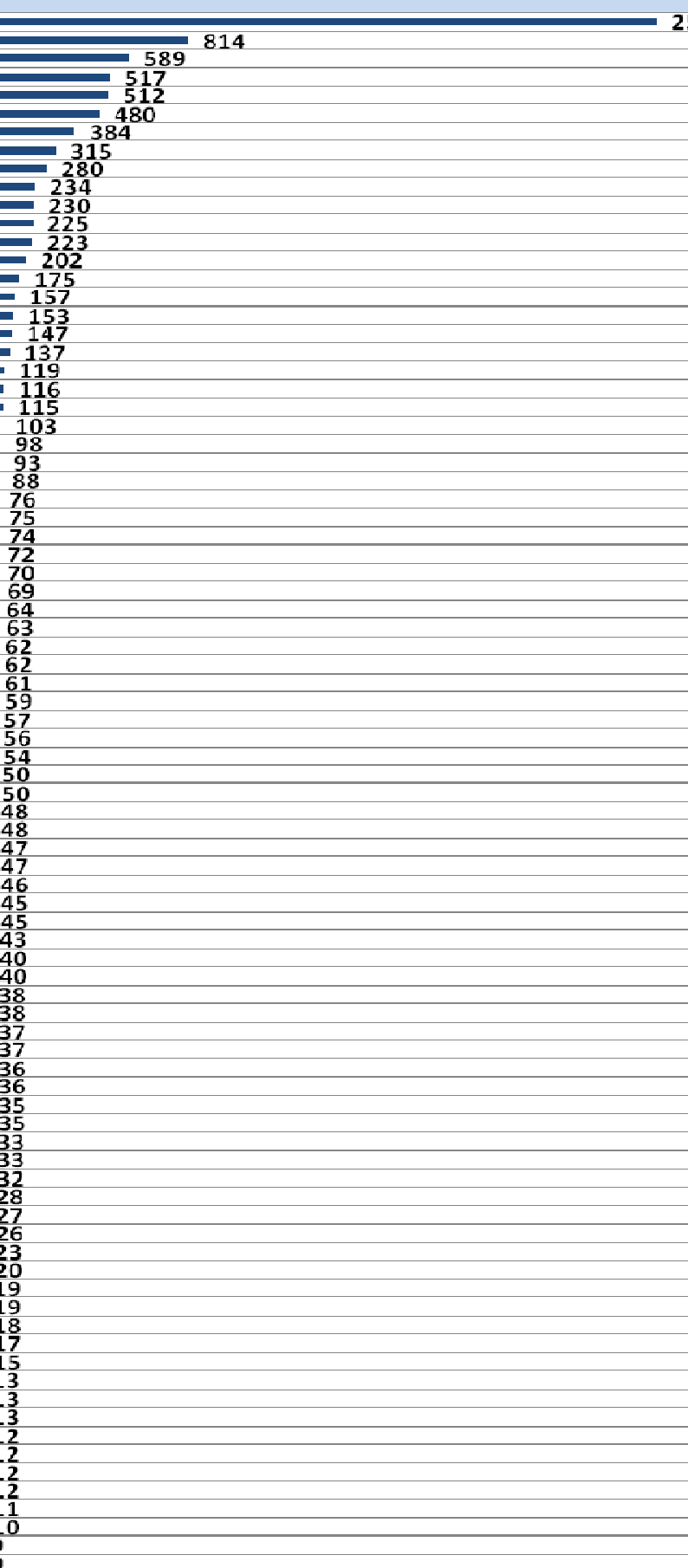
480

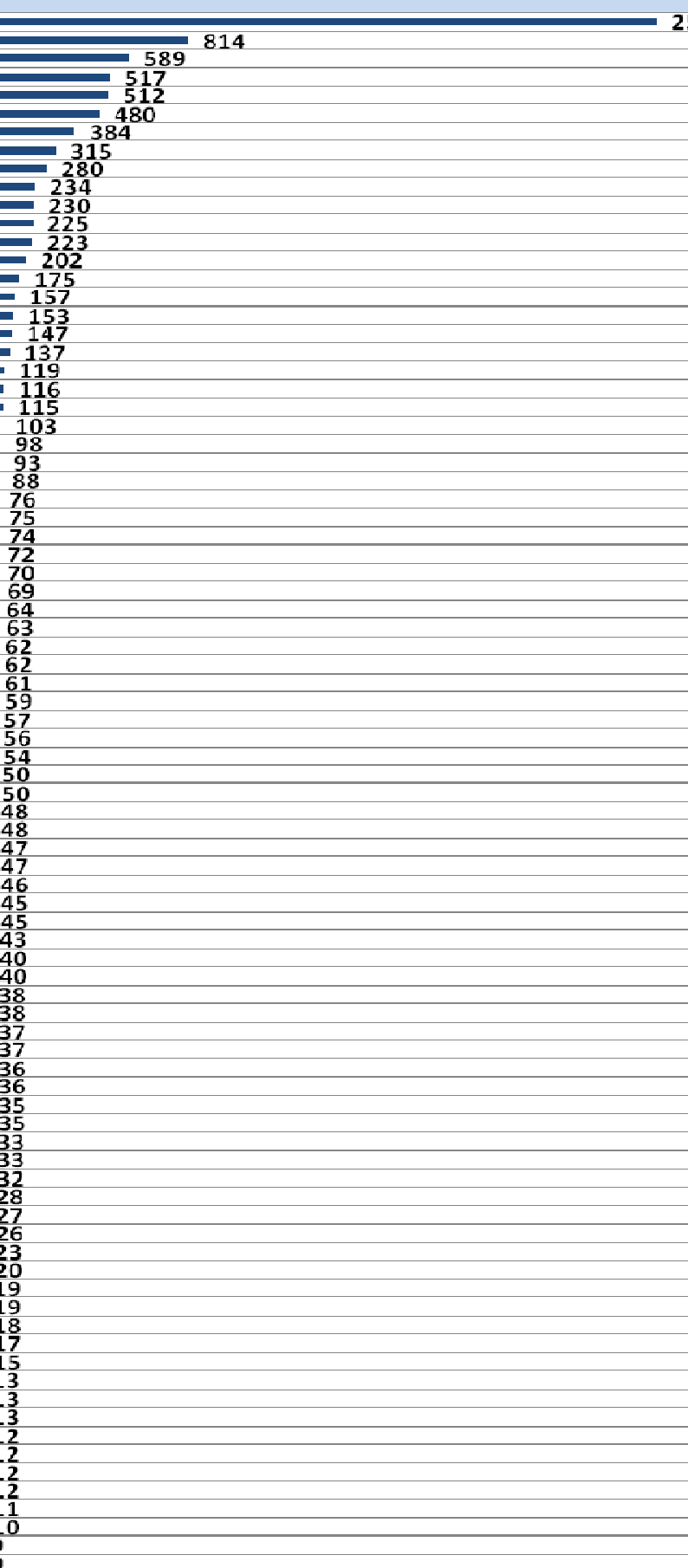

234

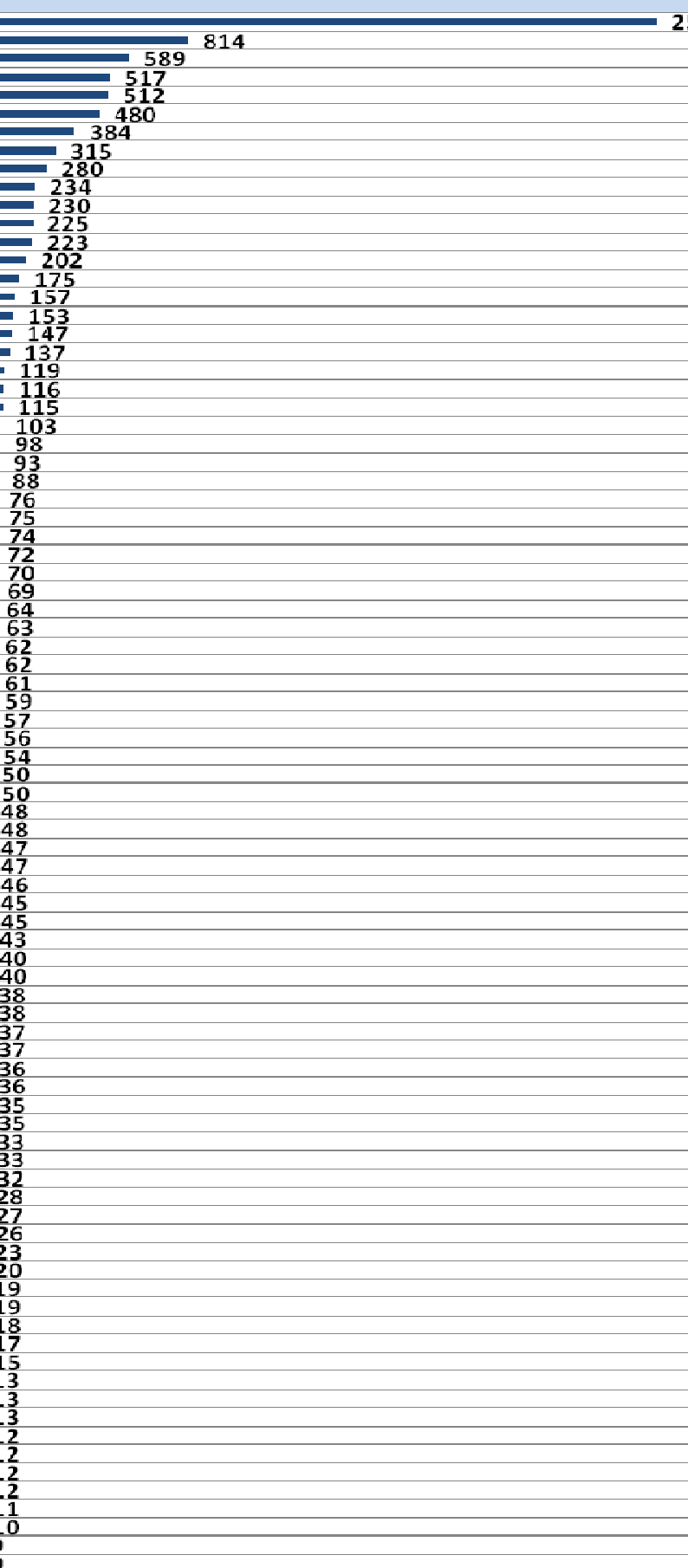

234
230
225

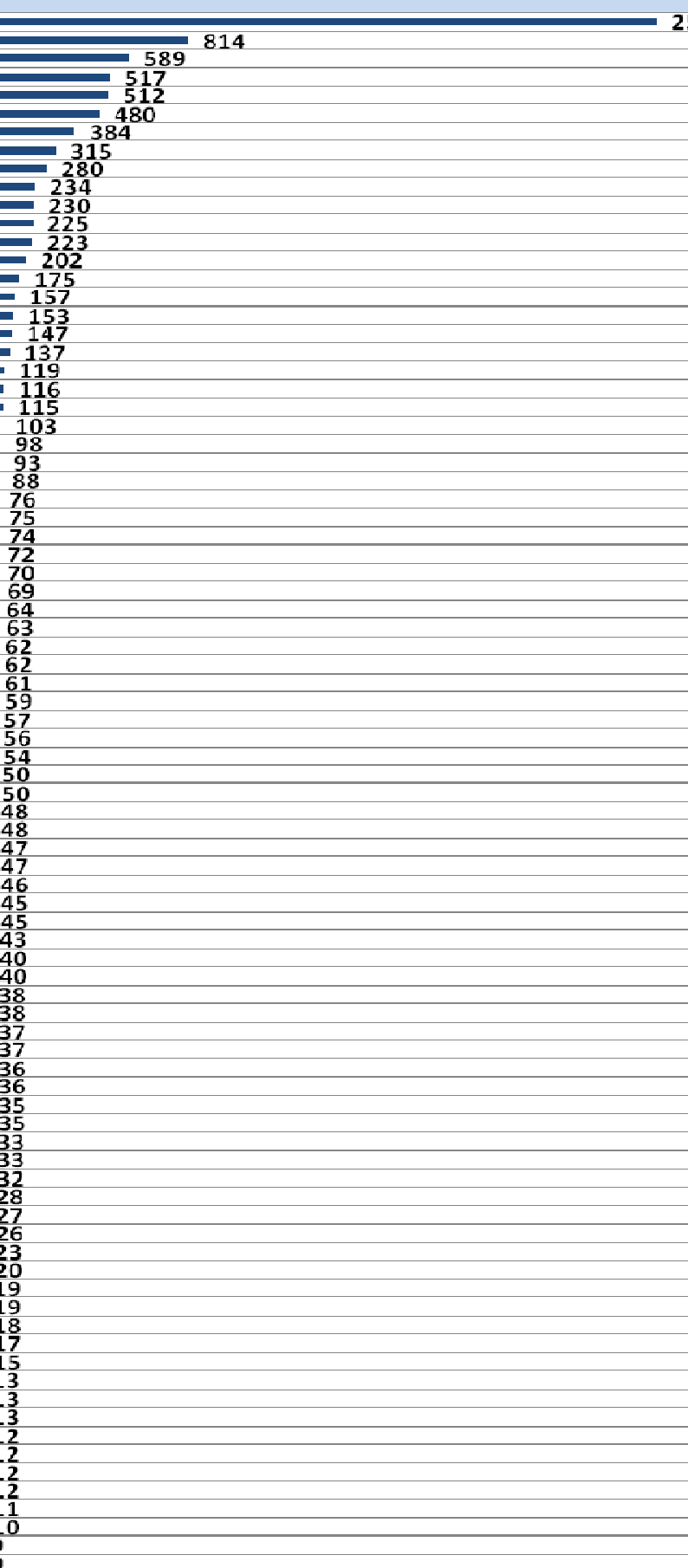

175

147

115

98

88

76

7

\begin{tabular}{l}
8 \\
7 \\
6 \\
6 \\
\hline 5
\end{tabular}

FONTE: Elaborado pela autora. 
Com os resultados obtidos, percebe-se que é crescente o uso da Web pelos PPG's para difusão da informação. Visto os valores que foram obtidos em relação à quantidade de links que estes sites disponibilizam para outras instituições.

Nesse contexto, observa-se que os critérios estabelecidos pela CAPES para construção das informações das páginas dos Programas de Pós-graduação do Brasil podem colaborar diretamente com os índices webométricos, considerando que a CAPES sugere a divulgação do corpo docente de cada Programa seguido de seus respectivos Currículos Lattes.

Desse modo, pode-se verificar que os PPG's que aderiram as sugestões da CAPES tenderam a se destacar no indicador luminosidade, diante da quantidade de links existentes nas páginas de seus Programas que remetem as páginas da Plataforma Lattes, responsável pela disponibilização do Currículo Lates dos docentes e discentes no âmbito do Brasil.

Também se observou que a maior parte dos links recuperados nesse estudo remete para páginas de outras instituições acadêmicas nacionais e internacionais, como também para periódicos científicos, repositórios digitais e agências de fomento.

Outro aspecto a ressaltar é que os Programas de Pós-graduação que fazem parte de instituições federais disponibilizam muitos links entre seus programas, 0 que não ocorre constantemente nos PPG's das Instituições privadas, pois as mesmas tendem a linkar apenas para programas de sua própria instituição.

Porém essa característica não comprometeu o mérito da Universidade Presbiteriana Mackenzie (UPM) que se destacou em primeiro lugar na análise da luminosidade. Isto se deve pela grande quantidade de links que a mesma disponibiliza em seu site, através da opção "links úteis" que abrange desde sites de institutos de pesquisas nacionais e internacionais até sites de fóruns de discussões científicas.

A partir dessas análises certifica-se a relevância da presença de links nas páginas dos Programas de Pós-graduação em engenharias, pois é notório que a disponibilização desses links favorece intensamente o processo de disseminação de fontes de informação e fluxo informacional, bem como contribui com a presença desses programas na rede. 


\subsubsection{Ranking webométrico dos programas de pós-graduação em engenharias}

Com o propósito de alcançar os objetivos deste trabalho foi estabelecido um ranking webométrico que indica qual grupo de engenharias e Programa de Pósgraduação se destaca em relação aos demais no espaço acadêmico virtual, no tocante ao processo de disponibilização de informações científicas na Web.

Nesse sentido, tomou-se o peso de todos os resultados dos indicadores utilizados nessa pesquisa, e pôde-se medir a presença de todos os sites na rede, identificando assim, sua relevância no mundo virtual, destacando qual destes sites oferece um maior índice de perspectiva de contribuição para a ciência ao utilizar a Web como suporte para a comunicação científica.

E a partir da obtenção de tais valores pôde-se definir o ranking webométrico que é apresentado na TABELA 5.

Ao avaliar os 5 primeiros colocados no ranking, observa-se que o Programa de Pós-graduação em engenharia civil da Universidade Federal do Rio de Janeiro e que integra o grupo de engenharias I, ocupa o primeiro lugar no ranking com um total de 1.674,64 de índice webométrico.

A Universidade Federal do Rio de Janeiro também se destaca no segundo lugar com o Programa de Pós-graduação em engenharia oceânica, que faz parte das engenharias III e que totalizou um valor de índice webométrico referente a $1.015,50$.

O terceiro colocado é o Programa de Pós-graduação em engenharia civil (engenharia de estruturas) da Universidade de São Paulo - Campus de São Carlos, que também integra as engenharias I e que possui 647,67 de índice webométrico.

A Universidade Federal do Ceará com seu Programa de Pós-graduação em engenharia de transportes, que faz parte das engenharias I, apresenta 632,53 de índice webométrico, ocupando a quarta colocação no ranking.

O quinto colocado é o Programa de Pós-graduação em engenharia elétrica da Universidade Presbiteriana Mackenzie, que integra as engenharias IV e que possui um índice de 518,40. 
TABELA 5 - Ranking webométrico.

\begin{tabular}{|c|c|c|c|c|}
\hline \multicolumn{5}{|c|}{ RANKING WEBOMÉTRICO } \\
\hline RANKING & IES & PPG's & $\begin{array}{l}\text { GRUPO DE } \\
\text { ENGENHARIA }\end{array}$ & $\begin{array}{c}\text { ÍNDICE } \\
\text { WEBOMÉTRICO }\end{array}$ \\
\hline 10 & UFRJ & ENGENHARIA CIVIL & 1 & 1674,64 \\
\hline 20 & UFRJ & ENGENHARIA OCEÂNICA & III & 1015,50 \\
\hline 3ㅇ & USP/SC & $\begin{array}{l}\text { ENGENHARIA CIVIL (ENGENHARIA } \\
\text { DE ESTRUTURAS) }\end{array}$ & I & 647,67 \\
\hline $4^{\circ}$ & UFC & ENGENHARIA DE TRANSPORTES & I & 632,53 \\
\hline $5^{\circ}$ & UPM & ENGENHARIA ELÉTRICA & IV & 518,40 \\
\hline $6^{\circ}$ & UFCG & ENGENHARIA ELÉTRICA & IV & 399,93 \\
\hline $7^{\circ}$ & USP/SC & ENGENHARIA ELÉTRICA & IV & 302,74 \\
\hline 80 & UFRGS & ENGENHARIA DE PRODUÇÃO & III & 284,90 \\
\hline $9 \underline{9}$ & UFRJ & ENGENHARIA ELÉTRICA & IV & 266,46 \\
\hline $10^{\circ}$ & UFMG & ENGENHARIA ELÉTRICA & IV & 211,25 \\
\hline $11^{\circ}$ & UFMA & ENGENHARIA DE ELETRICIDADE & IV & 210,60 \\
\hline $12^{\circ}$ & UFRJ & $\begin{array}{l}\text { TECNOLOGIA DE PROCESSOS } \\
\text { QUIIMICOS E BIOQUÍMICOS }\end{array}$ & II & 185,96 \\
\hline $13^{\circ}$ & USP & ENGENHARIA CIVIL & I & 177,09 \\
\hline $14^{\circ}$ & UFBA & ENGENHARIA INDUSTRIAL & III & 174,51 \\
\hline $15^{\circ}$ & UFRJ & $\begin{array}{l}\text { CIÊNCIA E TECNOLOGIA DE } \\
\text { POLÍMEROS }\end{array}$ & II & 170,31 \\
\hline $16^{\circ}$ & UFPB/J.P. & ENGENHARIA MECÂNICA & III & 152,29 \\
\hline $17^{\circ}$ & PUC-RIO & $\begin{array}{l}\text { ENGENHARIA MATERIAIS E DE } \\
\text { PROCESSOS QUÍMICOS E } \\
\text { METALÚRGICOS }\end{array}$ & II & 146,61 \\
\hline $18^{\circ}$ & USP/SC & BIOENGENHARIA & IV & 143,55 \\
\hline $19^{\circ}$ & UNB & GEOTECNIA & 1 & 139,20 \\
\hline $20^{\circ}$ & UTFPR & $\begin{array}{l}\text { ENGENHARIA ELÉTRICA E } \\
\text { INFORMÁTICA INDUSTRIAL }\end{array}$ & IV & 138,91 \\
\hline $21^{\circ}$ & USP/SC & $\begin{array}{l}\text { ENGENHARIA HIDRÁULICA E } \\
\text { SANEAMENTO }\end{array}$ & 1 & 133,22 \\
\hline $22^{\circ}$ & ITA & $\begin{array}{l}\text { ENGENHARIA ELETRÔNICA E } \\
\text { COMPUTAÇÃO }\end{array}$ & IV & 132,43 \\
\hline $23^{\circ}$ & UFU & ENGENHARIA MECÂNICA & III & 125,83 \\
\hline $24^{\circ}$ & UNB & ENGENHARIA ELÉTRICA & IV & 123,22 \\
\hline $25^{\circ}$ & UFRJ & ENGENHARIA BIOMÉDICA & IV & 122,17 \\
\hline $26^{\circ}$ & UFSC & ENGENHARIA CIVIL & 1 & 119,40 \\
\hline $27^{\circ}$ & UFRJ & ENGENHARIA QUÍMICA & II & 113,59 \\
\hline 289 & USP/SC & ENGENHARIA MECÂNICA & III & 113,36 \\
\hline 299 & UFSC & ENGENHARIA MECÂNICA & III & 112,57 \\
\hline $30^{\circ}$ & UFJF & ENGENHARIA ELÉTRICA & IV & 112,54 \\
\hline $31^{\circ}$ & UFRJ & PLANEJAMENTO ENERGÉTICO & III & 109,39 \\
\hline
\end{tabular}




\begin{tabular}{|c|c|c|c|c|}
\hline RANKING & IES & PPG's & $\begin{array}{l}\text { GRUPO DE } \\
\text { ENGENHARIA }\end{array}$ & $\begin{array}{c}\text { ÍNDICE } \\
\text { WEBOMÉTRICO }\end{array}$ \\
\hline $32^{\circ}$ & UFPR & $\begin{array}{l}\text { MÉTODOS NUMÉRICOS EM } \\
\text { ENGENHARIA }\end{array}$ & III & 93,98 \\
\hline $33^{\circ}$ & UFRJ & ENGENHARIA DE TRANSPORTES & 1 & 90,63 \\
\hline $34^{\circ}$ & UFPR & ENGENHARIA MECÂNICA & III & 88,81 \\
\hline $35^{\circ}$ & UNB & $\begin{array}{l}\text { ENGENHARIA DE SISTEMAS } \\
\text { ELETRÔNICOS E DE AUTOMAÇÃO }\end{array}$ & IV & 77,66 \\
\hline $36^{\circ}$ & UFRJ & ENGENHARIA DE PRODUÇÃO & III & 77,10 \\
\hline $37^{\circ}$ & UNESP/IS & ENGENHARIA ELÉTRICA & IV & 75,15 \\
\hline $38^{\circ}$ & USP & $\begin{array}{l}\text { ENGENHARIA (ENGENHARIA DE } \\
\text { PRODUÇÃO) }\end{array}$ & III & 74,98 \\
\hline $39 \div$ & USP/SC & ENGENHARIA DE TRANSPORTES & 1 & 74,96 \\
\hline $40^{\circ}$ & UFRJ & ENGENHARIA NUCLEAR & II & 69,84 \\
\hline $41^{\circ}$ & UFSCAR & ENGENHARIA DE PRODUÇÃO & III & 69,31 \\
\hline $42^{\circ}$ & UFMG & $\begin{array}{l}\text { SANEAMENTO, MEIO AMBIENTE E } \\
\text { RECURSOS HÍDRICOS }\end{array}$ & 1 & 67,03 \\
\hline $43^{\circ}$ & UNB & TRANSPORTES & 1 & 66,49 \\
\hline $44^{\circ}$ & UFSCAR & $\begin{array}{l}\text { CIÊNCIA E ENGENHARIA DOS } \\
\text { MATERIAIS }\end{array}$ & II & 63,31 \\
\hline $45^{\circ}$ & UFRN & ENGENHARIA QUÍMICA & II & 59,18 \\
\hline $46^{\circ}$ & UFOP & ENGENHARIA DE MATERIAIS & II & 52,02 \\
\hline $47^{\circ}$ & UFRGS & MICROELETRÔNICA & IV & 47,96 \\
\hline $48^{\circ}$ & UFF & ENGENHARIA DE PRODUÇÃO & III & 46,45 \\
\hline $49 \div$ & UFRGS & $\begin{array}{l}\text { ENGENHARIA DE MINAS, } \\
\text { METALÚRGICA E DE MATERIAIS }\end{array}$ & II & 45,56 \\
\hline $50^{\circ}$ & UFC & ENGENHARIA ELÉTRICA & IV & 45,34 \\
\hline $51^{\circ}$ & UFRGS & ENGENHARIA MECÂNICA & III & 44,99 \\
\hline $52^{\circ}$ & UFMG & $\begin{array}{l}\text { ENGENHARIA METALÚRGICA E DE } \\
\text { MINAS }\end{array}$ & II & 43,20 \\
\hline $53^{\circ}$ & UFSCAR & ENGENHARIA QUÍMICA & II & 42,78 \\
\hline $54^{\circ}$ & UFPA & ENGENHARIA ELÉTRICA & IV & 39,50 \\
\hline $55^{\circ}$ & UFPE & ENGENHARIA CIVIL & 1 & 38,20 \\
\hline $56^{\circ}$ & UFMG & ENGENHARIA DE ESTRUTURAS & 1 & 34,04 \\
\hline $57^{\circ}$ & UFMG & ENGENHARIA QUÍMICA & II & 33,80 \\
\hline $58^{\circ}$ & UFSC & ENGENHARIA QUÍMICA & II & 33,76 \\
\hline 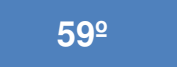 & UNICAMP & ENGENHARIA ELÉTRICA & IV & 33,60 \\
\hline $60^{\circ}$ & PUC-RIO & ENGENHARIA CIVIL & 1 & 32,58 \\
\hline $61^{\circ}$ & UFPR & $\begin{array}{l}\text { ENGENHARIA DE RECURSOS } \\
\text { HÍDRICOS E AMBIENTAL }\end{array}$ & 1 & 32,15 \\
\hline $62^{\circ}$ & UFOP & GEOTECNIA & I & 31,50 \\
\hline $63^{\circ}$ & UFSC & ENGENHARIA AMBIENTAL & 1 & 30,12 \\
\hline $64^{\circ}$ & UFES & ENGENHARIA AMBIENTAL & 1 & 30,07 \\
\hline $65^{\circ}$ & USP/SC & $\begin{array}{l}\text { CIÉNCIAS DA ENGENHARIA } \\
\text { AMBIENTAL }\end{array}$ & 1 & 29,36 \\
\hline
\end{tabular}




\begin{tabular}{|c|c|c|c|c|}
\hline RANKING & IES & PPG's & $\begin{array}{l}\text { GRUPO DE } \\
\text { ENGENHARIA }\end{array}$ & $\begin{array}{c}\text { ÍNDICE } \\
\text { WEBOMÉTRICO }\end{array}$ \\
\hline $66^{\circ}$ & USP & ENGENHARIA QUÍMICA & II & 28,40 \\
\hline $67^{\circ}$ & UFRGS & ENGENHARIA ELÉTRICA & IV & 28,39 \\
\hline $68^{\circ}$ & UFBA & ENGENHARIA ELÉTRICA & IV & 27,44 \\
\hline $69 \div$ & UFOP & ENGENHARIA CIVIL & I & 27,40 \\
\hline $70^{\circ}$ & UFRGS & ENGENHARIA QUÍMICA & II & 25,19 \\
\hline $71^{\circ}$ & USP/SC & GEOTECNIA & 1 & 23,89 \\
\hline $72^{\circ}$ & UEM & ENGENHARIA QUÍMICA & II & 23,80 \\
\hline $73^{\circ}$ & UFMS & TECNOLOGIAS AMBIENTAIS & 1 & 22,94 \\
\hline $74^{\circ}$ & UFMG & ENGENHARIA DE PRODUÇÃO & III & 22,33 \\
\hline $75^{\circ}$ & UNICAMP & $\begin{array}{l}\text { CIÊNCIAS E ENGENHARIA DE } \\
\text { PETRÓLEO }\end{array}$ & III & 22,31 \\
\hline $76^{\circ}$ & FUFSE & $\begin{array}{l}\text { CIÊNCIA E ENGENHARIA DE } \\
\text { MATERIAIS }\end{array}$ & II & 21,69 \\
\hline $77^{\circ}$ & UFU & ENGENHARIA ELÉTRICA & IV & 20,49 \\
\hline $78^{\circ}$ & USP & ENGENHARIA METALÚRGICA & II & 19,72 \\
\hline $79 \circ$ & UFSC & ENGENHARIA DE PRODUÇÃO & III & 18,26 \\
\hline $80^{\circ}$ & UFPE & ENGENHARIA ELÉTRICA & IV & 17,61 \\
\hline $81^{\circ}$ & UFSM & ENGENHARIA ELÉTRICA & IV & 16,98 \\
\hline $82^{\circ}$ & UFF & ENGENHARIA METALÚRGICA & II & 16,67 \\
\hline $83^{\circ}$ & UFPE & ENGENHARIA DE PRODUÇÃO & III & 16,57 \\
\hline $84^{\circ}$ & UERJ & ENGENHARIA MECÂNICA & III & 15,49 \\
\hline $85^{\circ}$ & UFF & ENGENHARIA MECÂNICA & III & 14,54 \\
\hline $86^{\circ}$ & UFCG & $\begin{array}{l}\text { CIÊNCIA E ENGENHARIA DE } \\
\text { MATERIAIS }\end{array}$ & II & 14,34 \\
\hline $87^{\circ}$ & UFSCAR & ENGENHARIA URBANA & 1 & 13,98 \\
\hline $88^{\circ}$ & PUC-RIO & ENGENHARIA MECÂNICA & III & 13,90 \\
\hline $89 \div$ & UFSC & $\begin{array}{l}\text { ENGENHARIA DE AUTOMAÇÃO E } \\
\text { SISTEMAS }\end{array}$ & IV & 13,63 \\
\hline $90^{\circ}$ & USP & ENGENHARIA ELÉTRICA & IV & 13,20 \\
\hline $91^{\circ}$ & UFRJ & $\begin{array}{l}\text { ENGENHARIA METALÚRGICA E DE } \\
\text { MATERIAIS }\end{array}$ & II & 13,00 \\
\hline $92^{\circ}$ & UFRGS & $\begin{array}{l}\text { RECURSOS HÍDRICOS E } \\
\text { SANEAMENTO AMBIENTAL }\end{array}$ & I & 12,60 \\
\hline $93^{\circ}$ & USP & ENGENHARIA MECÂNICA & III & 11,62 \\
\hline $94^{\circ}$ & UFC & $\begin{array}{l}\text { ENGENHARIA CIVIL (RECURSOS } \\
\text { HÍDRICOS) }\end{array}$ & I & 10,34 \\
\hline $95^{\circ}$ & UFRN & ENGENHARIA ELÉTRICA & IV & 10,00 \\
\hline $96^{\circ}$ & UFMG & CIÊNCIAS TÉCNICAS NUCLEARES & II & 9,81 \\
\hline $97^{\circ}$ & UNICASTELO & ENGENHARIA BIOMÉDICA & IV & 9,80 \\
\hline $98^{\circ}=$ & UFPE & ENGENHARIA MECÂNICA & III & 9,22 \\
\hline $99 \div$ & UFRGS & ENGENHARIA CIVIL & 1 & 7,89 \\
\hline $100^{\circ}$ & UNIVAP & ENGENHARIA BIOMÉDICA & IV & 7,80 \\
\hline $101^{\circ}$ & PUC-RIO & ENGENHARIA ELÉTRICA & IV & 7,30 \\
\hline
\end{tabular}




\begin{tabular}{|c|l|l|c|c|}
\hline RANKING & IES & \multicolumn{1}{|c|}{ PPG's } & $\begin{array}{c}\text { GRUPO DE } \\
\text { ENGENHARIA }\end{array}$ & $\begin{array}{c}\text { ÍNDICE } \\
\text { WEBOMÉTRICO }\end{array}$ \\
\hline $102^{\circ}$ & UFSC & ENGENHARIA ELÉTRICA & IV & 6,70 \\
\hline $103^{\circ}$ & UFU & ENGENHARIA QUÍMICA & II & 5,80 \\
\hline $10^{\circ}$ & USP & ENGENHARIA NAVAL E OCEÂNICA & III & 5,50 \\
\hline $105^{\circ}$ & UFPE & $\begin{array}{l}\text { TECNOLOGIAS ENERGÉTICAS } \\
\text { NUCLEARES }\end{array}$ & II & 5,37 \\
\hline $106^{\circ}$ & UFPE & ENGENHARIA QUÍMICA & II & 4,66 \\
\hline $107^{\circ}$ & UFF & ENGENHARIA CIVIL & I & 3,60 \\
\hline $100^{\circ}$ & UFES & ENGENHARIA ELÉTRICA & IV & 1,30 \\
\hline $109^{\circ}$ & UFRN & ENGENHARIA MECÂNICA & III & 0,60 \\
\hline
\end{tabular}

FONTE: Elaborada pela autora.

Diante do ranking webométrico estabelecido torna-se oportuno analisar e comentar acerca dos 10 primeiros colocados nesse estudo, que nos aponta algumas características muito pertinentes acerca dos resultados. O ranking completo com todos os indicadores encontra-se detalhado no APÊNDICE F, APÊNDICE G, APÊNDICE H e APÊNDICE I.

Inicialmente, quando investigadas as Universidades que fazem parte do topo do ranking webométrico, observa-se que a Universidade Federal do Rio de Janeiro com seus Programas de engenharia civil, engenharia oceânica e engenharia elétrica e a Universidade de São Paulo, campus de São Carlos, com os programas de engenharia civil (engenharia de estruturas) e engenharia elétrica sobressaem as demais com sua presença, o que nos dá a possibilidade de afirmar que a UFRJ e a USP/SC são as instituições que possuem um maior reconhecimento na rede, quando analisados os Programas em engenharias do Brasil.

No tocante aos grupos de engenharias, examina-se que os PPG's que integram as engenharias IV são os que mais se destacam no ranking. E esse fato deve-se, notoriamente, aos Programas de Pós-graduação em engenharia elétrica que se sobressaem dos demais PPG's devido aos elevados valores obtidos nesse estudo, e, consequentemente ao reconhecimento dessa área no meio científico.

Para que haja uma maior compreensão acerca dos resultados obtidos no ranking, apresenta-se nos APÊNDICE J, APÊNDICE K, APÊNDICE L e APÊNDICE M, os rankings webométricos dos grupos das respectivas engenharias: I, II, III e IV.

De modo geral, verifica-se que entre os PPG's, os 4 primeiros colocados no ranking webométrico foram: engenharia civil da UFRJ; engenharia oceânica da 
UFRJ; Engenharia civil (engenharia de estruturas) da USP/SC; e engenharia de transportes da UFC, que também ocuparam essas mesmas colocações ao se analisar o indicador tamanho dos sites Web.

Isso se deve aos altos valores coletados no uso desse indicador e que nos faz atentar para a relevância de quantidade de páginas a serem disponibilizadas na Web para que um site alcance uma boa colocação no ranking webométrico.

Dentre os 10 PPG's que ficaram entre os primeiros colocados no ranking, observa-se a presença de 2 cursos de Pós-graduação em engenharia civil, sendo um da UFRJ e outro da USP/SC e os 5 em engenharia elétrica da UPM, UFCG, USP/SC, UFRJ e UFMG.

Isso nos faz perceber o quanto esses programas têm contribuído com a comunicação científica na Web ao utilizar seus sites como fonte para a disseminação de informações acerca de estudos e pesquisas que contribuem com suas respectivas áreas de estudo.

Ainda cita-se a presença dentre os primeiros colocados no ranking, os programas de engenharia oceânica da Universidade Federal do Rio de Janeiro, engenharia de transportes da Universidade Federal do Ceará, e engenharia de produção da Universidade Federal do Rio Grande do Sul.

Nessa perspectiva, se supõe que estes PPG's em engenharias se destacam no espaço Web, em relação ao processo de comunicação e disseminação de informações científicas ao meio acadêmico. Como também, contribuem com o processo informacional e colaboram diretamente com as mudanças sociais, visto que a informação é considerada fator de geração e produção de conhecimentos necessários para que essas mudanças ocorram. Nesse sentido, observa-se o apreço do uso adequado das informações e sua disponibilização no meio científico.

As IES e os Programas de Pós-graduação que se destacam nesse estudo contribuem com a produção e divulgação de pesquisas científicas, concernente ao acesso, uso e disponibilidade dessas informações. E ainda colaboram com o reconhecimento nacional e internacional diante de outras instituições. Sendo este reconhecimento caracterizado em suma, pela integridade, disponibilidade e credibilidade das informações que são fornecidas por estes sites através dos seus links. 
Diante dos resultados alcançados, torna-se oportuno fazer uma análise dos resultados obtidos pelos PPG's da Universidade Federal do Rio Grande do Norte, a qual a autora desse estudo faz parte, com a finalidade de identificar as características que podem favorecer e viabilizar a presença dos sites dos PPG's da UFRN na Web.

Nessa perspectiva, verifica-se que os programas de Engenharia mecânica, Engenharia elétrica e Engenharia química da UFRN ocuparam, respectivamente, as seguintes colocações: 109ํㅜ 95ํe e 45ํ no ranking webométrico.

Ao se aplicar o método webométrico no site do programa em Engenharia mecânica da UFRN, pôde-se constatar que os valores obtidos em seus indicadores foram muito baixos. Porém, nota-se que o site analisado modificou recentemente sua interface, integrando-se ao Sistema Integrado de Gestão de Atividades Acadêmicas (SIGAA) o que favoreceu a perda de muitas informações que estavam armazenadas em seu antigo domínio, bem como a mudança de sua URL. Fatores estes que podem ter contribuído com os baixos valores obtidos nesse estudo.

Já os programas de Engenharia elétrica e Engenharia química da UFRN, apesar de também terem se integrado ao SIGAA, continuam com seus sites alternativos em funcionamento. Sendo estes endereços de URL fornecidos ao portal CAPES como fonte informacional, por isso justifica-se o uso destes sites alternativos no presente estudo.

Ao se analisar o programa em engenharia elétrica da UFRN, observa-se que o mesmo apresentou em seus indicares tamanho, visibilidade e luminosidade valores baixos, porém no fator de impacto se obteve valores relevantes, podendo-se constatar a necessidade do aumento do número de páginas deste site, bem como o aumento de links que possam remeter às páginas de outras instituições e dessa forma contribuir com a visibilidade de seu próprio site.

Dentre os três programas da UFRN analisados, verifica-se que o de Engenharia química é o que apresenta os melhores valores nos indicadores webométricos e a boa colocação alcançada por este programa, deve-se em suma pela quantidade de páginas existente em seu site e atualização das informações fornecidas pelo mesmo, bem como o uso de links externos que remetem a outras instituições. 
De modo geral, ressalta-se que essa análise webométrica faz com que se reflita sobre a importância das tecnologias de informação e comunicação no contexto atual, e, em especial, a Web como fonte disseminadora de informações.

Sendo assim, foi possível constatar como os Programas de Pós-graduação e as universidades brasileiras podem utilizar essas tecnologias a seu favor, contribuindo sobremaneira com a divulgação de informações científicas no meio acadêmico e consequentemente, com o desenvolvimento de pesquisas que colaboram com melhorias em diversos contextos, sobretudo com o desenvolvimento do país.

\subsection{RESULTADOS DAS CONEXÕES DOS PROGRAMAS DE PÓS-GRADUAÇÃO EM ENGENHARIAS}

Para um entendimento mais completo acerca dos estudos webométricos são abordadas nesse capítulo as conexões dos sites (nós), ou seja, as redes sociais existentes entre os grupos de engenharias e nas engenharias como um todo. Para tanto, utiliza-se a matriz de adjacências, o indicador densidade e os grafos de rede. Através dessas ferramentas é possível definir o quanto a população se relaciona entre si. A análise das redes sociais nos permite verificar através dos links dos sites, como os Programas de Pós-graduação estão se linkando na Web, identificando assim, as conexões sociais existentes entre estes programas.

\subsubsection{Conexões existentes entre as engenharias I}

As conexões das Engenharias I podem ser observadas através da matriz de adjacências na FIGURA 2 e das conexões na FIGURA 3, que apresentam as redes sociais existentes entre essa população.

De modo geral, ao se analisar a matriz e as conexões constata-se que 21 Programas de Pós-graduação que integram as Engenharias I, não disponibilizam em seus sites links para outros PPG's que abarcam esse grupo de estudo, como também não recebem nenhuma conexão.

Mas, observa-se que a Universidade de São Paulo, campus de São Carlos apresenta a maior quantidade de nós, porém linkando sempre para os PPG's que fazem parte do seu domínio. 
Nesse sentido, verificamos que na USP/SC, o Programa de engenharia civil (engenharia de estruturas) linka para dois outros programas de sua instituição que seriam respectivamente: geotecnia; e engenharia hidráulica e saneamento.

Ainda analisando os PPG's da USP/SC, observa-se que o programa de ciência da engenharia ambiental também linka para o PPG de engenharia hidráulica e saneamento.

Outra Universidade que se destaca em relação aos seus nós é a Universidade Federal de Ouro Preto, através do PPG em Geotecnia que linka para o programa de engenharia civil também da UFOP.

Nesse tocante, observa-se que as Engenharias I, possuem uma rede social pouco significativa e poderia apresentar uma relação maior, visto que ao se calcular a densidade da rede das engenharias I, obteve-se o valor de apenas $1 \%$, pois dentre as 702 conexões possíveis a serem estabelecidas, só 4 efetivaram-se. Os dados da densidade de rede podem ser visualizados na tabela geral da densidade (TABELA 6.)

FIGURA 2 - Matriz de adjacências dos PPG's em engenharias I.

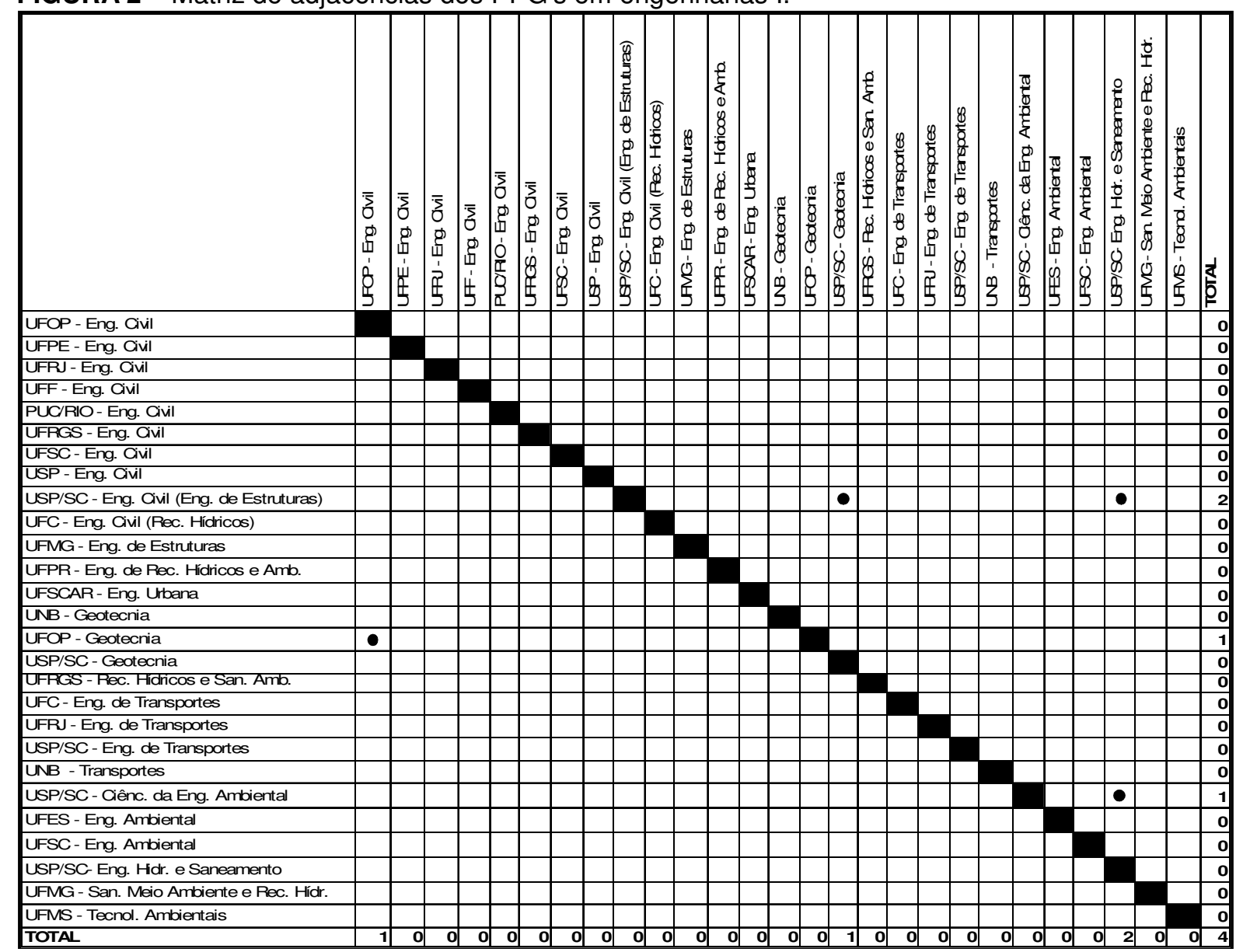

Fonte: Elaborada pela autora. 
FIGURA 3 - Representação gráfica das conexões das redes sociais dos PPG's em engenharias I.

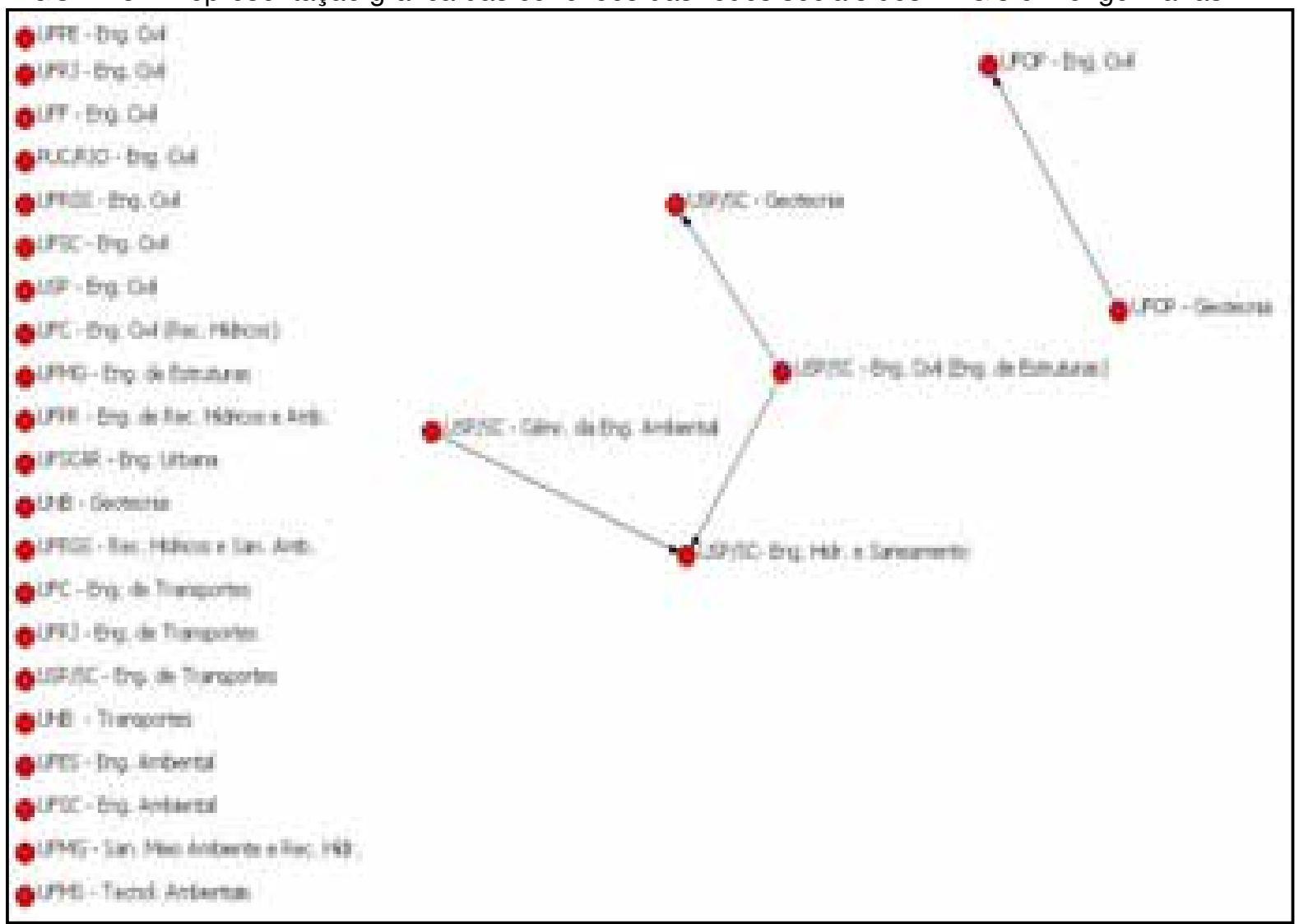

Fonte: Elaborada pela autora.

\subsubsection{Conexões existentes entre as engenharias II}

A partir da análise da FIGURA 4 e FIGURA 5, pôde-se identificar que 21 Programas de Pós-graduação em engenharias II não possuem nenhum tipo de relação social com os demais PPG's do seu grupo de engenharias.

Destacando-se apenas 3 nós na rede que referem-se inicialmente a Universidade Federal do Rio de Janeiro com seu PPG em ciência e tecnologia de polímeros que disponibiliza um link para o Programa de Pós-graduação em engenharia química da Universidade Federal de Santa Catarina. A UFRJ com o Programa de Engenharia química disponibiliza dois links, um que remete para o Programa de Engenharia química da UFRGS e o outro remete ao programa de ciência e tecnologia de polímeros da sua própria instituição, a UFRJ.

Nessa perspectiva, observa-se que a Universidade Federal do Rio de Janeiro destaca-se em relação às redes sociais do grupo de engenharias II ao linkar tanto 
para um programa de seu próprio domínio Web, como também para as Universidades da região Sul do país, expandindo suas relações virtuais na Web.

E que os Programas em Engenharia química representam a maior parte dos nós, bem como são o mais participativos da rede e se integram ao grupo de engenharias II.

Porém é notória a baixa densidade de rede do grupo de engenharias II, que possui a possibilidade de ter um total de 600 conexões possíveis. Mas que, porém só apresenta 3 nós em sua rede. Isso nos faz perceber que a densidade de rede do grupo de engenharias II equivale-se a $1 \%$, sendo considerada bastante baixa (TABELA 6).

FIGURA 4 - Matriz de adjacências dos PPG's em engenharias II.

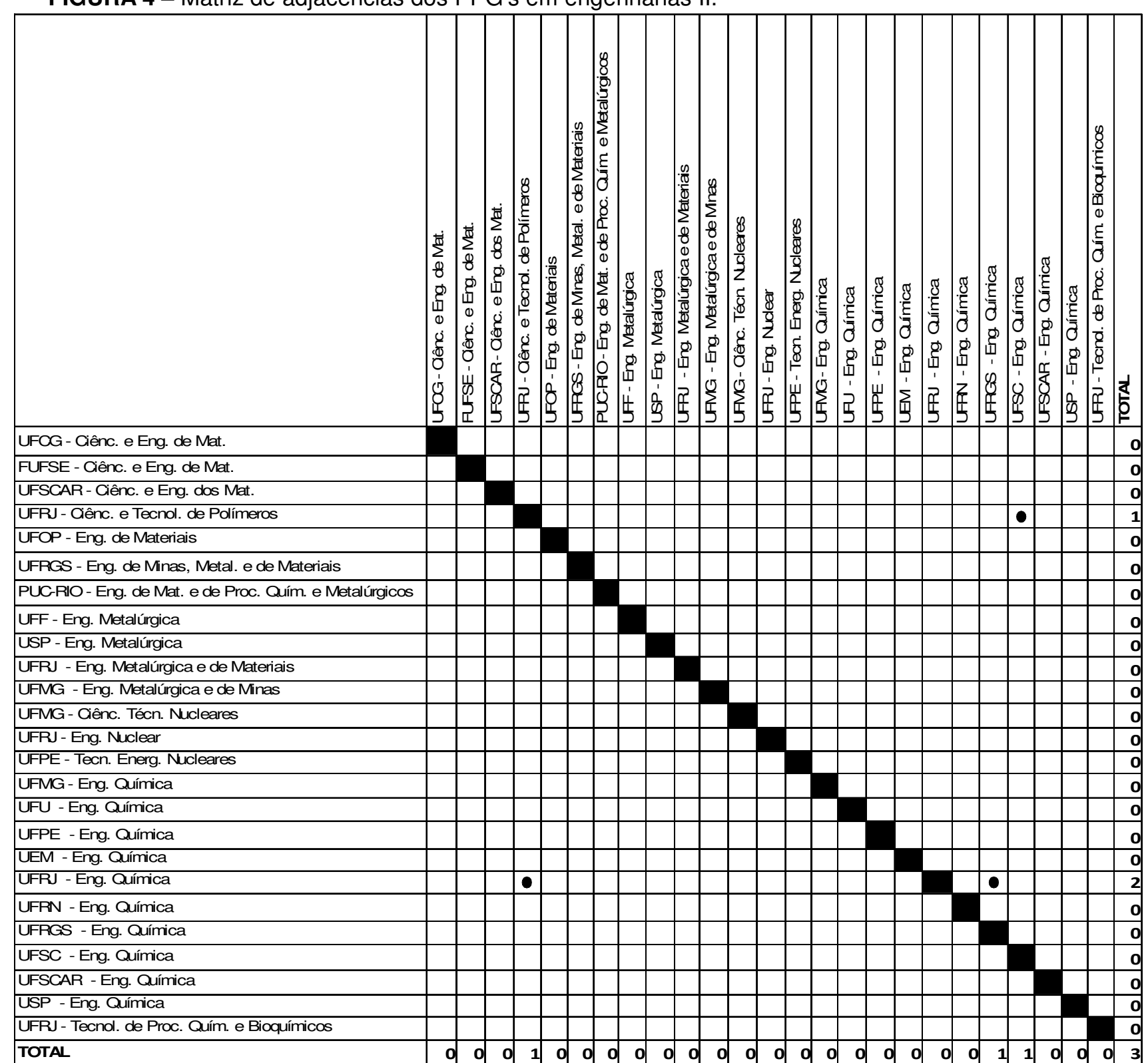

Fonte: Elaborada pela autora. 
FIGURA 5 - Representação gráfica das conexões das redes sociais dos PPG's em engenharias II.

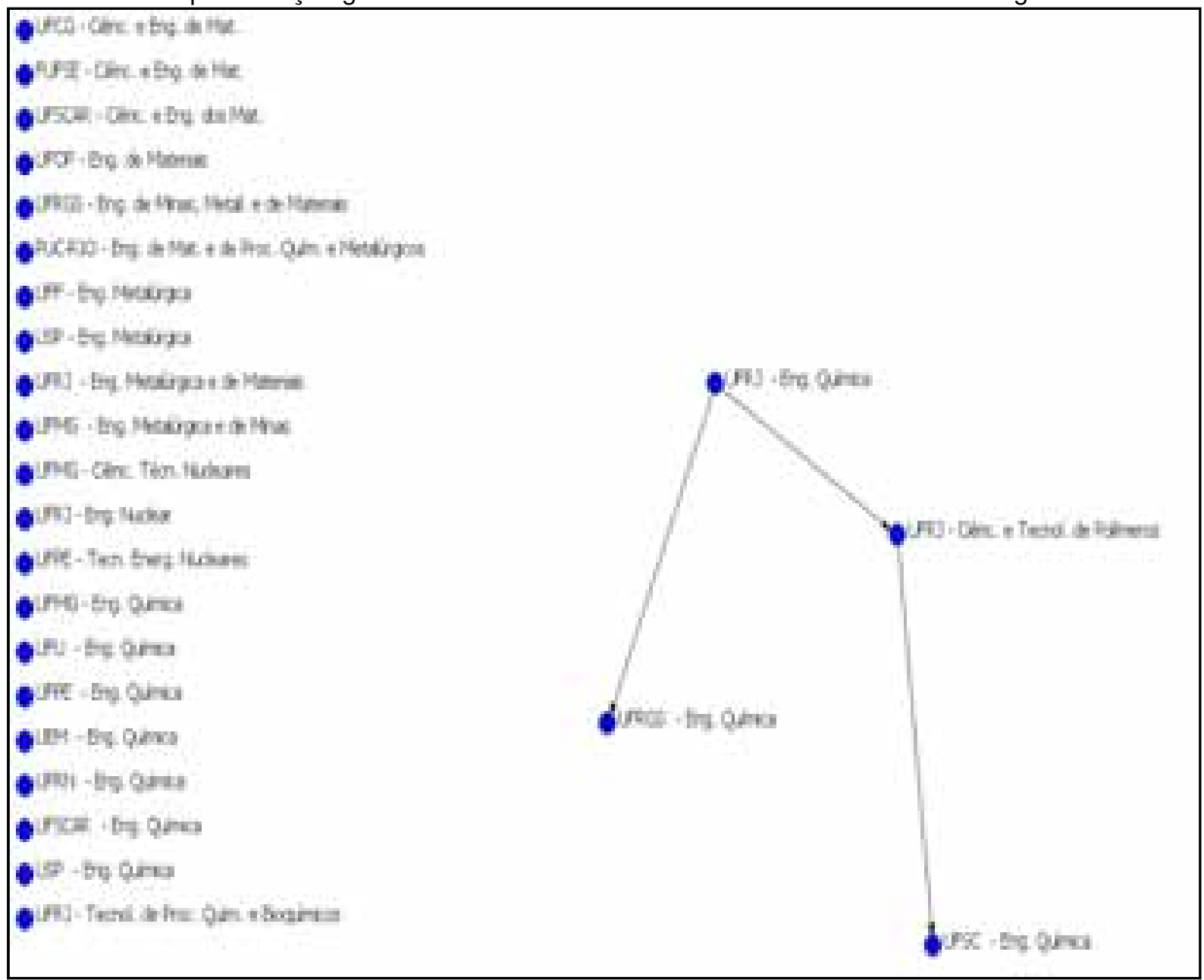

Fonte: Elaborada pela autora.

\subsubsection{Conexões existentes entre as engenharias III}

Ao se analisar as redes sociais das engenharias III, através da FIGURA 6 e da FIGURA 7 identifica-se que 20 Programas de pós-graduação não possuem nenhuma relação de links entre o grupo de engenharias III.

Apresenta-se uma rede de conexões com apenas três nós, dos quais 6 programas fazem parte. Dentre os quais se citam o PPG em engenharia mecânica da Pontifícia Universidade Católica do Rio de Janeiro que disponibiliza 1 link para o Programa de engenharia mecânica da UFRN.

Outra universidade que se integra na rede é a Universidade Federal do Rio de Janeiro com seu programa de engenharia de produção que permite o acesso a um link para o PPG em engenharia de produção da Universidade Federal de São Carlos. 
Também se destaca a Universidade Federal do Rio Grande do Sul com seu Programa de Pós-graduação em engenharia mecânica que oferece o acesso ao programa de engenharia de produção dessa mesma instituição.

Nota-se que somente os programas de engenharia mecânica e engenharia de produção integram a rede de conexões do grupo de engenharias III. Nesse contexto, observa-se que esse grupo de engenharias possui uma densidade de rede nula, pois ao se calcular a densidade, é verificado um valor de $0 \%$, esse resultado deve-se ao entendimento de que as engenharias III possuem um valor de 650 conexões possíveis a serem estabelecidas, porém somente 3 dessas conexões ocorrem. (FIGURA 6).

Esses dados nos confirmam a necessidade dos Programas de Pós-graduação em engenharias III, em melhorar suas relações sociais entre seu grupo de engenharia, possibilitando assim uma maior disseminação das informações entre os pesquisadores dessa área de estudo.

FIGURA 6 - Matriz de adjacências dos PPG's em engenharias III.

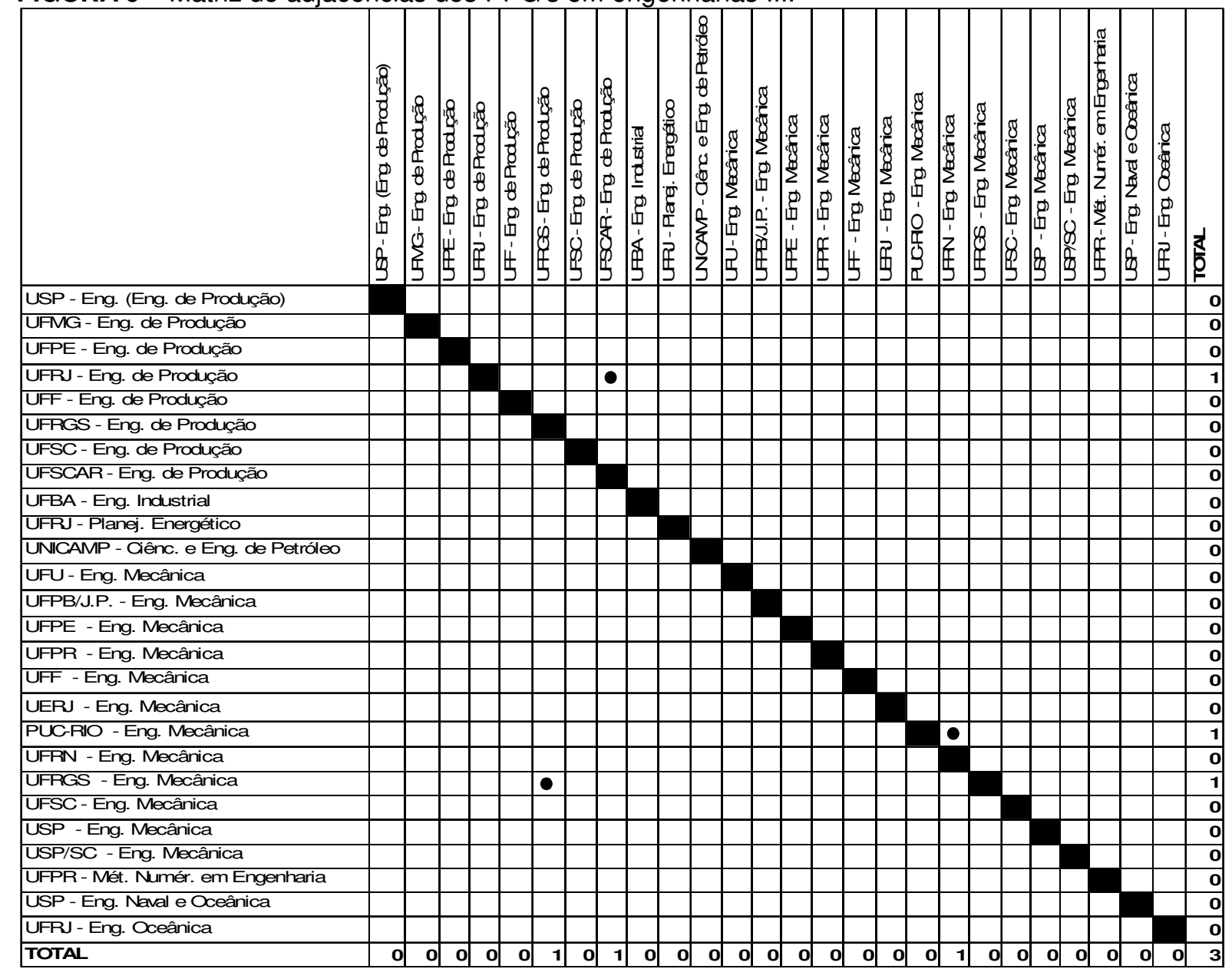

Fonte: Elaborada pela autora. 
FIGURA 7 - Representação gráfica das conexões das redes sociais dos PPG's em engenharias II.

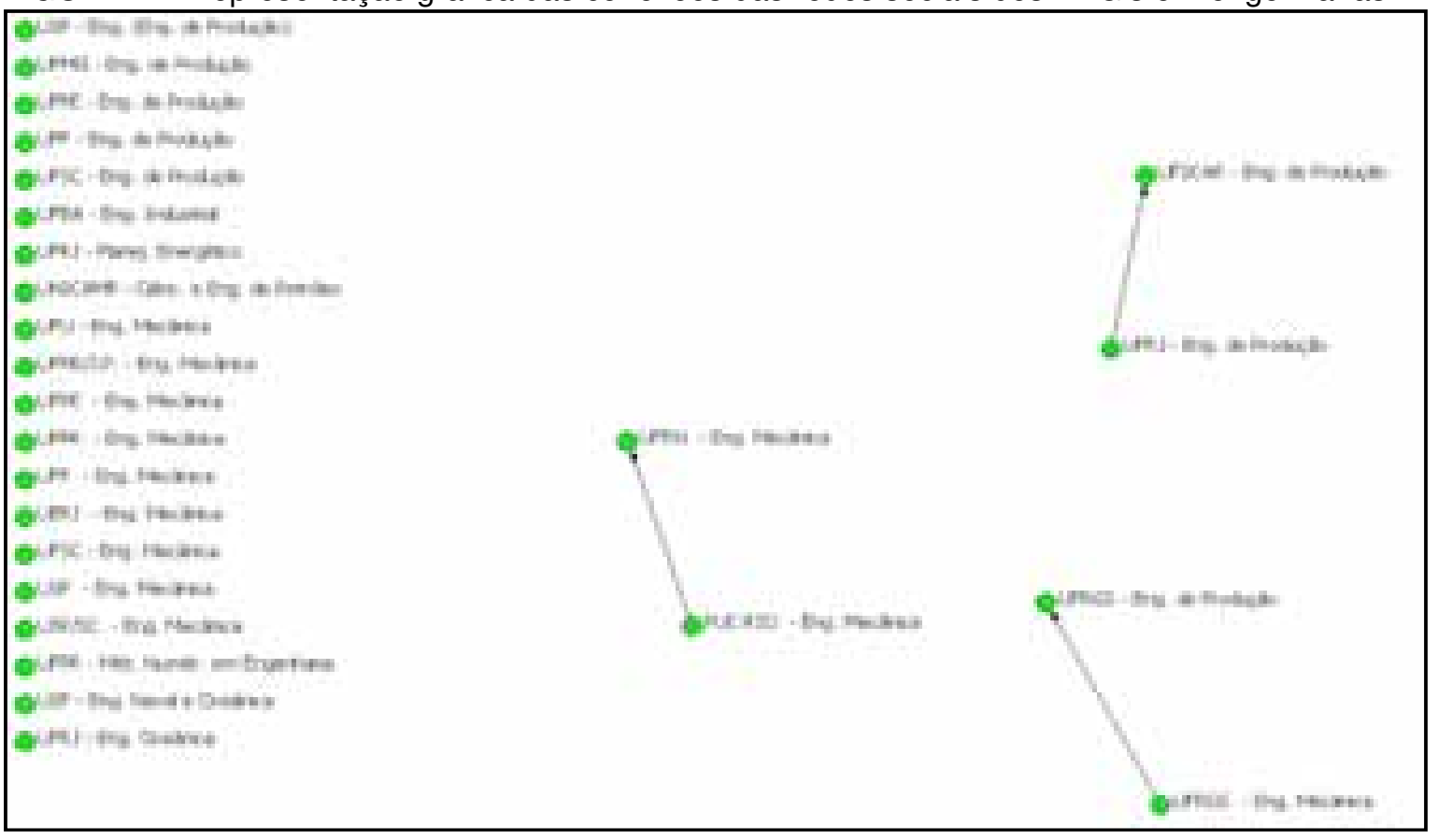

Fonte: Elaborada pela autora.

\subsubsection{Conexões existentes entre as engenharias IV}

Ao verificar as conexões existentes entre este grupo de engenharias pôde-se perceber que dentre os demais grupos analisados, as engenharias IV são as que apresentam uma maior quantidade de relações sociais. As engenharias IV apresenta 17 PPG's, dentre seus 31, que não possuem relações sociais na Web com as demais engenharias.

O Programa de Pós-graduação em engenharia elétrica da UNICAMP é o que apresenta uma maior quantidade de links remetidos ao seu site, com 3 programas, sendo estes: Engenharia biomédica da UFRJ, engenharia elétrica da UESP/IS e engenharia de sistemas eletrônicos e de automação da UNB.

O Programa em engenharia elétrica da Universidade Federal do Rio Grande de Sul é o receptor de dois links, sendo um do programa em microeletrônica de sua própria instituição (UFRGS) e outro do Programa em engenharia biomédica da UFRJ.

A Universidade Federal de Santa Catarina através do programa em engenharia elétrica recebe dois links, um do Programa em engenharia biomédica da UFRJ e outro do programa em engenharia elétrica da UNB. 
O Programa em engenharia elétrica de automação e sistemas da UFSC recebe links do programa em engenharia elétrica de sua própria instituição e do programa em engenharia elétrica da UNESP/IS.

A Universidade Federal de Pernambuco através do Programa em engenharia elétrica recebe uma conexão do programa em engenharia de sistemas eletrônicos e de automação da Universidade de Brasília.

A Universidade Federal de Minas Gerais com o seu programa em engenharia elétrica recebe duas conexões, sendo as duas dos programas em engenharia elétrica da UFBA e da USP/SC.

O programa de engenharia elétrica da UFCG é linkado pelo programa em engenharia elétrica da Universidade Federal da Bahia.

Observa-se também que o programa em engenharia elétrica da USP/SC é linkado pelo programa em engenharia elétrica da UNB.

Do mesmo modo, a Universidade Federal da Bahia através do seu programa em engenharia elétrica recebe um link do programa em engenharia elétrica da Universidade Federal de Minas Gerais.

O programa em engenharia elétrica da Universidade de Brasília recebe uma conexão de sua própria universidade, sendo do programa de engenharia de sistemas eletrônicos e de automação. Este por sua vez, recebe uma conexão recíproca do programa em engenharia elétrica da UNB e outro link do programa em engenharia elétrica da USP/SC.

De modo geral, observa-se a presença de duas relações recíprocas, uma destas conexões foi verificada entre os programas de engenharia elétrica e o programa em engenharia de sistemas eletrônicos e de automação, ambos da Universidade de Brasília. A outra conexão recíproca ocorre entre o PPG em engenharia elétrica da UFBA e o programa em engenharia elétrica da UFMG.

Quando avaliado os programas envolvidos nessa rede, verifica-se que 10 são do curso em engenharia elétrica, 1 em engenharia biomédica, 1 em microeletrônica e 1 em engenharia de sistemas eletrônicos e de automação.

Em relação à densidade da rede dessas conexões, as engenharias IV foi a que mais se sobressaiu ao estabelecer um valor de $2 \%$ de densidade. Esse grupo 
de engenharias possui um total de 930 conexões possíveis, mas apresenta 18 nós em suas conexões (TABELA 6).

FIGURA 8 - Matriz de adjacências dos PPG's em engenharias IV.

\begin{tabular}{|c|c|c|c|c|c|c|c|c|c|c|c|c|c|c|c|c|c|c|c|}
\hline & 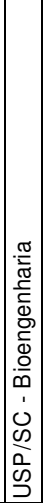 & 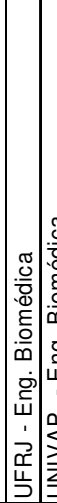 & 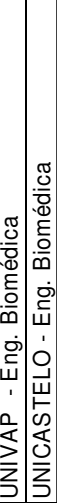 & 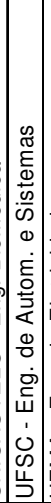 & 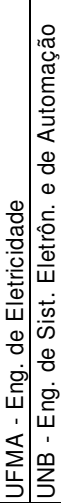 & 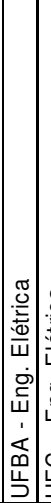 & 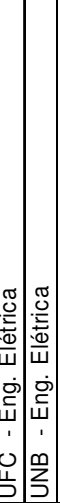 & 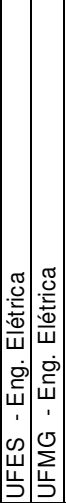 & 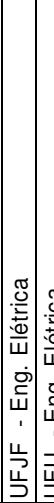 & 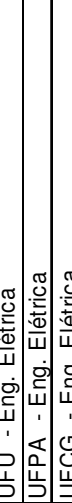 & 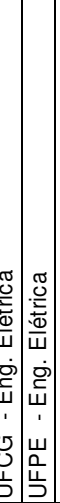 & 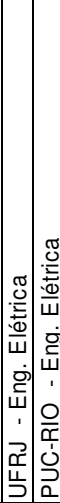 & 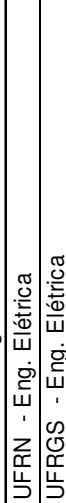 & 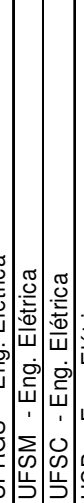 & 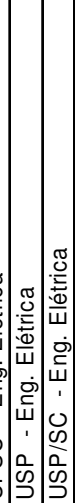 & 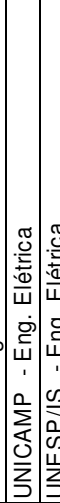 & 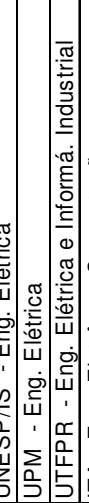 & 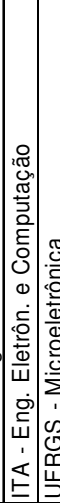 & 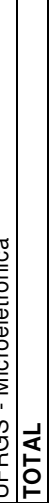 \\
\hline USP/SC - Bioengenharia & & & & & & & & & & & & & & & & & & & 0 \\
\hline UFRJ-Eng. Biomédica & & & & & & & & & & & & & 0 & 0 & & 0 & & & 3 \\
\hline UNIVAP - Eng. Biomédica & & & & & & & & & & & & & & & & & & & 0 \\
\hline UNICASTELO - Eng. Biomédica & & & & & & & & & & & & & & & & & & & 0 \\
\hline UFSC - Eng. de Autom. e Sistemas & & & & & & & & & & & & & & & & & & & 0 \\
\hline UFMA - Eng. de Eletricidade & & & & & & & & & & & & & & & & & & & 0 \\
\hline UNB - Eng. de Sist. Eletrôn. e de Automação & & & & & & & - & & & & - & & & & & 0 & & & 3 \\
\hline UFBA - Eng. Elétrica & & & & & & & & 0 & & 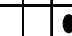 & & & & & & & & & 2 \\
\hline UFC - Eng. Elétrica & & & & & & & & & & & & & & 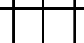 & & & & & 0 \\
\hline UNB - Eng. Elétrica & & & & & $\bullet$ & & & & & & & & & 0 & $\bullet$ & & & & 3 \\
\hline UFES - Eng. Elétrica & & & & & & & & & & & & & & & & & & & 0 \\
\hline UFMG - Eng. Elétrica & & & & & & 0 & & & & & & & & & & & & & 1 \\
\hline UFJF - Eng. Elétrica & & & & & & & & & & & & & & & & & & & 0 \\
\hline UFU - Eng. Elétrica & & & & & & & & & & & & & & & & & & & 0 \\
\hline UFPA - Eng. Elétrica & & & & & & & & & & & & & & & & & & & 0 \\
\hline UFCG - Eng. Elétrica & & & & & & & & & & & & & & & & & & & 0 \\
\hline UFPE - Eng. Elétrica & & & & & & & & & & & & & & & & & & & 0 \\
\hline UFRJ - Eng. Elétrica & & & & & & & & & & & & & & & & & & & 0 \\
\hline PUC-RIO - Eng. Elétrica & & & & & & & & & & & & & & & & & & & 0 \\
\hline UFRN - Eng. Elétrica & & & & & & & & & & & & & & & & & & & 0 \\
\hline UFRGS - Eng. Elétrica & & & & & & & & & & & & & & & & & & & 0 \\
\hline UFSM - Eng. Elétrica & & & & & & & & & & & & & & & & & & & 0 \\
\hline UFSC - Eng. Elétrica & & & & $\bullet$ & & & & & & & & & & & & & & & 1 \\
\hline USP - Eng. Elétrica & & & & & & & & & & & & & & & & & & & 0 \\
\hline USP/SC - Eng. Elétrica & & & & & 0 & & & 0 & & & & & & & & & & & 2 \\
\hline UNICAMP - Eng. Elétrica & & & & & & & & & & & & & & & & & & & 0 \\
\hline UNESP/IS - Eng. Elétrica & & & & 0 & & & & & & & & & & & & $\bullet$ & & & 2 \\
\hline UPM - Eng. Elétrica & & & & & & & & & & & & & & & & & & & 0 \\
\hline UTFPR - Eng. Elétrica e Informá Industrial & & & & & & & & & & & & & & & & & & & 0 \\
\hline ITA - Eng. Eletrôn. e Computação & & & & & & & & & & & & & & & & & & & 0 \\
\hline UFRGS - Microeletrônica & & & & & & & & & & & & & $\bullet$ & & & & & & 1 \\
\hline TOTAL & 0 & \begin{tabular}{ll|}
0 & 0 \\
\end{tabular} & 0 & $\begin{array}{lll}0 & 2\end{array}$ & \begin{tabular}{|lll}
0 & 2 \\
\end{tabular} & 1 & \begin{tabular}{l|l|l}
0 & 1 & \\
\end{tabular} & \begin{tabular}{|l|l|}
0 & 2 \\
\end{tabular} & 0 & \begin{tabular}{l|l}
0 & 0 \\
\end{tabular} & \begin{tabular}{l|l|l}
1 & 1 \\
\end{tabular} & 00 & 002 & \begin{tabular}{|l|l|l}
2 & 0 & 2
\end{tabular} & \begin{tabular}{|l|l|}
0 & 1 \\
\end{tabular} & 3 & \begin{tabular}{l|l|l|}
0 & 0 & 0 \\
\end{tabular} & & $\begin{array}{lll}0 & 18 \\
\end{array}$ \\
\hline
\end{tabular}

Fonte: Elaborada pela autora. 
FIGURA 9 - Representação gráfica das conexões das redes sociais dos PPG's em engenharias IV.

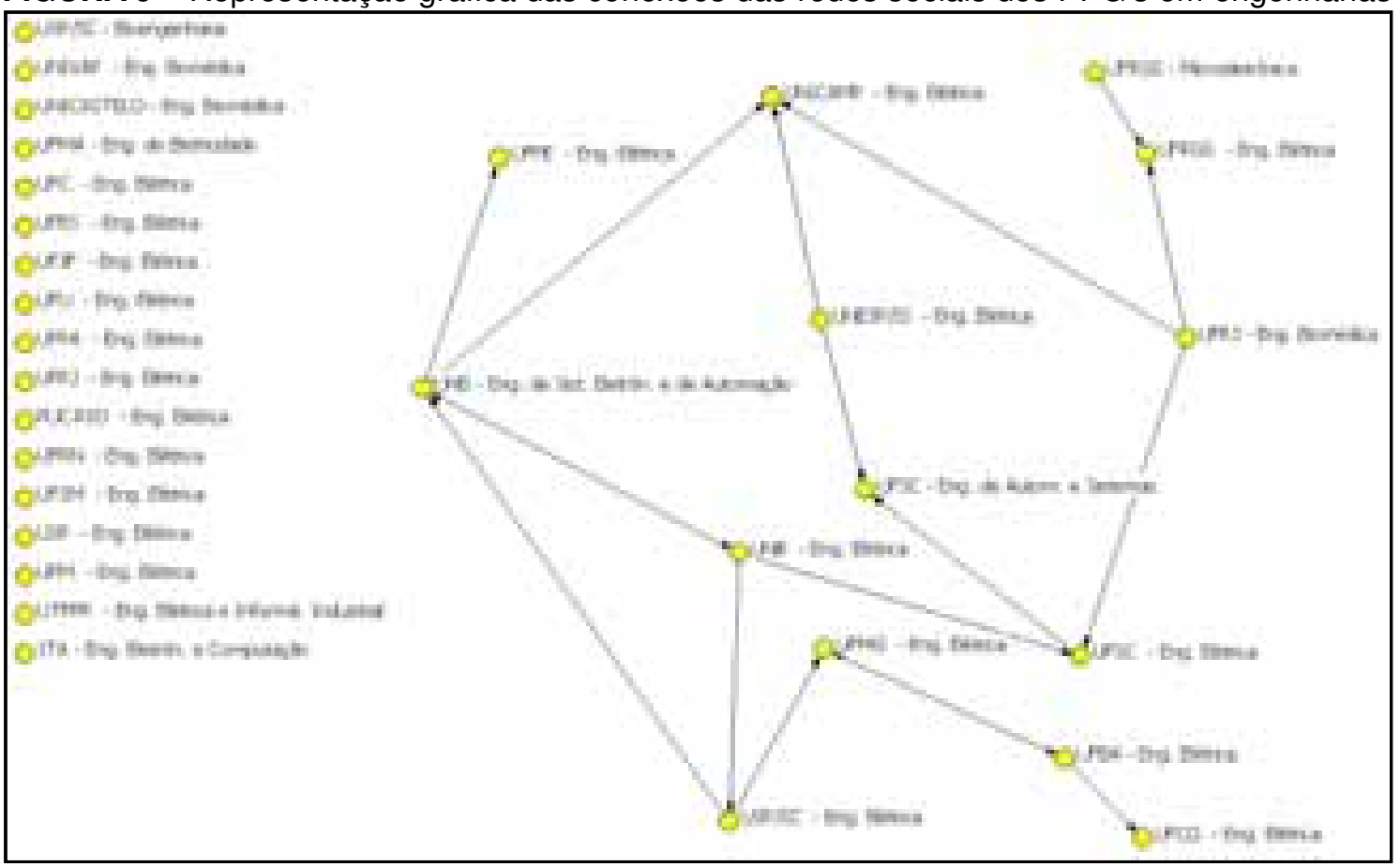

Fonte: Elaborada pela autora.

\subsubsection{Conexões existentes nas engenharias}

Para se avaliar as conexões existentes nos Programas de Pós-graduação em engenharias, utiliza-se a representação gráfica das conexões das redes sociais (FIGURA 10). Através dessa representação é possível identificar que os PPG's em engenharias I possuem uma rede interligada no tocante aos programas que fazem parte de uma mesma instituição.

As engenharias II, apesar de possuírem poucas conexões, possuem uma ligação entre os todos os nós existentes, formando uma única rede interligada. Já as engenharias III apesar de possuir algumas conexões, não possuem uma rede interligada entre essas conexões dos PPG's. Os programas que integram as Engenharias IV são os que possuem uma melhor relação social na Web.

As engenharias IV demonstram uma rede social unificada, na qual todos os programas que integram a rede estão ligadas uns as outros, mostrando uma relação participativa.

Outro ponto relevante é a presença de relações recíprocas entre alguns programas, ou seja, quando 2 PPG's recebem e disponibilizam conexões entre si simultaneamente. 
De modo geral, depreende-se que as relações sociais entre os grupos de engenharias do Brasil ainda precisam ser aperfeiçoadas, buscando alcançar um maior reconhecimento entre eles, e, consequentemente utilizá-las como fontes de informações nesse imenso depósito intelectual que se tornou a Web.

FIGURA 10 - Representação gráfica das conexões das redes sociais dos PPG's em engenharias.

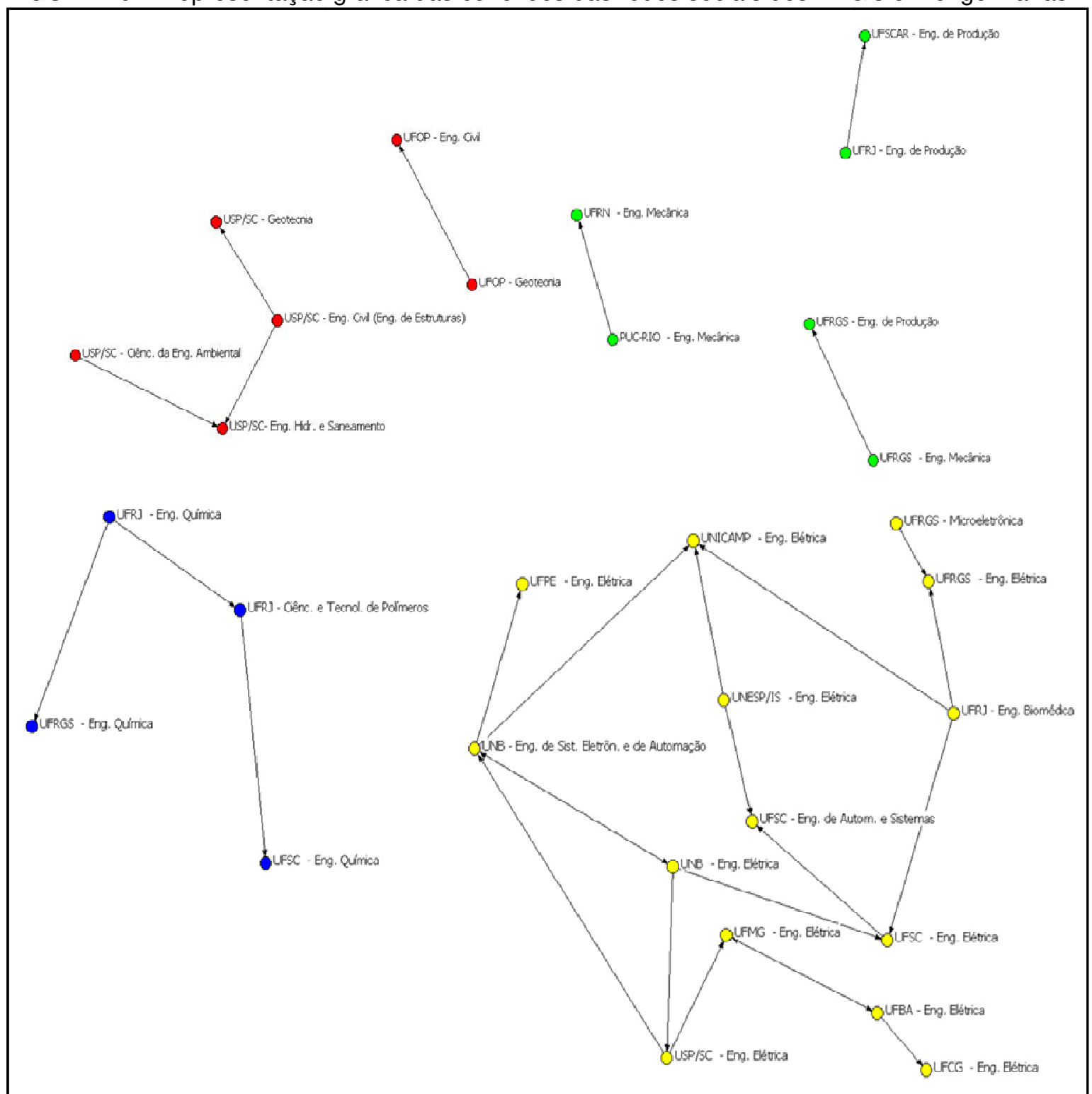

Fonte: Elaborada pela autora.

Com o pressuposto de explanar as informações coletadas nessa pesquisa, buscou-se construir a rede social de todos os Programas de Pós-graduação em engenharias do Brasil. A partir dessa representação gráfica (FIGURA 11), torna-se possível identificar como estes PPG's estão se linkando no âmbito acadêmico virtual. 
Identifica-se que dentre os 109 sites dos PPG's que integram essa pesquisa, 76 não participam da rede social que integra todas as engenharias e 33 apresentam algum tipo de relação.

Nota-se que há relações entre os grupos de engenharias II, III e IV nessa rede. Pois o programa de engenharia mecânica (engenharias III) recebe dois links dos programas em engenharia de automação e sistemas da UFSC (engenharias IV) e do programa em engenharia elétrica da UFSC (engenharias IV).

O programa em engenharia química da UFRGS (engenharias II) recebe 3 links, dentre os quais: 1 é do programa em microeletrônica da UFRGS (engenharias IV), 1 é do programa em engenharia mecânica da UFRGS (engenharias III) e o outro link é oriundo da programa em engenharia química da UFRJ (engenharias II).

As engenharias I mantêm relações somente com as engenharias III, entre os programas de engenharia oceânica da UFRJ e o programa de Recursos hídricos e saneamento ambiental da UFRGS.

Através dessas observações é possível verificar a relação existente entre algumas engenharias e depreender que essas áreas de estudo se relacionam quando são de áreas correlatas e que favorecem o compartilhamento de suas informações e interesses.

Do mesmo modo, enfoca-se que dentre os 109 programas estudados é possível estabelecer 2.882 conexões, porém só foram apresentados 33 nós de conexões, o que nos dá um percentual de apenas $1 \%$ de densidade existente na rede dos Programas em Pós-graduação em engenharias. (TABELA 6)

Os valores obtidos no indicador densidade de rede nos desperta a importância das relações sociais na Web, bem como a relevância de conexões que oferecem uma maior disseminação de informações e troca de conhecimentos entre esta área de estudo. 
FIGURA 11 - Representação gráfica das conexões das redes sociais entre os PPG's em engenharias.

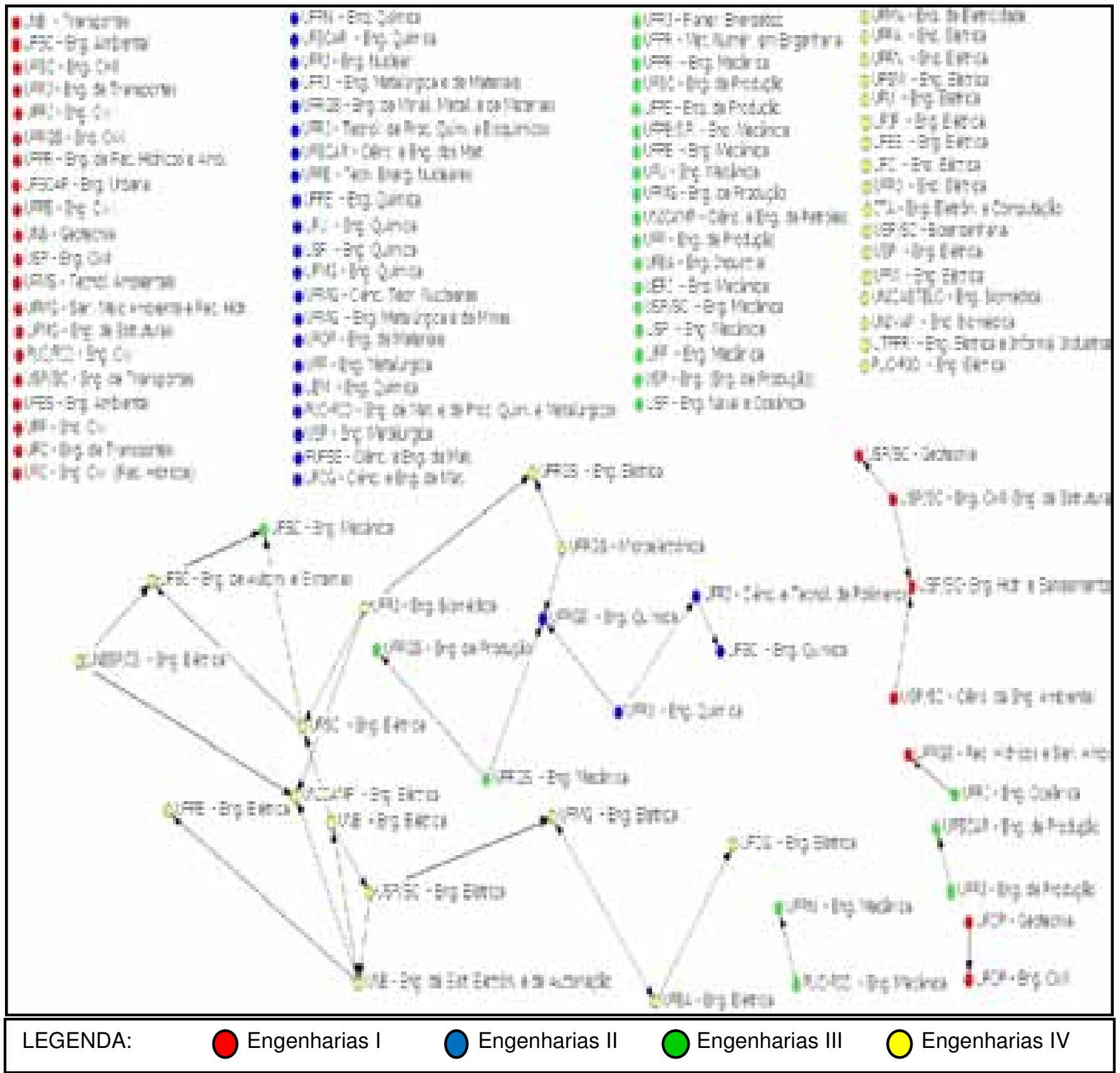

Fonte: Elaborada pela autora.

TABELA 6 - Dados gerais da densidade de rede entre as engenharias.

\begin{tabular}{lccc} 
& Conexões possíveis & Nós existentes & Densidade da rede \\
\hline Engenharias I & 702 & 4 & $1 \%$ \\
Engenharias II & 600 & 3 & $1 \%$ \\
Engenharias III & 650 & 3 & $0 \%$ \\
Engenharias IV & 930 & 18 & $2 \%$ \\
Engenharias I, II, III e IV & $\mathbf{2 . 8 8 2}$ & $\mathbf{3 3}$ & $\mathbf{1} \%$ \\
\hline
\end{tabular}

Fonte: Elaborada pela autora. 
CAPÍTULO 6

\section{CONCLUSÕES}

Este capítulo apresenta as conclusões obtidas através dos resultados da pesquisa em questão, como também sugerem melhorias ao processo de disponibilização de informações, com base no estudo webométrico dos sites dos Programas de Pós-graduação em Engenharias do Brasil.

Com o princípio de explanar detalhadamente as conclusões e recomendações, define-se a subdivisão deste capítulo para traçar as conclusões alinhadas aos objetivos específicos e geral dessa pesquisa.

\subsection{CONCLUSÕES ALINHADAS AOS OBJETIVOS}

A partir dos objetivos traçados na elaboração e desenvolvimento desse estudo foi possível fundamentar a possibilidade de aplicação do método webométrico na área dos estudos das engenharias.

E através da obtenção dos resultados alcançados, torna-se preponderante elaborar conclusões baseadas nos objetivos inicialmente propostos, para que dessa forma se constate se foi possível alcançá-los, bem como confirmar ou não a eficácia da aplicabilidade das ferramentas e indicadores webométricos escolhidos para a elaboração dessa pesquisa.

\subsubsection{Quanto ao objetivo geral}

Pode-se constatar que o método webométrico aplicado nesse estudo foi capaz de identificar que o Programa de Pós-graduação em engenharia civil da Universidade Federal do Rio de Janeiro, seguido pelo programa em engenharia oceânica, também da Universidade Federal do Rio de Janeiro e do Programa de Pós-graduação em engenharia civil (engenharia de estruturas) da Universidade de São Paulo - Campus de São Carlos destacaram-se com primazia no tocante a disponibilização de informações e comunicação científica no meio acadêmico virtual.

Além de identificar quais PPG's já estão mostrando-se interessados pela melhoria da qualidade das informações disponibilizada virtualmente, também foi possível apontar quais precisam se aperfeiçoar para atenderem às novas 
necessidades oriundas da adoção das TIC's no meio acadêmico, visto que é cada vez mais intenso o uso desse sistema de informação virtual no meio social. É fato que a Web tem colaborado intensamente com mudanças nos contextos sociais e científicos, e nesse prisma há a necessidade da participação do meio acadêmico e científico na disponibilização de informações preponderantes para essas mudanças.

Desse modo, essa análise quantitativa de informações digitais também serviu para reafirmar a importância do processo informacional acadêmico na medida em que desperta o valor da difusão de informações científicas na Web.

Em suma, a aplicação dos indicadores webométricos nos PPG's em Engenharias possibilitou avaliar metodicamente a quantidade das informações disponibilizadas por esses sites, e pôde contribuir para enfatizar a importância de criar, disponibilizar e atualizar informações de cunho acadêmico nas páginas Web dos Programas de Pós-Graduação brasileiros.

\subsubsection{Quanto aos objetivos específicos}

Através da aplicação dos indicadores webométricos nos sites de Pósgraduação em engenharias, torna-se possível ressaltar que o método webométrico é bastante satisfatório no processo de medição da quantidade de informações científicas disponíveis no âmbito virtual. Pois, todos os sites que abarcaram esse estudo foram mensurados e apontaram características de grande relevância para a compreensão do uso dos links acadêmicos.

Desse modo, observa-se que a webometria através de suas ferramentas e indicadores contribuiu no processo de medição da quantidade de informações, pois ao definir valores que indicaram como determinado site está disponibilizando suas informações e suas relações sociais na Web, foi possível comparar estrategicamente uma determinada população na Web, nesse caso os PPG's em engenharias. E também verificar como estes se destacaram em relação ao uso e qualidade das informações disponibilizadas.

A partir da corroboração da funcionalidade da webometria aplicada nesse estudo, depreende-se que esta pode ser utilizada como mensurador das informações disponibilizadas por sites acadêmicos, sendo possível sua utilização por agências de fomentos de pesquisas para indicar o grau de importância das 
informações e da comunicação que está sendo disponibilizada pelos PPG's através dos seus sites acadêmicos no âmbito virtual.

Ressalta-se que o estudo aqui explanado foi capaz de identificar quais PPG's em engenharias das IES brasileiras possuem uma boa disponibilização de suas informações, pois apontou que o Programa de Pós-graduação em Engenharia civil da Universidade Federal do Rio de Janeiro fornece uma quantidade relevante de informações na Web, como também apontou que o programa de Ciência e tecnologia de polímeros da Universidade Federal do Rio de Janeiro destaca-se em relação ao uso de suas informações, já o programa que se sobressaiu no tocante ao fator de impacto foi novamente o de Engenharia civil da UFRJ e o programa de Engenharia elétrica da UPM é aquele que oferece uma maior quantidade de links que servem como fonte de informação para seus usuários, contribuindo, por sua vez, com a navegabilidade dos mesmos na rede.

Através da aplicação da webometria também se torna possível identificar algumas melhorias que podem ser empregadas para a boa funcionalidade deste estudo métrico, tais como o uso de softwares adequados, utilização de mecanismos de buscas com interfaces de pesquisas avançadas, entre outros. Colaborando assim, com a mensuração das informações que possuem valores tão significativos na atual sociedade.

Desse modo, no tocante a este estudo, depreende-se que diante da realidade investigada são muitas as vantagens do uso desse tipo de estudo métrico na denominada Sociedade da Informação e, consequentemente, para as redes e sistemas de informação. Aliada a isso, as TIC's contribuem, sobremaneira, para com a webometria no campo científico.

\subsection{RECOMENDAÇÕES ALINHADAS ÀS LIMITAÇÕES ENCONTRADAS}

Percebe-se ao desenvolver esse projeto que as novas tecnologias de informação e comunicação, em especial, a Web tem contribuído, consideravelmente, com o desenvolvimento de resultados e pesquisas científicas, a sua disseminação e 0 acesso.

A experiência de abordar os estudos métricos de informação, ou seja, bibliometria, cientometria, informetria, webometria e cibermetria, representam uma fundamentação de ordem teórico-conceitual, bem como metodológica, para a autora 
deste trabalho, tendo em vista a importância dos mesmos no contexto científico atual.

Tal perspectiva tornou possível abordar, mais especificamente, o estudo da webometria, como uma ferramenta avaliativa capaz de estabelecer um método estatístico de medição da quantidade de informações disponibilizadas digitalmente na Web.

Em suma, pode-se perceber que o estudo webométrico realizado alcançou os objetivos propostos nesse estudo, como também indo mais além, ao identificar fatores que contribuem significativamente para a boa visualização desses sites na rede, colaborando assim com a disseminação de informações e comunicação científica através do uso da Web.

Porém, torna-se preponderante ressaltar os desafios encontrados na realização desse trabalho, buscando definir melhorias para o uso desse estudo métrico na denominada Sociedade da Informação.

Nesse contexto, observa-se que ao realizar a coleta dos sites através do Portal da CAPES responsável por disponibilizar informações dos Programas de Pósgraduação brasileiros, inclusive seu endereço Web, foi verificado que alguns endereços de sites não estão sendo disponibilizados, outros apresentam URL's que remetem ao site da Instituição como um todo e não dos Programas de Pósgraduação, já outros apresentam URL's que não existem ou estão desativadas.

Desse modo houve a necessidade da utilização de motores busca para obter os endereços Web dos sites necessários para o desenvolvimento do trabalho em questão. Tal fato nos faz perceber a importância da atualização das páginas dos PPG's do Brasil, bem como a disponibilização de informações corretas à Coordenação de Aperfeiçoamento de Pessoal de Nível Superior por parte desses programas.

Também se pode constatar que a CAPES sugere uma estruturação dos sites dos PPG's brasileiros, porém essas sugestões não foram encontradas na maioria dos sites visitados, ressaltando que alguns destes sites apresentam suas atualizações somente anualmente, o que faz com que se tome a ressaltar a importância do uso de indicadores que mensurem a quantidade de informações que 
são utilizadas nos sites de modo a aguçar a importância da disponibilização e divulgação dos sites dos PPG's do Brasil.

Outro ponto importante a ser destacado é o uso de subdiretórios extensos nas URL's dos Programas de Pós-graduação em engenharias, pois quando uma URL apresenta um endereço muito extenso, torna-se difícil localizá-la dentro de um site, visto que quanto mais subdiretórios a URL possui, mais links é necessário acessar para encontrar a página requerida.

Isso dificulta o acesso às informações disponibilizadas pela página deste PPG, também tornando difícil conseguir realizar o mapeamento dessa URL para a realização dessa pesquisa, pois através do software utilizado, Xenu Link Sleuth, só é possível mapear sites que possuam diretórios e subdiretórios, não incluindo subsubdiretórios, visto que as informações coletadas poderiam apresentar resultados errôneos ao se colher dados que não pertencem a página que se busca.

Dessa forma, percebe-se a importância de utilizar um endereço específico para identificar a URL de cada Programa de Pós-graduação, o que também é sugerido pela CAPES, quando a mesma recomenda a adoção de um aplicativo gratuito e simples lançado em parceria pela CAPES e a Universidade Federal de Pernambuco para a criação das páginas Web de cursos de pós-graduação do Brasil $^{4}$.

Em relação às ferramentas e indicadores webométricos utilizados na realização desse estudo, foi constatada uma dificuldade ao se utilizar o programa mapeador Xenu Link Sleuth, pois o mesmo apresentou alguns problemas em seus resultados e foram detectados resultados muito divergentes no mapeamento dos sites realizado, o que desencadeou a necessidade de reavaliação do mapeamento de todos os sites, visto as oscilações entre os seus resultados iniciais e finais, chegando por sua vez a valores possíveis e compatíveis com o estudo em questão.

No desenvolver desse estudo pôde-se também identificar através da literatura, utilizada como base para compreensão, que alguns autores como Vanti (2007) e Silva (2008) já confirmavam a pouca funcionalidade do indicador Fator de Impacto Web, visto que os resultados alcançados sempre se mostravam de pouca relevância. Nesse tocante, buscou-se utilizar uma nova fórmula que foi idealizada e

\footnotetext{
${ }^{4}$ http://capes.gov.br/avaliacao/aplicativo-gratuito-para-criacao-de-paginas-Web.
} 
divulgada em outra publicação com a participação da autora ${ }^{5}$ e que, apresentou resultados significativos permitindo a continuidade de pesquisas acerca deste indicador, como forma de estabelecer parâmetros mais consistentes em relação aos resultados esperados, visto que o mesmo tem sido alvo de questionamentos entre pesquisadores dessa área métrica.

Após a obtenção dos resultados da pesquisa observou-se um fato bastante pertinente a ser ressaltado, o qual aponta que os PPG's em engenharias que se destacaram no topo do ranking do indicador tamanho apresentaram-se em sua maioria no topo do ranking webométrico geral estabelecido, fato que desperta algumas inquietações no entendimento desse estudo, pois mesmo o indicador tamanho compondo o índice webométrico do ranking com apenas $10 \%$ do peso total, observa-se a forte influência desse indicador.

Nesse tocante, torna-se preponderante ressaltar que diante desses valores referentes ao tamanho das páginas Web dos programas de pós-graduação em engenharias é perceptível a quantidade de informações que estão sendo disponibilizadas através dessas páginas, bem como a forte presença desses sites no âmbito virtual, o que corrobora a importância da comunicação científica na Web e sua disponibilização de informações para o meio acadêmico virtual.

Contudo, apesar das dificuldades encontradas para a realização desse estudo, pôde-se verificar a pertinência da aplicabilidade dos indicadores webométricos. $E$ que os mesmos foram capazes de detectar falhas nos sites pesquisados, como também apontar as características que podem ser melhoradas nos sites em questão, de forma a possibilitar uma melhor divulgação das informações e pesquisas científicas elaboradas no Brasil, por esses programas de Pós-Graduação de Engenharias.

E considerando-se que vários são os desafios atuais na Sociedade da Informação e que grandes são a complexidade e a rapidez de atualizações da Web, os estudos métricos têm se mostrado de grande relevância para o contexto científico e espera-se que, com a evolução dos modelos atuais, possam contribuir de modo mais eficaz no entendimento dos fluxos de links e suas importâncias, principalmente para o desenvolvimento da ciência.

\footnotetext{
${ }^{5}$ http://www.jistem.fea.usp.br/index.php/contecsi/article/viewArticle/1914.
} 


\section{REFERÊNCIAS}

AGUILLO, Isidro. Measuring the institution's footprint on the web. Library Hi Tech. v.27, n.4, p.540-556, 2009.

AGUILLO, Isidro F.; ORTEGA, José Luís; FERNÁNDEZ, Mario. Webometric Ranking of world universities: introduction, methodology, and future developments. Higher Education in Europe. v. 33, n. 2/3, jul.- oct., 2008.

AGUILLO, Isidro F. et al. Indicators for a webometric ranking of open access repositories. Scientometrics. v. 82, n.3, p.477-486, 2010 a.

AGUILLO, Isidro F. et al. Comparing university rankings. Scientometrics, v. 85, p.243-256, 2010b.

BORSCHIVER, Suzana; GUEDES, Vânia L. S. Bibliometria: uma ferramenta estatística para a gestão da informação e do conhecimento, em sistemas de informação, de comunicação e de avaliação científica e tecnológica. Salvador (BA), 2005. Disponível em: <www.cinform.ufba.br/vi_anais/docs>. Acesso em: 30 maio 2010.

COORDENAÇÃO de Aperfeiçoamento de Pessoal de Nível Superior. Qualis.

Disponível em: <http://www.capes.gov.br/avaliacao/qualis>. Acesso em 12 fev. 2011.

DANIEL, Florian; FACCA, Michele Federico. Current trends in web engineering. Germany: Springer, 2010.

DEA, Mauri Paulo. Análise de produção da revista HSM management. 2006. $47 \mathrm{f}$. Monografia (Graduação) - Curso de Gestão da Informação, Universidade Federal do Paraná, Curitiba, 2006.

ECO, Humberto. Comissário da nova exposição no Louvre, em Paris, fala do lugar que as listas ocupam na história da cultura e dos modos como tentamos não pensar na morte: um intelectual em discurso directo. 2009. Disponível em: < http://www.ionline.pt/conteudo/36209-umberto-eco-o-google-e-uma-tragedia-osjovens >. Acesso em: 01 fev. 2010.

FONSECA, Edson Nery da et al. Bibliometria: teoria e prática. São Paulo: Cultrix, 1986.

GLÄNZEL, Wolfgang. On reliability and robustness of scientometrics indicators based on tochastic models. An evidence-based opinion paper. Journal of Informetrics. v.10, n.1016, p. 1-7, jan, 2010.

JACOBS, Andrew. Fraudes generalizadas ameaçam ascensão econômica chinesa falsificação em pesquisa científica prejudica escalada econômica do país. Disponível em: <http://g1.globo.com/mundo/noticia/2010/10/fraudesgeneralizadas-ameacam-ascensao-economica-chinesa.html >. Acesso em: 21 out. 2010. 
JALAL, Samir Kumar; BISWAS, Subal Chandra; MUKHOPADHYAY, Parthasarathi. Bibliometrics to Webometrics. Information Studies, v. 15, n.1, p. 3-20, Jan., 2009.

LEITE, Fernando César Lima . Como gerenciar e ampliar a visibilidade da informação científica brasileira: repositórios institucionais de acesso aberto. Brasília: IBICT, 2009.

MOREIRA, Ney Paulo. Análise da eficiência dos programas de pós-graduação acadêmicos em administração, contabilidade e turismo. 2008. 130 f. Dissertação (Mestrado) - Curso de Administração, Departamento de Programa de PósGraduação em Administração, Universidade Federal de Viçosa, Minas Gerais, 2008.

RODRÍGUEZ, Ailín Martínez . Indicadores cibermétricos: nuevas propuestas para medir la información en el entorno digital. 14(4), jul.-ago. 2006. Disponível em: <http://bases.bireme.br/cgi-bin/wxislind.exe/iah/online/>. Acesso em: 1 out. 2010.

RODRIGUES, L. O. C. Publicar mais, ou melhor?: o tamanduá olímpico. Revista Brasileira Ciência do Esporte, Vol. 29, n. 1, p. 35-48, set. 2007.

SANCHEZ, Oscar Adolfo; ARAÚJO, Marcelo. O Governo Eletrônico no Estado de São Paulo. São Paulo: Cedec, jul. 2003, 35p. (Série Didática, no 7)

SHINNIN, Fang. Fraudes generalizadas ameaçam ascensão econômica chinesa falsificação em pesquisa científica prejudica escalada econômica do país. The New York Times. Entrevista concedida a Andrew Jacobs.

SILVA, Ilaydiany C. O. da. Webometria: um estudo de caso de sítios de PósGraduação em engenharia de produção no Brasil. 2008. 65 f. Monografia (Graduação) - Curso de Biblioteconomia, Departamento de Biblioteconomia, Universidade Federal do Rio Grande do Norte, Natal, RN, 2008. (Trabalho não publicado).

SILVA, Ilaydiany Cristina O. da; COSTA, José Alfredo Ferreira; RAMOS, Anatália Saraiva Martins. Management of information technology: a profile of professional information in adoption of tecnochange in information systems. In: International Conference on Information Systems and Technology Management, 7, May 19-21, 2010, São Paulo, SP, Brazil. Anais... São Paulo, SP: TECSI/FEA/USP.

SILVA, Ilaydiany Cristina O. da; COSTA, José Alfredo Ferreira; VANTI VITULLO, Nadia Aurora. Webometrics analysis of academic sites: a case study of federal institutions of higher education in south Brazil. In: International Conference on Information Systems and Technology Management, 7, May 19-21, 2010, São Paulo, SP, Brazil. Anais... São Paulo, SP: TECSI/FEA/USP. p. 1483-1497.

STUMPF, Ida Regina C. et al. Usos dos termos cienciometria e cientometria pela comunidade científica brasileira. In: POBLACION, Dinah Aguiar; WITTER, Geraldina Porto; SILVA, José Fernando Modesto da. (org.). Comunicação e produção científica: contexto, indicadores e avaliação. São Paulo: Angellara, 2006. p. 343369.

TAGUE-SUTCLIFFE, Jean. An introduction to informetrics. Information Processing \& Management, v. 28, n. 1, 1992, p. 1-3. 
THELWALL, Mike. Bibliometrics to webometrics. Journal of information science, v.34, n.4, p. 1-18, 2007.

THELWALL, Mike. Introduction to webometrics: quantitative Web research for the social sciences. San Rafael, CA: Morgan \& Claypool, 2009.

TURBAN, E. et al. Tecnologia de informação para gestão: transformando os negócios na economia digital. Porto Alegre: Bookman, 2004.

VANTI VITULLO, Nadia. Os Links e os Estudos webométricos. Ciência da Informação, Brasília, v. 34, n. 1, p. 78-88, 2005.

VANTI VITULLO, Nadia . Métodos Quantitativos para Avaliação do Fluxo da Informação e do Conhecimento: bibliometria, cientometria e informetria. In: GUAZINA, Liziane; VANTI, Nadia. (Org.). Comunicação e Informação: ensaios e críticas. Porto Alegre: Sulina, 2006. p. 102-113.. Porto Alegre: Sulina, 2006, p. 102113.

VANTI VITULLO, Nadia Aurora. Links hipertextuais na comunicação científica: análise Webométrica dos sítios acadêmicos latino-americanos em Ciências Sociais. 2007. 299 f. Tese (Doutorado em Comunicação e Informação) - Curso de Programa de Pós-Graduação em Comunicação e Informação, Universidade Federal do Rio Grande do Sul, Porto Alegre, 2007.

WEBOMETRICS Ranking Universities. Disponível em:

<http://www.webometrics.info/about_rank.html>. Acesso em: 10 ago. 2010. 
APÊNDICES 
APÊNDICE A - Relação dos Programas e sites das Engenharias I dos IES do Brasil a serem contempladas no estudo.

\begin{tabular}{|c|c|c|c|c|c|}
\hline \multicolumn{6}{|c|}{ ENGENHARIAS I } \\
\hline \multirow[t]{2}{*}{ PROGRAMA } & \multirow[t]{2}{*}{ IES } & \multirow[t]{2}{*}{ UF } & \multicolumn{2}{|c|}{ CONCEITO } & \multirow[t]{2}{*}{ SITE/URL } \\
\hline & & & M & D & \\
\hline ENGENHARIA CIVIL & UFOP & MG & 4 & 4 & http://www.propec.ufop.br/ \\
\hline ENGENHARIA CIVIL & UFPE & PE & 5 & 5 & http://www.poscivil.ufpe.br/ \\
\hline ENGENHARIA CIVIL & UFRJ & RJ & 7 & 7 & http://www.coc.ufrj.br/ \\
\hline ENGENHARIA CIVIL & UFF & RJ & 4 & 4 & http://www.poscivil.h-br.com/ \\
\hline ENGENHARIA CIVIL & PUC-RIO & RJ & 6 & 6 & http://www.civ.puc-rio.br \\
\hline ENGENHARIA CIVIL & UFRGS & RS & 6 & 6 & http://www.engcivil.ufrgs.br \\
\hline ENGENHARIA CIVIL & UFSC & SC & 5 & 5 & http://www.pos.ufsc.br/engcivil \\
\hline ENGENHARIA CIVIL & USP & SP & 5 & 5 & http://PPG'Sec.poli.usp.br/ \\
\hline $\begin{array}{l}\text { ENGENHARIA CIVIL } \\
\text { (ENGENHARIA DE } \\
\text { ESTRUTURAS) }\end{array}$ & USP/SC & SP & 7 & 7 & http://www.set.eesc.usp.br/ \\
\hline $\begin{array}{l}\text { ENGENHARIA CIVIL } \\
\text { (RECURSOS HÍDRICOS) }\end{array}$ & UFC & CE & 5 & 5 & http://www.posdeha.ufc.br/ \\
\hline $\begin{array}{l}\text { ENGENHARIA DE } \\
\text { ESTRUTURAS }\end{array}$ & UFMG & MG & 5 & 5 & http://www.pos.dees.ufmg.br/ \\
\hline $\begin{array}{l}\text { ENGENHARIA DE } \\
\text { RECURSOS HÍDRICOS E } \\
\text { AMBIENTAL }\end{array}$ & UFPR & PR & 4 & 4 & http://www.PPG'Serha.ufpr.br/ \\
\hline ENGENHARIA URBANA & UFSCAR & SP & 4 & 4 & http://www.ufscar.br/ PPG'Seu/ \\
\hline GEOTECNIA & UNB & DF & 6 & 6 & http://www.geotecnia.unb.br/?p=posgrad \\
\hline GEOTECNIA & UFOP & MG & 3 & 4 & http://www.nugeo.ufop.br/ \\
\hline GEOTECNIA & USP/SC & SP & 5 & 5 & http://www.eesc.usp.br/geopos/ \\
\hline $\begin{array}{l}\text { RECURSOS HIIDRICOS E } \\
\text { SANEAMENTO } \\
\text { AMBIENTAL }\end{array}$ & UFRGS & RS & 5 & 5 & http://www.iph.ufrgs.br/posgrad/ \\
\hline $\begin{array}{l}\text { ENGENHARIA DE } \\
\text { TRANSPORTES }\end{array}$ & UFC & CE & 5 & 4 & http://www.det.ufc.br/ \\
\hline $\begin{array}{l}\text { ENGENHARIA DE } \\
\text { TRANSPORTES }\end{array}$ & UFRJ & RJ & 5 & 5 & http://www.pet.coppe.ufrj.br/ \\
\hline $\begin{array}{l}\text { ENGENHARIA DE } \\
\text { TRANSPORTES }\end{array}$ & USP/SC & SP & 5 & 5 & http://www.stt.eesc.usp.br/ \\
\hline TRANSPORTES & UNB & DF & 5 & 5 & http://www.transportes.unb.br/ \\
\hline $\begin{array}{l}\text { CIÊNCIAS DA } \\
\text { ENGENHARIA AMBIENTAL }\end{array}$ & USP/SC & SP & 4 & 4 & http://www.eesc.usp.br/PPG'Ssea/ \\
\hline ENGENHARIA AMBIENTAL & UFES & ES & 4 & 4 & http://www.ct.ufes.br/PPG'Sea/ \\
\hline ENGENHARIA AMBIENTAL & UFSC & SC & 5 & 5 & http://www.PPG'Sea.ufsc.br/ \\
\hline $\begin{array}{l}\text { ENGENHARIA } \\
\text { HIDRÁULICA E } \\
\text { SANEAMENTO }\end{array}$ & USP/SC & SP & 7 & 7 & http://www.eesc.usp.br/PPG'Sshs/ \\
\hline $\begin{array}{l}\text { SANEAMENTO, MEIO } \\
\text { AMBIENTE E RECURSOS } \\
\text { HÍDRICOS }\end{array}$ & UFMG & MG & 5 & 5 & http://www.smarh.eng.ufmg.br/ \\
\hline $\begin{array}{l}\text { TECNOLOGIAS } \\
\text { AMBIENTAIS }\end{array}$ & UFMS & MS & 4 & 4 & http://www.pgta.ufms.br/ \\
\hline
\end{tabular}


APÊNDICE B - Relação dos Programas e sites das Engenharias II dos IES do Brasil a serem contempladas no estudo.

\begin{tabular}{|c|c|c|c|c|c|}
\hline \multicolumn{6}{|c|}{ ENGENHARIAS II } \\
\hline \multirow[t]{2}{*}{ PROGRAMA } & \multirow[t]{2}{*}{ IES } & \multirow[t]{2}{*}{ UF } & \multicolumn{2}{|c|}{ CONCEITO } & \multirow[t]{2}{*}{ SITE/URL } \\
\hline & & & M & D & \\
\hline $\begin{array}{l}\text { CIÊNCIA E ENGENHARIA } \\
\text { DE MATERIAIS }\end{array}$ & UFCG & PB & 4 & 4 & $\begin{array}{l}\text { http://www.dema.ufcg.edu.br/pos- } \\
\text { graduacao/ }\end{array}$ \\
\hline $\begin{array}{l}\text { CIÊNCIA E ENGENHARIA } \\
\text { DE MATERIAIS }\end{array}$ & FUFSE & SE & 4 & 4 & http://www.pos.ufs.br/p2cem/ \\
\hline $\begin{array}{l}\text { CIÊNCIA E ENGENHARIA } \\
\text { DOS MATERIAIS }\end{array}$ & UFSCAR & SP & 7 & 7 & http://www.PPG'Scem.ufscar.br/ \\
\hline $\begin{array}{l}\text { CIÊNCIA E TECNOLOGIA } \\
\text { DE POLÍMEROS }\end{array}$ & UFRJ & RJ & 6 & 6 & http://www.ima.ufrj.br/ \\
\hline $\begin{array}{l}\text { ENGENHARIA DE } \\
\text { MATERIAIS }\end{array}$ & UFOP & MG & 4 & 4 & http://www.redemat.ufop.br/ \\
\hline $\begin{array}{l}\text { ENGENHARIA DE MINAS, } \\
\text { METALÚRGICA E DE } \\
\text { MATERIAIS }\end{array}$ & UFRGS & RS & 7 & 7 & http://www.ufrgs.br/PPG'Sem \\
\hline $\begin{array}{l}\text { ENGENHARIA MATERIAIS } \\
\text { E DE PROCESSOS } \\
\text { QUÍMICOS E } \\
\text { METALÚRGICOS }\end{array}$ & PUC-RIO & RJ & 5 & 5 & http://www.dema.puc-rio.br/ \\
\hline $\begin{array}{l}\text { ENGENHARIA } \\
\text { METALÚRGICA }\end{array}$ & UFF & RJ & 4 & 4 & http://www.eeimvr.uff.br/ \\
\hline $\begin{array}{l}\text { ENGENHARIA } \\
\text { METALÚRGICA }\end{array}$ & USP & SP & 6 & 6 & http://www.pmt.usp.br/POSTGRAD/ \\
\hline $\begin{array}{l}\text { ENGENHARIA } \\
\text { METALÚRGICA E DE } \\
\text { MATERIAIS }\end{array}$ & UFRJ & RJ & 6 & 6 & http://www.metalmat.ufrj.br/posgrad.htm \\
\hline $\begin{array}{l}\text { ENGENHARIA } \\
\text { METALÚRGICA E DE } \\
\text { MINAS }\end{array}$ & UFMG & MG & 6 & 6 & http://www.pos.demet.ufmg.br/hpcpgem/ \\
\hline $\begin{array}{l}\text { CIÊNCIAS TÉCNICAS } \\
\text { NUCLEARES }\end{array}$ & UFMG & MG & 4 & 4 & http://www.cctn.nuclear.ufmg.br/ \\
\hline ENGENHARIA NUCLEAR & UFRJ & RJ & 5 & 5 & http://www.con.ufrj.br/ \\
\hline $\begin{array}{l}\text { TECNOLOGIAS } \\
\text { ENERGÉTICAS } \\
\text { NUCLEARES }\end{array}$ & UFPE & PE & 5 & 5 & http://www.proten.ufpe.br/ \\
\hline ENGENHARIA QUÍMICA & UFMG & MG & 4 & 4 & http://www.qui.ufmg.br/pg \\
\hline ENGENHARIA QUÍMICA & UFU & MG & 4 & 4 & http://www.PPG'Seq.feq.ufu.br/ \\
\hline ENGENHARIA QUÍMICA & UFPE & PE & 4 & 4 & http://www.ufpe.br/PPG'Seq/ \\
\hline ENGENHARIA QUIIMICA & UEM & PR & 4 & 4 & http://www.deq.uem.br/peq/ \\
\hline ENGENHARIA QUÍMICA & UFRJ & RJ & 7 & 7 & http://www.peq.coppe.ufrj.br/ \\
\hline ENGENHARIA QUÍMICA & UFRN & RN & 5 & 5 & http://www.eq.ufrn.br/ \\
\hline ENGENHARIA QUÍMICA & UFRGS & RS & 5 & 5 & http://www.PPG'Seq.ufrgs.br/ \\
\hline ENGENHARIA QUÍMICA & UFSC & SC & 5 & 5 & http://www2.enq.ufsc.br/ \\
\hline ENGENHARIA QUÍMICA & UFSCAR & SP & 6 & 6 & http://www.ufscar.br/ PPG'Seq/ \\
\hline ENGENHARIA QUIIMICA & USP & SP & 6 & 6 & http://pqi.poli.usp.br/pos/ \\
\hline $\begin{array}{l}\text { TECNOLOGIA DE } \\
\text { PROCESSOS QUÍMICOS E } \\
\text { BIOQUÍMICOS }\end{array}$ & UFRJ & RJ & 6 & 6 & http://www.eq.ufrj.br/sipeq/ \\
\hline
\end{tabular}


APÊNDICE C - Relação dos Programas e sites das Engenharias III dos IES do Brasil a serem contempladas no estudo.

\begin{tabular}{|c|c|c|c|c|c|}
\hline \multicolumn{6}{|c|}{ ENGENHARIAS III } \\
\hline \multirow[t]{2}{*}{ PROGRAMA } & \multirow[t]{2}{*}{ IES } & \multirow[t]{2}{*}{ UF } & \multicolumn{2}{|c|}{ CONCEITO } & \multirow[t]{2}{*}{ SITE/URL } \\
\hline & & & M & D & \\
\hline $\begin{array}{l}\text { ENGENHARIA } \\
\text { (ENGENHARIA DE } \\
\text { PRODUÇÃO) }\end{array}$ & USP & SP & 5 & 5 & http://www.prd.usp.br/ \\
\hline $\begin{array}{l}\text { ENGENHARIA DE } \\
\text { PRODUÇÃOO }\end{array}$ & UFMG & MG & 4 & 4 & http://www.dep.ufmg.br/pos/ \\
\hline $\begin{array}{l}\text { ENGENHARARIA DE } \\
\text { PRODUÇÃO }\end{array}$ & UFPE & PE & 5 & 5 & http://www.ufpe.br/PPG'sep/ \\
\hline $\begin{array}{l}\text { ENGENHARIA DE } \\
\text { PRODUÇÃO }\end{array}$ & UFRJ & RJ & 6 & 6 & http://www.producao.ufrj.br/ \\
\hline $\begin{array}{l}\text { ENGENHARIA DE } \\
\text { PRODUÇÃO }\end{array}$ & UFF & RJ & 4 & 4 & http://www.producao.uff.br/ \\
\hline $\begin{array}{l}\text { ENGENHARIA DE } \\
\text { PRODUÇÃO }\end{array}$ & UFRGS & RS & 5 & 5 & http://www.producao.ufrgs.br/ \\
\hline $\begin{array}{l}\text { ENGENHARIA DE } \\
\text { PRODUÇÃO }\end{array}$ & UFSC & SC & 3 & 3 & $\begin{array}{l}\text { http://www.PPG'Sep.ufsc.br/viewer.php? } \\
\text { indpg=principal }\end{array}$ \\
\hline $\begin{array}{l}\text { ENGENHARIA DE } \\
\text { PRODUÇÃO }\end{array}$ & UFSCAR & SP & 4 & 4 & http://www.PPG'Sep.dep.ufscar.br/ \\
\hline $\begin{array}{l}\text { ENGENHARIA } \\
\text { INDUSTRIAL }\end{array}$ & UFBA & BA & 4 & 4 & http://www.pei.ufba.br/ \\
\hline $\begin{array}{l}\text { PLANEJAMENTO } \\
\text { ENERGÉTICO }\end{array}$ & UFRJ & RJ & 5 & 5 & http://www.ppe.ufrj.br/ \\
\hline $\begin{array}{l}\text { CIÊNCIAS E ENGENHARIA } \\
\text { DE PETRÓLEO }\end{array}$ & $\begin{array}{l}\text { UNICAM } \\
\text { P }\end{array}$ & SP & 4 & 4 & http://www.dep.fem.unicamp.br/cep/ \\
\hline ENGENHARIA MECÂNICA & UFU & MG & 6 & 6 & http://www.posgrad.mecanica.ufu.br/ \\
\hline ENGENHARIA MECÂNICA & UFPB/J.P. & PB & 4 & 4 & http://www.ct.ufpb.br/PPG'Sem/ \\
\hline ENGENHARIA MECÂNICA & UFPE & PE & 4 & 4 & http://www.PPG'Sem.ufpe.br/ \\
\hline ENGENHARIA MECÂNICA & UFPR & PR & 5 & 5 & http://www.pgmec.ufpr.br/ \\
\hline ENGENHARIA MECÂNICA & UFF & RJ & 4 & 4 & http://www.pg.mec.uff.br/ \\
\hline ENGENHARIA MECÂNICA & UERJ & RJ & 4 & 4 & http://www.PPG'S-em.eng.uerj.br/ \\
\hline ENGENHARIA MECÂNICA & PUC-RIO & RJ & 7 & 7 & $\begin{array}{l}\text { http://www.mec.puc- } \\
\text { rio.br/dem_pos_graduacao_apresentaca } \\
\text { o.php }\end{array}$ \\
\hline ENGENHARIA MECÂNICA & UFRN & $\mathrm{RN}$ & 4 & 4 & $\begin{array}{l}\text { http://www.posgraduacao.ufrn.br/PPG'S } \\
\text { em }\end{array}$ \\
\hline ENGENHARIA MECÂNICA & UFRGS & RS & 5 & 5 & http://www.mecanica.ufrgs.br/promec/ \\
\hline ENGENHARIA MECÂNICA & UFSC & SC & 6 & 6 & http://www.posmec.ufsc.br/ \\
\hline ENGENHARIA MECÂNICA & USP & SP & 5 & 5 & http://www.usp.br/PPG'Sem/ \\
\hline ENGENHARIA MECÂNICA & USP/SC & SP & 5 & 5 & http://www.eesc.usp.br/PPG'S-em/ \\
\hline $\begin{array}{l}\text { MÉTODOS NUMÉRICOS } \\
\text { EM ENGENHARIA }\end{array}$ & UFPR & PR & 4 & 4 & http://www.PPG'Smne.ufpr.br/ \\
\hline $\begin{array}{l}\text { ENGENHARIA NAVAL E } \\
\text { OCEÂNICA }\end{array}$ & USP & SP & 3 & 3 & $\begin{array}{l}\text { http://www.pnv.poli.usp.br/posGraduaca } \\
\text { o.php }\end{array}$ \\
\hline ENGENHARIA OCEÂNICA & UFRJ & RJ & 5 & 5 & http://www.oceanica.ufrj.br/ \\
\hline
\end{tabular}


APÊNDICE D - Relação dos Programas e sites das Engenharias IV dos IES do Brasil a serem contempladas no estudo.

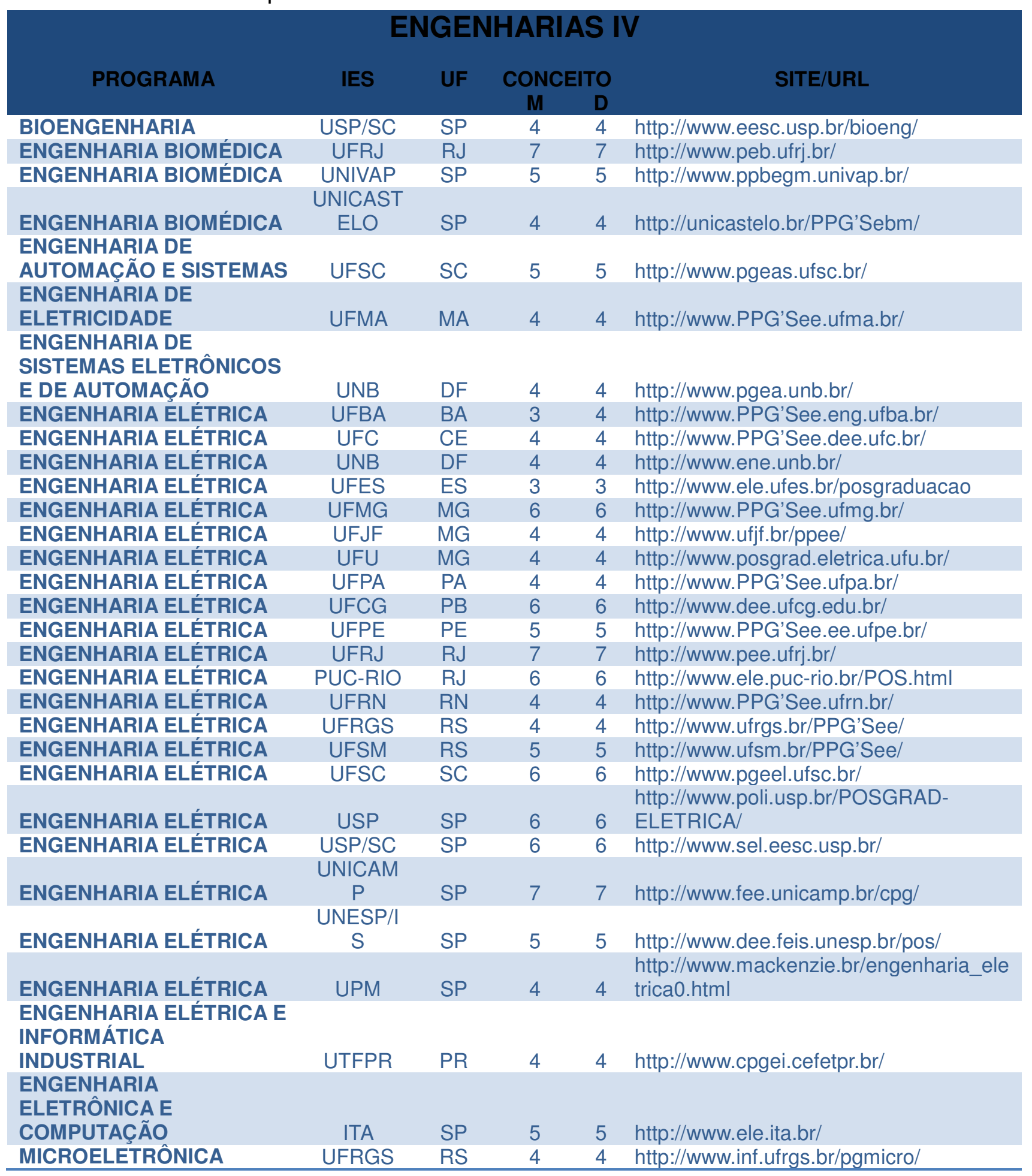


APÊNDICE E - Relação dos cursos de acordo com os Programas.

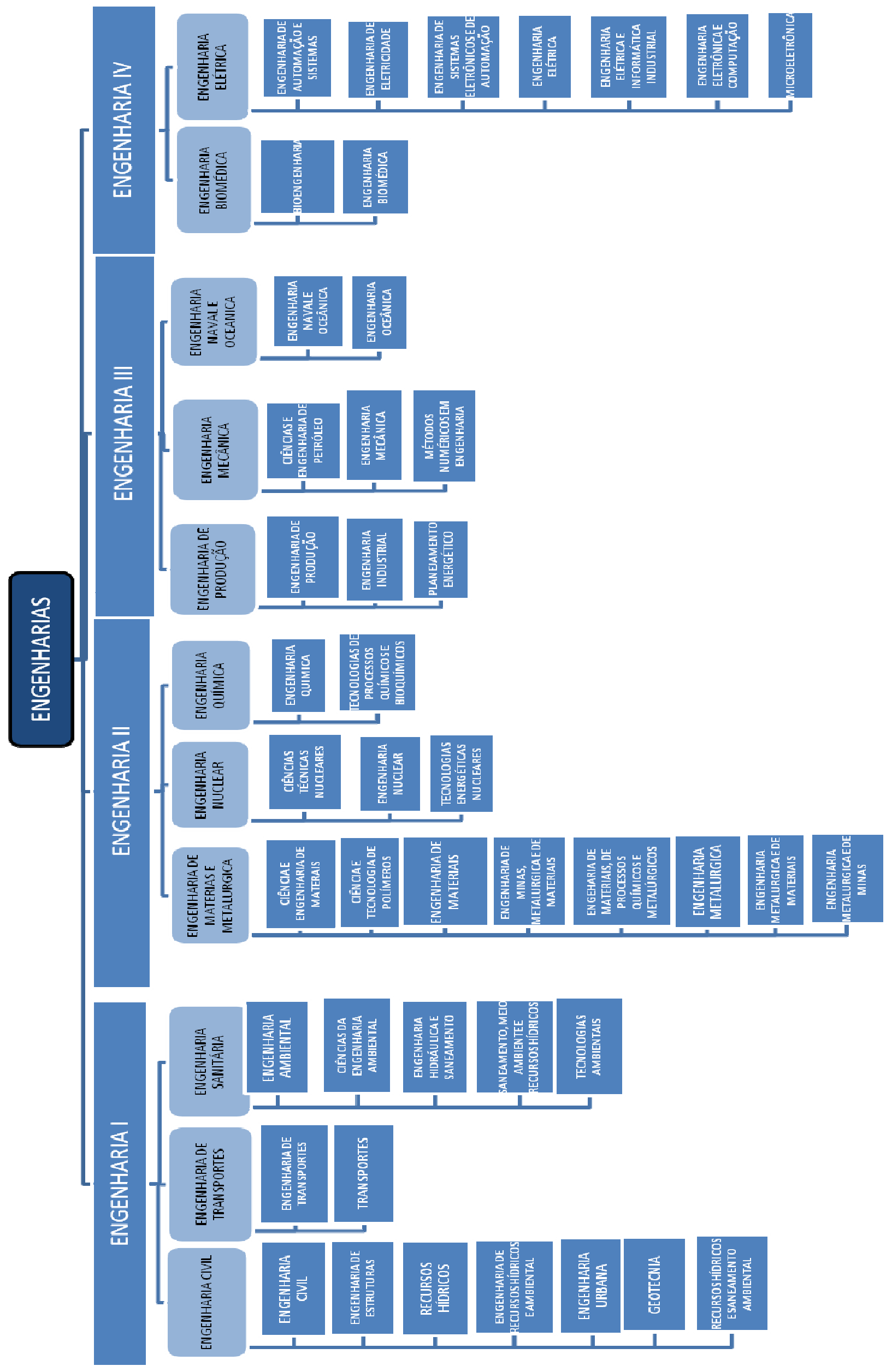


APÊNDICE F - Dados Webométricos gerais das engenharias I.

\begin{tabular}{|c|c|c|c|c|c|c|}
\hline SIGLA & PROGRAMA & TAM. & VIS. & FIW & LUM. & $\begin{array}{c}\text { RANKING } \\
\text { WEBOMETRICO }\end{array}$ \\
\hline UFOP & ENGENHARIA CIVIL & 151 & 12 & 5,507 & 26 & 27,40 \\
\hline UFPE & ENGENHARIA CIVIL & 51 & 6 & 3,514 & 147 & 38,20 \\
\hline UFRJ & ENGENHARIA CIVIL & 16600 & 22 & 5,213 & 13 & 1674,64 \\
\hline UFF & ENGENHARIA CIVIL & 10 & 2 & 2,000 & 6 & 3,60 \\
\hline PUC-RIO & ENGENHARIA CIVIL & 91 & 39 & 19,908 & 0 & 32,58 \\
\hline UFRGS & ENGENHARIA CIVIL & 4 & 9 & 14,949 & 0 & 7,89 \\
\hline UFSC & ENGENHARIA CIVIL & 1 & 3 & 0,000 & 589 & 119,40 \\
\hline USP & ENGENHARIA CIVIL & 119 & 4 & 1,927 & 814 & 177,09 \\
\hline USP/SC & ENGENHARIA CIVIL (ENGENHARIA DE ESTRUTURAS) & 6290 & 7 & 1,843 & 74 & 647,67 \\
\hline UFC & ENGENHARIA CIVIL (RECURSOS HÍDRICOS) & 65 & 4 & 2,206 & 7 & 10,34 \\
\hline UFMG & ENGENHARIA DE ESTRUTURAS & 280 & 9 & 3,678 & 4 & 34,04 \\
\hline UFPR & ENGENHARIA DE RECURSOS HÍDRICOS E AMBIENTAL & 240 & 3 & 1,260 & 32 & 32,15 \\
\hline UFSCAR & ENGENHARIA URBANA & 46 & 9 & 5,413 & 19 & 13,98 \\
\hline UNB & GEOTECNIA & 1160 & 0 & 0,000 & 116 & 139,20 \\
\hline UFOP & GEOTECNIA & 250 & 6 & 2,502 & 15 & 31,50 \\
\hline USP/SC & GEOTECNIA & 107 & 7 & 3,449 & 45 & 23,89 \\
\hline UFRGS & RECURSOS HÍDRICOS E SANEAMENTO AMBIENTAL & 110 & 1 & 0,490 & 5 & 12,60 \\
\hline UFC & ENGENHARIA DE TRANSPORTES & 5430 & 23 & 6,158 & 384 & 632,53 \\
\hline UFRJ & ENGENHARIA DE TRANSPORTES & 603 & 38 & 13,668 & 43 & 90,63 \\
\hline USP/SC & ENGENHARIA DE TRANSPORTES & 459 & 38 & 14,276 & 36 & 74,96 \\
\hline UNB & TRANSPORTES & 362 & 5 & 1,954 & 137 & 66,49 \\
\hline USP/SC & CIÊNCIAS DA ENGENHARIA AMBIENTAL & 134 & 7 & 3,291 & 59 & 29,36 \\
\hline UFES & ENGENHARIA AMBIENTAL & 255 & 2 & 0,831 & 17 & 30,07 \\
\hline UFSC & ENGENHARIA AMBIENTAL & 159 & 20 & 9,085 & 12 & 30,12 \\
\hline USP/SC & ENGENHARIA HIDRÁULICA E SANEAMENTO & 1230 & 5 & 1,618 & 37 & 133,22 \\
\hline UFMG & SANEAMENTO, MEIO AMBIENTE E RECURSOS HÍDRICOS & 571 & 17 & 6,167 & 1 & 67,03 \\
\hline UFMS & TECNOLOGIAS AMBIENTAIS & 71 & 5 & 2,701 & 64 & 22,94 \\
\hline
\end{tabular}


APÊNDICE G - Dados Webométricos gerais das engenharias II.

\begin{tabular}{|c|c|c|c|c|c|c|}
\hline SIGLA & PROGRAMA & TAM. & VIS. & FIW & LUM. & $\begin{array}{c}\text { RANKING } \\
\text { WEBOMETRICO }\end{array}$ \\
\hline UFCG & CIÊNCIA E ENGENHARIA DE MATERIAIS & 17 & 7 & 5,689 & 40 & 14,34 \\
\hline FUFSE & CIÊNCIA E ENGENHARIA DE MATERIAIS & 111 & 5 & 2,445 & 38 & 21,69 \\
\hline UFSCAR & CIÊNCIA E ENGENHARIA DOS MATERIAIS & 365 & 45 & 17,562 & 4 & 63,31 \\
\hline UFRJ & CIÊNCIA E TECNOLOGIA DE POLÍMEROS & 896 & 71 & 24,049 & 202 & 170,31 \\
\hline UFOP & $\begin{array}{l}\text { ENGENHARIA DE MATERIAIS } \\
\text { ENGENHARIA DE MINAS, METALÚRGICA E DE }\end{array}$ & 410 & 16 & 6,124 & 9 & 52,02 \\
\hline UFRGS & MATERIAIS & 303 & 7 & 2,821 & 56 & 45,56 \\
\hline PUC-RIO & $\begin{array}{l}\text { ENGENHARIA MATERIAIS E DE PROCESSOS } \\
\text { QUIIMICOS E METALÚRGICOS }\end{array}$ & 1310 & 11 & 3,529 & 47 & 146,61 \\
\hline UFF & ENGENHARIA METALÚRGICA & 57 & 12 & 6,834 & 18 & 16,67 \\
\hline USP & ENGENHARIA METALÚRGICA & 40 & 5 & 3,121 & 63 & 19,72 \\
\hline UFRJ & ENGENHARIA METALÚRGICA E DE MATERIAIS & 1 & 1 & 0,000 & 62 & 13,00 \\
\hline UFMG & ENGENHARIA METALÚRGICA E DE MINAS & 372 & 9 & 3,501 & 4 & 43,20 \\
\hline UFMG & CIÊNCIAS TÉCNICAS NUCLEARES & 6 & 9 & 11,566 & 12 & 9,81 \\
\hline UFRJ & ENGENHARIA NUCLEAR & 621 & 9 & 3,222 & 13 & 69,84 \\
\hline UFPE & TECNOLOGIAS ENERGÉTICAS NUCLEARES & 14 & 5 & 4,363 & 3 & 5,37 \\
\hline UFMG & ENGENHARIA QUÍMICA & 152 & 0 & 0,000 & 93 & 33,80 \\
\hline UFU & ENGENHARIA QUÍMICA & 1 & 9 & 0,000 & 6 & 5,80 \\
\hline UFPE & ENGENHARIA QUÍMICA & 34 & 2 & 1,306 & 0 & 4,66 \\
\hline UEM & ENGENHARIA QUÍMICA & 146 & 0 & 0,000 & 46 & 23,80 \\
\hline UFRJ & ENGENHARIA QUÍMICA & 399 & 48 & 18,455 & 230 & 113,59 \\
\hline UFRN & ENGENHARIA QUÍMICA & 237 & 20 & 8,422 & 119 & 59,18 \\
\hline UFRGS & ENGENHARIA QUÍMICA & 190 & 1 & 0,439 & 28 & 25,19 \\
\hline UFSC & ENGENHARIA QUÍMICA & 300 & 2 & 0,807 & 13 & 33,76 \\
\hline UFSCAR & ENGENHARIA QUÍMICA & 231 & 8 & 3,385 & 75 & 42,78 \\
\hline USP & $\begin{array}{l}\text { ENGENHARIA QUÍMICA } \\
\text { TECNOLOGIA DE PROCESSOS QUÍMICOS E }\end{array}$ & 54 & 0 & 0,000 & 115 & 28,40 \\
\hline UFRJ & BIOQUÍMICOS & 773 & 11 & 3,809 & 512 & 185,96 \\
\hline
\end{tabular}


APÊNDICE H - Dados Webométricos gerais das engenharias III.

\begin{tabular}{|c|c|c|c|c|c|c|}
\hline SIGLA & PROGRAMA & TAM. & VIS. & FIW & LUM. & $\begin{array}{c}\text { RANKING } \\
\text { WEBOMETRICO }\end{array}$ \\
\hline USP & ENGENHARIA (ENGENHARIA DE PRODUÇÃO) & 555 & 34 & 12,389 & 0 & 74,98 \\
\hline UFMG & ENGENHARIA DE PRODUÇÃO & 81 & 7 & 3,668 & 50 & 22,33 \\
\hline UFPE & ENGENHARIA DE PRODUÇÃO & 7 & 21 & 24,849 & 2 & 16,57 \\
\hline UFRJ & ENGENHARIA DE PRODUÇÃO & 352 & 42 & 16,493 & 88 & 77,10 \\
\hline UFF & ENGENHARIA DE PRODUÇÃO & 395 & 11 & 4,236 & 3 & 46,45 \\
\hline UFRGS & ENGENHARIA DE PRODUÇÃO & 2300 & 42 & 12,494 & 157 & 284,90 \\
\hline UFSC & ENGENHARIA DE PRODUÇÃO & 16 & 4 & 3,322 & 70 & 18,26 \\
\hline UFSCAR & ENGENHARIA DE PRODUÇÃO & 563 & 7 & 2,545 & 45 & 69,31 \\
\hline UFBA & ENGENHARIA INDUSTRIAL & 1220 & 14 & 4,536 & 223 & 174,51 \\
\hline UFRJ & PLANEJAMENTO ENERGÉTICO & 751 & 56 & 19,474 & 12 & 109,39 \\
\hline UNICAMP & CIÊNCIAS E ENGENHARIA DE PETRÓLEO & 91 & 3 & 1,531 & 57 & 22,31 \\
\hline UFU & ENGENHARIA MECÂNICA & 1130 & 5 & 1,638 & 50 & 125,83 \\
\hline UFPB & ENGENHARIA MECÂNICA & 1440 & 3 & 0,950 & 33 & 152,29 \\
\hline UFPE & ENGENHARIA MECÂNICA & 47 & 6 & 3,588 & 4 & 9,22 \\
\hline UFPR & ENGENHARIA MECÂNICA & 749 & 3 & 1,044 & 61 & 88,81 \\
\hline UFF & ENGENHARIA MECÂNICA & 9 & 4 & 4,192 & 54 & 14,54 \\
\hline UERJ & ENGENHARIA MECÂNICA & 129 & 1 & 0,474 & 10 & 15,49 \\
\hline PUC-RIO & ENGENHARIA MECÂNICA & 1 & 0 & 0,000 & 69 & 13,90 \\
\hline UFRN & ENGENHARIA MECÂNICA & 1 & 1 & 0,000 & 0 & 0,60 \\
\hline UFRGS & ENGENHARIA MECÂNICA & 207 & 8 & 3,454 & 98 & 44,99 \\
\hline UFSC & ENGENHARIA MECÂNICA & 955 & 16 & 5,369 & 40 & 112,57 \\
\hline USP & ENGENHARIA MECÂNICA & 8 & 15 & 16,610 & 0 & 11,62 \\
\hline USP/SC & ENGENHARIA MECÂNICA & 126 & 8 & 3,809 & 480 & 113,36 \\
\hline UFPR & MÉTODOS NUMÉRICOS EM ENGENHARIA & 875 & 10 & 3,399 & 4 & 93,98 \\
\hline USP & ENGENHARIA NAVAL E OCEÂNICA & 1 & 0 & 0,000 & 27 & 5,50 \\
\hline UFRJ & ENGENHARIA OCEÂNICA & 9850 & 38 & 9,516 & 48 & 1015,50 \\
\hline
\end{tabular}


APÊNDICE I - Dados Webométricos gerais das engenharias IV.

\begin{tabular}{|c|c|c|c|c|c|c|}
\hline SIGLA & PROGRAMA & TAM. & VIS. & FIW & LUM. & $\begin{array}{c}\text { RANKING } \\
\text { WEBOMETRICO }\end{array}$ \\
\hline USP/SC & BIOENGENHARIA & 1350 & 7 & 2,236 & 23 & 143,55 \\
\hline UFRJ & ENGENHARIA BIOMÉDICA & 472 & 49 & 18,325 & 234 & 122,17 \\
\hline UNIVAP & ENGENHARIA BIOMÉDICA & 2 & 0 & 0,000 & 38 & 7,80 \\
\hline UNICASTELO & ENGENHARIA BIOMÉDICA & 32 & 0 & 0,000 & 33 & 9,80 \\
\hline UFSC & ENGENHARIA DE AUTOMAÇÃO E SISTEMAS & 54 & 2 & 1,154 & 35 & 13,63 \\
\hline UFMA & $\begin{array}{l}\text { ENGENHARIA DE ELETRICIDADE } \\
\text { ENGENHARIA DE SISTEMAS ELETRÔNICOS E DE }\end{array}$ & 2060 & 5 & 1,509 & 9 & 210,60 \\
\hline UNB & AUTOMAÇÃO & 315 & 2 & 0,801 & 225 & 77,66 \\
\hline UFBA & ENGENHARIA ELÉTRICA & 211 & 4 & 1,721 & 20 & 27,44 \\
\hline UFC & ENGENHARIA ELÉTRICA & 342 & 3 & 1,184 & 47 & 45,34 \\
\hline UNB & ENGENHARIA ELÉTRICA & 515 & 64 & 23,600 & 175 & 123,22 \\
\hline UFES & ENGENHARIA ELÉTRICA & 1 & 2 & 0,000 & 1 & 1,30 \\
\hline UFMG & ENGENHARIA ELÉTRICA & 1460 & 4 & 1,264 & 315 & 211,25 \\
\hline UFJF & ENGENHARIA ELÉTRICA & 531 & 6 & 2,202 & 280 & 112,54 \\
\hline UFU & ENGENHARIA ELÉTRICA & 105 & 5 & 2,474 & 35 & 20,49 \\
\hline UFPA & ENGENHARIA ELÉTRICA & 196 & 8 & 3,490 & 76 & 39,50 \\
\hline UFCG & ENGENHARIA ELÉTRICA & 3750 & 38 & 10,632 & 19 & 399,93 \\
\hline UFPE & ENGENHARIA ELÉTRICA & 84 & 3 & 1,559 & 37 & 17,61 \\
\hline UFRJ & ENGENHARIA ELÉTRICA & 2540 & 18 & 5,287 & 12 & 266,46 \\
\hline PUC-RIO & ENGENHARIA ELÉTRICA & 1 & 0 & 0,000 & 36 & 7,30 \\
\hline UFRN & ENGENHARIA ELÉTRICA & 44 & 9 & 5,476 & 0 & 10,00 \\
\hline UFRGS & ENGENHARIA ELÉTRICA & 110 & 5 & 2,449 & 72 & 28,39 \\
\hline UFSM & ENGENHARIA ELÉTRICA & 130 & 3 & 1,419 & 11 & 16,98 \\
\hline UFSC & ENGENHARIA ELÉTRICA & 1 & 10 & 0,000 & 8 & 6,70 \\
\hline USP & ENGENHARIA ELÉTRICA & 132 & 0 & 0,000 & 0 & 13,20 \\
\hline USP/SC & ENGENHARIA ELÉTRICA & 1870 & 22 & 6,724 & 517 & 302,74 \\
\hline UNICAMP & ENGENHARIA ELÉTRICA & 100 & 5 & 2,500 & 103 & 33,60 \\
\hline UNESP/IS & ENGENHARIA ELÉTRICA & 604 & 9 & 3,236 & 48 & 75,15 \\
\hline UPM & $\begin{array}{l}\text { ENGENHARIA ELÉTRICA } \\
\text { ENGENHARIA ELÉTRICA E INFORMÁTICA }\end{array}$ & 1 & 3 & 0,000 & 2584 & 518,40 \\
\hline UTFPR & INDUSTRIAL & 890 & 34 & 11,528 & 153 & 138,91 \\
\hline ITA & ENGENHARIA ELETRÔNICA E COMPUTAÇÃO & 1200 & 22 & 7,145 & 0 & 132,43 \\
\hline UFRGS & MICROELETRÔNICA & 280 & 13 & 5,312 & 62 & 47,96 \\
\hline
\end{tabular}


APÊNDICE J - Ranking webométrico das engenharias I.

\begin{tabular}{|c|c|c|c|}
\hline \multicolumn{4}{|c|}{ RANKING WEBOMÉTRICO DAS ENGENHARIAS I } \\
\hline RANKING & IES & PROGRAMA & $\begin{array}{l}\text { ÍNDICE } \\
\text { WEBOMÉTRICO }\end{array}$ \\
\hline 1 & UFRJ & ENGENHARIA CIVIL & 1674,643 \\
\hline 2 & USP/SC & $\begin{array}{l}\text { ENGENHARIA CIVIL (ENGENHARIA DE } \\
\text { ESTRUTURAS) }\end{array}$ & 647,669 \\
\hline 3 & UFC & ENGENHARIA DE TRANSPORTES & 632,532 \\
\hline 4 & USP & ENGENHARIA CIVIL & 177,085 \\
\hline 5 & UNB & GEOTECNIA & 139,200 \\
\hline 6 & USP/SC & $\begin{array}{l}\text { ENGENHARIA HIDRÁULICA E } \\
\text { SANEAMENTO }\end{array}$ & 133,224 \\
\hline 7 & UFSC & ENGENHARIA CIVIL & 119,400 \\
\hline 8 & UFRJ & ENGENHARIA DE TRANSPORTES & 90,634 \\
\hline 9 & USP/SC & ENGENHARIA DE TRANSPORTES & 74,955 \\
\hline 10 & UFMG & $\begin{array}{l}\text { SANEAMENTO, MEIO AMBIENTE E } \\
\text { RECURSOS HÍDRICOS }\end{array}$ & 67,033 \\
\hline 11 & UNB & TRANSPORTES & 66,491 \\
\hline 12 & UFPE & ENGENHARIA CIVIL & 38,203 \\
\hline 13 & UFMG & ENGENHARIA DE ESTRUTURAS & 34,036 \\
\hline 14 & $\begin{array}{l}\text { PUC- } \\
\text { RIO }\end{array}$ & ENGENHARIA CIVIL & 32,582 \\
\hline 15 & UFPR & $\begin{array}{l}\text { ENGENHARIA DE RECURSOS HÍDRICOS } \\
\text { E AMBIENTAL }\end{array}$ & 32,152 \\
\hline 16 & UFOP & GEOTECNIA & 31,500 \\
\hline 17 & UFSC & ENGENHARIA AMBIENTAL & 30,117 \\
\hline 18 & UFES & ENGENHARIA AMBIENTAL & 30,066 \\
\hline 19 & USP/SC & CIÊNCIAS DA ENGENHARIA AMBIENTAL & 29,358 \\
\hline 20 & UFOP & ENGENHARIA CIVIL & 27,401 \\
\hline 21 & USP/SC & GEOTECNIA & 23,890 \\
\hline 22 & UFMS & TECNOLOGIAS AMBIENTAIS & 22,940 \\
\hline 23 & UFSCAR & ENGENHARIA URBANA & 13,983 \\
\hline 24 & UFRGS & $\begin{array}{l}\text { RECURSOS HÍDRICOS E SANEAMENTO } \\
\text { AMBIENTAL }\end{array}$ & 12,598 \\
\hline 25 & UFC & $\begin{array}{l}\text { ENGENHARIA CIVIL (RECURSOS } \\
\text { HÍDRICOS) }\end{array}$ & 10,341 \\
\hline 26 & UFRGS & ENGENHARIA CIVIL & 7,890 \\
\hline 27 & UFF & ENGENHARIA CIVIL & 3,600 \\
\hline
\end{tabular}


APÊNDICE K - Ranking webométrico das engenharias II.

\begin{tabular}{|c|c|c|c|}
\hline \multicolumn{4}{|c|}{ RANKING WEBOMÉTRICO DAS ENGENHARIAS II } \\
\hline RANKING & IES & PROGRAMA & $\begin{array}{c}\text { ÍNDICE } \\
\text { WEBOMÉTRICO }\end{array}$ \\
\hline 1 & UFRJ & $\begin{array}{l}\text { TECNOLOGIA DE PROCESSOS QUÍMICOS } \\
\text { E BIOQUÍMICOS }\end{array}$ & 185,962 \\
\hline 2 & UFRJ & CIÊNCIA E TECNOLOGIA DE POLÍMEROS & 170,310 \\
\hline 3 & $\begin{array}{l}\text { PUC- } \\
\text { RIO }\end{array}$ & $\begin{array}{l}\text { ENGENHARIA MATERIAIS E DE } \\
\text { PROCESSOS QUÍMICOS E } \\
\text { METALÚRGICOS }\end{array}$ & 146,606 \\
\hline 4 & UFRJ & ENGENHARIA QUIIMICA & 113,591 \\
\hline 5 & UFRJ & ENGENHARIA NUCLEAR & 69,844 \\
\hline 6 & UFSCAR & CIÊNCIA E ENGENHARIA DOS MATERIAIS & 63,312 \\
\hline 7 & UFRN & ENGENHARIA QUÍMICA & 59,184 \\
\hline 8 & UFOP & ENGENHARIA DE MATERIAIS & 52,025 \\
\hline 9 & UFRGS & $\begin{array}{l}\text { ENGENHARIA DE MINAS, METALÚRGICA E } \\
\text { DE MATERIAIS }\end{array}$ & 45,564 \\
\hline 10 & UFMG & ENGENHARIA METALÚRGICA E DE MINAS & 43,200 \\
\hline 11 & UFSCAR & ENGENHARIA QUÍMICA & 42,777 \\
\hline 12 & UFMG & ENGENHARIA QUÍMICA & 33,800 \\
\hline 13 & UFSC & ENGENHARIA QUÍMICA & 33,761 \\
\hline 14 & USP & ENGENHARIA QUÍMICA & 28,400 \\
\hline 15 & UFRGS & ENGENHARIA QUÍMICA & 25,188 \\
\hline 16 & UEM & ENGENHARIA QUÍMICA & 23,800 \\
\hline 17 & FUFSE & CIÊNCIA E ENGENHARIA DE MATERIAIS & 21,689 \\
\hline 18 & USP & ENGENHARIA METALÚRGICA & 19,724 \\
\hline 19 & UFF & ENGENHARIA METALÚRGICA & 16,667 \\
\hline 20 & UFCG & CIÊNCIA E ENGENHARIA DE MATERIAIS & 14,338 \\
\hline 21 & UFRJ & $\begin{array}{l}\text { ENGENHARIA METALÚRGICA E DE } \\
\text { MATERIAIS }\end{array}$ & 13,000 \\
\hline 22 & UFMG & CIÊNCIAS TÉCNICAS NUCLEARES & 9,813 \\
\hline 23 & UFU & ENGENHARIA QUÍMICA & 5,800 \\
\hline 24 & UFPE & $\begin{array}{l}\text { TECNOLOGIAS ENERGÉTICAS } \\
\text { NUCLEARES }\end{array}$ & 5,373 \\
\hline 25 & UFPE & ENGENHARIA QUÍMICA & 4,661 \\
\hline
\end{tabular}


APÊNDICE L - Ranking webométrico das engenharias III.

\begin{tabular}{|c|c|c|c|}
\hline \multicolumn{4}{|c|}{ RANKING WEBOMÉTRICO DAS ENGENHARIAS III } \\
\hline RANKING & IES & PROGRAMA & $\begin{array}{c}\text { ÍNDICE } \\
\text { WEBOMÉTRICO }\end{array}$ \\
\hline 1 & UFRJ & ENGENHARIA OCEÂNICA & 1015,503 \\
\hline 2 & UFRGS & ENGENHARIA DE PRODUÇÃO & 284,899 \\
\hline 3 & UFBA & ENGENHARIA INDUSTRIAL & 174,507 \\
\hline 4 & UFPB/J.P. & ENGENHARIA MECÂNICA & 152,290 \\
\hline 5 & UFU & ENGENHARIA MECÂNICA & 125,828 \\
\hline 6 & USP/SC & ENGENHARIA MECÂNICA & 113,362 \\
\hline 7 & UFSC & ENGENHARIA MECÂNICA & 112,574 \\
\hline 8 & UFRJ & PLANEJAMENTO ENERGÉTICO & 109,395 \\
\hline 9 & UFPR & MÉTODOS NUMÉRICOS EM ENGENHARIA & 93,980 \\
\hline 10 & UFPR & ENGENHARIA MECÂNICA & 88,809 \\
\hline 11 & UFRJ & ENGENHARIA DE PRODUÇÃO & 77,099 \\
\hline 12 & USP & $\begin{array}{l}\text { ENGENHARIA (ENGENHARIA DE } \\
\text { PRODUÇÃO) }\end{array}$ & 74,978 \\
\hline 13 & UFSCAR & ENGENHARIA DE PRODUČÃO & 69,309 \\
\hline 14 & UFF & ENGENHARIA DE PRODUÇÃO & 46,447 \\
\hline 15 & UFRGS & ENGENHARIA MECÂNICA & 44,991 \\
\hline 16 & UFMG & ENGENHARIA DE PRODUÇÃO & 22,334 \\
\hline 17 & UNICAMP & CIÊNCIAS E ENGENHARIA DE PETRÓLEO & 22,306 \\
\hline 18 & UFSC & ENGENHARIA DE PRODUÇÃO & 18,264 \\
\hline 19 & UFPE & ENGENHARIA DE PRODUÇÃO & 16,570 \\
\hline 20 & UERJ & ENGENHARIA MECÂNICA & 15,495 \\
\hline 21 & UFF & ENGENHARIA MECÂNICA & 14,538 \\
\hline 22 & PUC-RIO & ENGENHARIA MECÂNICA & 13,900 \\
\hline 23 & USP & ENGENHARIA MECÂNICA & 11,622 \\
\hline 24 & UFPE & ENGENHARIA MECÂNICA & 9,218 \\
\hline 25 & USP & ENGENHARIA NAVAL E OCEÂNICA & 5,500 \\
\hline 26 & UFRN & ENGENHARIA MECÂNICA & 0,600 \\
\hline
\end{tabular}


APÊNDICE M - Ranking webométrico das engenharias IV.

\section{RANKING WEBOMÉTRICO DAS ENGENHARIAS IV}

\begin{tabular}{|c|c|c|c|}
\hline RANKING & IES & PROGRAMA & $\begin{array}{c}\text { ÍNDICE } \\
\text { WEBOMÉTRICO }\end{array}$ \\
\hline 1 & UPM & ENGENHARIA ELÉTRICA & 518,400 \\
\hline 2 & UFCG & ENGENHARIA ELÉTRICA & 399,926 \\
\hline 3 & USP/SC & ENGENHARIA ELÉTRICA & 302,745 \\
\hline 4 & UFRJ & ENGENHARIA ELÉTRICA & 266,457 \\
\hline 5 & UFMG & ENGENHARIA ELÉTRICA & 211,253 \\
\hline 6 & UFMA & ENGENHARIA DE ELETRICIDADE & 210,602 \\
\hline 7 & USP/SC & BIOENGENHARIA & 143,547 \\
\hline 8 & UTFPR & $\begin{array}{l}\text { ENGENHARIA ELÉTRICA E } \\
\text { INFORMÁTICA INDUSTRIAL }\end{array}$ & 138,906 \\
\hline 9 & ITA & $\begin{array}{l}\text { ENGENHARIA ELETRÔNICA E } \\
\text { COMPUTAÇÃO }\end{array}$ & 132,429 \\
\hline 10 & UNB & ENGENHARIA ELÉTRICA & 123,220 \\
\hline 11 & UFRJ & ENGENHARIA BIOMÉDICA & 122,165 \\
\hline 12 & UFJF & ENGENHARIA ELÉTRICA & 112,540 \\
\hline 13 & UNB & $\begin{array}{l}\text { ENGENHARIA DE SISTEMAS } \\
\text { ELETRÔNICOS E DE AUTOMAÇÃO }\end{array}$ & 77,660 \\
\hline 14 & UNESP/IS & ENGENHARIA ELÉTRICA & 75,147 \\
\hline 15 & UFRGS & MICROELETRÔNICA & 47,962 \\
\hline 16 & UFC & ENGENHARIA ELÉTRICA & 45,337 \\
\hline 17 & UFPA & ENGENHARIA ELÉTRICA & 39,498 \\
\hline 18 & UNICAMP & ENGENHARIA ELÉTRICA & 33,600 \\
\hline 19 & UFRGS & ENGENHARIA ELÉTRICA & 28,390 \\
\hline 20 & UFBA & ENGENHARIA ELÉTRICA & 27,444 \\
\hline 21 & UFU & ENGENHARIA ELÉTRICA & 20,495 \\
\hline 22 & UFPE & ENGENHARIA ELÉTRICA & 17,612 \\
\hline 23 & UFSM & ENGENHARIA ELÉTRICA & 16,984 \\
\hline 24 & UFSC & $\begin{array}{l}\text { ENGENHARIA DE AUTOMAÇÃO E } \\
\text { SISTEMAS }\end{array}$ & 13,631 \\
\hline 25 & USP & ENGENHARIA ELÉTRICA & 13,200 \\
\hline 26 & UFRN & ENGENHARIA ELÉTRICA & 9,995 \\
\hline 27 & UNICASTELO & ENGENHARIA BIOMÉDICA & 9,800 \\
\hline 28 & UNIVAP & ENGENHARIA BIOMÉDICA & 7,800 \\
\hline 29 & PUC-RIO & ENGENHARIA ELÉTRICA & 7,300 \\
\hline 30 & UFSC & ENGENHARIA ELÉTRICA & 6,700 \\
\hline 31 & UFES & ENGENHARIA ELÉTRICA & 1,300 \\
\hline
\end{tabular}

